FACULTAD DE CIENCIAS NATURALES Y MUSEO UNIVERSIDAD NACIONAL DE LA PLATA

\title{
ANÁLISIS DE LA DIVERSIDAD MORFOLÓGICA VINCULADA A LA CAPACIDAD FOSORIAL EN ESPECIES DEL GÉNERO CTENOMYS (RODENTIA, OCTODONTIDAE)
}

Lic. Cecilia Clara Morgan

Director: Dr. Diego H. Verzi

Codirectora: Dra. Ma. Guiomar Vucetich

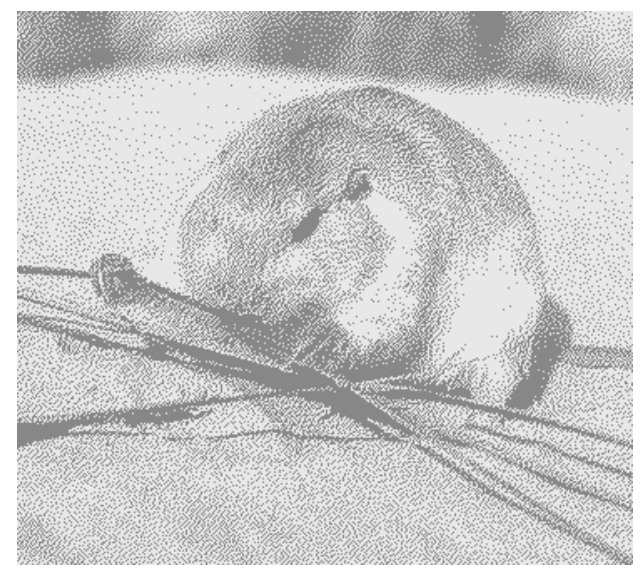

2009 
Fotografía de la portada: Ctenomys flamarioni.

Autor: J.F.B. Stolz (tomada de Projeto Tuco-Tuco -UFRGS) 
A mis padres y abuelos 


\section{ÍNDICE DE CONTENIDOS}

Agradecimientos

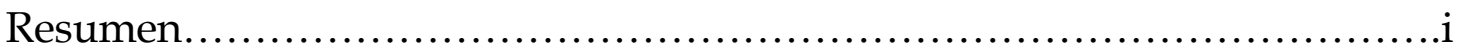

Abstract............................................................... iv

I. Introducción...........................................................

II. Objetivos e hipótesis.....................................................

II.1. Objetivo general...................................................

II.2. Hipótesis de trabajo ............................................

II.3. Objetivos particulares vinculados con las hipótesis de trabajo.............3

III. Antecedentes........................................................... 5

Caracterización del género Ctenomys....................................5

Relaciones de Ctenomys con otros octodontoideos.........................7

Estado del conocimiento de las especializaciones excavatorias de Ctenomys en el contexto de Octodontidae y Ctenomyinae .................................8

IV. Materiales y métodos................................................. 12

IV.1. Materiales examinados ............................................12

IV.1.1. Material de Ctenomys..........................................12

IV.1.2. Material comparativo..............................................14

IV.2. Marco conceptual.................................................... 16

La morfología funcional...............................................16

Morfometría: el enfoque cuantitativo...................................18

IV.3. Metodología....................................................20

IV.3.1. Análisis cualitativo................................................20

IV.3.2. Morfometría tradicional ...........................................20

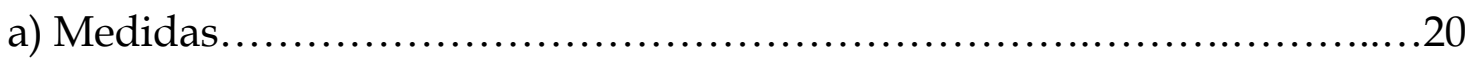

b) Índices morfo-funcionales.............................................29

Índices utilizados en el análisis de cintura escapular y miembro anterior......30 Índices utilizados en el análisis de cráneo..................................33

IV.4. Morfometría geométrica....................................... 34

IV.5. Análisis estadísticos............................................. 34

IV.6. Métodos filogenéticos comparativos...............................35 


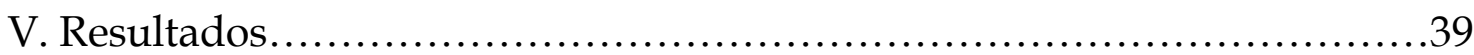

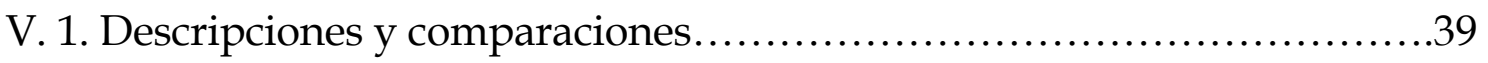

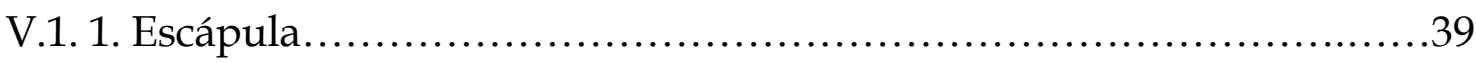

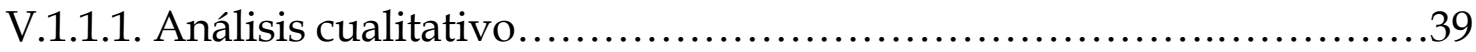

V.1.1.1.a. Morfología escapular en Ctenomys...................................39

V.1.1.1.b. Comparación con otros géneros de ctenominos.........................44

V.1.1.1.c. Comparación con otros caviomorfos..................................45

V.1.1.2. Análisis cuantitativo general.....................................47

V.1.1.3. Análisis cuantitativo de la variabilidad morfológica en Ctenomys......49

V.1.1.3.1. Análisis morfométrico tradicional.....................................49

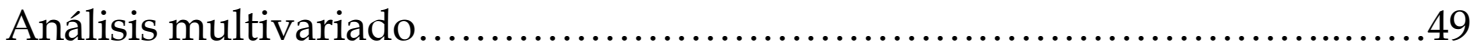

Análisis estadístico descriptivo..............................................

Alometrías en la escápula de Ctenomys.....................................54

V.1.1.3.2. Análisis morfométrico geométrico.................................56

V.1.1.4. Análisis funcional de la morfología escapular .........................61

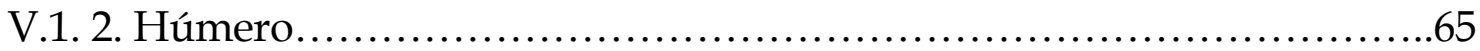

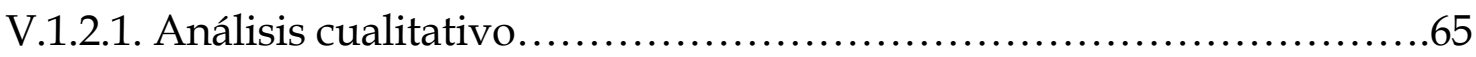

V.1.2.1.a. Morfología humeral en Ctenomys.....................................65

V.1.2.1.b. Comparación con otros géneros de ctenominos.....................70

V.1.2.1.c. Comparación con otros caviomorfos................................72

V.1.2.2. Análisis cuantitativo general.........................................74

V.1.2.3. Análisis cuantitativo de la variabilidad morfológica en Ctenomys.... 75

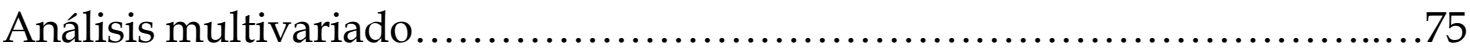

Análisis estadístico descriptivo..........................................77

Alometrías en el húmero de Ctenomys...................................... 81

V.1.2.4. Análisis funcional de la morfología humeral............................83

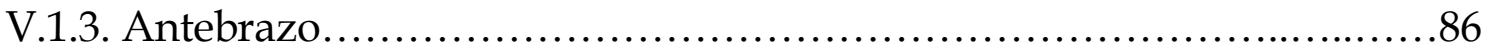

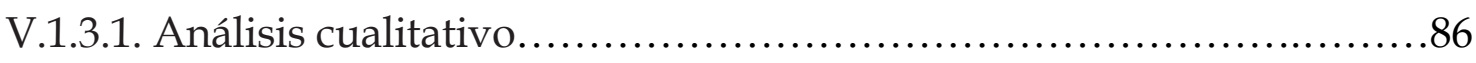

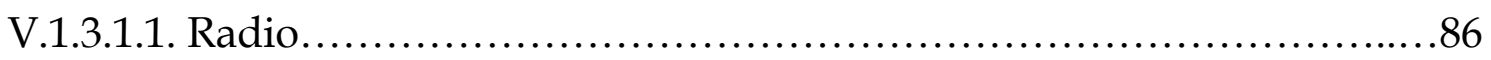

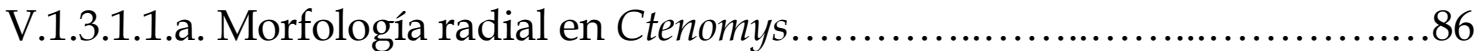

V.1.3.1.1.b. Comparación con otros géneros de ctenominos ....................99

V.1.3.1.1.c. Comparación con otros caviomorfos.................................90 
V.1.3.1.2.a. Morfología ulnar en Ctenomys ....................................91

V.1.3.1.2.b. Comparación con otros géneros de ctenominos ...................94

V.1.3.1.2.c. Comparación con otros caviomorfos...............................99

V.1.3.2. Análisis cuantitativo general......................................96

V.1.3.3. Análisis cuantitativo de la variabilidad morfológica en Ctenomys.....98

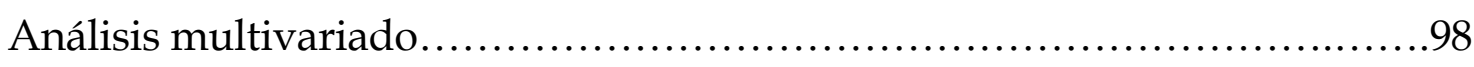

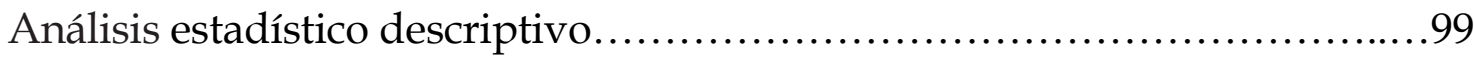

Alometrías en el antebrazo de Ctenomys..................................102

V.1.3.4. Análisis funcional de la morfología del antebrazo.....................103

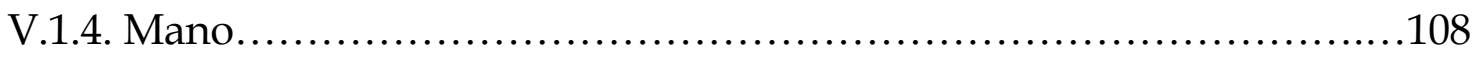

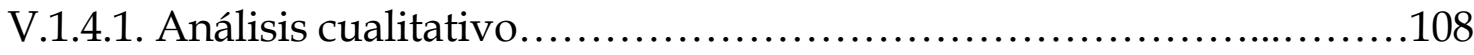

V.1.4.1.a. Morfología de la mano en Ctenomys..................................108

V.1.4.1.b. Comparación con otros géneros de ctenominos.....................112

V.1.4.1.c. Comparación con otros caviomorfos...............................113

V.1.4.2. Análisis cuantitativo general.........................................115

V.1.4.3. Análisis cuantitativo de la variabilidad morfológica en Ctenomys....116 Análisis estadístico descriptivo...............................................116

Alometrías en la mano de Ctenomys.......................................118

V.1.4.4. Análisis funcional de la morfología de la mano........................119

V.2. Análisis de patrones de especialización morfológica vinculados con la

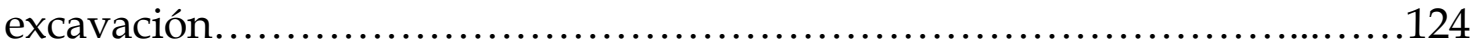

V.2.1. Patrones de especialización en el miembro anterior.....................124

V.2.2. Patrones de especialización en el cráneo.................................126

Análisis multivariado de índices morfofuncionales cráneo-dentarios.........131

V.2.3. Análisis multivariado de especializaciones craneanas y del miembro

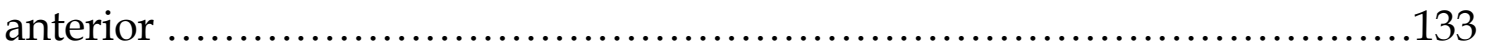

V.2.4. Patrón de especialización de Ctenomys en el contexto de la subfamilia

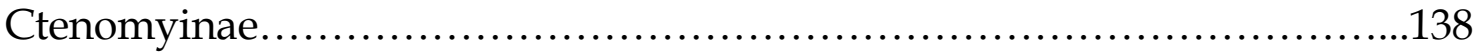

V.3. Grados de variabilidad en cráneo y miembro anterior...................140

V. 4. Análisis filogenético comparativo......................................142

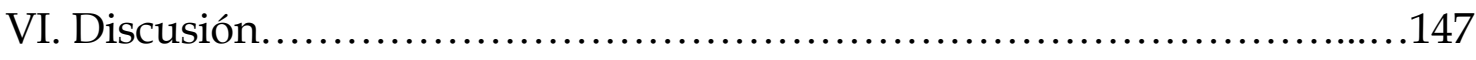

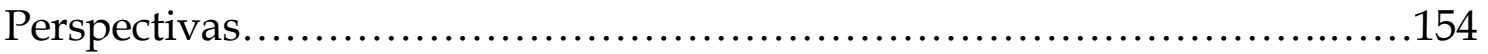




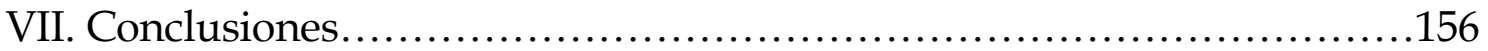

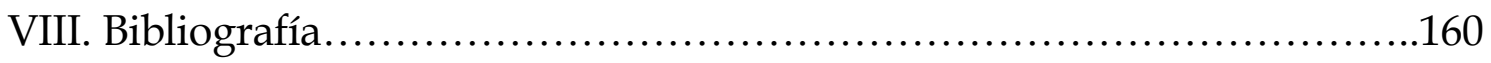

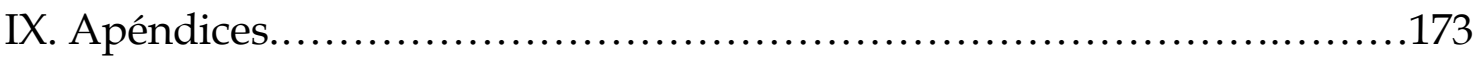

Apéndice I. Materiales examinados.....................................173

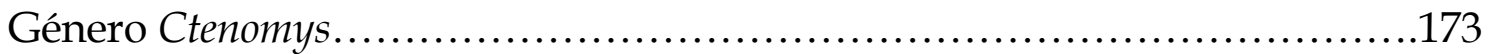

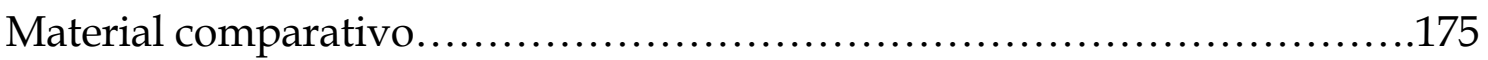

Apéndice II. Medidas e índices utilizados...................................177

Apéndice III. Origen e inserción de los principales músculos mencionados en

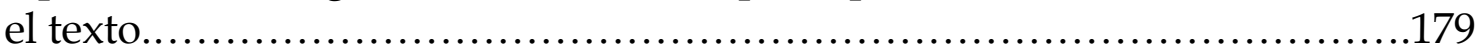

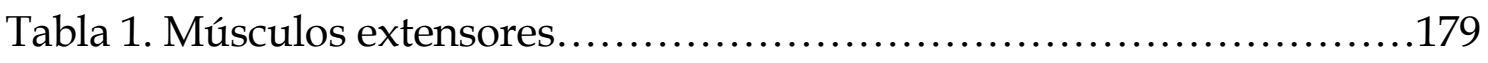

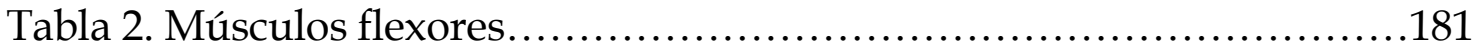

Apéndice IV. Medidas de los materiales examinados..........................184

Tabla 1. Medidas craneanas de Ctenomys......................................184

Tabla 2. Medidas de cintura escapular y miembro anterior de Ctenomys......186

Tabla 3. Medidas de cintura escapular y miembro anterior de material

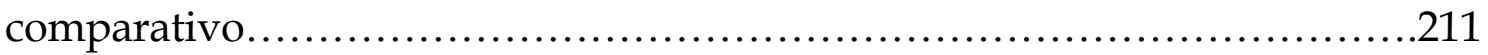

Tabla 4. Estadística descriptiva de indices morfo-funcionales de la escápula en

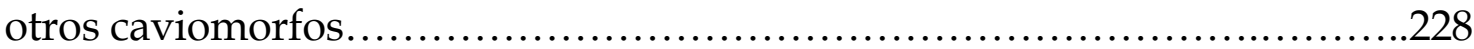

Tabla 5. Estadística descriptiva de índices morfo-funcionales del húmero en

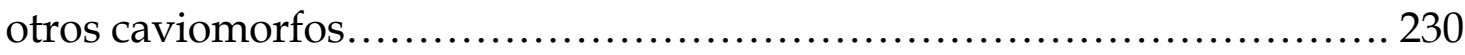

Tabla 6. Estadística descriptiva de índices morfo-funcionales del radio en

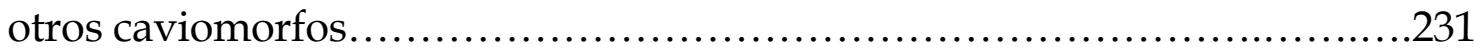

Tabla 7. Estadística descriptiva de índices morfo-funcionales de la ulna en

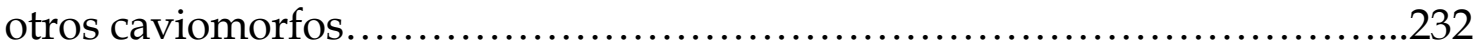

Tabla 8. Estadística descriptiva de índices morfo-funcionales de la mano en otros caviomorfos. 


\section{AGRADECIMIENTOS}

A mi director Dr. Diego H. Verzi por la guía constante, la paciencia y la confianza durante todas las etapas de realización de este trabajo.

A mi codirectora Dra. María Guiomar Vucetich por su estímulo, sus consejos y las valiosas discusiones en torno a este trabajo.

Al Dr. Hugo López por permitirme realizar este trabajo dentro de la División Zoología Vertebrados.

Al personal a cargo de las colecciones que visité, en particular:

Rubén Bárquez y Miriam Morales, del Instituto Lillo.

Damián Romero y Alejandro Dondas, del Museo Municipal de Mar del Plata.

Alejandro Kramarz, Olga Vaccaro y David Flores, del Museo Argentino de Ciencias Naturales.

A Carlos Quintana por cederme generosamente sus datos e ilustraciones originales inéditos acerca de C. chapalmalensis, y por permitirme reproducirlas en este trabajo.

A Iván Pérez, Paula González y Valeria Bernal por la generosa asistencia técnica en relación con la morfometría geométrica.

Al Dr. Aldo Vassallo por su ayuda con cuestiones metodológicas.

A la gente de los Departamentos Científicos Paleontología Vertebrados y Zoología Vertebrados del Museo de La Plata, que me vio crecer (literalmente) en la vida y en la profesión; en especial a la Dra. Mirta García por el apoyo y estímulo desde las primeras etapas de mi desarrollo profesional.

A mis amigos y compañeros de trabajo, Carolina Vieytes y Mariano Merino, por innumerables buenos momentos, consejos y apoyo - incluyendo la ahijada más hermosa del mundo; y a mis estimadísimas Itatí Olivares y Alicia Álvarez, por compartir mucho más que un lugar de trabajo.

A Natalia Martino, por el trabajo compartido, la hospitalidad en Mar del Plata, el apoyo y las charlas.

A todos los amigos de la Cátedra de Zoología Vertebrados, que siento como mi casa, por todo su apoyo y aliento.

A mis padres y hermanos por estar siempre, y a mis abuelos que siempre están presentes. 
A mis padrinos Olinda y Claudio, que siempre me apoyaron incondicionalmente, tal como lo siguen haciendo.

A Dar, por tantas cosas que no puedo empezar a enumerarlas, y a toda su familia por su cariño y confianza.

A todos mis amigos, por compartir sus vidas conmigo. Mención especial para Maru Picasso y Javier Gelfo por su amistad siempre presente y además por facilitarme material esqueletario de su colección personal, y para Mariano Donato por las charlas y consejos (y los asados!).

La realización de este trabajo fue posible gracias a las becas otorgadas por CONICET y Universidad Nacional de La Plata, así como los subsidios otorgados por CONICET, Universidad Nacional de La Plata, y Agencia de Promoción Científica y Tecnológica a los Dres. Guiomar Vucetich y Diego Verzi. 


\section{RESUMEN}

Entre los roedores Hystricomorpha del Nuevo Mundo, Ctenomys, el único género viviente de la subfamilia Ctenomyinae (Octodontidae), ha sido considerado hasta el momento homogéneo en cuanto a su diversidad morfológica y adaptativa. El género comprende unas 85 especies nominales de hábito subterráneo que ocupan gran variedad de ambientes en América del Sur. En este trabajo se explora la diversidad morfológica de rasgos esqueletarios del miembro anterior y cráneo vinculados con la capacidad excavatoria en Ctenomys, en un contexto comparativo que incluye otros géneros de caviomorfos, especialmente de la superfamilia Octodontoidea. Los objetivos son: evaluar el grado de especialización excavadora en las especies de Ctenomys, comparar la disparidad en los rasgos estudiados, y detectar posibles patrones morfo-funcionales y su grado de relación con factores filogenéticos.

Se estudió material esqueletario craneano y del miembro anterior de 20 especies vivientes y 5 especies extintas de Ctenomys, incluyendo a $† C$. chapalmalensis, la especie más antigua conocida en forma relativamente completa. El material comparativo incluyó cuatro especies de 3 géneros extintos de ctenominos, nueve especies vivientes de octodontinos, cinco especies de otros octodontoideos y el cávido Cavia aperea. Para identificar rasgos derivados vinculados con la mayor capacidad fosorial en el cráneo (dento-excavación) y miembro anterior (braquio-excavación), se realizó un análisis cuali- y cuantitativo; esto último mediante medidas lineales, índices y morfometría geométrica. La variación morfológica encontrada se exploró mediante Análisis de Componentes Principales. La posible influencia del tamaño corporal se analizó mediante análisis de alometrías. El grado de variabilidad morfológica de rasgos craneanos y del miembro anterior se cuantificó mediante el coeficiente de variación. Se utilizaron métodos filogenéticos comparativos para analizar la influencia filogenética sobre los rasgos estudiados. 
De acuerdo con los resultados obtenidos, el grado de especialización morfológica vinculada a la capacidad fosorial de Ctenomys es moderado. Mientras que a nivel craneano el género presenta varios rasgos distintivos, en el miembro anterior los únicos detectados como exclusivos son la forma del extremo de la espina escapular, la gran amplitud de la gran muesca escapular, el proceso pseudoestiloide de la epífisis distal del radio y el gran escafolunar de forma compleja. El género no difiere de otros octodontoideos en otros caracteres de importancia morfo-funcional del esqueleto del miembro anterior.

El grado de expresión de las especializaciones braquio- $y$ dentoexcavadoras varió entre las especies estudiadas. Se definieron cuatro morfotipos: morfotipo flamarioni con cráneo y miembro anterior más generalizados; morfotipo "'perucho'" con especializaciones esencialmente dentoexcavadoras, morfotipo "mármol" con especializaciones esencialmente braquioexcavadoras, y morfotipo lewisi con fuertes especializaciones en ambos sentidos. En este último morfotipo estuvieron presentes los siguientes rasgos morfológicos derivados: mayor procumbencia de los incisivos superiores, incisivos inferiores de implantación más profunda, especialización morfológica en la región postglenoidea; escápula muy robusta, con proceso coracoides largo y curvado, espina larga, robusta y curvada con respecto al plano escapular, ausencia de metacromion y proceso teres major bien desarrollado; húmero robusto, con cresta deltoidea distalizada, epicóndilos bien desarrollados, y superficie articular distal alta y ancha; radio y ulna robustos, con diáfisis curvada, articulaciones profundas y bien definidas, y porción distal engrosada; la epífisis distal del radio con un proceso pseudoestiloide adicional; carpo con escafolunar relativamente grande y con superficie articular irregular, en contacto amplio con el unciforme; central muy reducido; metacarpianos II-V robustos y firmemente encajados entre el carpiano distal y los metacarpianos adyacentes. 
La variabilidad detectada en los rasgos estudiados del miembro anterior es algo mayor que la de los rasgos craneanos, aunque la diferencia no es estadísticamente significativa. Los índices morfo-funcionales de cráneo presentaron alta correlación, posiblemente debida a la acentuada integración entre los rasgos analizados.

Los patrones morfo-funcionales de especialización excavadora no se distribuyeron al azar en la filogenia del grupo. Se detectaron fuertes especializaciones excavadoras en un clado de especies bolivianas (C. frater, $C$. conoveri, y C. lewisi), incluidas en el morfotipo lewisi, y escasa especialización morfológica en especies del grupo mendocinus (C. australis, C. azarae, C. flamarioni). La existencia de estos grupos de especies sugiere que la disparidad en estas especializaciones excavadoras se fijó tempranamente en la evolución del género. Además, la existencia de los morfotipos definidos anteriormente señala que las especializaciones morfológicas braquio- y dentoexcavadoras de las especies de Ctenomys no están necesariamente correlacionadas ni son necesariamente excluyentes entre sí.

$\dagger$ C. chapalmalensis fue incluida en el morfotipo flamarioni sobre la base de su escasa especialización en el cráneo y miembro anterior, pero la variabilidad morfológica existente en el Plioceno no puede ser evaluada por la escasez de material. Ya en el Pleistoceno, el rango de disparidad morfológica es comparable con el actual.

En el contexto de los roedores subterráneos del mundo, las especializaciones braquioexcavadoras de Ctenomys, y al menos parte de las dentoexcavadoras, fueron moderadas. La antigüedad de los taxones puede jugar un papel importante en esta diferencia, ya que la subfamilia Ctenomyinae es relativamente joven con respecto a otros clados de roedores subterráneos. 


\begin{abstract}
Among the New World hystricomorph rodents, Ctenomys, the only living genus of the subfamily Ctenomyinae (Octodontidae), has been thus far considered homogeneous in terms of its morphological and adaptive diversity. The genus includes about 85 nominal species with subterranean habit, distributed in a wide range of South American environments. This work explores the morphological diversity of features of the forelimb skeleton and the skull associated to the digging ability of Ctenomys, in a comparative context that includes other caviomorph genera, especially other members of the superfamily Octodontoidea. The goals of this study are: to assess the degree of digging specialization in the species of Ctenomys, to compare the disparity among the features studied, and to detect possible morphofunctional patterns and their degree of association with phylogenetic factors.

The materials studied included skulls and forelimb skeletons of 20 living and 5 extinct Ctenomys species, including $† C$. chapalmalensis, the oldest species known through relatively more complete remains. The comparative material included four species belonging to three extinct ctenomyine genera, nine living species of octodontines, five other octodontoids and the caviid Cavia aperea. To identify derived features associated with greater fossorial ability in the skull (tooth-digging) and forelimb (scratch-digging), a qualitative and quantitative analysis was performed; the latter comprised linear measurements, indexes and geometric morphometrics. The detected morphological variation was explored by means of Principal Components Analysis. The possible influence of body size was analyzed by analyses of allometry. The degree of morphological variability of skull and forelimb features was quantified through the coefficient of variation. Phylogenetic comparative methods were applied to analyze the influence of phylogeny on the studied characters.
\end{abstract}

The results showed that the degree of morphological specialization of Ctenomys linked to fossorial ability is moderate in the context of the 
caviomorph rodents. Several distinctive features are present in the skull of the genus, but the only unique features of its forelimb were the rounded shape of the tip of the scapular spine, ample greater scapular notch, pseudostyloid process in the distal radius, and large, complex-shaped scapholunar bone. The genus does not differ from other octodontoids in other morpho-functionally significant characters of the forelimb skeleton.

There was ample variation in the morphological specialization of the forelimb among Ctenomys species. In this context, the degree of manifestation of scratch- and tooth-digging specializations varied among the studied species. Four morphotypes were defined: flamarioni morphotype with more generalized skull and forelimb, "perucho" morphotype with essentially toothdigging specializations, "mármol" morphotype with essentially scratchdigging specializations, and lewisi morphotype with strong tooth- and scratchdigging specializations. The latter morphotype presented the following derived morphological features: greater upper incisor procumbency, deeper implantation of lower incisors, morphologically specialized postglenoid region; markedly robust scapula with long curved coracoid process, long robust spine curved with respect to the scapular plane, no metacromion and well developed teres major process; robust humerus with distally placed deltoid process, expanded epicondyles and deep broad distal articular surface; robust radius and ulna with curved diaphyses, deep well-defined joints and expanded distal portion; distal epiphysis of radius with additional pseudostyloid process; relatively large scapholunar with irregular articular surfaces, broadly contacting the unciform carpal; reduced central; metacarpals II-V robust and firmly wedged between the adjacent distal carpals and metacarpals.

The variability detected in the features of the forelimb was somewhat higher than that of the skull features, although the difference was not statistically significant. The morpho-functional indexes of the skull were 
highly correlated, possibly due to the marked integration between the analyzed features.

The morpho-functional patterns of digging specialization were not randomly distributed in the phylogeny of the group. Strong digging specializations were detected in a clade of Bolivian species (C. frater, $C$. conoveri and C. lewisi) that were assigned to the lewisi morphotype, and scarce morphological specialization was found in species belonging to the mendocinus group (C. australis, C. azarae, C. flamarioni). The existence of these species groups suggests that the disparity in these digging specializations was fixed early in the evolution of the genus. In addition, the existence of the morphotypes defined above indicates that the scratch- and tooth-digging specializations in the especies of Ctenomys are not necessarily correlated or mutually exclusive.

†C. chapalmalensis was assigned to the flamarioni morphotype on the basis of its weak fossorial specialization at skull and forelimb level, but the morphological variability during the Pliocene could not be assessed due th the scarcity of materials. The range of morphological disparity has been similar to the current one at least since the Pleistocene.

In the context of the subterranean rodents of the world, the scratchdigging specializations of Ctenomys, and at least part of its tooth-digging ones, were moderate. The ages of the taxa may be an important factor in regards to this difference, since the subfamily Ctenomyinae is relatively young with respect to other subterranean rodent clades. 


\section{INTRODUCCIÓN}

El estudio de las especies de los roedores sudamericanos del género Ctenomys (Octodontidae, Ctenomyinae), conocidos vulgarmente como tucotucos, resulta interesante desde diversas perspectivas, dado su modo de vida, alto politipismo, amplia distribución y diversidad de ambientes ocupados, e historia evolutiva integrada tanto por patrones anagenéticos como por fuerte cladogénesis (Reig et al., 1990; Verzi, 2002). Los análisis de aspectos sistemáticos, citogenéticos, genético-moleculares, ecológicos, fisiológicos y anatómicos craneanos de Ctenomys, a menudo más ricos que los realizados para otros caviomorfos, han abarcado sólo parcialmente la inusual diversidad del género (Reig et al., 1990; ver citas más adelante). Aunque de un modo general los tuco-tucos han sido considerados como ecomorfológicamente homogéneos (Reig et al., 1990; Lacey et al., 2000), también se ha señalado la existencia de variación interespecífica en los hábitos subterráneos (Pearson, 1984). En este sentido, el trabajo pionero de Vassallo (1998) evidenció la existencia de diferencias interespecíficas en algunos aspectos morfofuncionales relacionados con la capacidad de excavación. Sin embargo, a pesar de que a lo largo de los últimos treinta años muchos investigadores señalaron el particular interés del estudio de la diversidad morfológica de Ctenomys (Nevo, 1979; Lessa, 1990, 1993, 2000; Cook et al., 2000), los aspectos morfológicos y morfo-funcionales del esqueleto sólo se han estudiado en unas pocas especies. Esta situación se ve reflejada en las relativamente escasas menciones de Ctenomys en la más reciente revisión de la morfología de los roedores subterráneos del mundo (Stein, 2000), especialmente en lo referente a caracteres poscraneanos.

Este trabajo constituye una exploración de la variabilidad morfológica esqueletaria vinculada a la capacidad fosorial de Ctenomys, en el marco comparativo brindado por otros roedores Hystricomorpha sudamericanos (caviomorfos), especialmente de la superfamilia Octodontoidea. En este 
contexto, se pretende evaluar el grado de especialización excavadora en las especies de Ctenomys, comparar la disparidad en los rasgos estudiados, y detectar posibles patrones morfo-funcionales y su grado de relación con factores filogenéticos. 


\section{OBJETIVOS E HIPÓTESIS}

\section{II.1. Objetivo general}

El objetivo de este trabajo es analizar la diversidad morfológica de rasgos esqueletarios del miembro anterior y cráneo vinculados con la capacidad excavatoria en Ctenomys, en un contexto comparativo que incluya otros géneros de caviomorfos, especialmente de la superfamilia Octodontoidea.

\section{II.2. Hipótesis de trabajo}

Para la realización de este trabajo se plantearon las siguientes hipótesis (generadas a partir de información en la literatura sobre Ctenomys y otros roedores subterráneos):

1) Ctenomys es el roedor sudamericano viviente con hábitos más fuertemente subterráneos, pero, dentro del contexto de los octodontoideos, esto se refleja sólo parcialmente en su morfología esqueletaria.

2) La estrategia excavatoria de Ctenomys es dual, y el grado de expresión de las especializaciones braquio- y dentoexcavadoras es variable entre especies o grupos de especies.

3) La amplitud de los cambios detectados en los miembros anteriores es mayor que en el aparato masticatorio.

4) Existe correlación entre el grado de especialización excavadora a nivel del miembro anterior (braquioexcavación) y del cráneo (dentoexcavación).

5) Desde una perspectiva histórica, los patrones morfo-funcionales no se distribuyen al azar en la filogenia del grupo. La disparidad en las especializaciones excavadoras se fijó tempranamente en la evolución de Ctenomys. 


\section{II.3. Objetivos particulares vinculados con las hipótesis de trabajo}

1) Identificar rasgos especializados en la cintura escapular y miembro anterior del género Ctenomys, en el contexto de los Octodontoidea.

2) Caracterizar cuali- y cuantitativamente la diversidad morfológica interespecífica de rasgos asociados con la capacidad fosorial en la cintura escapular y miembro anterior de Ctenomys.

3) Comparar la diversidad morfológica mencionada anteriormente con los patrones de diversidad morfo-funcional del cráneo. Contrastar patrones de especialización excavadora en cráneo y miembro anterior.

4) Utilizar métodos filogenéticos comparativos para evaluar la influencia de la genealogía sobre la evolución de dichas especializaciones. 


\section{ANTECEDENTES}

\section{Caracterización del género Ctenomys}

El género Ctenomys Blainville, 1826 es el más altamente politípico entre los roedores subterráneos del mundo (Reig et al., 1990; Cook et al., 2000), e incluye más de 85 especies nominales (Woods y Kilpatrick, 2005), la mayoría de las cuales requiere revisión. En Argentina se reconocen 42 especies y 11 subespecies (Bidau, 2006).

Ctenomys es endémico de América del Sur, encontrándose desde los $10^{\circ}$ hasta los $54^{\circ}$ de latitud Sur, y desde la costa pacífica hasta la atlántica. Su rango actual incluye Perú, Bolivia, Chile, Paraguay, Uruguay, el sudeste de Brasil, y Argentina hasta Tierra del Fuego. Dentro de su amplia área de distribución, los tuco-tucos se hallan en hábitats muy diversos: pastizales, zonas semiáridas, dunas costeras, estepas y zonas arboladas; desde el nivel del mar hasta los $5000 \mathrm{~m}$ snm en los Andes (Bidau, 2006). La mayoría de las especies habita en suelos arenosos, o al menos bien drenados (Contreras, 1973), aunque algunas (e.g. C. tuconax, C. lewisi) lo hacen en suelos bastante compactos, francos y ricos en humus (Reig et al., 1990; Cook et al., 1990). Sin embargo, existe relativamente poca información acerca de las características edáficas de las zonas ocupadas por cada especie; se presume que diversos factores, incluyendo la topografía, estructura y densidad de la vegetación, proporción de fracción arenosa en el perfil del suelo, humedad, etc., influyen sobre la selección de hábitat y limitan la distribución geográfica de estas especies (Rosi et al., 2002; Luna y Antinuchi, 2006). La Tabla 1 (Materiales y Métodos) resume la distribución geográfica e información disponible acerca del hábitat de las especies estudiadas.

Los tuco-tucos son especialistas ecológicos (Ferry-Graham et al., 2002). Pasan la mayor parte de su vida bajo tierra en sistemas de túneles construidos por ellos mismos, y sólo se desplazan sobre la superficie en el momento de la dispersión de los juveniles, y en parte para buscar su alimento (menos del 1\% 
del total de su tiempo transcurre fuera de las madrigueras; Lessa et al., 2008). Son herbívoros generalistas, y consumen principalmente gramíneas (Rosi et al., 2003). En la mayoría de las especies, los sistemas de túneles son exclusivos para cada individuo, aunque las hembras conviven con sus crías juveniles durante unos meses, antes de que éstas se dispersen; son excepciones conocidas Ctenomys sociabilis y C. peruanus, cuyas cuevas son compartidas por varios individuos (Pearson, 1959; Lacey, 2000). Las cuevas varían en profundidad $(30-300 \mathrm{~cm})$ y complejidad; el plan básico comprende túneles centrales y túneles secundarios ramificados, los cuales abren a la superficie mediante múltiples bocas que los animales mantienen normalmente obturadas con tapones de tierra (Pearson, 1959; Altuna, 1983; Antinuchi y Busch, 1992). Esto les asegura no sólo protección ante posibles depredadores, sino también el mantenimiento de un ambiente notablemente constante en temperatura, presión y humedad. La estabilidad del ambiente de las cuevas seguramente facilita que Ctenomys haya podido colonizar la diversidad de ambientes que ocupa en la actualidad (Reig et al., 1990).

La morfología externa de los tuco-tucos presenta muchos de los rasgos morfológicos clásicamente asociados con los hábitos subterráneos (Dubost, 1968; Nevo, 1979): cabeza grande, pabellón auricular reducido, cuello no distinguible; cuerpo robusto, con miembros pares fuertes y cortos, los anteriores provistos de fuertes garras, y las falanges distales de manos y pies provistas de cerdas dispuestas en dos hileras, formando un característico "peine" supraungueal. Los incisivos son grandes, generalmente con esmalte de color anaranjado.

Hasta el momento, el género Ctenomys ha sido considerado homogéneo en cuanto a su diversidad morfo-funcional y adaptativa (Reig et al., 1990), siendo caracterizado básicamente como un braquioexcavador que usa secundariamente sus incisivos en el cavado, de acuerdo a las exigencias del medio (Weir, 1974; Frailey et al., 1980; De Santis et al., 1998; Stein, 2000). Sin embargo, una comparación detallada de dos de sus especies (C. australis y C. 
talarum) ha revelado la existencia de importantes diferencias en este sentido (Vassallo, 1998).

\section{$\underline{\text { Relaciones de Ctenomys con otros octodontoideos }}$}

Los Ctenomyinae forman un grupo monofilético de Hystricomorpha del Nuevo Mundo (comúnmente conocidos como caviomorfos), que incluye a los roedores sudamericanos más fuertemente adaptados a la fosorialidad y la vida subterránea (Reig, 1989; Reig y Quintana, 1992; Quintana, 1994; Fernández et al., 2000; Verzi, 2002, 2008). En el presente trabajo, los Ctenomyinae se incluyen con los Octodontinae en una única familia, Octodontidae, siguiendo el criterio de Reig (1989) y Verzi (2001), quienes lo utilizan para denotar más claramente el grado de vinculación de estos grupos hermanos dentro de la superfamilia Octodontoidea. A su vez, los Octodontidae s.l. (Octodontinae+Ctenomyinae) se consideran estrechamente emparentados con los Echimyidae (Winge, 1941; Wood y Patterson, 1959; Reig, 1986; Verzi, 2002; Honeycutt et al., 2003; Opazo, 2005).

Ctenomys es el único representante viviente de esta subfamilia, pero ésta tuvo en el pasado una diversidad genérica mucho mayor. La subfamilia Ctenomyinae se diferenció durante el Mioceno tardío, muy probablemente en el área pampásica (Reig et al., 1990; Verzi et al., 1991; Verzi, 1999), y alcanzó su máxima diversidad genérica durante el Plioceno (Cook et al., 2000, Verzi, 2008). Los taxones más antiguos conocidos son †Palaeoctodon y †Chasichimys del Mioceno tardío. Los ctenómidos "corona" (Mioceno tardío a Reciente) comprenden cuatro linajes: †Eucelophorus (Plioceno temprano - Pleistoceno medio), †Xenodontomys-†Actenomys (Mioceno tardío - Plioceno), †Praectenomys (Plioceno) y Ctenomys (incluyendo a †Paractenomys). †Xenodontomys es considerado como un ancestro parafilético de †Actenomys (Verzi, 2008). Con excepción de †Palaeoctodon, los géneros extintos son probablemente monotípicos, en fuerte contraste con el patrón de extensa cladogénesis de Ctenomys (Reig, 1989; Verzi, 2002), único género que 
sobrevivió más allá del límite Plio-Pleistoceno (Tonni et al., 1992; Verzi, 2002).

La historia temprana de Ctenomys se conoce sólo en forma fragmentaria, pero datos paleontológicos y estimaciones moleculares sugieren una edad mínima de aproximadamente 3,5 millones de años (Plioceno tardío) (Castillo et al., 2005; Verzi, 2008). El registro más antiguo corresponde a materiales del Plioceno tardío de Uquía (Jujuy, Argentina, Verzi, 2008; Verzi et al., en prensa), pero la especiación explosiva del género habría ocurrido a partir del Pleistoceno (Reig et al., 1990).

\section{Estado del conocimiento de las especializaciones excavatorias de Ctenomys en el contexto de Octodontidae y Ctenomyinae}

Un reciente estudio comparado de las especializaciones morfológicas de Ctenomyinae y Octodontinae asociadas con la fosorialidad y el hábito subterráneo, reveló considerable flexibilidad estructural en los elementos esqueletarios involucrados en la actividad excavadora (Lessa et al., 2008). Este trabajo mostró, también, importantes diferencias en la distribución de adaptaciones para la vida subterránea entre ctenominos y octodontinos. Entre los octodontinos, las mayores especializaciones subterráneas ocurrieron en un único clado que incluye a Spalacopus y al estrechamente relacionado Aconaemys, mientras que entre los ctenominos, los rasgos morfológicos asociados con la vida subterránea se distribuyeron en un patrón de tipo mosaico, en los diferentes linajes de la subfamilia (Reig y Quintana, 1992).

Los ctenominos muestran diversos grados de especialización relacionada con la vida subterránea y la capacidad excavadora (Reig y Quintana, 1992). No se conocen restos esqueletarios poscraneanos de los géneros miocénicos †Palaeoctodon y †Chasichimys-†Xenodontomys (Montalvo y Casadío, 1988; Verzi et al., 1991). El pliocénico †Actenomys es un género monoespecífico representado por $\dagger A$. priscus, un ctenomino de tamaño relativamente grande cuyo hábito ha sido interpretado como fosorial sobre la base de caracteres craneodentarios y poscraneanos (Fernández et al., 2000; De 
Santis y Moreira, 2000); además, ha sido encontrado en estrecha asociación con paleocuevas en los acantilados marítimos de la costa bonaerense (Genise, 1989). El paleoambiente en el que vivía esta especie habría sido un área con productividad primaria media a alta y buena cobertura vegetal, posiblemente en un bioma de tipo pastizal, con suelos duros y altamente cohesivos (Fernández et al., 2000). Se conocen abundantes y completos restos poscraneanos para esta especie.

†Eucelophorus, del Plioceno temprano - Pleistoceno medio de Argentina central, presenta fuertes especializaciones excavadoras, las cuales se conocen esencialmente a nivel craneodentario (Reig y Quintana, 1992; Verzi, 2002; Verzi y Olivares, 2006; Vieytes et al., 2007). A la descripción publicada de los escasos restos poscraneanos conocidos se suman nuevos materiales no descriptos que fueron incluidos en este trabajo.

$\dagger$ Praectenomys se conoce a través de una única especie, $\uparrow P$. rhombidens del Plioceno de Bolivia, representada por fragmentos craneanos y poscraneanos que fueron figurados y descriptos por Villarroel (1975) y Quintana (1994). Sobre la base de su estudio, se ha sugerido un hábito posiblemente dentoexcavador para esta especie (Quintana, 1994).

La especie más antigua de Ctenomys para la cual se conocen restos esqueletarios bastante completos es $† C$. chapalmalensis. Para el Pleistoceno medio se conocen más de 10 especies (Argentina, Uruguay y Bolivia; Reig et al., 1990), sobre la base de restos craneanos y dentarios; por el contrario, los restos poscraneanos son escasos, a excepción de la muy bien preservada $† C$. subassentiens del Pleistoceno de Bolivia (Frailey et al., 1980).

La diversidad morfológica cráneo-dentaria de Ctenomys ha sido explorada en varios trabajos recientes, especialmente en relación con las especializaciones dentoexcavadoras. Mora et al. (2003) analizaron la relación entre las alometrías y la variación o conservación de la forma en la morfología craneana de 23 especies; hallaron gran variación en la procumbencia de los incisivos, independiente del tamaño corporal, pero asociada con la alometría 
positiva del rostro. Verzi y Olivares (2006) exploraron las especializaciones de la articulación cráneo-mandibular, en particular de la zona postcondílea, vinculadas con la capacidad de dentoexcavación; estos autores definieron dos morfotipos extremos con respecto al grado de especialización para la dentoexcavación, y hallaron que las especies de Ctenomys estudiadas se distribuyen en un rango morfológico continuo entre estos extremos. Vasallo y Mora (2007) evaluaron el efecto del tamaño sobre el desarrollo del ángulo mandibular y la cresta masetérica, y la robustez de los incisivos, en 21 especies de Ctenomys, †Actenomys, y distintos géneros de octodontinos. Esta aproximación alométrica mostró diferencias importantes entre Ctenomys y los otros géneros.

La microestructura del esmalte dentario ha sido descripta y analizada en forma comparativa en algunas especies de Ctenomys (Martin, 1992; Koenigswald et al., 1994; Justo et al., 1995; De Santis et al., 2001; Vieytes, 2003; Vieytes et al., 2007). Dentro de un contexto de escasa variación, el esmalte de los incisivos de tres especies ( $†$ C. chapalmalensis, C. australis y C. talarum) mostró menos especialización que el de †E. chapalmalensis.

En contraste con los avances en el estudio de especializaciones craneodentarias, el esqueleto poscraneano no ha sido objeto de un nivel similar de análisis; si bien algunos aspectos han sido examinados, los estudios incluyeron sólo unas pocas especies en un marco de interpretación mucho más general. Lehmann (1963) estudió la morfología del miembro anterior de Ctenomys y Octodon en forma comparativa junto con otros roedores fosoriales, describiendo por primera vez rasgos especializados de la escápula, húmero, radio y ulna, que son discutidos más adelante en este trabajo. Casinos et al. (1993) analizaron las alometrías de los huesos largos en ctenominos y hallaron que éstos son gruesos y cortos en Ctenomys vivientes, mientras que este diseño estructural derivado no fue detectado en los ctenominos extintos $† C$. chapalmalensis, †Actenomys priscus, y †Eucelophorus sp. Más recientemente, Vassallo (1998) halló diferencias en el comportamiento de excavación y la 
morfología mioesqueletaria poscraneana entre C. talarum y C. australis, dos especies geográficamente simpátricas, aunque ecológicamente parapátricas (alotópicas sensu Reig et al., 1990). De acuerdo con el análisis de su comportamiento, C. australis, que habita en dunas costeras, es braquioexcavador y su actividad dentoexcavadora es ocasional, mientras que C. talarum, habitante de un mayor rango de sustratos, incluyendo suelos arcillosos muy duros, utiliza tanto los miembros anteriores como los incisivos en el cavado. Vassallo propuso la hipótesis de que el mayor tamaño de algunos músculos extensores del miembro anterior y la curvatura de la ulna más acentuada observados en C. talarum podrían conferir una ventaja mecánica para la producción de mayores fuerzas externas durante el cavado; en el caso de C. australis, la capacidad excavadora podría ser un subproducto de su mayor tamaño. Morgan y Verzi (2006) analizaron el húmero en numerosas especies de Ctenomys vivientes y extintas, mostrando que existe amplia disparidad morfológica dentro del género y que el incremento del ancho epicondilar podría ser la única especialización morfo-funcional del húmero que distingue a Ctenomys de otros géneros menos especializados para la vida fosorial. Ctenomys fue incluido también en un análisis de la diversidad autopodial de roedores histricognatos (Weisbecker y Schmid, 2007); los resultados señalaron diferencias anatómicas en la mano de este género con respecto a otros roedores fosoriales analizados, pero no identificaron rasgos funcionalmente significativos en esta estructura. Morgan (2008) abordó el estudio de la escápula de los caviomorfos mediante morfometría geométrica en un análisis que incluyó tres especies de Ctenomys. De acuerdo con dicho trabajo, la morfología escapular está fuertemente influida por la filogenia y la escápula de Ctenomys es similar a la de otros octodontoideos; el análisis morfo-funcional sugiere que los rasgos típicos de la escápula de los Octodontoidea, más allá de su origen, pueden ser ventajosos para el cavado. 


\section{MATERIALES Y MÉTODOS}

\section{IV.1. Materiales examinados (Apéndice I)}

Los materiales estudiados en este trabajo se encuentran depositados en las siguientes colecciones mastozoológicas y/o paleontológicas: Museo de La Plata (MLP), Museo Argentino de Ciencias Naturales “Bernardino Rivadavia” (MACN), Instituto Miguel Lillo, Tucumán (CML), Museo Municipal de Ciencias Naturales de Mar del Plata “L. Scaglia” (MMP y MMPMa), Instituto Argentino de Investigaciones de las Zonas Áridas (CM), Facultad de Ciencias Exactas y Naturales, Universidad Nacional de La Pampa (FCEN-UNLPam), Museo Nacional de Historia Natural de La Paz, Bolivia (CBF), y Facultad de Ciencias, Uruguay (CA, EV).

\section{IV.1.1. Material de Ctenomys}

Se examinó material esqueletario craneano y/o poscraneano de las siguientes especies: C. australis, C. azarae, C. conoveri, C. dorbignyi, C. flamarioni, C. frater, C. fulvus, C. leucodon, C. lewisi, C. maulinus, C. opimus, C. rionegrensis, C. steinbachi, y C. talarum, así como ejemplares de especies no determinadas, denominados de acuerdo con las localidades de colección: Ctenomys "perucho", arroyo Perucho Verna, Entre Ríos; Ctenomys "palmar", arroyo El Palmar, Entre Ríos; Ctenomys "mármol", arroyo Mármol, Entre Ríos; Ctenomys "vista", Bella Vista, Corrientes; Ctenomys "monte", Monte Hermoso, Buenos Aires; Ctenomys "somuncurá", Meseta de Somuncurá, Río Negro. La Tabla 1 resume la distribución geográfica de las especies examinadas y la caracterización del ambiente que ocupan (según fuentes bibliográficas).

Tabla 1 (página siguiente). Especies de Ctenomys estudiadas en este trabajo. La información sobre características ambientales fue tomada de la literatura (Pearson, 1959; Cook et al., 1990; Freitas, 1995; Anderson, 1997; Eisenberg y Redford, 1999; Charron, 2002; Mora et al., 2003; Brashear y Yahnke, 2004; Jurich y Myers, 2006; Fernandes et al., 2007; Chebez y Nigro, 2008; Udrizar Sauthier et al., 2008). 


\begin{tabular}{|c|c|c|c|}
\hline Especie & $\mathrm{N}$ & Distribución/Localidad & $\begin{array}{l}\text { Características } \\
\text { ambientales }\end{array}$ \\
\hline Ctenomys australis & 12 & $\begin{array}{l}\text { Costa atlántica } \text { de la } \\
\text { provincia de } \\
\text { Aires, Argentina }\end{array}$ & $\begin{array}{l}\text { Primera línea de dunas; } \\
\text { suelos arenosos muy } \\
\text { friables }\end{array}$ \\
\hline Ctenomys azarae & 4 & $\begin{array}{l}\text { La Pampa y oeste de Bs } \\
\text { As, Argentina }\end{array}$ & $\begin{array}{l}\text { Suelos arenosos en zonas } \\
\text { de bosque bajo y abierto } \\
\text { (matorrales); lomas con } \\
\text { vegetación psamófila }\end{array}$ \\
\hline Ctenomys conoveri & 1 & Bolivia, Paraguay & $\begin{array}{l}\text { Ambientes chaqueños } \\
\text { (primariamente sabanas } \\
\text { y matorrales); áreas de } \\
\text { suelos francos o arenosos }\end{array}$ \\
\hline Ctenomys dorbignyi & 2 & $\begin{array}{l}\text { Corrientes y Entre Ríos, } \\
\text { Argentina }\end{array}$ & $\begin{array}{l}\text { Albardones arenosos, no } \\
\text { ingresa en parches } \\
\text { boscosos }\end{array}$ \\
\hline Ctenomys flamarioni & 2 & $\begin{array}{l}\text { Rio Grande do Sul, SE de } \\
\text { Brasil }\end{array}$ & $\begin{array}{l}\text { Primera línea de dunas } \\
\text { costeras }\end{array}$ \\
\hline Ctenomys frater & 2 & $\begin{array}{l}\text { SO de Bolivia, NO de } \\
\text { Argentina: Salta y Jujuy }\end{array}$ & $\begin{array}{l}\text { Selvas húmedas, } \\
\text { pastizales de altura } \\
\text { Suelos maduros, } \\
\text { húmicos y } \\
\text { presumiblemente } \\
\text { compactos }\end{array}$ \\
\hline Ctenomys fulvus & 4 & $\begin{array}{l}\text { N de Chile, O de Salta, } \\
\text { Catamarca, La Rioja y } \\
\text { San Juan, NO de } \\
\text { Mendoza, Argentina }\end{array}$ & $\begin{array}{l}\text { Semidesierto del monte, } \\
\text { áreas áridas hasta } 2700 \mathrm{~m} \\
\text { snm }\end{array}$ \\
\hline Ctenomys leucodon & 2 & La Paz, Bolivia & $\begin{array}{l}\text { Puna árida a semiárida, } \\
\text { suelos inmaduros }\end{array}$ \\
\hline Ctenomys lewisi & 4 & Tarija, SO de Bolivia & $\begin{array}{l}\text { Suelos maduros, } \\
\text { frecuentemente cerca de } \\
\text { arroyos o ríos }\end{array}$ \\
\hline Ctenomys maulinus & 3 & Neuquén, Chile central & $\begin{array}{l}\text { Hábitats variados desde } \\
\text { arenas volcánicas en } \\
\text { ambientes abiertos hasta } \\
\text { bosques de Nothofagus y } \\
\text { Araucaria, 900-2000 m } \\
\text { snm }\end{array}$ \\
\hline Ctenomys opimus & 3 & $\begin{array}{l}\text { S de Perú, SO de Bolivia, } \\
\mathrm{N} \text { de Chile, NO de } \\
\text { Argentina: Catamarca, } \\
\text { Jujuy, Salta }\end{array}$ & $\begin{array}{l}\text { Vegetación escasa con } \\
\text { gramíneas, suelo arenoso } \\
\text { o poco compacto, áreas } \\
\text { inclinadas. Estepa del } \\
\text { altiplano } 2000 \text { a } 5000 \mathrm{~m} \\
\text { snm }\end{array}$ \\
\hline Ctenomys & 3 & Entre Ríos, Argentina; & Pastizales \\
\hline
\end{tabular}




\begin{tabular}{|c|c|c|c|}
\hline rionegrensis & & Uruguay & \\
\hline Ctenomys steinbachi & 3 & $\begin{array}{l}\text { O del Depto de Santa } \\
\text { Cruz, Bolivia }\end{array}$ & $\begin{array}{l}\text { No hay información } \\
\text { disponible }\end{array}$ \\
\hline Ctenomys talarum & 13 & $\begin{array}{l}\text { Buenos Aires y La } \\
\text { Pampa, Argentina }\end{array}$ & $\begin{array}{l}\text { Suelos francos a } \\
\text { arcillosos }\end{array}$ \\
\hline $\begin{array}{l}\text { Ctenomys } \\
\text { "mármol" }\end{array}$ & 4 & $\begin{array}{l}\text { Cercanías del arroyo } \\
\text { Mármol, Colón, E. Ríos, } \\
\text { Argentina }\end{array}$ & $\begin{array}{l}\text { No hay información } \\
\text { disponible }\end{array}$ \\
\hline Ctenomys "monte" & 10 & $\begin{array}{l}\text { Monte Hermoso, Buenos } \\
\text { Aires, Argentina }\end{array}$ & $\begin{array}{l}\text { Suelos arenosos, en } \\
\text { parapatría con C. talarum } \\
\text { y C. australis }\end{array}$ \\
\hline Ctenomys "palmar" & 1 & $\begin{array}{l}\text { Parque Nacional "El } \\
\text { Palmar", Colón, E. Ríos, } \\
\text { Argentina }\end{array}$ & $\begin{array}{l}\text { No hay información } \\
\text { disponible }\end{array}$ \\
\hline $\begin{array}{l}\text { Ctenomys } \\
\text { "perucho" }\end{array}$ & 4 & $\begin{array}{l}\text { Cercanías del } \mathrm{A}^{\circ} \text { Perucho } \\
\text { Verna, E. Ríos, Argentina }\end{array}$ & Suelos arenosos \\
\hline $\begin{array}{l}\text { Ctenomys } \\
\text { "somuncurá" }\end{array}$ & 4 & $\begin{array}{l}\text { Estancia "El Rincón", } \\
\text { Meseta de Somuncurá, } \\
\text { Río Negro, Argentina }\end{array}$ & $\begin{array}{l}\text { No hay información } \\
\text { disponible }\end{array}$ \\
\hline Ctenomys "vista" & 1 & $\begin{array}{l}\text { Bella Vista, Corrientes, } \\
\text { Argentina }\end{array}$ & Suelos arenosos \\
\hline
\end{tabular}

También se estudiaron materiales correspondientes a 5 especies extintas del género Ctenomys: $† C$. chapalmalensis del Plioceno tardío del área de Chapadmalal, Buenos Aires, Argentina; †Ctenomys sp. 1, †Ctenomys sp. 2, †Ctenomys sp. 3 y †Ctenomys sp. 4 del Pleistoceno de la costa de provincia de Buenos Aires. †C. subassentiens, del Pleistoceno medio de Tarija, Bolivia, se estudió mediante estereofotografías (Frailey et al., 1980).

\section{IV.1.2. Material comparativo}

El material comparativo incluyó ctenominos extintos, nueve especies vivientes de Octodontinae (Aconaemys "porteri", A. sagei, Octodon degus, O. "bridgesi", Octodontomys gliroides, Octomys mimax, Pipanacoctomys aureus, Spalacopus cyanus y Tympanoctomys barrerae), cuatro especies de la familia Echimyidae (Proechimys poliopus, Thrichomys apereoides, Euryzygomatomys 
spinosus y Myocastor coypus), una especie de la familia Abrocomidae (Abrocoma sp.), y el Caviidae Cavia aperea.

De los ctenominos extintos se seleccionaron aquéllos representados por restos craneanos y poscraneanos: †Actenomys, †Eucelophorus y †Praectenomys; †Praectenomys fue analizado sobre la base de ilustraciones inéditas y de la literatura (Quintana, 1994).

La subfamilia Octodontinae fue seleccionada como grupo de comparación para el análisis de la diversidad morfológica y adaptativa de Ctenomys, sobre la base de dos aspectos. Por un lado, es el grupo hermano de los Ctenomyinae (de acuerdo con un consenso creciente, ver Verzi, 2002; Opazo, 2005) y comparte con Ctenomys su distribución endémica en el sur de América del Sur; por otro lado, en contraste con los Ctenomyinae, esta subfamilia comprende una considerable diversidad ecomorfológica en la fauna actual (Contreras et al., 1987; Mares y Ojeda, 1982), desde géneros fosoriales morfológicamente generalizados (Octodontomys, Octodon, Octomys), semisubterráneos (Aconaemys, Tympanoctomys), hasta subterráneos (Spalacopus). La mayoría de las especies habita biomas de tipo matorral, en zonas semiáridas costeras, montañosas y desérticas, desde el nivel del mar hasta regiones andinas a $5000 \mathrm{~m}$ snm. La evolución del hábito subterráneo y los cambios morfológicos asociados con el mismo han sido muy diferentes a los de los ctenominos (Lessa et al., 2008).

Con respecto a los otros octodontoideos utilizados para comparación, los equímidos son considerados el grupo hermano de Octodontidae (Winge, 1941; Wood y Patterson, 1959; Reig, 1986; Verzi, 2002; Honeycutt et al, 2003; Opazo, 2005). Se incluyeron el fosorial Euryzygomatomys, los esencialmente epigeos Thrichomys y Proechimys, y el semiacuático Myocastor; este último también puede excavar extensas y complejas galerías en las orillas y barrancos de los cuerpos de agua donde habita (Nowak, 1991). El género Abrocoma (Abrocomidae) habita áreas abiertas en los Andes (Nowak, 1991; Hoyle, 2004).

La especie Cavia aperea (Caviidae) fue incluida en el grupo externo de 
comparación como ejemplo de caviomorfo de hábito generalizado (deambulador) y epigeo (Nowak, 1991; Honeycutt, 2003). Esta especie, conocida vulgarmente como cuis pampeano, está ampliamente distribuida en América del Sur, primariamente en pastizales de tipo sabana, praderas y márgenes de zonas forestadas.

\section{IV.2. Marco conceptual}

\section{La morfología funcional}

La morfología, el estudio de la forma, se ocupa tanto de describir hechos anatómicos en sí (estructura y disposición de las partes de los organismos), como de explicar las estructuras, analizar los patrones estructurales (cómo esas partes se integran para constituir un todo), comprender el significado de esta integración para el desempeño del organismo, y analizar las posibilidades y restricciones que implica una morfología dada para los procesos evolutivos (Kardong, 1999). Para lograr una mejor comprensión de las formas biológicas, los estudios morfológicos utilizan además información de numerosas y variadas fuentes, tales como la paleontología, paleobiología, taxonomía y fisiología (Hildebrand, 1988). Mientras que la morfología descriptiva se ocupa de la descripción de la forma (Bock, 1994), la morfología funcional se centra en aquellos caracteres anatómicos relevantes para comprender el funcionamiento de los organismos, sobre la base de información biomecánica, fisiológica, ecológica y/o comportamental (Hildebrand, 1988). La morfología funcional desempeña un papel fundamental en los análisis históricos de forma y función, ya que proporciona la base experimental, teórica y mecánica para entender la evolución de caracteres correlacionados.

En cuanto a la interpretación de cualquier rasgo anatómico (o de otro tipo) como una adaptación a una función determinada, ésta es compleja; si se utiliza una definición histórica de este último término, el análisis requiere contrastar dicha hipótesis con datos ambientales precisos que permitan 
especificar cuáles son las fuerzas selectivas a las que responderían las supuestas adaptaciones (Bock, 1980), en un marco filogenético adecuado (Lauder, 1981). Incluso una definición ahistórica, tal como la propuesta por Reeve y Sherman (1993: 9, "An adaptation is a phenotypic variant that results in the highest fitness among a specified set of variants in a given environment."), requiere de datos proporcionados por el análisis del desempeño (performance de Arnold, 1983). Como alternativa, el análisis morfofuncional permite identificar rasgos derivados cuyas características sugieren un desempeño mejor o peor para un modelo biomecánico dado, independientemente de si estas especializaciones morfológicas representan o no adaptaciones para el taxón analizado. El análisis funcional contribuye también a comprender por qué ciertos caracteres están correlacionados históricamente, y a discernir cuáles de ellos están relacionados causalmente con los cambios históricos de función o desempeño observados en la evolución de un clado (Lauder, 1990).

El uso de análogos mecánicos para analizar el significado funcional de una forma o estructura corresponde al campo de la biomecánica (Koehl, 1996). Las metodologías utilizadas incluyen los análisis mecánicos para estimar la resistencia de una estructura determinada, así como el análisis de fuerzas (cálculo de brazos de palanca y descomposición de fuerzas, Fig. 1). La aplicación de modelos biomecánicos, tanto teóricos como derivados de mediciones reales, representa el aspecto cuantitativo de la morfología funcional. Los índices morfo-funcionales utilizados en este trabajo se basan en los modelos biomecánicos clásicos de cálculo de resistencia de los huesos largos (modelados como vigas; Hildebrand, 1985) y de producción y transmisión de fuerzas a nivel de los sistemas mio-esqueletarios (Hildebrand, 1988). En el caso de la actividad excavadora, para estimar la Fo (outforce o fuerza externa efectivamente ejercida por el organismo sobre el sustrato) transmitida a partir de una determinada Fi (inforce, o fuerza interna generada 
por los músculos) es necesario conocer los brazos de palanca interno y externo (Li y Lo, respectivamente) de la palanca que transmite esas fuerzas (Fig. 1).

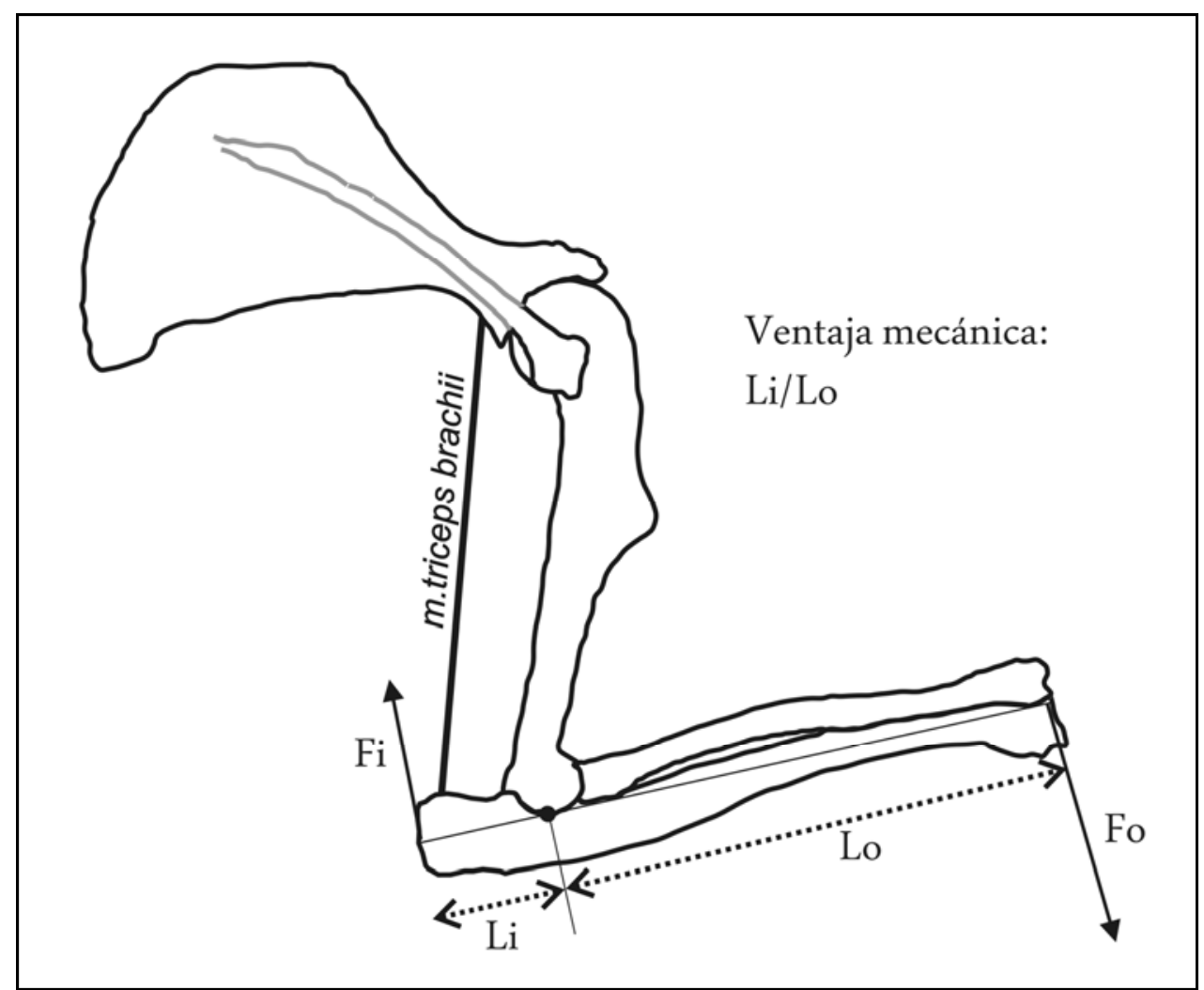

Figura 1. Miembro anterior de Ctenomys mostrando la transmisión de la fuerza generada por el músculo triceps brachii (inspirado en Price, 1993).

La ventaja mecánica de la palanca, es decir el cociente entre el trabajo realizado y el esfuerzo aplicado (Li/Lo), permite evaluar en forma comparativa la potencialidad biomecánica de una estructura en la producción de una fuerza externa (Fig. 1).

\section{Morfometría: el enfoque cuantitativo}

Los dos enfoques básicos para la morfometría o estudio cuantitativo de la forma son el enfoque basado en medidas lineales y el enfoque basado en coordenadas. Dentro de los métodos algebraicos, el uso de medidas lineales e índices construidos sobre la base de las mismas se ha utilizado clásicamente para describir y comparar la forma de los organismos. Existe una gran 
cantidad de análisis estadísticos que permiten abordar tanto medidas únicas como estudiar en forma simultánea conjuntos de medidas multivariadas extraídas de los organismos en estudio (Sokal y Rohlf, 1995; Legendre y Legendre, 1998; Zar, 1998). Este enfoque incluye también el análisis de alometrías, definidas como el crecimiento diferencial de las partes del organismo o "la relación entre los cambios de forma y el tamaño global" (Levinton, 1988). Las ecuaciones alométricas expresan las diferencias en las tasas de crecimiento de estas partes, sea en relación al tamaño corporal (o un estimador de tamaño), o de diversas partes entre sí. El análisis de alometrías permite identificar los cambios de forma que están directamente vinculados con el cambio de tamaño del organismo, los cuales pueden funcionar como restricciones o bien canalizar la dirección de dichos cambios.

Por su parte, el enfoque basado en coordenadas tiene otras características que lo hacen particularmente interesante para el estudio de ciertas formas biológicas. Las coordenadas de puntos seleccionados del organismo (puntos homólogos o landmarks) retienen tanto la información acerca de las distancias entre los puntos (dimensiones lineales) como de la geometría de la forma descripta (la ubicación relativa de cada punto en el espacio). La técnica de placas delgadas (thin-plate splines) desarrollada por Bookstein (1991) sobre la propuesta de Thompson (1917), permite modelar los cambios complejos de forma, utilizando técnicas multivariadas.

En el campo de la morfología, ambos enfoques se han desarrollado en forma paralela y constituyen herramientas útiles para los análisis cuantitativos. En este trabajo se utiliza principalmente morfometría lineal, ya que las medidas lineales permiten un análisis más directo cuando se pretende testear modelos funcionales claramente definidos como los mencionados previamente. Además, se aplica por primera vez morfometría geométrica al estudio de la escápula, una estructura morfológicamente compleja (Monteiro y Abe, 1999) cuya forma no puede ser capturada por completo mediante medidas lineales (ver apartado V.1.1.6 Análisis morfométrico geométrico). 


\section{IV.3. Metodología}

\section{IV.3.1. Análisis cualitativo}

Los materiales fueron examinados a ojo desnudo, bajo lupa de pie y lupa binocular. Los dibujos se realizaron utilizando una lupa binocular con cámara clara modelo MS5 (Leica). La nomenclatura de los rasgos craneanos y poscraneanos sigue a Lessertisseur y Saban (1967), Woods y Howland (1979), Hildebrand (1985), Argot (2001), Sargis (2002), y Verzi y Olivares (2006).

\section{IV.3.2. Morfometría tradicional}

a) Medidas

Las medidas lineales utilizadas en el análisis se detallan a continuación. Todas las medidas fueron tomadas utilizando calibre digital Digimess con $0.01 \mathrm{~mm}$ de precisión. El Apéndice II contiene una tabla de referencia con las medidas e índices utilizados.

Medidas tomadas en el cráneo (Fig. 2):

1. Largo basilar (Lb)

2. Ancho bicigomático $(\mathrm{Ab})$

3. Ancho mandibular (Amd)

4. Largo de diastema superior (Diast)

5. Profundidad de inserción del incisivo inferior (Pi): distancia entre margen anterior del foramen mandibular, el cual acompaña a la base del incisivo, y la parte superior del cóndilo.

6. Procumbencia de los incisivos superiores (ángulo de Thomas, Proc).

7. Concavidad del meato auditivo externo (Cma): distancia máxima entre el margen ántero-externo del meato auditivo externo y el punto de máxima concavidad sobre el margen del mismo, en vista dorsal.

8. Largo del cóndilo (Lc): largo máximo de la superficie articular del cóndilo mandibular. 
9. Altura anterior de la bula auditiva (Hab): alto de la bula por delante del meato auditivo externo, desde el contacto dorsal con el escamosoalisfenoides hasta el margen ventral de la bula.

10. Ancho de la base del proceso postcondíleo (Pc)

11. Alto de la región articular postglenoidea $(\mathrm{Hpg})$ : distancia máxima entre la fosa postglenoidea y el margen dorsal del meato auditivo externo.

12. Ancho de la fosa postglenoidea (Apg): medido a nivel del origen de la apófisis posterior del escamoso.

13. Espesor de la apófisis paraoccipital (Ep).
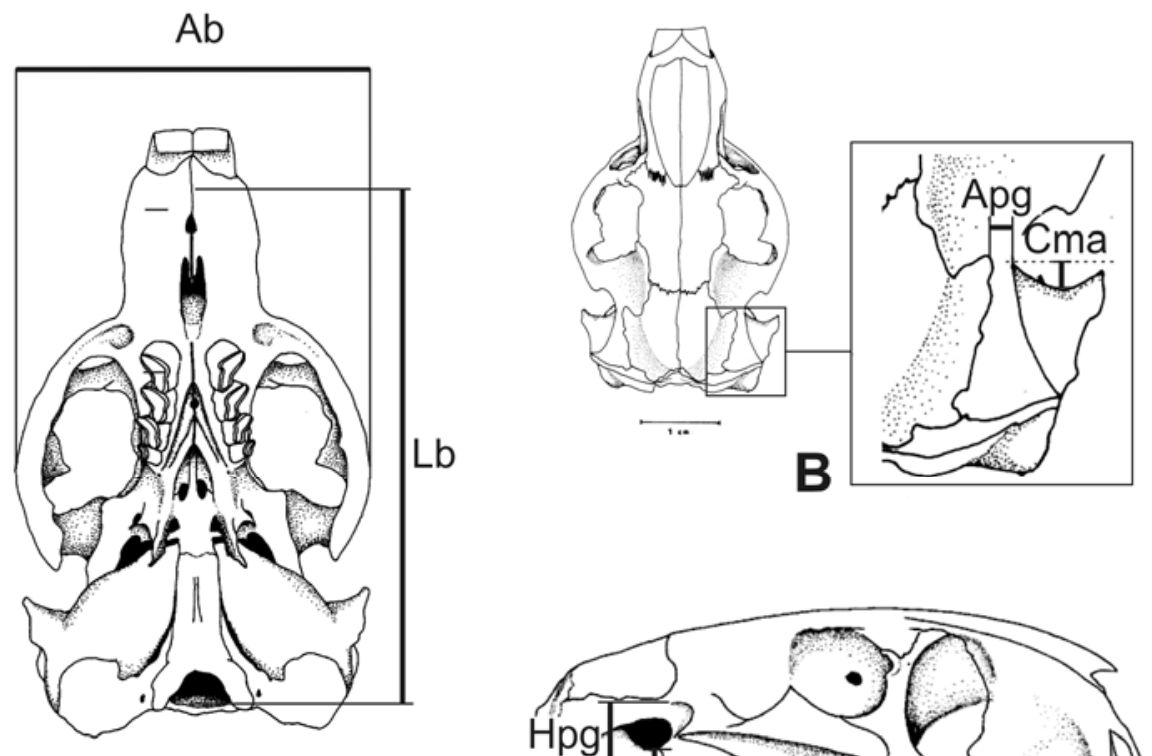

A
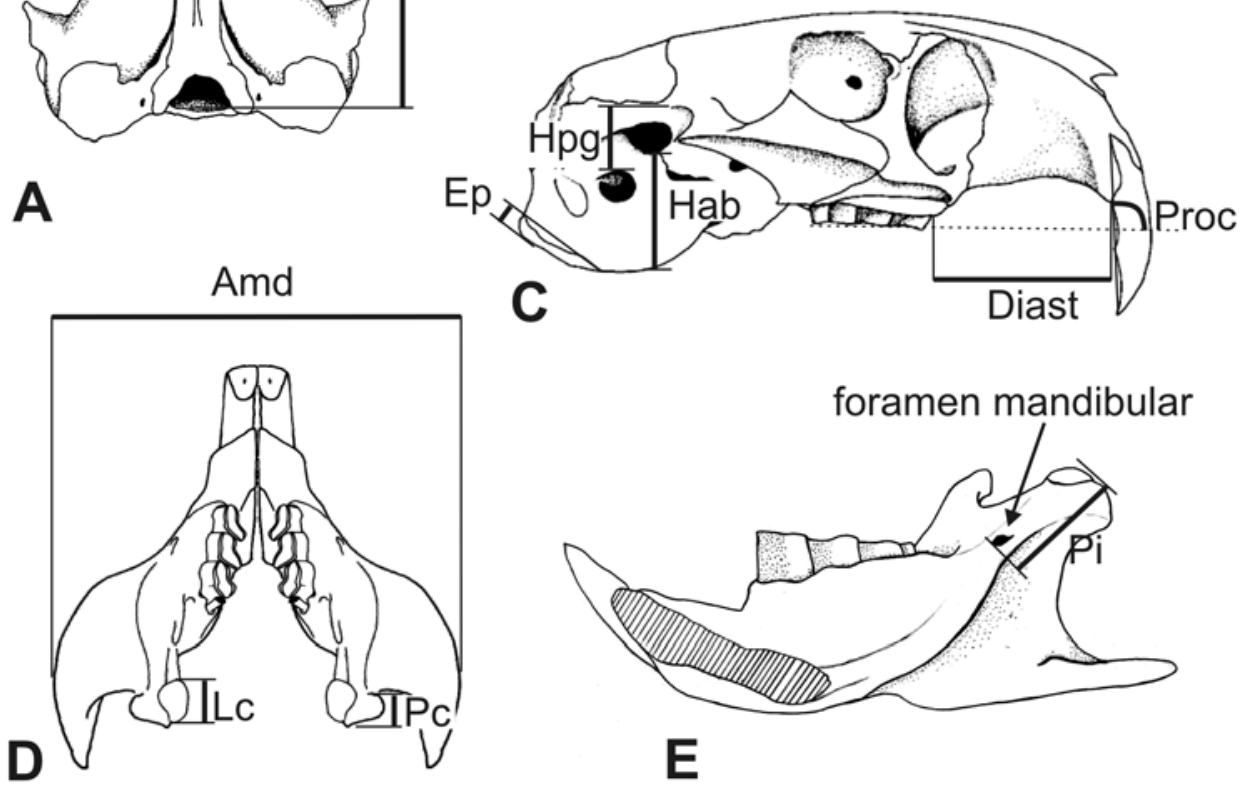
Figura 2. Medidas tomadas en el cráneo. A. vista ventral; B. vista dorsal y detalle de la región articular; C. Vista lateral; D. Vista dorsal de la mandíbula; E. vista medial de la hemimandíbula derecha. Las abreviaturas se explican en el texto. Modificado de Verzi y Olivares (2006).

Medidas tomadas en la escápula (Fig. 3):

1. Largo total de la escápula (LTE): distancia desde el labio de la cavidad glenoidea hasta el punto de intersección entre la base de la espina escapular y el borde vertebral;

2. largo del borde craneal (LBC): distancia desde el labio de la cavidad glenoidea hasta el punto de máxima curvatura del ángulo craneal;

3. largo del borde axilar (LBAX): distancia desde el labio de la cavidad glenoidea hasta el punto de máxima curvatura del ángulo caudal;

4. largo del borde vertebral (LBV); distancia desde el punto de máxima curvatura del ángulo craneal hasta el punto de máxima curvatura del ángulo caudal;

5. alto de la fosa supraespinosa (SUPRA): distancia desde el punto de intersección entre la base de la espina escapular y el borde vertebral, y el punto de máxima curvatura del ángulo craneal;

6. alto de la fosa infraespinosa (INFRA): distancia desde el punto de intersección entre la base de la espina escapular y el borde vertebral, y el punto de máxima curvatura del ángulo caudal;

7. largo del proceso teres major (LTM): medido a nivel de la base del mismo;

9. largo de la base de la espina (LBS): a nivel de máximo desarrollo de la gran muesca escapular;

10. altura de la gran muesca escapular (ASP): distancia máxima entre el plano escapular y la espina;

11. largo total de la espina (LES): medido desde la intersección entre la base de la espina y el borde vertebral, hasta el extremo distal del acromion; 
12. superficie de la escápula (SES): calculado aplicando la fórmula para superficie de triángulo de lados irregulares:

$$
\begin{gathered}
\operatorname{SES}=\sqrt{[}[\mathrm{s} *(\mathrm{~s}-\mathrm{a}) *(\mathrm{~s}-\mathrm{b}) *(\mathrm{~s}-\mathrm{c})] \\
\mathrm{s}=(\mathrm{a}+\mathrm{b}+\mathrm{c}) / 2
\end{gathered}
$$

donde los tres lados están representados por a (LBC), b (LBAX) y c (LBV).

13. superficie de la fosa supraespinosa (SFS): calculada según la misma fórmula:

$$
\begin{gathered}
\mathrm{SFS}=\sqrt{ }[\mathrm{s} *(\mathrm{~s}-\mathrm{a}) *(\mathrm{~s}-\mathrm{b}) *(\mathrm{~s}-\mathrm{c})] \\
\mathrm{s}=(\mathrm{a}+\mathrm{b}+\mathrm{c}) / 2
\end{gathered}
$$

donde

$$
\begin{aligned}
& a=\text { LBC } \\
& b=\text { SUPRA } \\
& c=\text { LTE }
\end{aligned}
$$

14. superficie de la fosa infraespinosa (SFI):

$$
\begin{gathered}
\mathrm{SFI}=\sqrt{[\mathrm{s} *}(\mathrm{s}-\mathrm{a}) *(\mathrm{~s}-\mathrm{b}) *(\mathrm{~s}-\mathrm{c})] \\
\mathrm{s}=(\mathrm{a}+\mathrm{b}+\mathrm{c}) / 2
\end{gathered}
$$

donde

$\mathrm{a}=\mathrm{LBAX}$

$b=$ INFRA

$\mathrm{c}=\mathrm{LTE}$ 


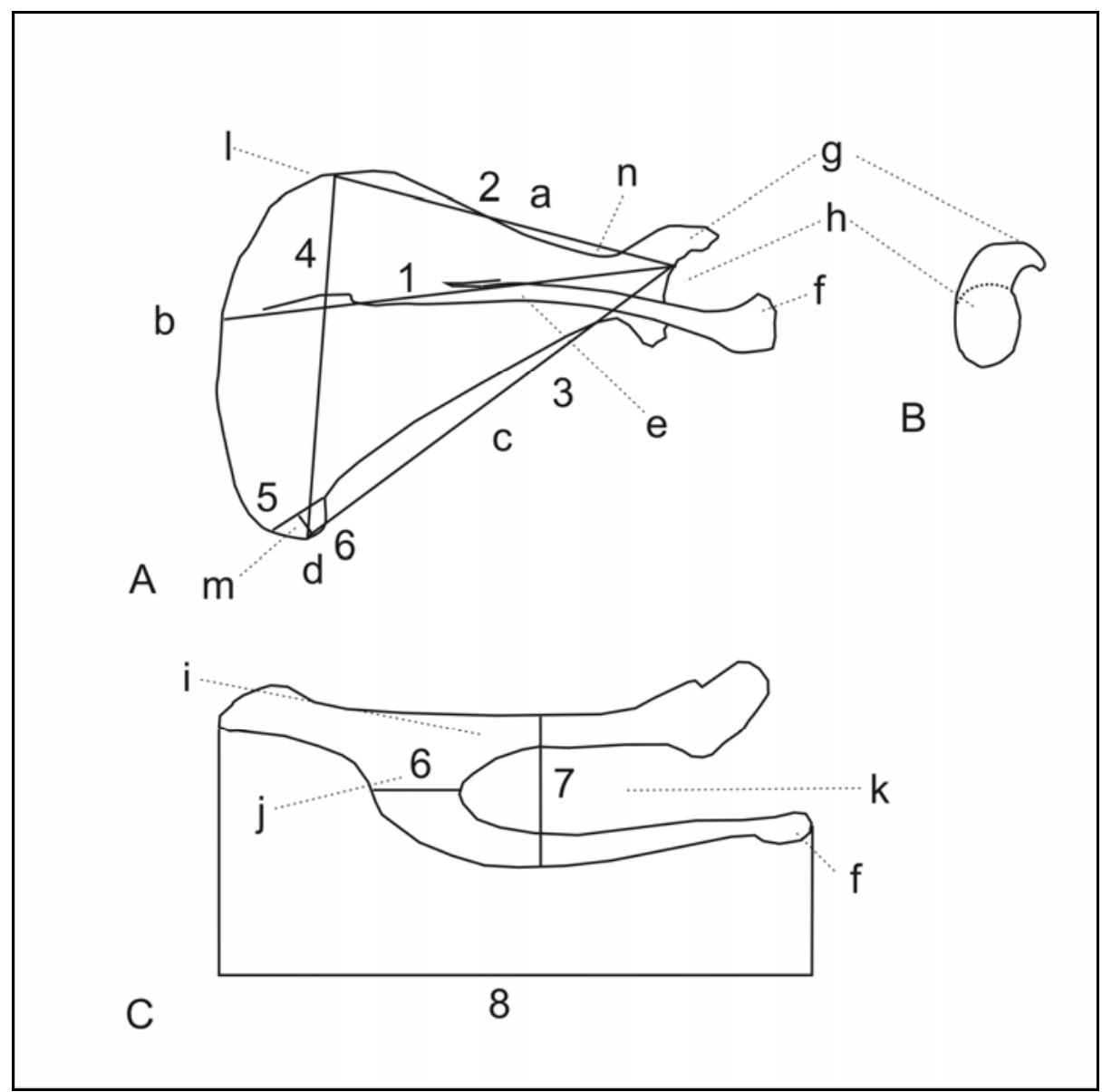

Figura 3. Esquema de la escápula derecha de Ctenomys mostrando los principales caracteres anatómicos y las medidas tomadas. A. Vista externa o lateral; B. Detalle de la superficie articular; C. Vista cráneo-dorsal; a. borde craneal; b. borde vertebral; c. borde axilar; d. ángulo caudal; e. espina escapular; f. acromion; g. apófisis coracoides; h. cavidad glenoidea; i. hoja escapular; j. base de la espina; $\mathrm{k}$. gran muesca escapular; l. ángulo craneal; $\mathrm{m}$. proceso teres major (puede formar una fosa postescapular); n. cuello. Medidas: 1. largo de la escápula (LTE); 2. largo del borde craneal (LBC); 3. largo del borde axilar (LBAX); 4. largo del borde vertebral (LBV); 5. largo del proceso teres major (LTM); 6. largo de la base de la espina (LBS); 7. altura de la gran muesca escapular (ASP); 8. largo total de la espina (LES).

Medidas tomadas en el húmero (Fig. 4)

1. Largo total del húmero (LTH): medido desde el extremo de la cabeza articular hasta el punto más distal de la tróclea

2. Distancia deltoidea (DELT): distancia entre cabeza humeral y base distal de la cresta deltoidea

3. Ancho de la epífisis proximal (TUB): medido a nivel de las tuberosidades humerales 
4. Ancho de la cabeza articular (ACA): medido en el diámetro máximo en sentido lateromedial

4. Diámetro anteroposterior de la diáfisis humeral (DAP): medido en la mitad de la diáfisis

5. Diámetro lateromedial de la diáfisis humeral (DLMH): medido en la mitad de la diáfisis

5. Ancho máximo a nivel de los epicóndilos (AEPI)

6. Ancho de la superficie articular distal (tróclea y capítulo) (ASAD)

7. Profundidad (altura) de la tróclea (HTRO): medida tal como se indica en la Fig. 4.

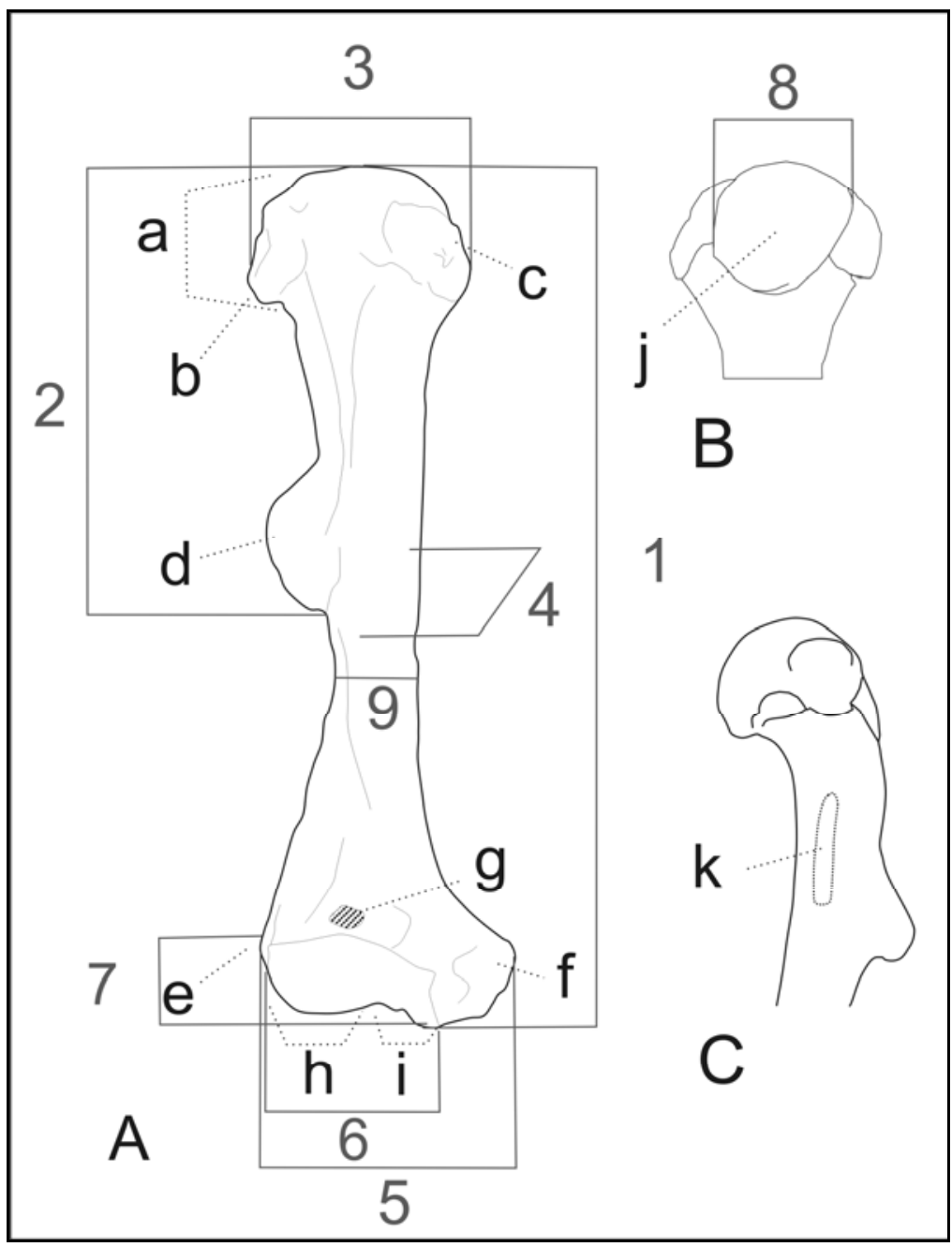

Figura 4. Esquema del húmero derecho de Ctenomys mostrando los principales caracteres anatómicos y las medidas tomadas. A. Vista anterior; B. Detalle de la cabeza humeral en vista posterior; C. Detalle de la diáfisis en 
vista medial. a. cabeza humeral; b. tuberosidad mayor; c. tuberosidad menor; d. cresta deltoidea; e. epicóndilo lateral; f. epicóndilo medial; g. foramen supratroclear; h. capítulo; i. tróclea; j. cabeza articular; k. inserción del m. teres major. Medidas: 1. largo total del húmero (LTH); 2. distancia cabeza humeralbase de la cresta deltoidea (DELT); 3. ancho de la epífisis proximal, incluyendo tuberosidades (TUB); 4. diámetro anteroposterior del húmero (DAP); 5. ancho a nivel de los epicóndilos; 6 . ancho de la superficie articular distal (tróclea y capítulo); 7. profundidad de la tróclea; 8. ancho de la cabeza humeral; 9. diámetro láteromedial del húmero (DLMH).

Medidas tomadas en la ulna (Fig. 5):

1. Largo total de la ulna (LTU): distancia máxima entre el extremo del olécranon y el extremo del proceso estiloide

2. diámetro máximo dorso-ventral (DMU): o anteroposterior (en posición anatómica) medido en la mitad de la diáfisis

3. largo del olécranon (LOL): medido desde el extremo del olécranon hasta el borde posterior de la cavidad sigmoidea

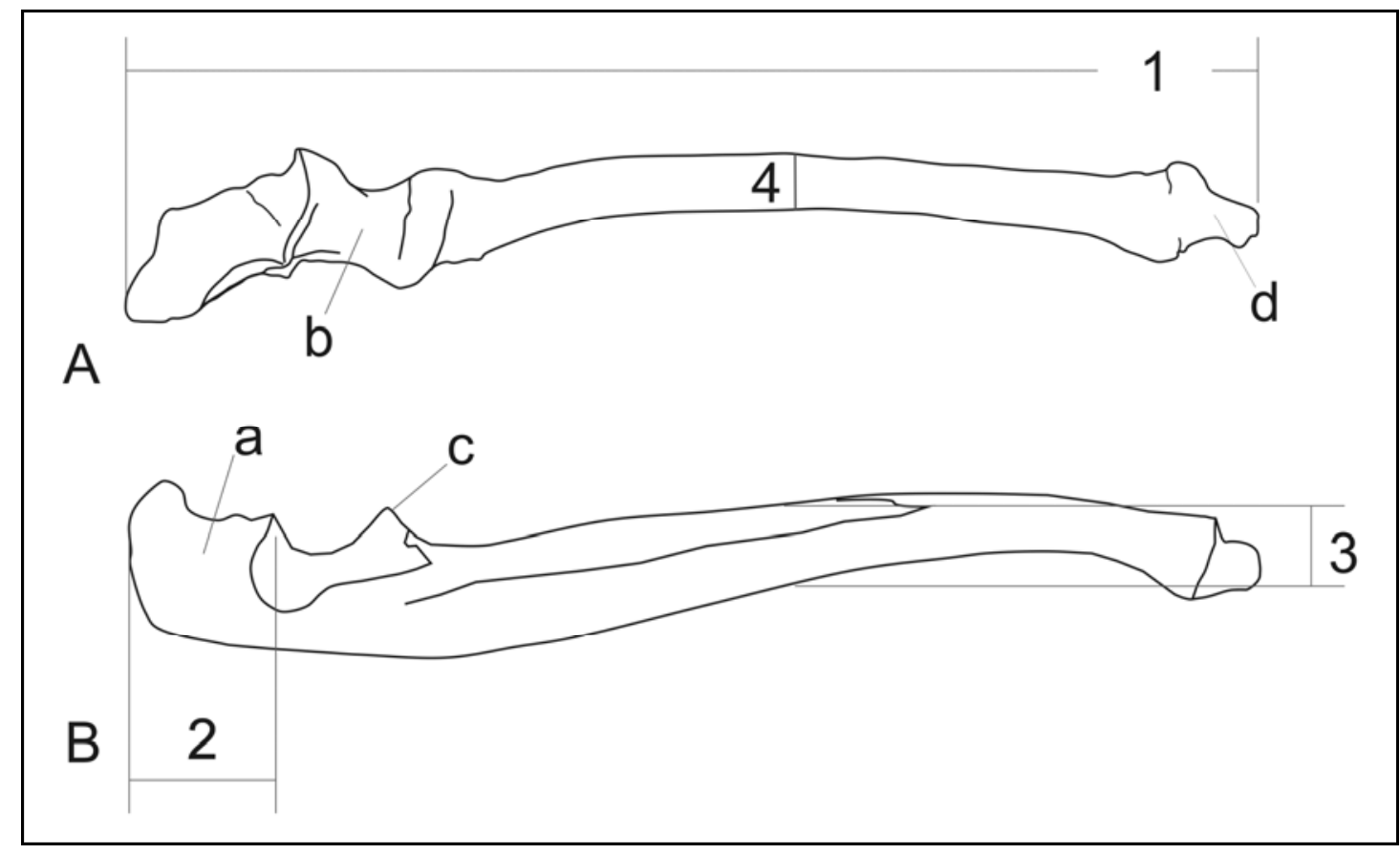

Figura 5. Esquema de la ulna izquierda de Ctenomys mostrando los principales caracteres anatómicos y las medidas tomadas. A. Vista superior. B. Vista medial. a. olécranon; b. fosa sigmoidea; c. apófisis coronoides; d. proceso estiloide. Medidas: 1. largo total de la ulna (LTU); 2. largo del olécranon 
(LOL); 3. diámetro máximo dorsoventral (anteroposterior) de la ulna (DMU):

4. diámetro máximo lateromedial de la ulna (DLMU)

Medidas tomadas en el radio (Fig. 6):

1. Largo total del radio (LTR): largo máximo

2. Diámetro dorsoventral del radio (DMR): medido en la mitad de la diáfisis

3. Diámetro lateromedial del radio (DLMR): medido en la mitad de la diáfisis

4 Diámetro mayor de la fóvea radial (DMAF)

5. Diámetro menor de la fóvea radial (DMIF)

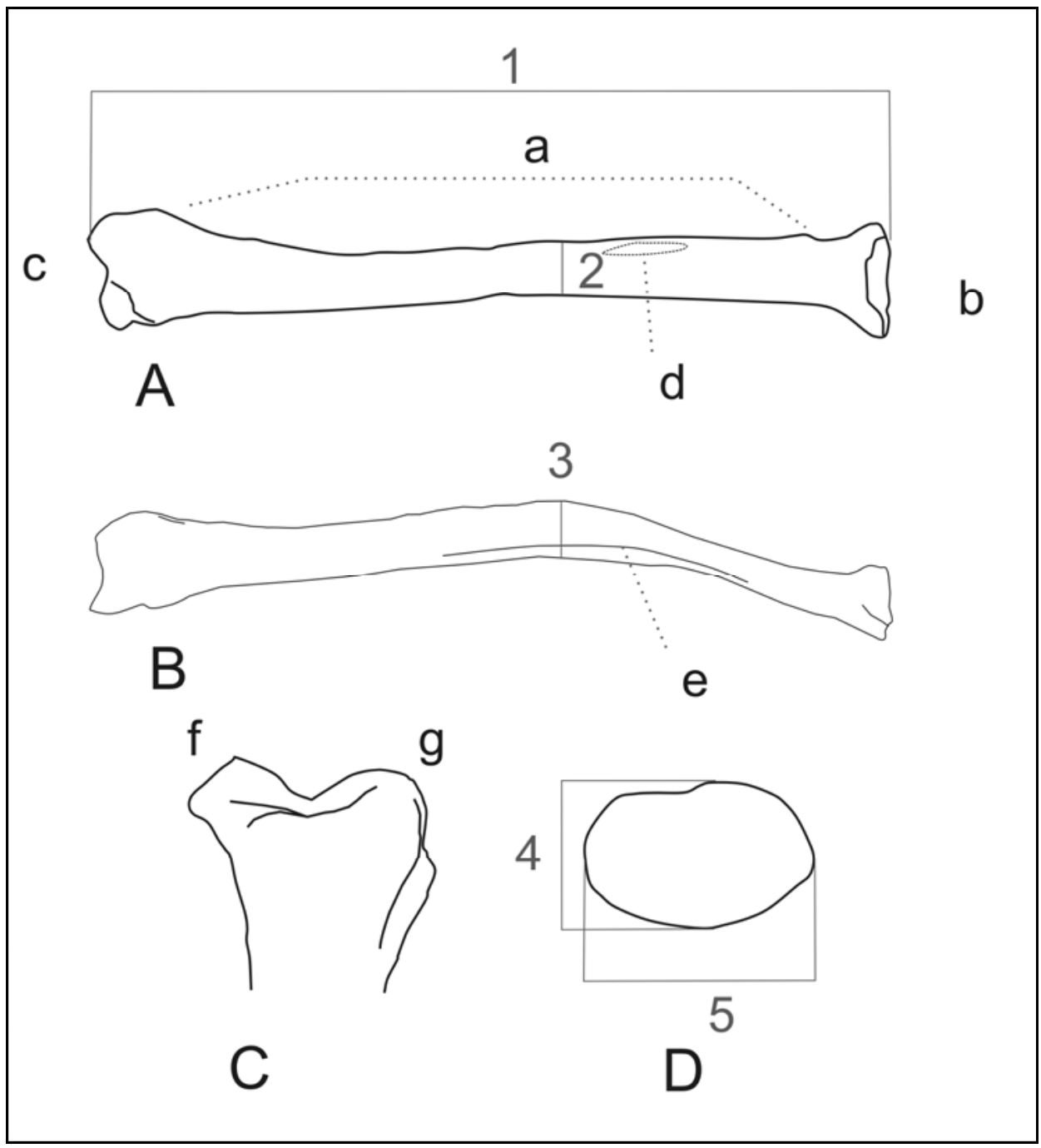

Figura 6. Esquema del radio izquierdo de Ctenomys mostrando los principales caracteres anatómicos y las medidas tomadas. A. Vista superior; B. Vista 
lateral externa, C. Detalle de la epífisis distal en vista dorsal; D. Fovea en vista frontal. a. Diáfisis; b. epífisis proximal; c. epífisis distal; d. Area de inserción del m. supinator; e. cresta interósea; f. proceso pseudoestiloide; g. proceso estiloide. Medidas: 1) Largo total del radio (LTR); 2) diámetro lateromedial (DLMR); 3) diámetro dorsoventral (DMR); 4) diámetro menor de la fóvea (DMIF); 5) diámetro mayor de la fóvea (DMAF).

Medidas tomadas en el autopodio (Fig. 7)

1. Ancho máximo del carpo (AMCA)

2. Largo máximo del carpo (LMCA)

3. Largo del metacarpiano III (LM3)

4. Ancho lateromedial del metacarpiano III (AM3): medido en la mitad de la diáfisis y en vista dorsal.

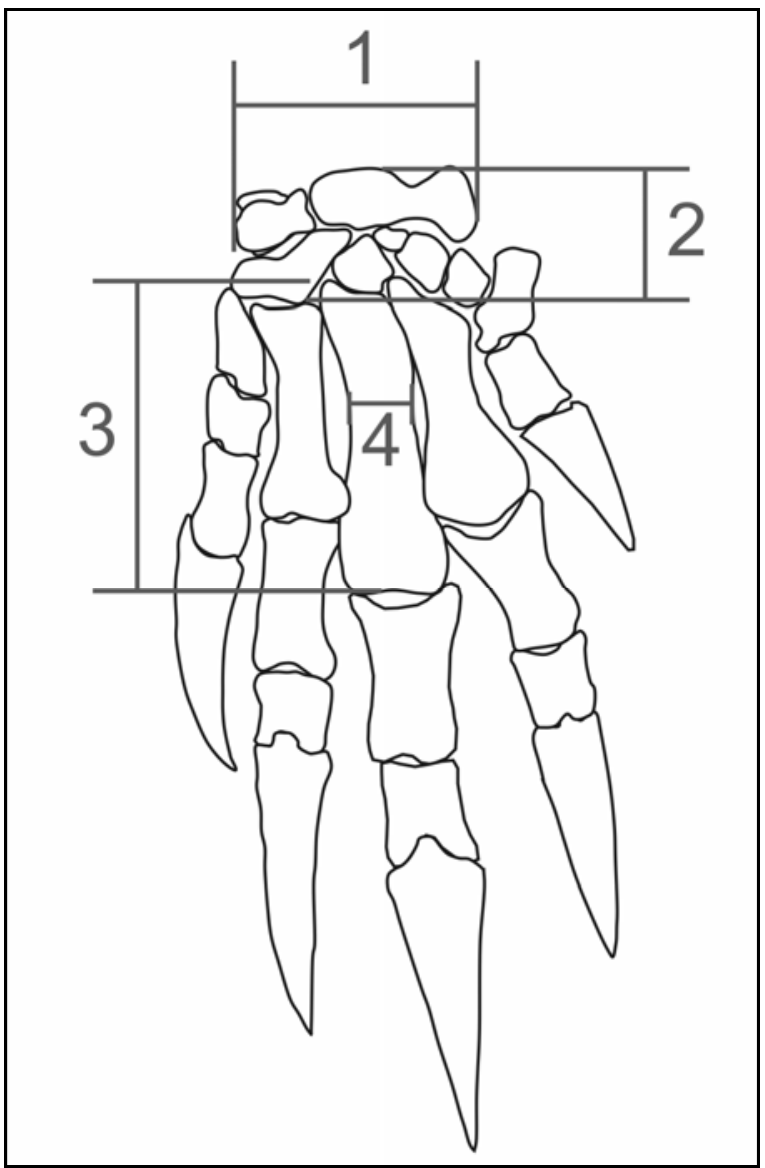

Figura 7. Esquema de la mano derecha de Ctenomys en vista dorsal, mostrando las medidas tomadas. 1. ancho del carpo (AMCA); 2. largo del carpo (LMCA); 3. largo del metacarpiano III (LM3); 4. ancho del metacarpiano III (AM3). Modificado de Quintana, 1994. 


\section{b) Índices morfo-funcionales}

Los índices se construyeron sobre la base de las medidas lineales tomadas, con el propósito de obtener variables capaces de describir tanto la forma de estructuras específicas, así como rasgos con posible significado funcional. La definición e interpretación funcional de cada índice se detallan en los apartados siguientes (ver también Apéndice II).

Más allá de su indiscutida utilidad como descriptores de formas y proporciones ("ratios may be the only meaningful way to interpret and understand certain types of biological problems", Sokal y Rohlf 1981, p. 17), el uso de índices para realizar análisis estadísticos es un tema debatido (ver revisiones y discusiones en Mosimann, 1970; Lemen, 1983; Jungers et al., 1995; Jackson y Somers, 1991, y literatura citada en estos trabajos). Por un lado, se argumenta que el uso de índices implica pérdida de información porque un aumento en el tamaño del valor del cociente puede deberse al aumento del numerador, disminución del denominador, o ambos fenómenos. Esto no resulta un obstáculo en este trabajo, ya que se utiliza el análisis alométrico de las medidas originales para dilucidar el comportamiento de cada variable. Por otro lado, los índices tienden a tener distribuciones de frecuencias muy asimétricas, alejadas de la normalidad. Para corregir este problema, se aplicaron varias transformaciones a las variables $(\log -10, \log -2$, logaritmo natural) de acuerdo con las recomendaciones de Lemen (1983) y Jungers et al. (1995); luego de verificar que el efecto normalizador de las mismas era similar en los tres casos, se utilizó la transformación a través de logaritmo en base 10 para todos los índices antes de incluirlos en los análisis estadísticos multivariados. Otro problema frecuentemente señalado es la posible introducción de correlaciones espurias entre variables que son originalmente independientes, debida a la división de las medidas por una variable común (utilizada para generar un índice); esto sería claramente un factor indeseable al momento de realizar análisis multivariados basados en la correlación entre variables. Sin embargo, esta crítica sólo es válida cuando las variables (X e Y) 
son independientes, en cuyo caso el cociente de Y/X debería estar correlacionado negativamente con X. En los índices utilizados en este trabajo, ambas variables son medidas lineales, de forma que $\mathrm{Y}$ aumenta a medida que lo hace X (correlación positiva); así, cualquier correlación negativa observada es real y no un artefacto metodológico (Jungers et al., 1995).

En estos análisis, los índices se usan como descriptores de la forma o características biomecánicas particulares, y no con el fin de "extraer" o "remover" el tamaño de los elementos u organismos estudiados (Lemen, 1983, Jungers et al., 1995, y bibliografía allí citada). Dado que los índices son caracteres de forma (Simpson et al., 1960; Corruccini, 1975, citados en Lemen, 1983), los ejes en el hiperespacio del análisis multivariado son esencialmente ejes de forma. Así, cualquier cambio a lo largo de un eje representa un cambio real de forma (Lemen, 1983).

Índices utilizados en el análisis de cintura escapular y miembro anterior

La musculatura del miembro anterior de Ctenomys se caracteriza por el fuerte desarrollo de los músculos flexores, así como de aquellos que estabilizan el hombro, la articulación más móvil de esta parte del cuerpo (Lehmann, 1963; Vassallo, 1998). A su vez, este desarrollo se refleja en el gran tamaño relativo de los rasgos anatómicos que funcionan como superficies de origen e inserción muscular, los cuales forman crestas, protuberancias, surcos y amplias superficies rugosas. El origen, inserción y desarrollo de los músculos (Apéndice III) se reflejan en rasgos de la morfología del esqueleto que fueron cuantificados mediante índices, y permiten realizar inferencias morfo-funcionales sobre la base de principios biomecánicos. Para el análisis miológico se utilizó la información disponible en la literatura (Lehmann, 1963; Woods, 1972; De Santis et al., 1998; Vassallo, 1998); además, se realizaron disecciones de la musculatura de cintura escapular y miembro anterior de las especies C. talarum, C. australis y C. "perucho", sobre ejemplares frescos y fijados de acuerdo con la metodología descripta en Woods (1972). 
En este trabajo, los índices DRE, OLR FFOV, PRD, PTR y SDH fueron tomados de la literatura (Hildebrand, 1985; Laville, 1990; Sargis, 2003 y Elissamburu y Vizcaíno, 2004), mientras que los índices ARCA, DEP, DFI, DRT, ELON, LRBE, LRBV, LRES, LRTM, RHU, RMC3, RULN y RRAD fueron diseñados para este trabajo de acuerdo con observaciones propias.

ARCA: ancho relativo del carpo (ancho del carpo/largo del carpo). Este es un indicador de la forma de la mano.

DEP: alto relativo de la gran muesca escapular (altura de la gran muesca escapular/largo total de la escápula). Este índice es un indicador del desarrollo relativo del m. infraspinatus; la mayor separación entre la espina y el cuerpo escapular también puede alterar las líneas de acción de los músculos originados e insertos en la primera (grupos musculares trapecios y deltoideos).

DFI: desarrollo relativo de la fosa infraespinosa (superficie de la fosa infraespinosa/superficie de la fosa supraespinosa). Este índice es un indicador del desarrollo relativo de los m. supraspinatus e infraspinatus.

DRE, ancho relativo del húmero a nivel de los epicóndilos (ancho a nivel epicóndilos/largo total del húmero). Este índice es un estimador del desarrollo de los músculos flexores de la mano.

DRT: desarrollo relativo de las tuberosidades humerales (tamaño relativo de las tuberosidades con respecto a la cabeza articular/largo total del húmero). Este índice estima el desarrollo de los músculos estabilizadores del hombro y la movilidad del brazo a nivel del hombro.

ELON: elongación de la escápula (largo del borde axilar/largo del borde craneal). Es un estimador de la diferencia en las líneas de acción de los músculos serratus y rhomboideus con respecto a las del m. trapezius.

FFOV: elongación relativa de la fóvea (diámetro mayor/diámetro menor de la fóvea). Este índice refleja grado de capacidad de rotación del radio (pronación/supinación). 
LRBE: largo relativo de la base de la espina (largo de la base de la espina/largo total de la escápula). Este índice es también un indicador del desarrollo del m. infraspinatus.

LRBV: largo relativo del borde vertebral (largo del borde vertebral/largo total de la escápula); este índice es un indicador del desarrollo de las superficies de origen de los músculos rhomboideus, levator scapulae y serratus s.s.

LRES: largo relativo de la espina escapular (largo de la espina escapular/largo total de la escápula).

LRTM: largo relativo del proceso teres major (largo de la base del proceso teres major/largo total de la escápula). Como su nombre lo indica, este proceso del borde axilar de la escápula es el sitio de origen del m. teres major.

OLR: desarrollo del olécranon ulnar (largo total del olécranon/largo total de la ulna). Este índice expresa la ventaja mecánica del m. triceps brachii; por otra parte, estima indirectamente la superficie disponible para origen de los principales flexores y extensores de la mano.

PRD: posición relativa de la cresta deltoidea sobre la diáfisis humeral (distancia entre el extremo de la cabeza humeral y la base del la cresta deltoidea/ largo total del húmero). Este índice es un estimador del brazo interno de palanca de los m. deltoideos y pectorales. La medida utilizada para calcular este índice es la distancia desde la cabeza humeral hasta el margen distal de la base de la cresta deltoidea (de acuerdo con Laville, 1990, y Elissamburu y Vizcaíno, 2004, fig. 1), considerando que los músculos mencionados, y en especial el $\mathrm{m}$. spinodeltoideus, se insertan sobre toda la superficie de la cresta deltoidea y no solamente sobre el punto más elevado de la misma, que puede ser subdistal.

PTR: profundidad relativa de la tróclea (profundidad de la tróclea/largo total del húmero). Este índice es otro estimador de la estabilización de la articulación del codo.

RHU: robustez humeral (diámetro anteroposterior del húmero en la mitad de la diáfisis/ largo total del húmero). Este índice es un indicador de la 
resistencia del hueso, particularmente con respecto a las fuerzas aplicadas en el plano sagital durante los movimientos de cavado.

RMC3: robustez del metacarpiano III (ancho lateromedial del metacarpiano III/largo del metacarpiano III). Indicador general de la resistencia del hueso.

RRAD: robustez del radio (diámetro dorsoventral del radio en la mitad de la diáfisis/largo total del radio). Este índice es un indicador de la resistencia del hueso, particularmente con respecto a la torsión y otras fuerzas experimentadas durante los movimientos de cavado.

RULN: robustez de la ulna: diámetro dorsoventral de la ulna en la mitad de la diáfisis/largo total de la ulna. Como en otros elementos, este índice es un indicador general de resistencia del hueso.

SDH: ancho relativo de la superficie articular distal del húmero: ancho de la superficie articular distal/largo total del húmero. Este índice es un estimador de la estabilización de la articulación del codo.

Índices utilizados en el análisis de cráneo

Estos índices corresponden a las medidas craneanas lineales descriptas (apartado IV.3.2 Morfometría tradicional) divididas por el largo basilar (de acuerdo a Verzi y Olivares, 2006); se excluye la medida de Procumbencia (PROC) de los incisivos por tratarse de una medida angular.

AB (Ab/ Lb) y AMD (Amd/ $\mathrm{Lb}$ ) son estimadores del desarrollo de los músculos adductores de la mandíbula.

CMA (Cma/ Lb), LC (Lc/ Lb), HAB (Hab/ Lb), PC (Pc/ Lb), HPG (Hpg/ Lb) y APG (Apg/ Lb) estiman el grado de ajuste del cóndilo en la región de articulación postglenoidea.

DIAST (Diast/ Lb) es un estimador del largo del incisivo superior.

EP (Ep/ Lb) estima el desarrollo de los $\mathrm{m}$. digastricus, retractores de la mandíbula. 
PI (Pi/ Lb), posición de la base del incisivo, es un estimador de la profundidad (largo relativo) de la inserción del incisivo inferior.

\section{IV.4. Morfometría geométrica}

Para el análisis de la forma de la escápula se utilizó tanto morfometría tradicional como geométrica. Este doble enfoque se debe a que la escápula ofrece pocos puntos homólogos que permitan describirla adecuadamente sólo mediante medidas lineales. En particular, la forma del borde craneal y del ángulo del mismo nombre son variables entre las especies analizadas. De esta manera, ambas metodologías se aplicaron de forma complementaria y permitieron explorar la variabilidad morfológica de manera más exhaustiva. Los detalles metodológicos se incluyen en el apartado V.1.1.6. Análisis morfométrico geométrico.

\section{IV.5. Análisis estadísticos}

Para explorar la variación morfológica encontrada, se utilizó Análisis de Componentes Principales (ACP) de los índices morfo-funcionales generados a partir de medidas lineales, o de las coordenadas de forma luego de realizar superposición de Procrustes, en el caso de los análisis morfométricos geométricos. Estos análisis exploratorios permitieron analizar relaciones entre caracteres y entre especies, con el objetivo de identificar posibles patrones (morfotipos y correlación entre variables). Luego, las variables que resultaron más influyentes en estos análisis fueron incluidas en un primer ACP general del miembro anterior, para evaluar la posible existencia de correlación entre las especializaciones de cada hueso detectadas en los análisis previos correspondientes, y en un segundo ACP que incluyó también índices morfo-funcionales del cráneo vinculados con la especialización dentoexcavadora. En todos los análisis, las variables fueron transformadas logarítmicamente para lograr una distribución más 
cercana a la normal, y se usó la matriz de correlación como base para los ACP.

La posible influencia del tamaño corporal sobre las medidas e índices estudiados se analizó mediante regresiones lineales en busca de posibles alometrías intra- o interespecíficas. Las variables fueron transformadas a través del logaritmo en base 10 y analizadas de acuerdo al modelo II (ejes principales estandarizados), mediante los paquetes de software Model II (Legendre, 2001) y SMATR (Warton et al., 2006).

La variabilidad morfológica intraespecífica se analizó cuantitativamente mediante el coeficiente de variación para las medidas tomadas en cráneo y poscráneo (Cullinane, 2000; Meiri et al., 2005). A partir de las medias por especie de cada medida tomada se generaron coeficientes de variación para cada variable considerada, de acuerdo con la siguiente fórmula:

\section{Coeficiente de variación $(\mathrm{CV})$ = desviación estándar/media}

Este valor expresa la variación en forma proporcional a las dimensiones de la medida considerada y puede ser usado para comparar directamente la variabilidad morfológica de la cintura pectoral y miembro anterior con respecto a la del cráneo.

Los análisis estadísticos bi- y multivariados se realizaron mediante los paquetes de software Statistica (Statsoft, 2004) y XLStat (Addinsoft, 2004).

\section{IV.6. Métodos filogenéticos comparativos}

Dado que pueden existir asociaciones no aleatorias de rasgos entre especies que se deben a la historia evolutiva común, en este trabajo se utilizaron diversos métodos filogenéticos comparativos (MFC) para controlar la dependencia jerárquica entre las especies analizadas (Felsenstein, 1985; Harvey y Pagel, 1991). Básicamente, los MFC particionan la varianza de un carácter entre una parte atribuida a la filogenia y una varianza residual; esta última es la que se utiliza para analizar las correlaciones entre los caracteres 
estudiados (Cheverud et al., 1985; Westoby et al., 1995; Desdevises et al., 2003; Claude, 2004). De todas maneras, debe tenerse en cuenta qué parte de la variación correlacionada con la filogenia puede estar también vinculada con factores ecológicos y fuerzas selectivas, ya que la filogenia y la ecología no son interpretaciones mutuamente excluyentes (Westoby et al., 1995), por lo cual estos análisis se utilizan como un complemento del estudio de los caracteres crudos.

En este trabajo, se aplicaron dos MFC diferentes para abordar los análisis.

a. Para el análisis de morfología escapular se aplicó el método Ecuaciones de Estimación Generalizada (GEE, Liang y Zeger, 1986). Se trata de una extensión de los Modelos Lineales Generalizados (GLM) que permite analizar tanto variables continuas como categóricas (Paradis y Claude, 2002), tales como las presentes en el conjunto de datos (variables cuantitativas continuas: deformaciones parciales y tamaño corporal; variable categórica: hábito locomotor). Este método acepta esquemas filogenéticos con politomías; en este caso se utilizó la filogenia ilustrada en la Fig. 8. Esta filogenia compuesta se basó en la filogenia propuesta por Huchon y Douzery (2001), complementada por los resultados de Honeycutt et al. (2003), Galewski et al. (2005), Slamovits et al. (2001), Gallardo y Kirsch (2001) y Castillo et al. (2005). Dado que se utilizó una filogenia compuesta, sin largos de rama comparables, los mismos fueron asignados arbitrariamente usando el método de Grafen (1989). Estos análisis fueron realizados en el entorno de programación " $R$ " ( $R$ Development Core Team, 2005) usando el paquete "Analysis of Phylogenetics and Evolution" (APE, Paradis et al., 2004; Paradis, 2006). 


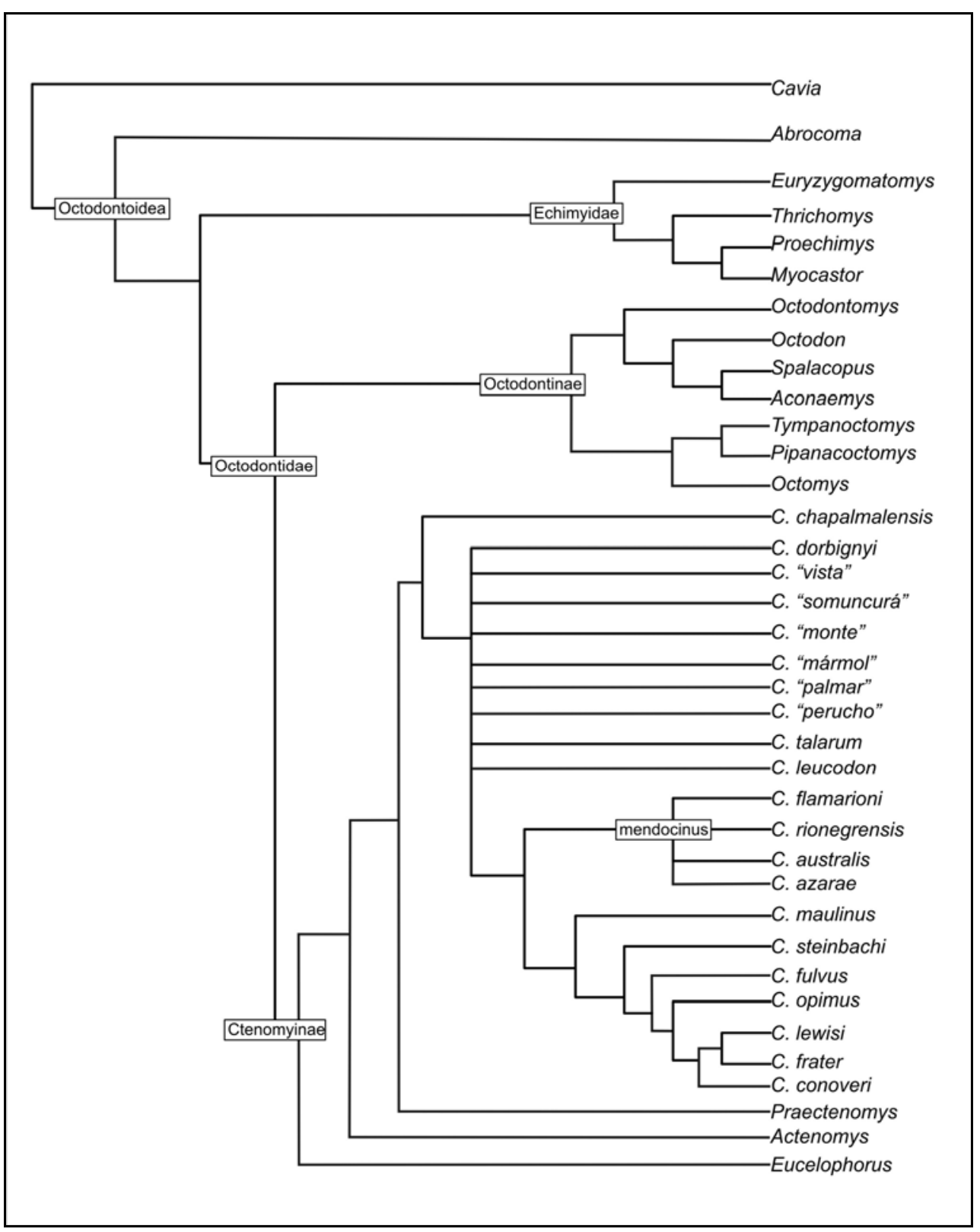

Figura 8. Cladograma compuesto utilizado para los análisis filogenéticos comparativos. Ver fuentes en el texto.

También se cuantificó la inercia filogenética, definida como una medida de la restricción o determinación del cambio evolutivo debida a la historia filogenética previa (Claude, 2004), mediante pruebas de Mantel de correlación entre distancia morfométrica y distancia filogenética utilizando el software XLStat (Addinsoft, 2004) corriendo bajo MS Excel (Microsoft, 2003). 
b. Para el análisis de las correlaciones entre índices craneanos y poscraneanos (caracteres cuantitativos continuos) en especies de Ctenomys se aplicó el método de Contrastes Independientes (CI). En el método de CI, sobre la base del cladograma de los taxones analizados, se calculan "contrastes" entre los valores que toma el rasgo en una y otra especie (terminales) así como entre todos los nodos internos, asumiendo un modelo de evolución según movimiento browniano (Felsenstein, 1985). Como los CI representan diferencias entre los valores de un rasgo de dos taxones hermanos, cada contraste puede ser positivo o negativo, dependiendo de la dirección elegida para calcular la diferencia entre taxones, pero debe usarse la misma dirección para todos los rasgos en cada nodo. Además, debido a la simetría que surge de esta arbitrariedad en la dirección de los contrastes, todos los análisis de correlación deben estar centrados sobre el origen; esto significa que las correlaciones analizadas en este trabajo no están centradas en las medias de las variables.

Para calcular las correlaciones entre CI se utilizó el software CACTUS 1.13 (Schwilk y Ackerly, 2001). 


\section{RESULTADOS}

\section{V.1. Descripciones y comparaciones}

\section{V.1. 1. Escápula}

\section{V.1.1.1. Análisis cualitativo}

\section{V.1.1.1.a. Morfología escapular en Ctenomys}

El cuerpo u hoja escapular es subtriangular; la espina escapular está libre del cuerpo en la mayor parte de su longitud y su extremo (acromion) sobrepasa largamente el nivel de la cavidad articular.

Ctenomys australis, C. maulinus, C. "perucho", C. flamarioni, C. maulinus y C. leucodon tienen escápula corta y alta, es decir con borde axilar relativamente corto con respecto al borde craneal y borde vertebral proporcionalmente largo, de manera que la forma del cuerpo escapular se aproxima a un triángulo isósceles. En las restantes especies, el ángulo caudal está relativamente más alejado del área articular, determinando un aspecto más elongado de la hoja escapular, generalmente acompañado por un ángulo craneal más obtuso. La mayor elongación relativa se observó en C. talarum, C. azarae, C. rionegrensis, y C. "vista"; en estas especies, la elongación de la hoja escapular se debe al alargamiento tanto del borde vertebral como del borde axilar, de manera que el ángulo caudal y el proceso teres major se encuentran más alejados de la cavidad glenoidea (Fig. 9).

La escápula de algunas especies difiere de la forma subtriangular típica. En C. fulvus, C. opimus y algunos ejemplares de C. lewisi, el ángulo craneal no describe una curva uniforme, sino que presenta dos puntos de mayor inflexión separados por un borde aproximadamente recto, determinando una forma menos triangular para la hoja escapular. Estos puntos de mayor inflexión forman ángulos marcados en C. “vista" (Fig. 9s). 


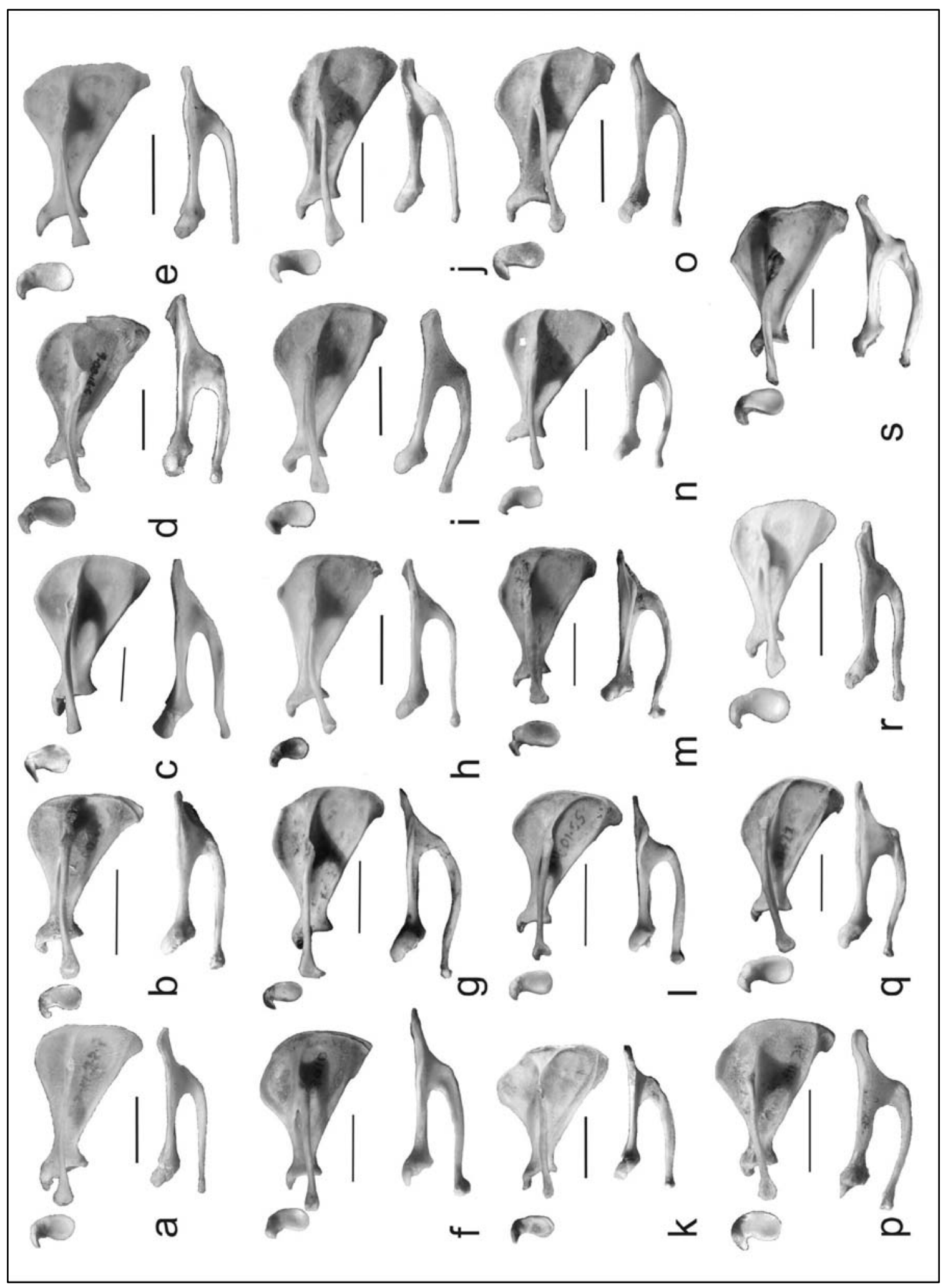


Figura 9 (página anterior). Escápula izquierda de especies vivientes de Ctenomys en vista externa (arriba), craneal (abajo), y detalle de la cavidad glenoidea (no a escala). a. C. australis; b. C. azarae; c. C. conoveri; d. C. dorbignyi; e. C. flamarioni; f. C. frater; g. C. fulvus; h. C. leucodon; i. C. lewisi; j. C. "mármol"; k. C. maulinus; 1. C. "monte"; m. C. opimus; n. C. "perucho"; o. C. rionegrensis; p. C. "somuncurá"; q. C. steinbachi; r. C. talarum; s. C. "vista”. Escala: 1 cm.

C. fulvus, C. "monte", C. frater, C. steinbachi y C. rionegrensis presentan desarrollo subigual de las fosas supra- e infraespinosa. Por el contrario, el menor tamaño relativo de la fosa supraespinosa se observa en $C$. dorbignyi, $C$. lewisi, C. leucodon, C. "mármol" y C. "perucho", mientras que las restantes especies estudiadas se hallan entre estos extremos. C. maulinus y C. leucodon se asemejan en la forma de la fosa supraespinosa, que en ambas species difiere de las demás por presentar un ángulo craneal más marcado, pero la fosa supraespinosa de C. maulinus es de gran tamaño mientras que en C. leucodon es pequeña (Fig. 9h y k).

En C. leucodon el proceso teres major está apenas insinuado y no se observa una fosa postescapular definida. En las restantes especies, este proceso tiene forma y desarrollo variable; es notoriamente pequeño en $C$. flamarioni y C. lewisi, mientras que las especies con proceso teres major más grande y diferenciado son C. steinbachi y C. "mármol". Dentro de la variabilidad registrada, se distinguen dos formas básicas para este proceso: el aquí denominado "tipo rionegrensis" tiene base corta y forma un lóbulo que sobresale más claramente del borde axilar (C. australis, C. flamarioni, C. leucodon, C. opimus, C. rionegrensis); mientras que el "tipo talarum" es bajo y de base larga, extendiéndose a lo largo del borde axilar (e.g. C. talarum, C. "mármol", C. maulinus, C. dorbignyi, C. "perucho"). La diferenciación del proceso teres major con respecto a la hoja escapular también es variable; en $C$. maulinus, C. dorbignyi y C. "mármol" hay una verdadera fosa postescapular bien definida, delimitada por un reborde axilar particularmente alto y fuerte. 
C. australis, C. flamarioni, C. leucodon y C. azarae tienen fosa glenoidea redondeada, es decir, con perímetro circular a subcircular, mientras que la misma es elongada en sentido dorsoventral en C. dorbignyi, C. fulvus, C. frater y C. "mármol". En la mayoría de las especies esta superficie articular elongada tiene forma ovoidal, mientras que en C. lewisi es más ancha y casi subcuadrangular. El proceso coracoides es casi tan largo como el diámetro mayor de la fosa glenoidea, y robusto en todas las especies examinadas. Presenta una inflexión de $90-100^{\circ}$ en la mitad de su longitud, de manera que su extremo libre se ubica medialmente a la cavidad glenoidea, rodeando parcialmente la cabeza articular del húmero.

La espina escapular tiene base corta (aproximadamente 20\% del largo total de la espina), y la gran muesca escapular es muy amplia; la porción libre de la espina describe una suave curva convexa con respecto al plano escapular, de forma que la gran muesca escapular tiene contorno elipsoidal (Fig. 9). C. dorbignyi presenta la base de la espina proporcionalmente más larga que en las demás especies (Fig. 9d); por el contrario, la base de la espina es especialmente corta en C. rionegrensis, C. fulvus y C. "monte".

La posición de la espina escapular con respecto al plano a lo largo del cual se ubica su base es variable. En C. "monte", C. maulinus y C. dorbignyi la espina está ubicada en el mismo plano de la base, mientras que en otras especies la espina presenta cierta curvatura en dirección ventral, de manera que el extremo libre de la misma está más alejado de la cavidad glenoidea. Esta curvatura es especialmente evidente en C. rionegrensis. Además, el grado de curvatura de la espina misma varía desde casi recta (C. opimus, $C$. "somuncurá", C. rionegrensis) hasta una curvatura acentuada (C. dorbignyi); existe, además, variación intraespecífica en este rasgo.

En la mayoría de las especies, el extremo libre del acromion es redondeado o subtriangular, sin procesos diferenciados; sólo se distingue una pequeña prolongación que podría ser interpretada como metacromion en $C$. fulvus, C. "mármol", C. "monte". C. opimus y C. steinbachi. En vista dorsal, el 
acromion de C. lewisi, C. steinbachi, C. frater, C. australis y C. dorbignyi presenta cierta rotación con respecto al plano seguido por el resto de la espina escapular, de manera que su posición con respecto a la lámina escapular ocupa un plano oblicuo en lugar de paralelo.

La escápula de †Ctenomys chapalmalensis se conoce a través de un resto fragmentario del ejemplar MACN 19249 (Fig. 10). Éste conserva la zona articular, el cuello y parte del plano escapular, principalmente la región del borde axilar y la porción más proximal del borde craneal. No es posible determinar la forma de la hoja escapular; de acuerdo con la posición de la base de la espina, la porción proximal de la fosa supraespinosa es relativamente estrecha. La cavidad glenoidea es ovoidal y el proceso coracoides no difiere del descripto en las especies vivientes. De la espina escapular sólo se ha preservado la parte libre sin su extremo terminal. Aunque la base no se ha conservado, la forma rectilínea de la porción de espina conservada parece sugerir una gran muesca escapular relativamente estrecha.

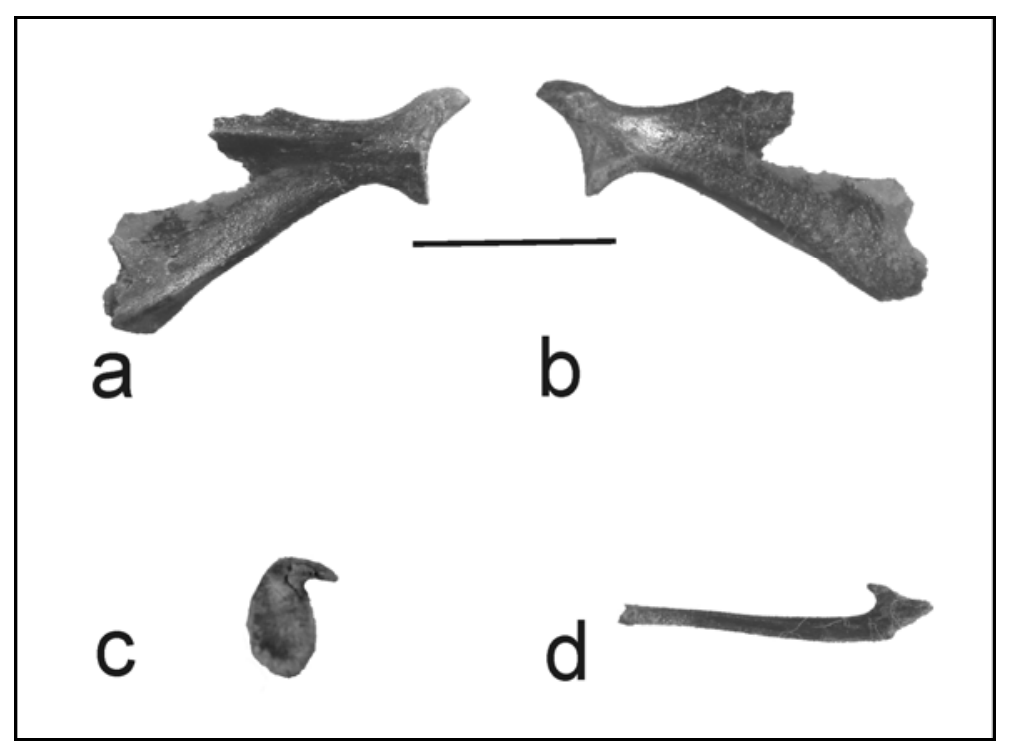

Figura 10. Escápula derecha de †C. chapalmalensis MACN 19249. a. Vista externa, b. Vista interna o costal, c. Detalle de la cavidad glenoidea, d. Espina escapular. Escala: $1 \mathrm{~cm}$. 


\section{V.1.1.1.b. Comparación con otros géneros de ctenominos}

La escápula de †Actenomys fue descripta por Fernández et al. (2000); es alta y corta, con borde axilar largo y levemente convexo, a diferencia del de Ctenomys (Figs. 11 y 12). La fosa supraespinosa es más grande que en Ctenomys; de acuerdo con el fragmento conservado, ésta podría alcanzar la mitad del tamaño de la fosa infraespinosa. En MMP 1566-M (Fig. 11), una expansión distal sobre el borde axilar parece indicar la presencia de proceso teres major; pero no es posible determinar su forma ni grado de desarrollo. El ejemplar MMP 703-S (Fig. 11) muestra un proceso teres major más pequeño que el de Ctenomys. La cavidad glenoidea (Fig. 12c) es ligeramente ovalada como la de Ctenomys, y el proceso coracoides es también semejante al de este último género. La base de la espina escapular que se ha conservado es corta como en Ctenomys, indicando que la muesca escapular era grande y la espina (no preservada) estaba libre en la mayor parte de su extensión.

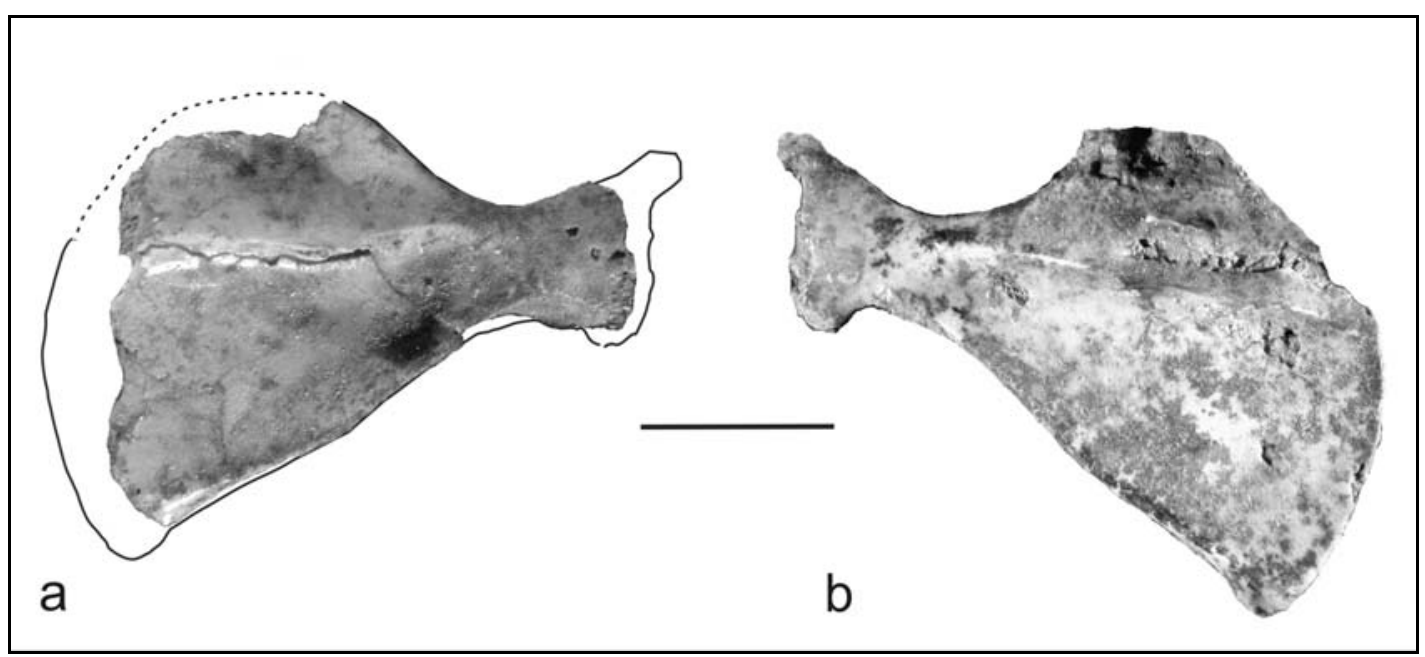

Figura 11. Escápula de †Actenomys priscus MMP 703-S. a. Escápula derecha; b. escápula izquierda. Las líneas en (a) muestran una reconstrucción de la escápula basada en ambos restos. 


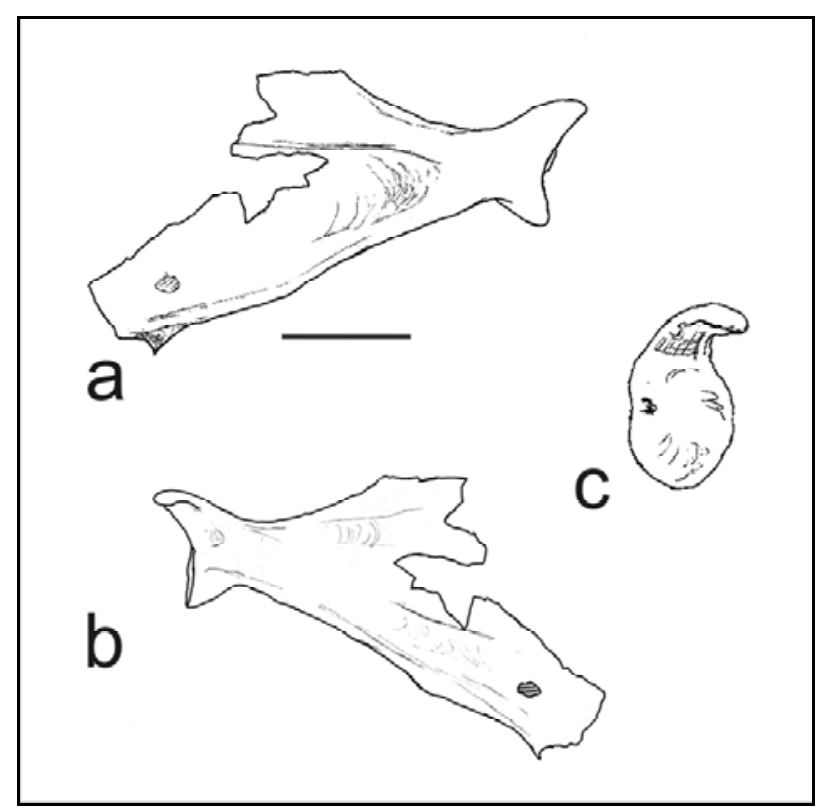

Figura 12. Escápula derecha de †Actenomys priscus MMP 1566-M. a. Vista externa, b. Vista interna o costal, c. Cavidad glenoidea. Escala: $1 \mathrm{~cm}$.

\section{V.1.1.1.c. Comparación con otros caviomorfos}

La escápula de Ctenomys difiere de otros octodontoideos examinados principalmente en la forma de la espina escapular, la cual es relativamente más larga y con extremo libre redondeado, en contraposición con la forma bilobulada con acromion y metacromion generalmente subiguales típica de los demás taxones; en Ctenomys, además, es más robusta.

En otros octodontoideos (Fig. 13), la espina escapular es más grácil que en Ctenomys, generalmente recta y paralela al plano escapular, y terminada en un extremo bilobado, con acromion y metacromion de desarrollo variable según los géneros, pero este último siempre está presente, a diferencia de Ctenomys. La forma de la hoja escapular varía desde corta y alta, similar a la de C. "perucho" en Euryzygomatomys, Octodon, Spalacopus, y Aconaemys, hasta igualmente o más elongada a nivel del borde vertebral que en Ctenomys, como ocurre en Octodontomys, Thrichomys, Proechimys y Myocastor. El ángulo craneal de los octodontinos es más obtuso que en la mayoría de las especies de Ctenomys, aunque semejante a C. opimus o C. fulvus. Los equímidos (Thrichomys, Proechimys, Euryzygomatomys y Myocastor) y algunos 
octodontinos presentan proceso teres major de desarrollo variable; en todos los casos la morfología del mismo corresponde al "tipo rionegrensis" descripto para Ctenomys. El tamaño relativo de la fosa supraespinosa es mayor que en Ctenomys (Abrocoma, Euryzygomatomys), tiene desarrollo similar (Myocastor, Proechimys, Octodontomys) o es relativamente menor (octodontinos). La cavidad glenoidea es generalmente más redondeada. El proceso coracoides es más corto y menos curvado.

La escápula de Cavia es más alargada y difiere de la forma triangular típica de Ctenomys; los bordes craneal y axilar tienen largo subigual mientras que el borde vertebral es más corto. No existe proceso teres major. La cavidad glenoidea es más redondeada y el proceso coracoides es mucho más corto que en Ctenomys. La espina es de base mucho más larga y su porción libre no es robusta sino alta y comprimida; el extremo libre presenta acromion y especialmente metacromion muy desarrollados.

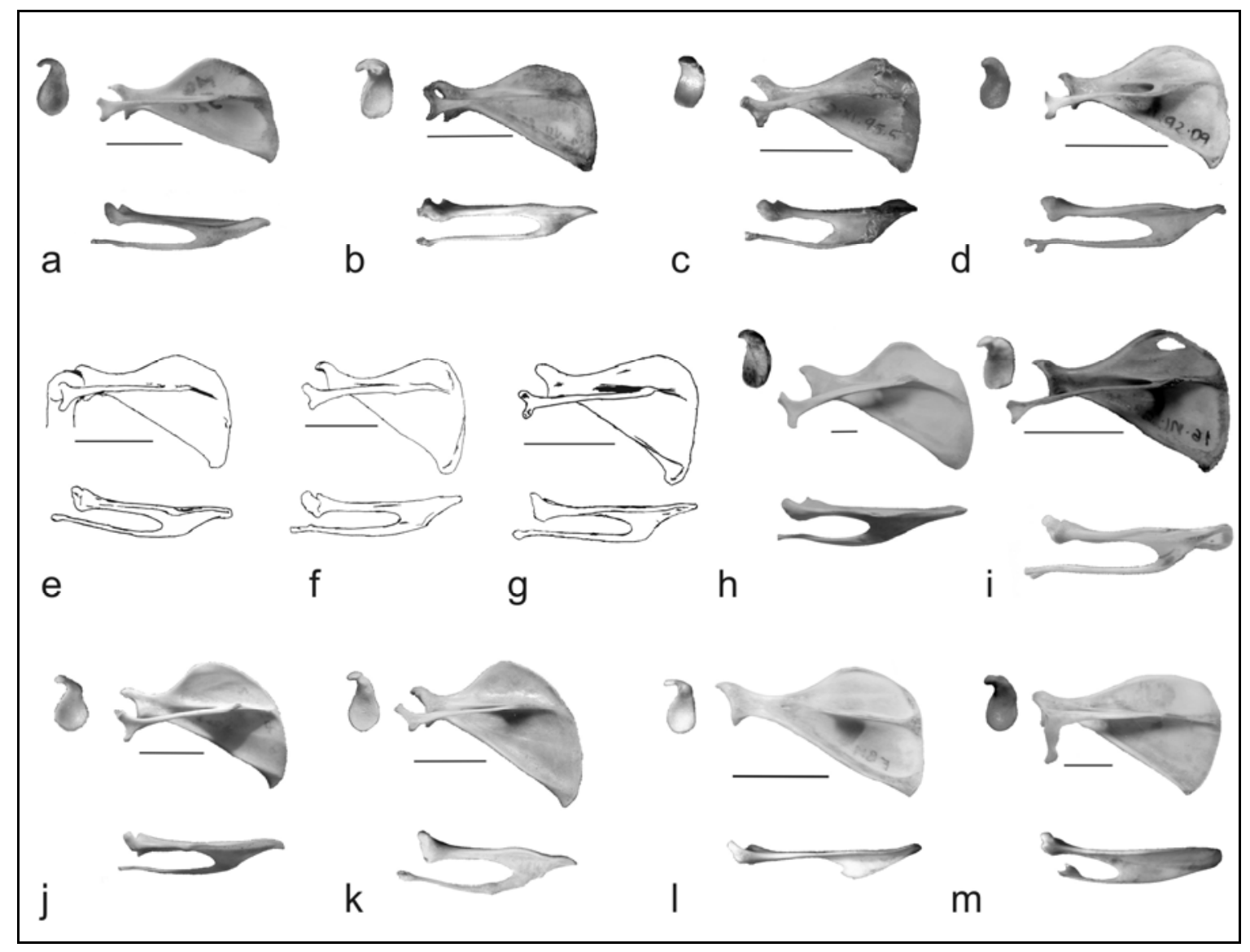


Figura 13. Escápula izquierda de Octodontoidea (a-l) y Caviidae (m) en vista externa (superior), dorsal (inferior) y detalle de la cavidad glenoidea (izquierda, no a escala). a. Octodontomys gliroides; b. Octodon "bridgesi"; c. Spalacopus cyanus; d. Aconaemys sagei.; e. Octomys mimax; f. Pipanacoctomys aureus g. Tympanoctomys barrerae; h. Myocastor coypus; i. Euryzygomatomys spinosus; j. Proechimys poliopus; k. Thrichomys apereoides; 1 . Abrocoma sp. (incompleta); m. Cavia aperea. Escala: $1 \mathrm{~cm}$.

\section{V.1.1.2. Análisis cuantitativo general}

Un ACP de Ctenomys, otros miembros de la superfamilia Octodontoidea y Cavia aperea mostró separación del morfoespacio ocupado por las especies de Ctenomys con respecto a la mayoría de los octodontinos, pero no con Octodontomys y los restantes octodontoideos analizados (Fig. 14, Tabla 2). Los dos primeros Componentes Principales explicaron $75,78 \%$ de la variación. El primer Componente Principal (CP 1) resumió 57,72\% de la variación, en relación con los índices LRBE, DEP, LRBV, LRES y ELON, y separó a Ctenomys y los demás octodontoideos de Cavia. El segundo Componente Principal (CP 2) explicó 18,06\% de la variación, expresando principalmente la variable DFI; en este componente Ctenomys se agrupó con los restantes taxones analizados, y sólo Aconaemys y Octodon se diferenciaron del resto. 


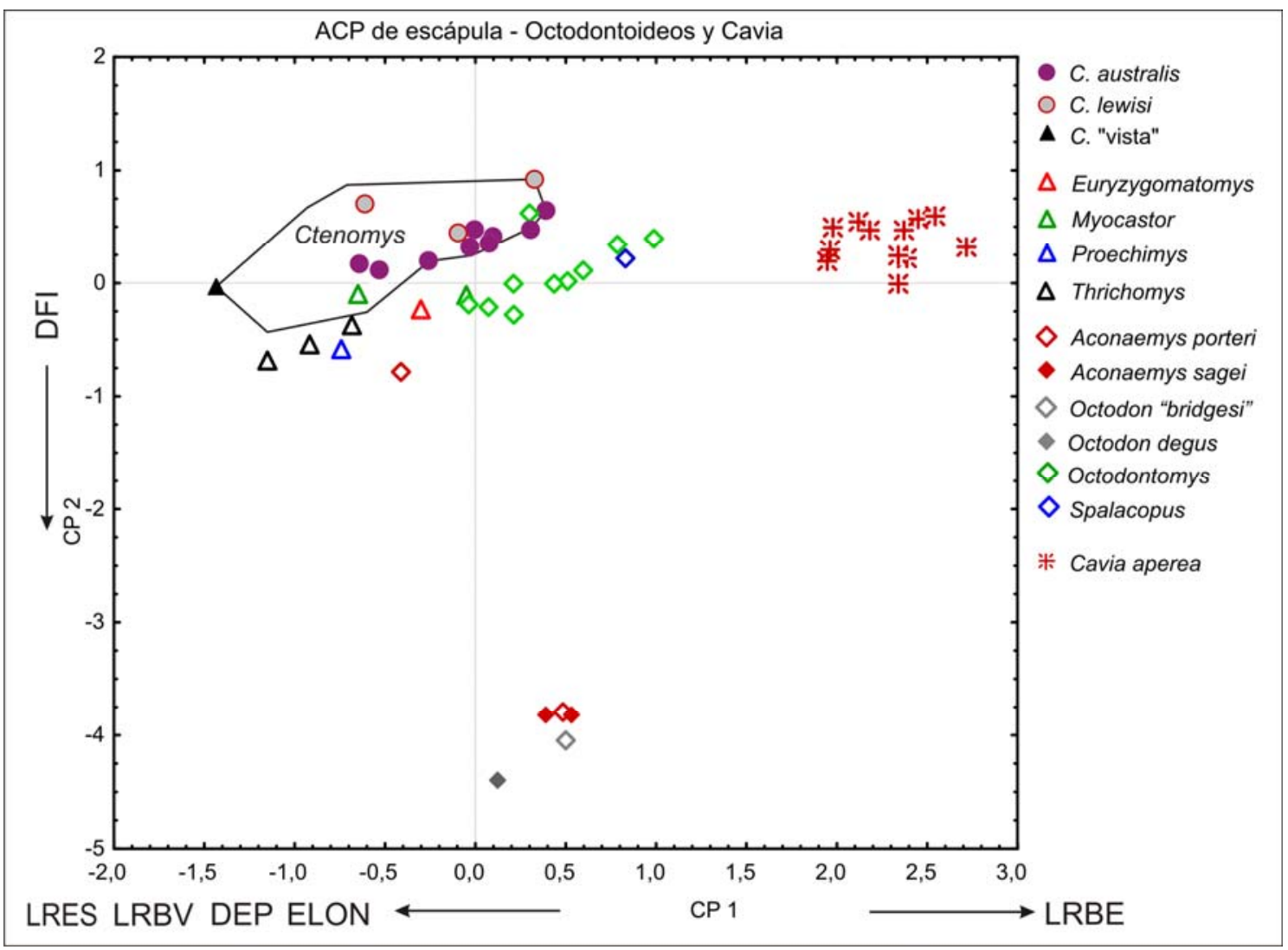

Figura 14. ACP de índices escapulares de Ctenomys (polígono), especies de Octodontoidea y Cavia aperea.

Dentro del amplio rango morfométrico ocupado por Ctenomys, las especies C. lewisi y C. australis ocuparon un extremo de la distribución, caracterizado por la posesión de escápula más corta, con espina más baja y corta; el otro extremo, con escápula más elongada, espina más larga, alta y de base más estrecha, estuvo ocupado por C. "vista".

Tabla 2. Correlaciones Factor-Variable (factor loadings) y porcentaje de variación explicada para los 2 primeros Componentes Principales del ACP de Fig. 14.

\begin{tabular}{lll}
\hline Índices & CP 1 & CP 2 \\
\hline LRBE & $\mathbf{0 , 8 4}$ & 0,045 \\
\hline DEP & $\mathbf{- 0 , 8 2}$ & 0,27 \\
\hline LRBV & $\mathbf{- 0 , 8 0}$ & $-0,27$ \\
\hline
\end{tabular}




\begin{tabular}{lll}
\hline LRES & $\mathbf{- 0 , 8 5}$ & $-0,08$ \\
\hline ELON & $\mathbf{- 0 , 8 2}$ & $-0,04$ \\
\hline DFI & 0,14 & $\mathbf{- 0 , 9 6}$ \\
\hline Autovalor & 3,46 & 1,08 \\
\hline $\begin{array}{l}\text { \% variación } \\
\text { explicada }\end{array}$ & 57,72 & 18,06 \\
\hline \% acumulativo & 57,62 & 75,78 \\
\hline
\end{tabular}

\section{V.1.1.3. Análisis cuantitativo de la variabilidad morfológica en Ctenomys}

\section{V.1.1.3.1. Análisis morfométrico tradicional}

\section{Análisis multivariado}

En un análisis que incluyó al género Ctenomys únicamente, las especies se distribuyeron tal como se muestra en la Fig. 15. Los dos primeros componentes principales resumieron el 51,07\% de la variación (Tabla 3). En el CP 1 (29,72\% de la variación explicada), las especies de Ctenomys mostraron una amplia variación, en la cual C. australis, C. "monte". C. rionegrensis y C. leucodon ocuparon el extremo negativo, mientras que C. talarum, C. maulinus, C. "perucho" y C. "vista" ocuparon el extremo opuesto, con los valores más altos en este eje (mayor largo de la espina y alto de la gran muesca, y mayor largo del borde vertebral). Por su parte, en el CP 2 el extremo positivo estuvo ocupado por las especies C. rionegrensis, C. talarum y C. "mármol", que son algunas de las especies con escápula más elongada (Fig. 9); C. flamarioni, C. leucodon y C. lewisi ocuparon el extremo negativo. A diferencia de lo ocurrido en el análisis anterior, la variable DFI no cargó significativamente en los dos primeros componentes, indicando que las diferencias de proporción entre la fosa supra- e infraespinosa no son importantes entre especies de Ctenomys. Por otro lado, el índice LRTM, que cuantifica la forma del proceso teres major, tampoco resultó importante para explicar la mayor parte de la variación encontrada. 


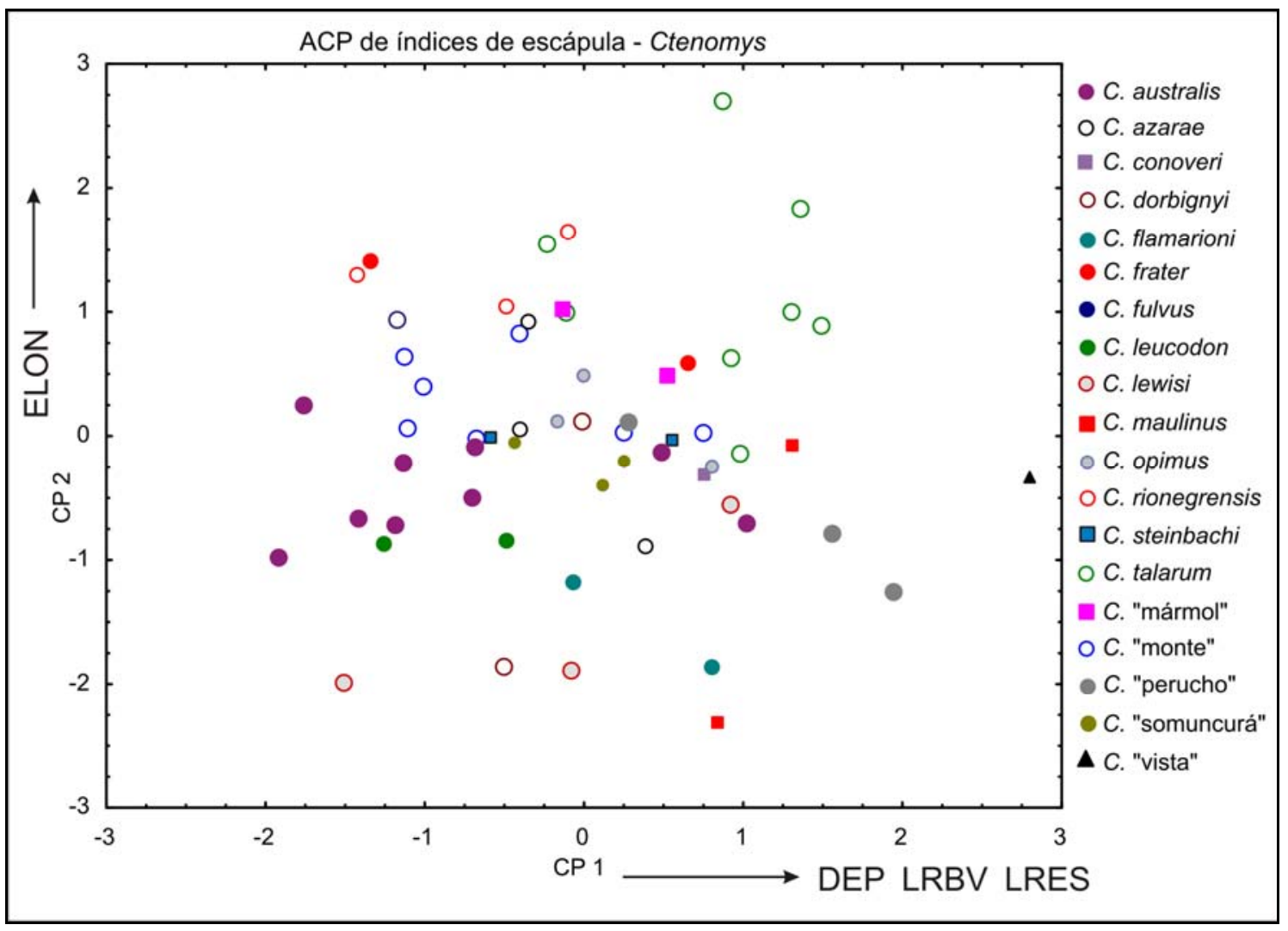

Figura 15. ACP de índices escapulares de especies de Ctenomys.

Tabla 3. Correlaciones Factor-Variable (factor loadings) y porcentaje de variación explicada para los 2 primeros Componentes Principales del ACP de Fig. 15.

\begin{tabular}{lll}
\hline Indices & CP 1 & CP 2 \\
\hline LRTM & 0,45 & 0,29 \\
\hline LRBE & 0,29 & $-0,53$ \\
\hline DEP & $\mathbf{0 , 6 1}$ & $-0,48$ \\
\hline LRBV & $\mathbf{0 , 8 1}$ & 0,30 \\
\hline LRES & $\mathbf{0 , 7 4}$ & $-0,39$ \\
\hline ELON & 0,43 & $\mathbf{0 , 8 1}$ \\
\hline DFI & 0,16 & 0,01 \\
\hline Autovalor & 2,08 & 1,49 \\
\hline \% variación & 29,72 & 21,35 \\
explicada & & \\
\hline \% acumulativo & 29,72 & 51,07 \\
\hline
\end{tabular}




\section{Análisis estadístico descriptivo}

Los resultados del análisis estadístico descriptivo de los índices morfofuncionales de Ctenomys, seleccionados sobre la base de los análisis cualitativo y multivariado, se presentan en las Figuras 16 a 21. Se observó una variación casi continua del rango de valores para cada índice morfo-funcional, dentro de la cual cada especie mostró un mosaico de especializaciones. Esto queda evidenciado por la falta de constancia en el ordenamiento de las especies en cada gráfico de caja (boxplot), con la excepción de C. "vista" que presentó valores altos o máximos en todos los casos.

El índice LRTM es particularmente interesante porque, tal como se describió anteriormente, la forma del proceso teres major en Ctenomys corresponde a dos tipos básicos, "tipo rionegrensis" y "tipo talarum", y este índice permite cuantificar la variación morfológica en este rasgo. La Fig. 20 muestra una separación entre dos grupos (aproximadamente en el valor 0,25 para este índice) que refleja la diferencia cualitativa descripta previamente.

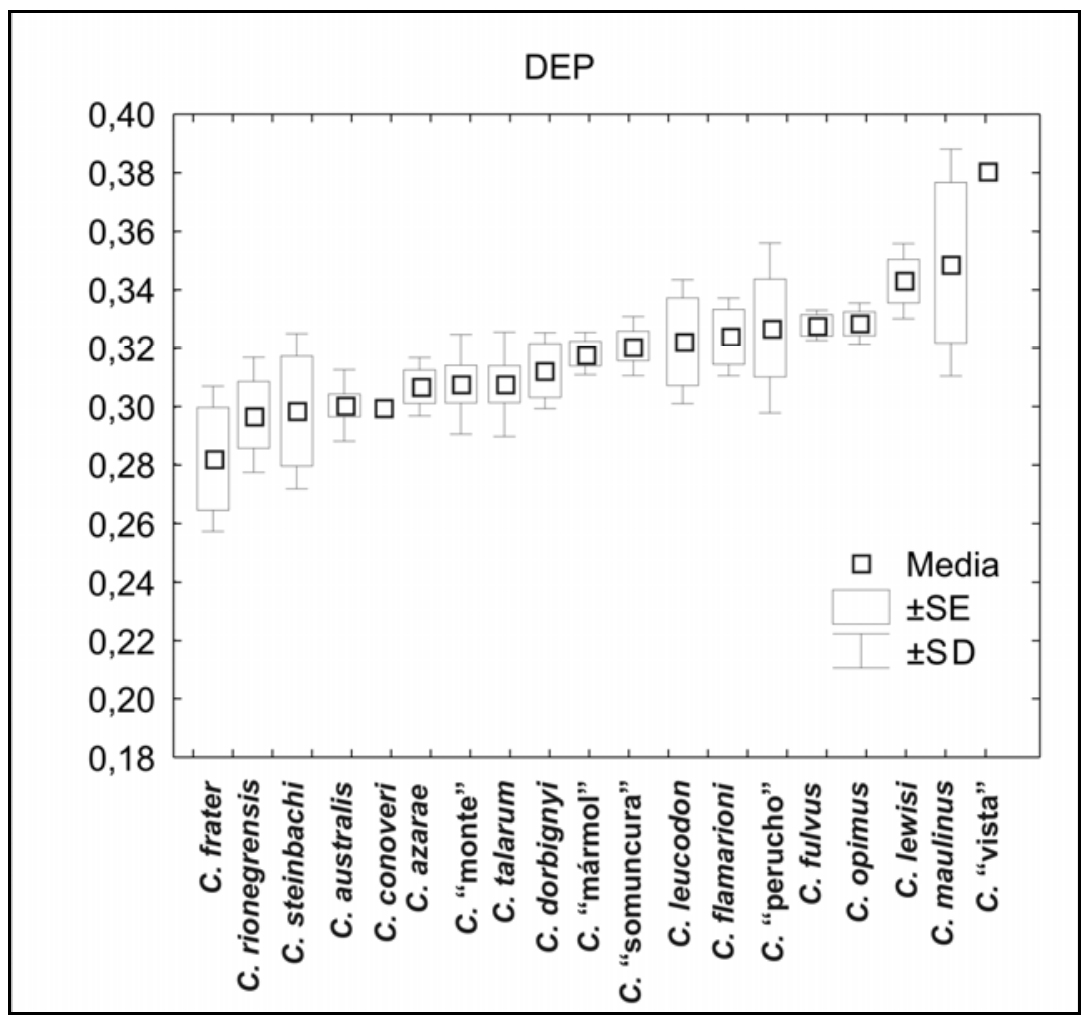

Figura 16. Alto relativo de la gran muesca escapular (DEP) por especie. 


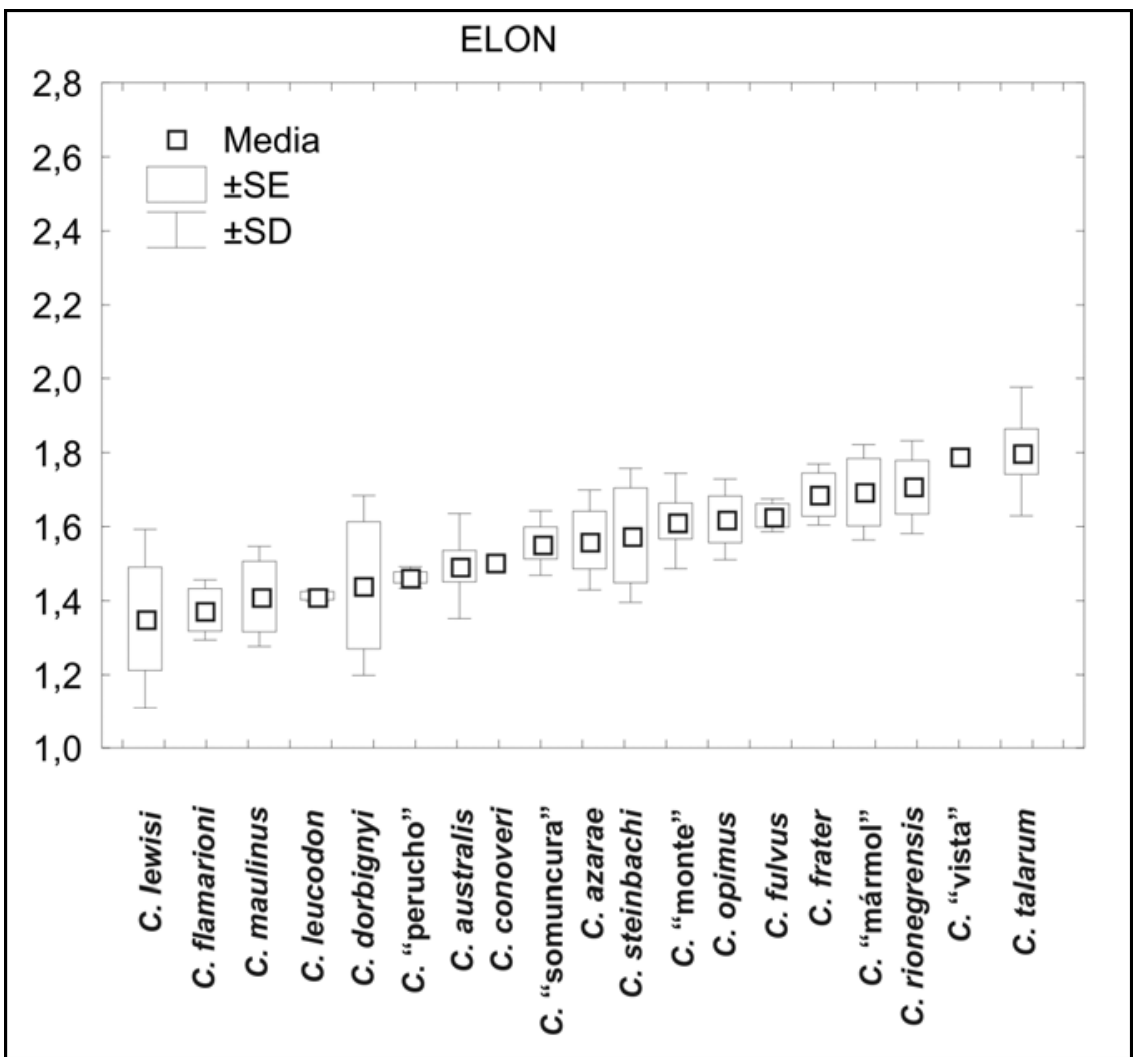

Figura 17. Índice de elongación (ELON) por especie.

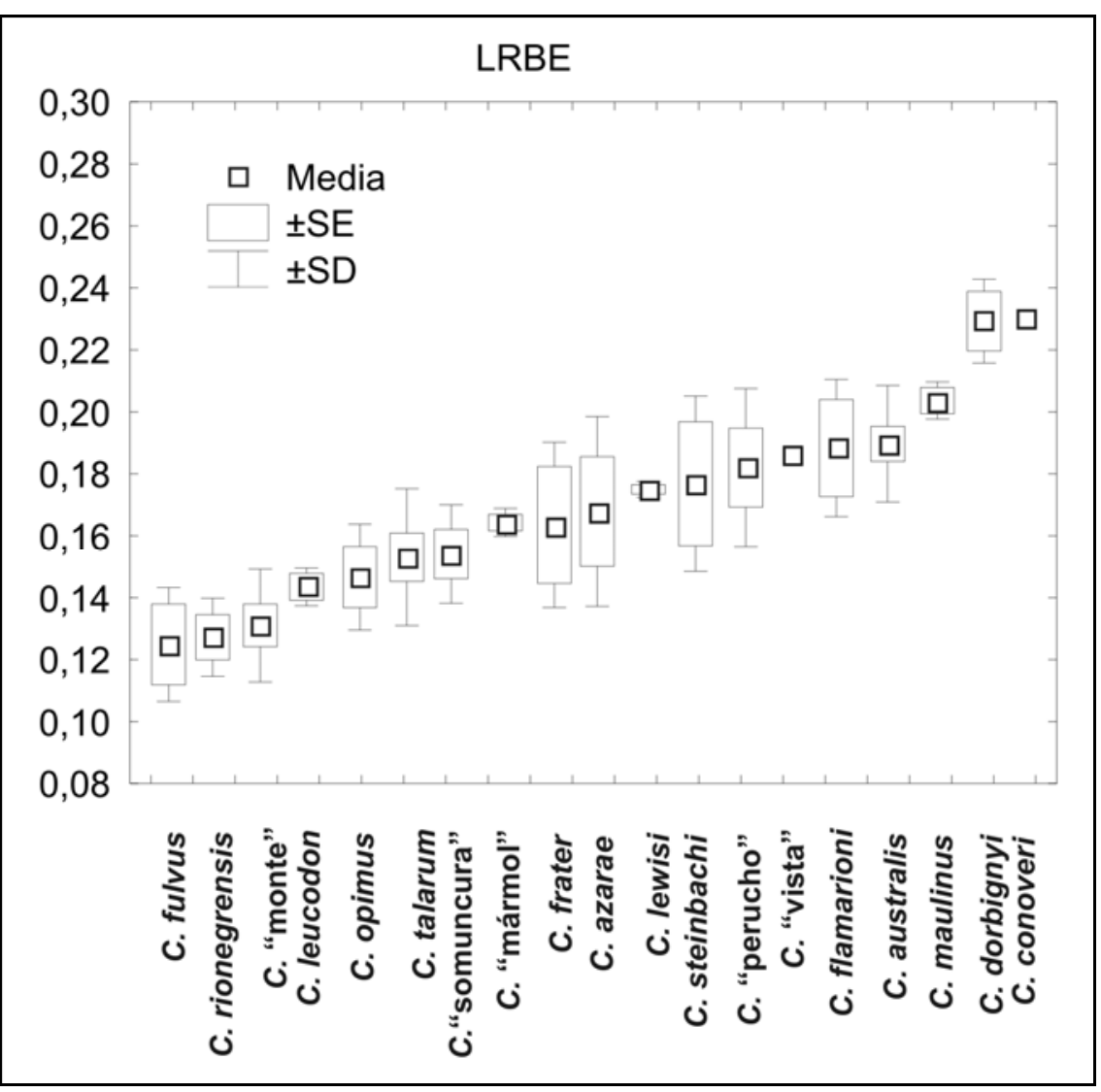

Figura 18. Largo relativo de la base de la espina (LRBE) por especie 


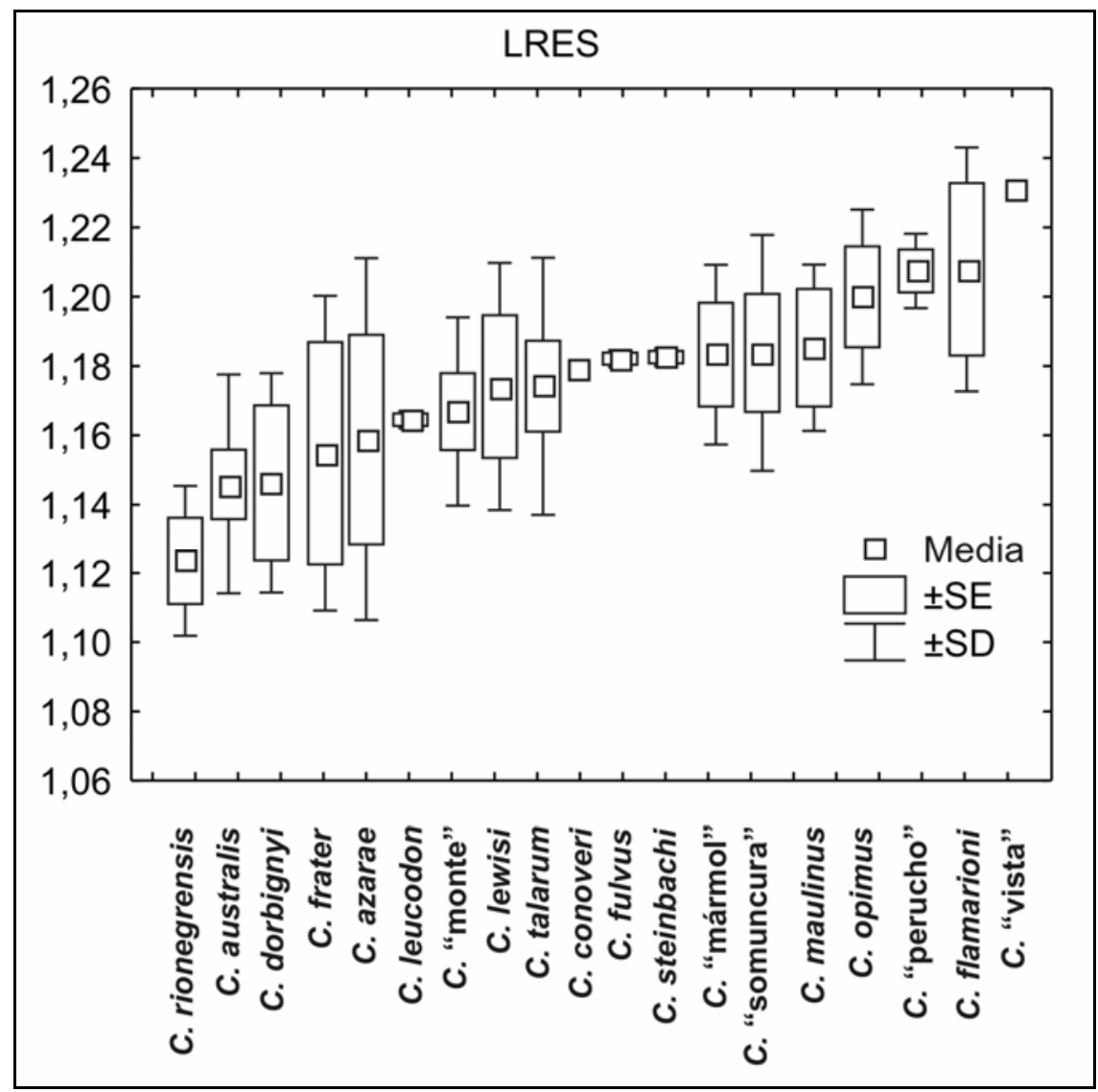

Figura 19. Largo relativo de la espina (LRES) por especie.

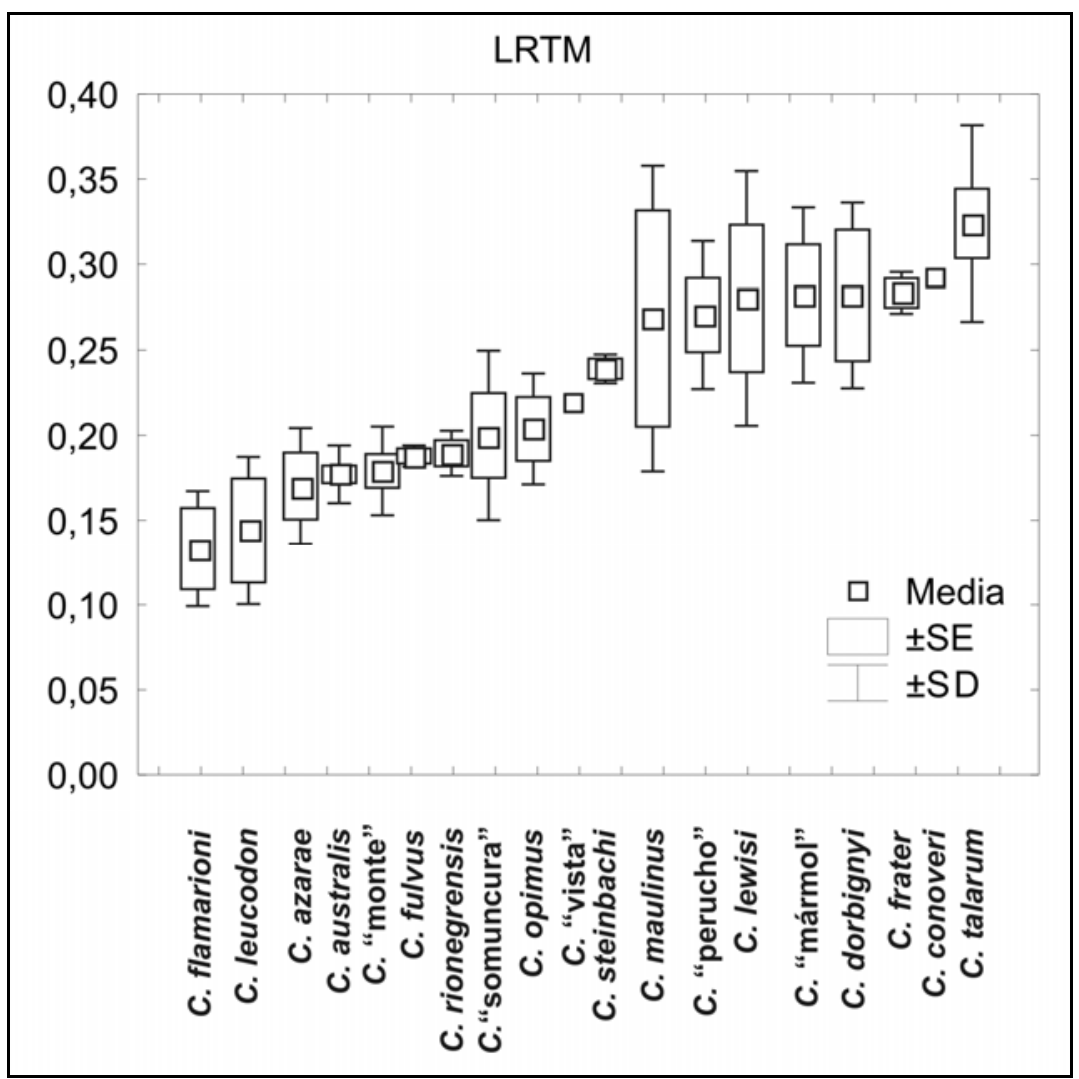


Figura 20. Largo relativo del proceso teres major (LRTM) por especie.

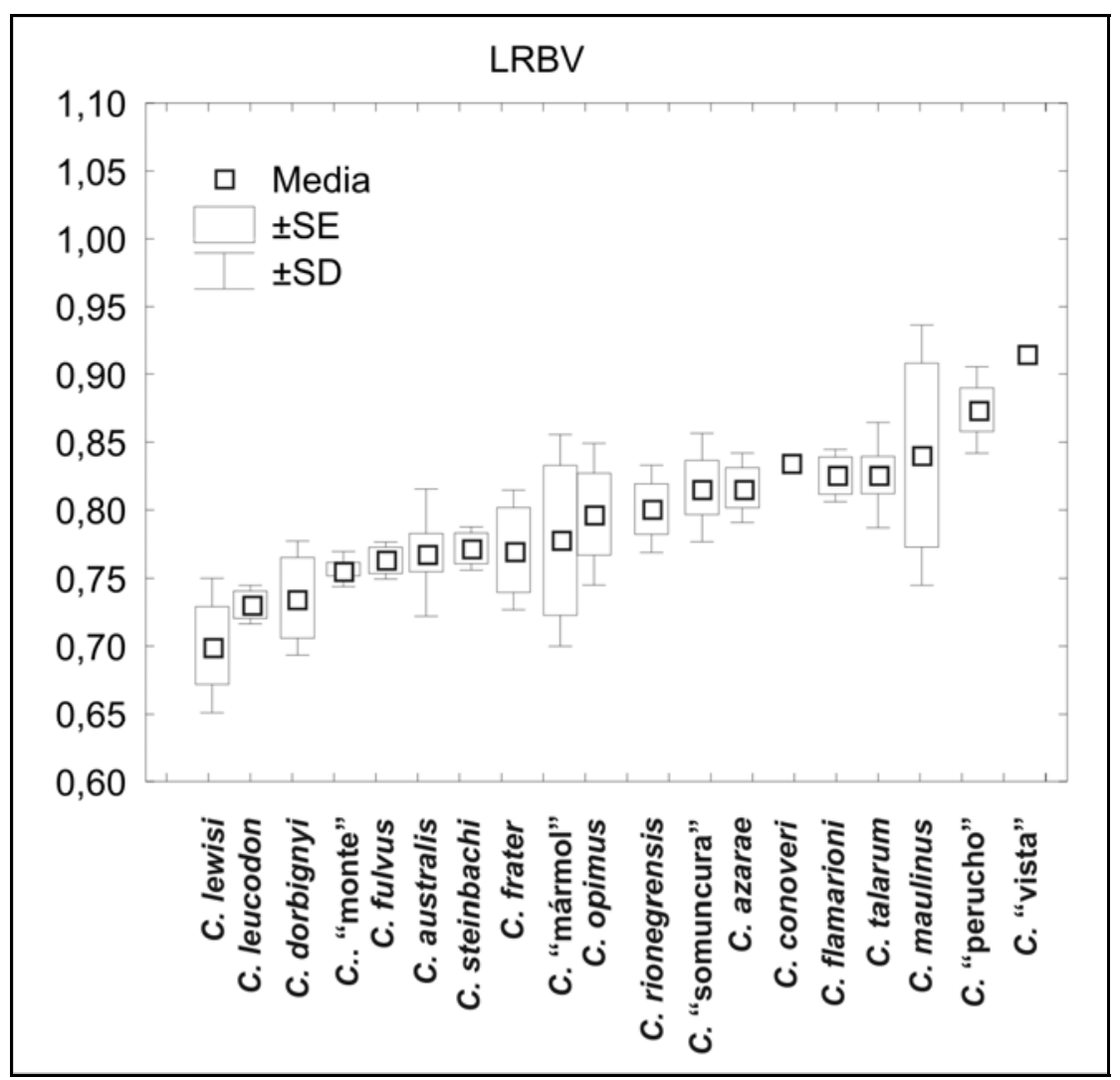

Figura 21. Largo relativo del borde vertebral (LRBV) por especie.

\section{Alometrías en la escápula de Ctenomys}

Los resultados del análisis alométrico se muestran en las Tablas 4 y 5 . La mayoría de las medidas lineales presentaron moderada alometría positiva $(b>1)$, siendo el largo total de la escápula (LTE) y el largo del borde axilar (LBAX) los más cercanos a la isometría con respecto al tamaño corporal (estimado mediante el largo DP4-M2). Por su parte, el largo del borde craneal (LBC) mostró más fuerte alometría positiva, la cual se vio reflejada también en el aumento relativo de la superficie de la fosa supraespinosa (SUPR), mayor que la correspondiente a la fosa infraespinosa (INFR). El largo de la base de la espina escapular mostró fuerte alometría positiva y moderada correlación con respecto al estimador de tamaño corporal. Por el contrario, la longitud del proceso teres major (LTM), muy variable entre especies (ver V.1.1.1. Análisis 
cualitativo), mostró baja correlación con el tamaño corporal. Todos los índices analizados mostraron muy baja correlación con el tamaño corporal (Tabla 5).

Tabla 4. Ecuaciones alométricas (regresión Modelo II, método de ejes principales) para medidas lineales de la escápula de Ctenomys vs. DP4-M2.

\begin{tabular}{|c|c|c|c|c|c|}
\hline $\begin{array}{l}\text { Variable } \\
\text { regresionada }\end{array}$ & $\begin{array}{l}\text { Ecuación }(\log y=a+b \\
\log x)\end{array}$ & $n$ & $r$ & $r^{2}$ & Intervalos de confianza \\
\hline LES & $\begin{array}{l}\log y=0,22+1,28 \log x \\
p=0,001\end{array}$ & 50 & 0,80 & 0,64 & $\begin{array}{l}a=-0,07-0,45 \\
b=1,03-1,61\end{array}$ \\
\hline LBV & $\begin{array}{l}\log y=-0,06+1,4 \log x \\
p=0,001\end{array}$ & 52 & 0,71 & 0,49 & $\begin{array}{l}a=-0,50-0,25 \\
b=1,06-1,89\end{array}$ \\
\hline LBAX & $\begin{array}{l}\log y=0,26+1,2 \log x \\
p=0,001\end{array}$ & 53 & 0,70 & 0,49 & $\begin{array}{l}a=-0,13-0,53 \\
b=0,90-1,64\end{array}$ \\
\hline LTE & $\begin{array}{l}\log y=0,17+1,26 \log x \\
p=0,001\end{array}$ & 53 & 0,80 & 0,64 & $\begin{array}{l}a=-0,11-0,39 \\
b=1,02-1,57\end{array}$ \\
\hline LBC & $\begin{array}{l}\log y=-0,28+1,6 \log x \\
p=0,001\end{array}$ & 52 & 0,73 & 0,53 & $\begin{array}{l}a=-0,76-0,05 \\
b=1,23-2,12\end{array}$ \\
\hline ASP & $\begin{array}{l}\log y=-0,62+1,58 \log x \\
p=0,001\end{array}$ & 53 & 0,68 & 0,46 & $\begin{array}{l}a=-1,18--0,26 \\
b=1,18-2,21\end{array}$ \\
\hline LBS & $\begin{array}{l}\log y=-2,42+3,27 \log x \\
p=0,001\end{array}$ & 55 & 0,62 & 0,38 & $\begin{array}{l}a=-3,91--1,65 \\
b=2,42-4,94\end{array}$ \\
\hline LTM & $\begin{array}{l}\log y=-4,82+16,1 \log x \\
p=0,001\end{array}$ & 55 & 0,40 & 0,16 & $\begin{array}{l}a=-13,93--2,68 \\
b=3,68-16,24\end{array}$ \\
\hline SUPR & $\begin{array}{l}\log y=-2,47+4,62 \log x \\
p=0,001\end{array}$ & 52 & 0,65 & 0,42 & $\begin{array}{l}a=-4,82--1,34 \\
b=3,36-7,23\end{array}$ \\
\hline INFR & $\begin{array}{l}\log y=-1,04+3,35 \log x \\
p=0,001\end{array}$ & 53 & 0,72 & 0,52 & $\begin{array}{l}a=-2,13--0,38 \\
b=2,62-4,57\end{array}$ \\
\hline
\end{tabular}

Tabla 5 (página siguiente). Ecuaciones alométricas (regresión Modelo II, método de ejes principales) para índices morfo-funcionales de la escápula de Ctenomys vs. DP4-M2. 


\begin{tabular}{|c|c|c|c|c|c|}
\hline $\begin{array}{l}\text { Variable } \\
\text { regresionada }\end{array}$ & $\begin{array}{l}\text { Ecuación }(\log y=a+b \\
\log x)\end{array}$ & $n$ & $r$ & $r^{2}$ & $\begin{array}{l}\text { Intervalos de } \\
\text { confianza }\end{array}$ \\
\hline \multirow[t]{2}{*}{ DEP } & $\log y=-0,36-0,15 \log x$ & 51 & $-0,14$ & 0,02 & $a=-0,63--0,07$ \\
\hline & $\mathrm{p}=0,16$ & & & & $b=-0,48-0,14$ \\
\hline \multirow[t]{2}{*}{ DFI } & $\log y=-264,6+294,6 \log x$ & 52 & 0,007 & $4,9 \times 10^{-}$ & $a=7,56--6,60$ \\
\hline & $p=0,49$ & & & & $b=7,66--8,09$ \\
\hline \multirow[t]{2}{*}{ ELON } & $\log y=0,81-0,69 \log x$ & 52 & $-0,25$ & 0,06 & $a=0,26-2,10$ \\
\hline & $\mathrm{p}=0,03$ & & & & $b=-2,13--0,09$ \\
\hline \multirow[t]{2}{*}{ LRBE } & $\log y=-3,41+2,93 \log x$ & 53 & 0,32 & 0,10 & $a=-12,95--2,14$ \\
\hline & $p=0,01$ & & & & $b=1,51-13,55$ \\
\hline \multirow[t]{2}{*}{ LRBV } & $\log y=-0,001-0,11 \log x$ & 52 & $-0,11$ & 0,01 & $a=-0,25-0,27$ \\
\hline & $p=0,20$ & & & & $\mathrm{~b}=-0,41-0,16$ \\
\hline \multirow[t]{2}{*}{ LRES } & $\log y=0,08-0,01 \log x$ & 50 & $-0,04$ & $1,6 \times 10^{-}$ & $\mathrm{a}=0,07-0,15$ \\
\hline & $\mathrm{p}=0,38$ & & & & $b=-0,09-0,07$ \\
\hline \multirow[t]{2}{*}{ LRTM } & $\log y=75,55-84,88 \log x$ & 53 & $-0,02$ & $4 \times 10^{-4}$ & $a=4,88--7,20$ \\
\hline & $\mathrm{p}=0,44$ & & & & $b=7,26--6,18$ \\
\hline
\end{tabular}

\section{V.1.1.3.2. Análisis morfométrico geométrico}

Dado que la escápula es un elemento morfológicamente complejo, la morfometría geométrica representa un enfoque muy adecuado para el estudio de algunos aspectos de su forma que son difíciles o imposibles de capturar mediante medidas lineales. Se digitalizaron 74 especímenes pertenecientes a las especies estudiadas (ver IV. Materiales y métodos y Apéndice I) a partir de fotografías de la faz lateral de la escápula. En cada imagen se determinaron 9 puntos anatómicos fijos o landmarks, para describir la forma de la hoja y espina escapulares, así como 9 puntos anatómicos deslizantes o semilandmarks (Bookstein, 1997) para describir la forma del borde craneal de la escápula, cuyo contorno curvo no puede ser capturado mediante landmarks (Fig. 22). Se realizó un análisis preliminar con todos los individuos, y luego de verificar la existencia de diferencias significativas entre las especies mediante un Análisis de la Varianza Multivariado (MANOVA), se utilizó la configuración media (consenso) de landmarks por especie para los análisis posteriores. La 
distribución de las especies en el espacio de la forma se investigó mediante Análisis de Deformaciones Relativas (Relative Warps Analysis, RWA; Monteiro y Dos Reis, 1999; Zelditch et al., 2004).

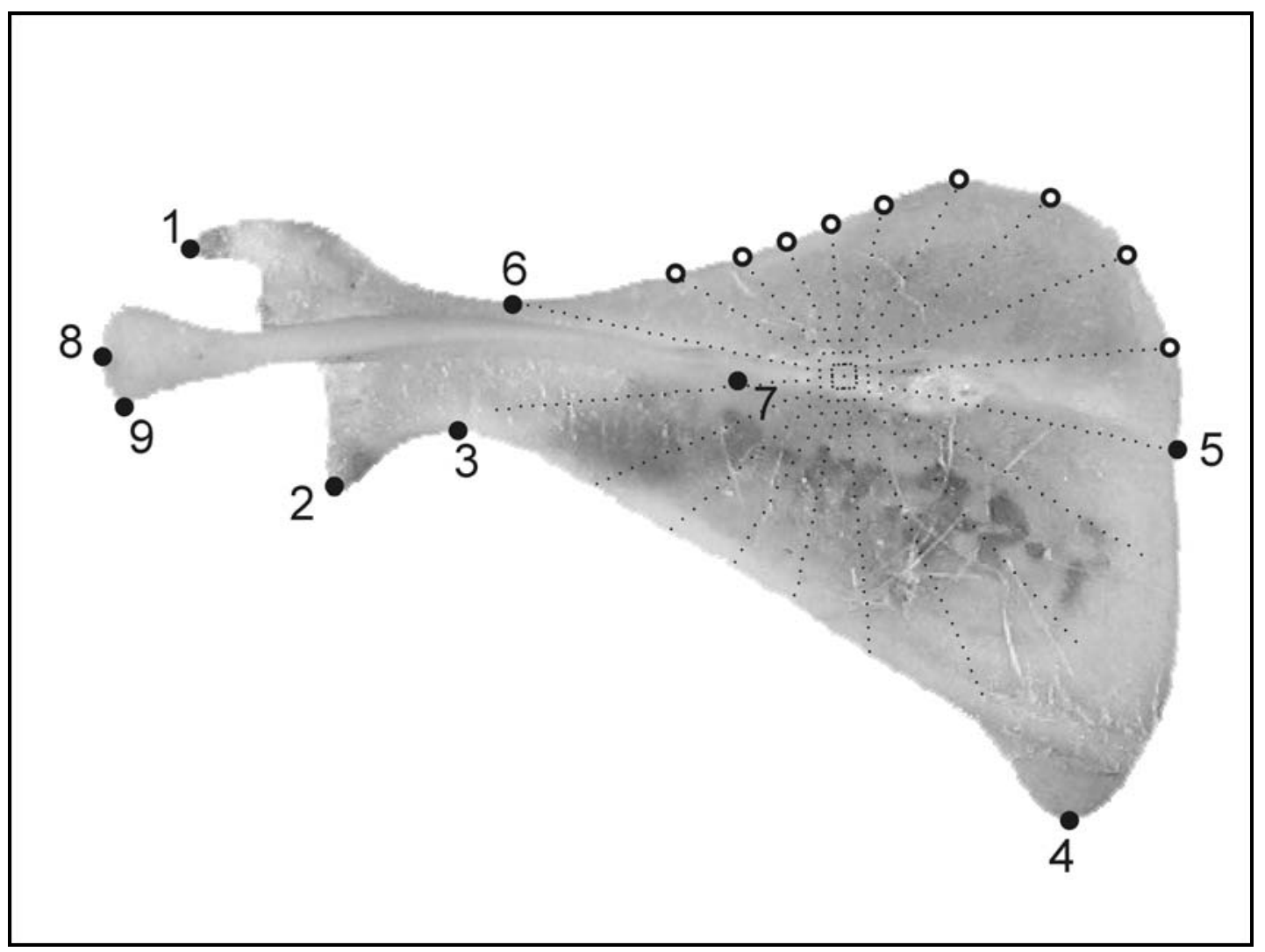

Figura 22. Escápula izquierda de Ctenomys australis mostrando la posición de los landmarks (círculos negros numerados) y semilandmarks (círculos blancos). La posición de cada landmark se describe en la Tabla 6.

Tabla 6. Descripción de los landmarks utilizados para el análisis morfométrico geométrico de la escápula en Ctenomys.

\begin{tabular}{cl}
\hline Landmark & Definición \\
\hline 1 & Extremo del proceso coracoides \\
\hline 2 & Punto más ventral en el labio de la fosa glenoidea \\
\hline 3 & Punto de máxima curvatura sobre el margen inferior del cuello \\
& escapular \\
\hline 4 & Ángulo caudal \\
\hline 5 & Intersección entre borde vertebral y base de la espina escapular
\end{tabular}




\begin{tabular}{cl}
\hline 6 & $\begin{array}{l}\text { Punto de maxima curvatura sobre le margen superior del cuello } \\
\text { escapular }\end{array}$ \\
\hline 7 & Unión entre espina y hoja scapular (punto de maxima concavidad \\
& sobre la gran muesca) \\
\hline 8 & Extremo cefálico del acromion \\
\hline 9 & Punto más ventral del extremo de la espina
\end{tabular}

Los dos primeros RW resumieron el 61,16\% de la variación observada (RW1=38,58\%, RW2=22,58\%). Se observó una clara diferenciación de la forma escapular de las especies de Ctenomys con respecto a los otros caviomorfos a lo largo del RW1, con la excepción de Aconaemys que de todas formas se ubicó por fuera del morfoespacio de Ctenomys. Las especies de Ctenomys se ubicaron sobre la parte negativa de este eje, mientras que los octodontinos y los equímidos ocuparon posiciones cercanas a cero o positivas, y Cavia se ubicó claramente separado de los demás taxones, en los valores máximos del RW1 (Fig. 24), siguiendo un gradiente de deformación que incluye espina escapular más larga, gran muesca escapular más amplia, y metacromion más reducido en Ctenomys. El RW2 mostró cambios en la forma del borde y ángulo craneal de la hoja escapular (Fig. 23), lo cual determina un aspecto más alongado de la misma (bordes axilar y vertebral relativamente largos, borde craneal relativamente corto) hacia el extremo positivo del eje. 


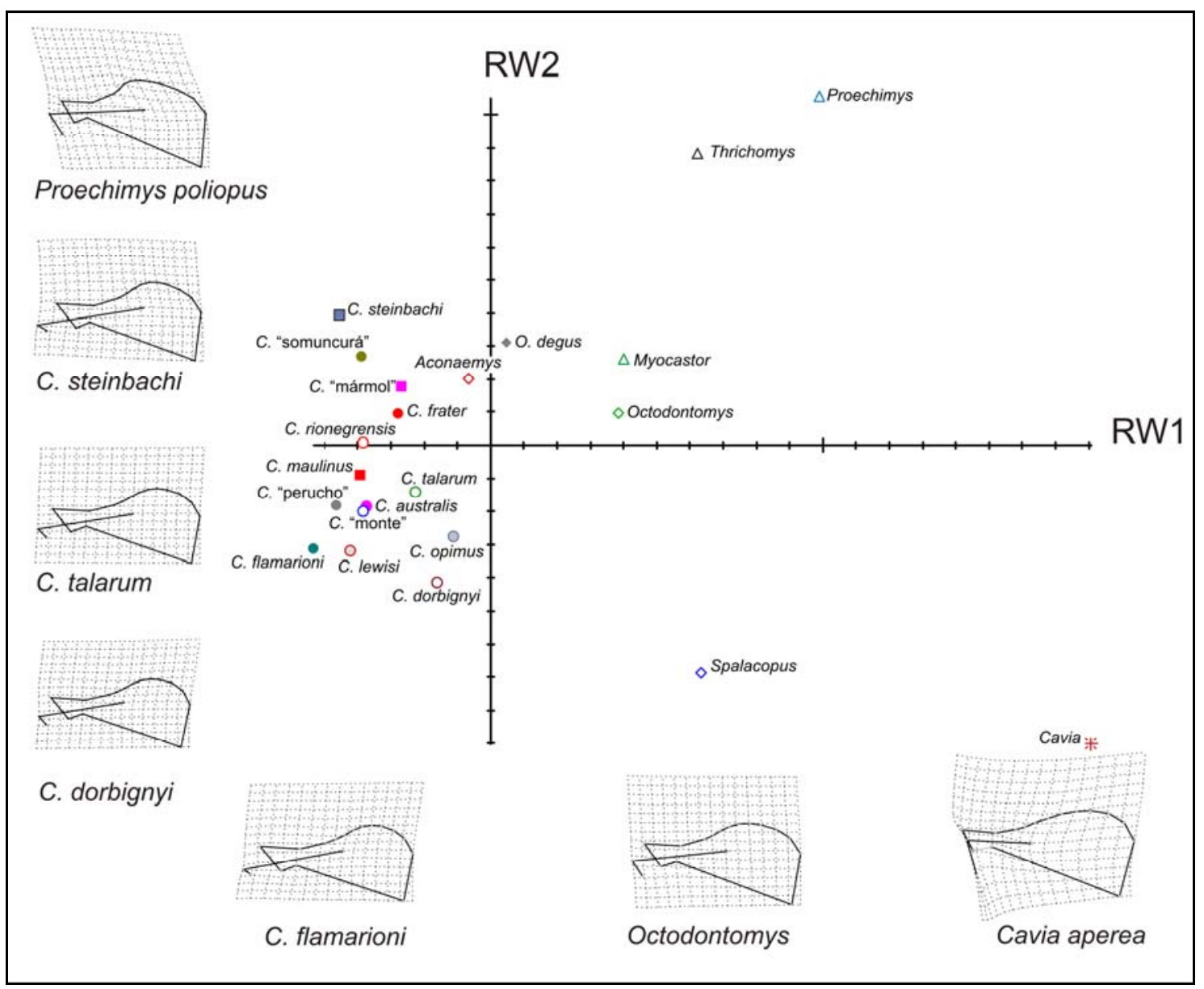

Figura 23. Distribución de los taxones en el espacio de las dos primeras deformaciones relativas (RW, relative warps). Valores promedio por especie. Las grillas muestran las morfologías extremas para cada RW, así como la variación morfológica hallada dentro de Ctenomys.

Un test de Mantel dio como resultado un alto coeficiente de correlación $(\mathrm{r}=0,719$; 99999 permutaciones) entre la distancia morfométrica y la distancia filogenética. La regresión múltiple de los valores de deformaciones parciales (matriz de peso o $W$ ) sobre el logarimo del tamaño de centroide (logCS) mostró que sólo 8,35\% de la variación detectada es explicada por el tamaño (Test $\mathrm{F}$ generalizado de Goodall, $\mathrm{F}_{32,649}=1,83$, $\mathrm{p}<0.005$ ). De la misma forma, las regresiones de los dos primeros RW con respecto al tamaño del centroide log-transformado no resultaron significativas (RW1 vs. $\log C S, r^{2}=0,101$, $\left.\mathrm{p}=0,15 ; \mathrm{RW} 2 \mathrm{vs} \log \mathrm{CS}, \mathrm{r}^{2}=0,002, \mathrm{p}=0,857\right)$. Estos análisis mostraron que el tamaño no explica directamente las variaciones de forma registradas, y que la 
escápula de los caviomorfos estudiados muestra elevada inercia filogenética (alta correlación entre distancia morfométrica y filogenética).

Este análisis confirmó por un lado, las claras diferencias morfológicas existentes entre la escápula de los octodontoideos y la de Cavia (superfamilia Cavioidea), y por otro, que las diferencias morfológicas entre los octodontoideos son moderadas. Resulta particularmente interesante que las especies de Ctenomys no se discriminaron unas de otras a lo largo del RW1, sino que se diferenciaron principalmente sobre el RW2, reflejando diferencias interespecíficas en la forma del borde craneal. C. steinbachi, C. "somuncurá" y C. "mármol", cuyo ángulo craneal ocupa una posición más cefálica, mostraron los valores (scores) más altos en este segundo RW, mientras que en el otro extremo se ubicaron C. lewisi, C. flamarioni y C. dorbignyi, con una hoja de aspecto menos alongado.

En una segunda etapa del análisis, se utilizó GEE para evaluar la influencia del hábito y el tamaño teniendo en cuenta las relaciones filogenéticas entre los taxones analizados (ver IV.6. Métodos filogenéticos comparativos). De acuerdo con los resultados (Tabla 7), ni el tamaño ni el hábito tienen efectos significativos sobre la forma escapular en la muestra de 21 especies examinadas.

Tabla 7. Análisis mediante GEE de los efectos del tamaño (estimado como $\log \mathrm{CS}$ ) y hábito (cuatro categorías) sobre la forma escapular (matriz W de scores de deformaciones parciales): pruebas de significación de los efectos. Coeficiente y error estándar (E.S.) entre paréntesis. Grados de libertad filogenéticos: 8,25.

\begin{tabular}{llll}
\hline Variables & Estimación (E,S,) & $T$ & $\begin{array}{l}\mathrm{P} \\
(\mathrm{T}>\mid t) \mid\end{array}$ \\
\hline $\log \mathrm{CS}$ & $-0,247(0,134)$ & $-1,846$ & 0,155 \\
\hline Hábito & & & \\
\hline Epigeo & $0,268(0,120)$ & 2,225 & 0,105 \\
\hline Semifosorial & $0,266(0,147)$ & 1,807 & 0,161 \\
\hline Fosorial & $0,293(0,118)$ & 2,476 & 0,083 \\
\hline Subterráneo & $-0,014(0,115)$ & $-0,119$ & 0,912 \\
\hline
\end{tabular}




\section{V.1.1.4. Análisis funcional de la morfología escapular}

Dada su posición como enlace entre el esqueleto axial y el miembro anterior, la escápula es un elemento muy rico en información funcional. Su morfología está influenciada por diversos factores, incluyendo su funcionalidad, el desarrollo relativo de los músculos vinculados y factores históricos, de manera que su análisis resulta complejo (Monteiro y Abe, 1999).

En general, la morfología escapular de Ctenomys responde al tipo morfológico característico de la superfamilia Octodontoidea, evidenciando una fuerte influencia de la genealogía. La existencia de inercia filogenética es un dato significativo para el análisis morfo-funcional, ya que confirma las observaciones cualitativas de que muchas de las características morfológicas de la escápula de este género son similares a las de otros octodontoideos, y que no representan rasgos especializados particularmente vinculados al hábito braquioexcavador; sin embargo, esto no representaría una restricción, sino que por el contrario, dicha morfología pudo ser potencialmente favorable para la evolución de este hábito en la superfamilia

De acuerdo con los resultados de los análisis cuali- y cuantitativos, los rasgos que distinguen al género dentro de los Octodontoidea son: a. gran robustez general; b. proceso coracoides largo y curvado; c. espina larga y robusta, curvada con respecto al plano escapular; d. ausencia de metacromion; y e. en la mayoría de las especies, proceso teres major bien desarrollado en la porción distal del borde axilar. Sin embargo, existe importante variación interespecífica, la cual se refleja en los índices analizados, indicando heterogeneidad de las especializaciones morfológicas en la mayoría de las especies. Mientras C. "vista" presenta valores altos para todos los índices analizados, el resultado es diferente para las demás especies. C. flamarioni, C. opimus y C. "perucho" tienen espina escapular relativamente larga; C. lewisi y C. maulinus poseen la muesca escapular más alta, y C. talarum y C. rionegrensis presentan mayor elongación. Estas diferencias no están 
influenciadas por el tamaño corporal (ver Alometrías en la escápula de Ctenomys).

En todas las especies, la escápula es más robusta que en octodontoideos de tamaño similar: la hoja escapular es más gruesa y más fuertemente osificada, con el borde axilar particularmente engrosado y reforzado. Estas características le otorgan mayor resistencia a las torsiones generadas por la contracción de los músculos supraspinatus, infraspinatus y subscapularis que proporcionan estabilidad al hombro, muy importante en braquioexcavadores para contrarrestar las fuerzas de resistencia del sustrato transmitidas por el brazo (Fig. 24). Además, el borde axilar proporciona una fuerte superficie de origen para la cabeza larga del m. triceps brachii, que alcanza un tamaño muy grande en Ctenomys. El proceso coracoides largo y fuerte se proyecta sobre la articulación gleno-humeral describiendo una curva que rodea parcialmente a la cabeza humeral, limitando el rango de movimientos de esta última y proporcionando refuerzo ante la posible dislocación de esta articulación (Hildebrand, 1985). De la misma forma, la larga espina escapular que suprayace a la cabeza humeral también limita los movimientos escapulares al plano parasagital (Lehmann, 1963); además, la prolongación de su extremo libre más allá del nivel de la fosa glenoidea otorga función protractora, además de abductora, al $\mathrm{m}$. acromiodeltoideus. Su gran robustez proporciona fuertes áreas de origen e inserción para los músculos deltoideus y trapezius, así como el fuerte proceso coracoides brinda mayor superficie de origen para los músculos biceps brachii y coracobrachialis, protractores del brazo (Fig. 24).

La región más claramente diferente en la escápula de Ctenomys con respecto a otros caviomorfos es el extremo libre de la espina escapular, el cual es redondeado o subtriangular y carece de metacromion diferenciado. Este rasgo exclusivo está asociado con un cambio de inserción del m. omocervicalis, que se une al acromion y parte de la clavícula, mientras que en otros caviomorfos se inserta en el acromion y/o metacromion (Woods, 1972). Este 
músculo es un flexor de pequeño tamaño en Ctenomys, y no se ha planteado ninguna hipótesis acerca del significado funcional de esta diferencia.

La gran muesca escapular de Ctenomys es extensa como en otros octodontoideos, pero difiere de la de estos últimos por presentar un contorno ovoide más convexo en vista craneal, dado por la curvatura de la espina escapular con respecto al cuerpo de la escápula. La corta base de la espina escapular y la enorme muesca escapular de Ctenomys, así como los altos valores de DEP (Fig. 16), reflejan el gran desarrollo de los m. supraspinatus e infraspinatus. Sin embargo, el hecho de que la amplitud de la gran muesca escapular sea similar en otros octodontoideos sugiere que este rasgo es plesiomórfico para Ctenomys, y la especialización dentro del género se manifiesta sólo en las relativamente pequeñas diferencias en los índices LRBE (máximo en C. conoveri y C. dorbigny), y DEP [con respecto al cual sólo C. "vista" tiene un valor elevado que escapa al rango continuo (Fig. 16)].

Vassallo (1998) señaló que el proceso teres major no muestra diferencias importantes entre C. australis y C. talarum. Sin embargo, más allá de que estas especies, como todas las restantes, presentan proceso teres major (lo cual indica buen desarrollo del m. teres major en todo el género), en este trabajo se detectó una variación importante en su tamaño y forma. Precisamente, la morfología del proceso teres major en estas dos especies corresponde a los extremos de esta variación ("tipo rionegrensis" y "tipo talarum”, ver V.1.1.1.a. Morfología escapular en Ctenomys). Esta variación podría estar correlacionada con el grado de desarrollo del músculo. En C. talarum, C. "vista", y C. rionegrensis la elongación anteroposterior del borde caudal es máxima, mientras que en $C$. maulinus y C. dorbignyi existe una verdadera fosa postescapular, y ambos rasgos, que proporcionan ventaja mecánica adicional al m. teres major, están presentes en C. "mármol".

Como se dijo anteriormente, otros rasgos de la escápula de Ctenomys no difieren de la morfología típica de los octodontoideos. Sin embargo, a pesar de que estos rasgos no son especializaciones morfológicas propias del género, las 
diferencias interespecíficas observadas en Ctenomys podrían reflejar diferencias en la potencialidad biomecánica para la actividad excavadora. El borde vertebral de la escápula de Ctenomys y otros octodontoideos proporciona amplio origen para los $\mathrm{m}$. rhomboideus y serratos (mm. serratus anterior y levator scapulae), y brinda mayor ventaja mecánica al $\mathrm{m}$. serratus anterior, especialmente durante posiciones extremadamente protraídas o retraídas del miembro anterior tales como las que pueden darse durante el cavado (Fig. 24). Dado que el m. serratus anterior s.s. actuaría resistiendo el desplazamiento de la escápula hacia arriba dado por la resistencia del suelo contra el miembro que se ejerce durante la braquioexcavación (Jolly, 1967), las especies con borde vertebral más largo y robusto (alto LRBV), tales como $C$. "perucho", C "vista". C. maulinus o C. talarum, poseerían ventaja mecánica con respecto a las de borde vertebral más corto, tales como C. lewisi y C. leucodon. Las diferencias interespecíficas en la forma del borde craneal, detectadas mediante el análisis morfométrico geométrico, podrían también reflejar variaciones en el desarrollo relativo de los $\mathrm{mm}$. supraspinatus, rhomboideus y especialmente del m. occipitoscapularis, el cual es continuo con el $\mathrm{m}$. rhomboideus anterior.

La gran robustez escapular, mayor largo de la espina y del proceso coracoides, y el desarrollo de proceso teres major observados en Ctenomys son especializaciones morfológicas que también se hallan presentes en otros roedores braquioexcavadores del mundo (Lehmann, 1963; Lessertisseur y Saban, 1967; Hildebrand, 1985; Stein, 2000). En este contexto, la forma escapular de Ctenomys no exhibe una especialización morfológica equivalente a la presente en especies subterráneas de otros subórdenes, tales como Spalax (Myomorpha, Spalacidae; cf. Fig. 9 y Özkan, 2002, Figs. 1 y 2) o Pappogeomys (Castorimorpha, Geomyidae), en los cuales la escápula posee hoja muy alongada (baja y larga), con prominentes crestas en los bordes craneal y axilar, y espina más robusta y larga. 


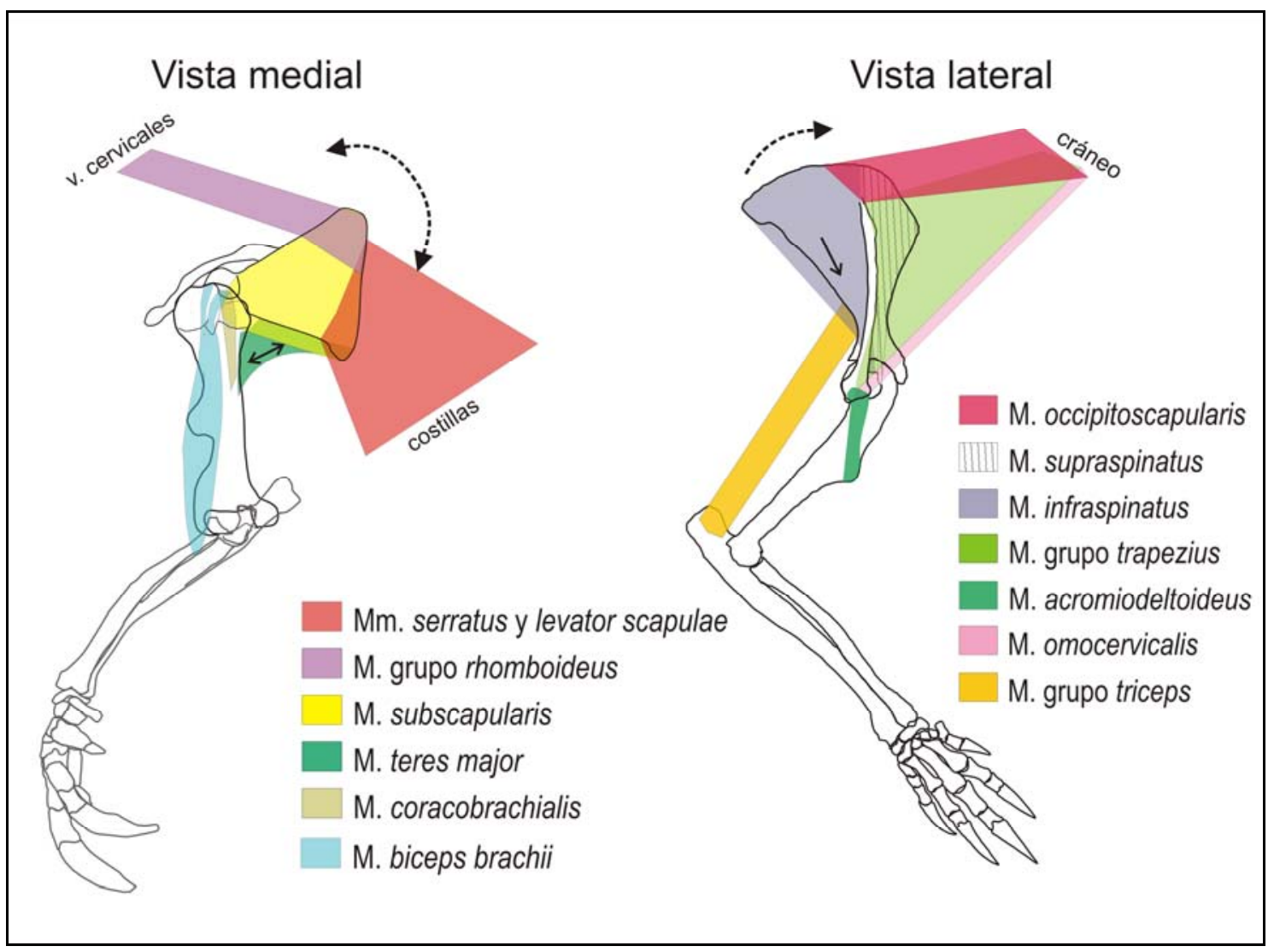

Figura 24. Representación esquemática de los principales músculos asociados con la escápula.

\section{V.1. 2. Húmero}

\section{V.1.2.1. Análisis cualitativo}

\section{V.1.2.1.a. Morfología humeral en Ctenomys}

El húmero es robusto, con superficies de origen e inserción muscular bien desarrolladas (cresta deltoidea, epicóndilos, tuberosidades humerales). La robustez humeral de las especies analizadas varía de manera continua desde el aspecto relativamente más grácil de C. flamarioni y C. leucodon hasta el fuertemente robusto de C. lewisi, C. "vista", C. dorbignyi y C. conoveri (Fig. 25). La robustez de las especies extintas varía en el mismo rango que la de las vivientes: el húmero de †Ctenomys chapalmalensis (ejemplar MMP 358-S) es moderadamente robusto, mientras que los de †Ctenomys sp. 3 y †Ctenomys sp. 4 son relativamente gráciles, y los de †Ctenomys sp. 1 y de †C. subassentiens son muy robustos (Fig. 25 y 27). 


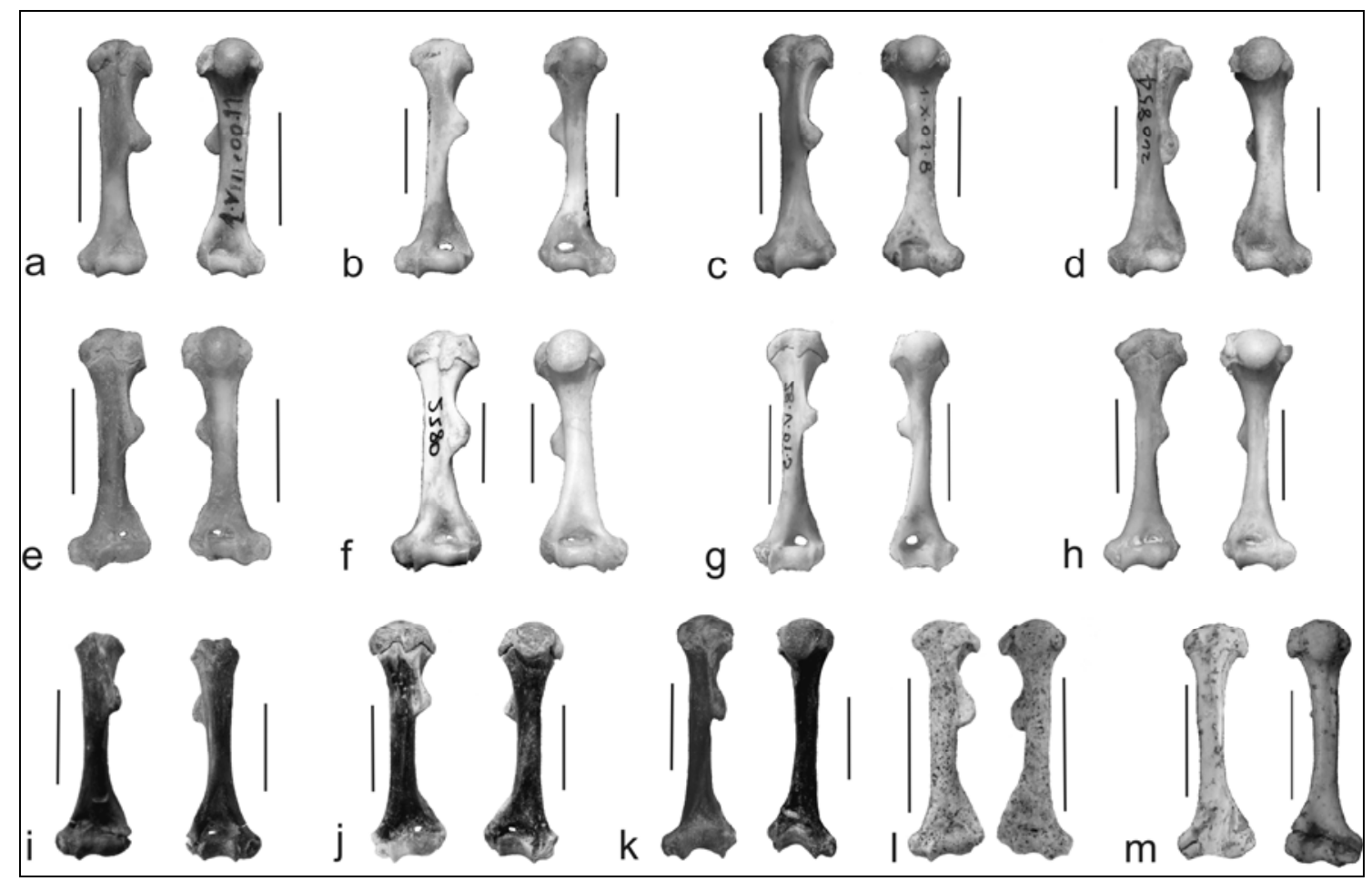

Figura 25. Húmero izquierdo (derecho invertido en b, f, g, j, k, l y m) en vista anterior (izquierda) y posterior (derecha) de especies de Ctenomys; a. C. talarum; b. C. australis; c. C. "mármol"; d. C. steinbachi; e. C. rionegrensis, f. C. lewisi; g. C. flamarioni; h. C. leucodon; i. †C. chapalmalensis (incompleto); j. †Ctenomys sp. 1; k. †Ctenomys sp. 2; 1. †Ctenomys sp. 3; m. †Ctenomys sp. 4 (incompleto). Escala: $1 \mathrm{~cm}$.

La cabeza articular tiene forma ovoide, ligeramente más redondeada en C. leucodon que en las demás especies examinadas. En aquellas especies con cabeza humeral relativamente más alongada (C. talarum, C. "perucho"), el alargamiento del eje mayor de la misma se refleja en la formación de un "pico" o arista formado por el borde distal de la cabeza articular (similar al beaking descripto para el húmero de marsupiales por Szalay y Sargis, 2001; Fig. 26). En C. leucodon, C. flamarioni, C. maulinus, C. fulvus, y C. "somuncurá" este borde es más suave y no presenta una arista definida en vista lateral. Las tuberosidades mayor y menor muestran facetas de inserción muscular bien definidas en los ejemplares adultos de todas las especies estudiadas; debido a que el tamaño absoluto de las mismas es similar en todas las especies 
analizadas, resultan relativamente menos desarrolladas en aquéllas de mayor tamaño.

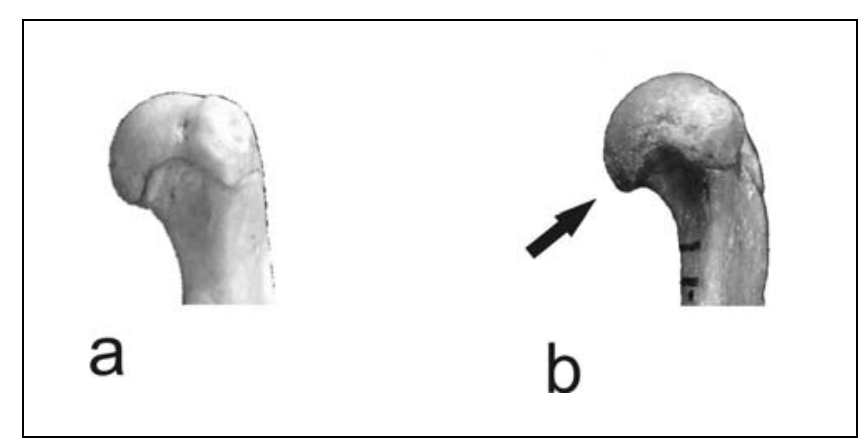

Figura 26. Detalle de la cabeza del húmero izquierdo en vista medial; a. C. flamarioni, b. C. talarum. La flecha señala la arista saliente de la cabeza humeral o beaking.

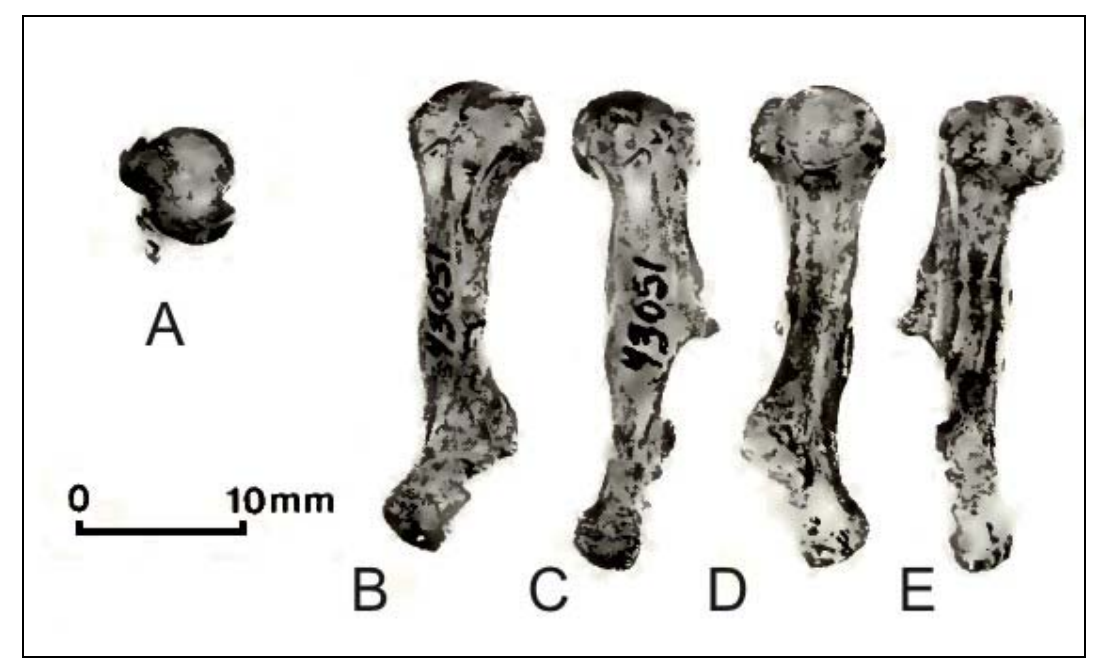

Figura 27. Húmero izquierdo de †C. subassentiens KUVP 43051 (incompleto). A. Epífisis proximal en vista axial; B. vista anterior; C. vista medial; D. vista posterior; E. vista lateral. Modificado de Frailey et al. (1980).

La morfología de las especies extintas es en general semejante a lo descripto anteriormente. En †C. chapalmalensis MMP 358-S la cabeza humeral es suboval. Las tuberosidades son relativamente pequeñas y el surco bicípito está poco definido; esta condición podría deberse en parte al estado de conservación del espécimen. †Ctenomys sp. 1 es posiblemente un ejemplar subadulto, ya que sus epífisis no están completamente soldadas y las superficies de inserción muscular en las tuberosidades están poco definidas, 
tal como ocurre en ejemplares juveniles de especies vivientes. En †Ctenomys sp. 2 la tuberosidad mayor está parcialmente dañada, pero se observan superficies de inserción muscular bien definidas. En esta especie las tuberosidades son pequeñas en comparación con especies vivientes de tamaño similar, tales como $C$. australis y $C$. fulvus. †Ctenomys sp. 3 y $†$. subassentiens (Fig. 27) presentan cabeza articular redondeada, con tuberosidades bien desarrolladas, mientras que †Ctenomys sp. 4 tiene cabeza articular ligeramente alongada y tuberosidades de desarrollo similar al de especies vivientes.

El área de inserción del m. teres major está indicada por una depresión en la porción próximo-medial de la diáfisis. Esta depresión forma un surco definido en C. conoveri, C. lewisi, C. maulinus, y en menor medida C. dorbignyi, y sobresale como una pequeña cresta en C. rionegrensis y C. "vista", mientras que en el resto de las especies examinadas, la inserción del m. teres major está indicada por un área rugosa paralela al eje diafisario. En †C. chapalmalensis MMP 358-S se presenta como una superficie rugosa levemente deprimida ubicada en el tercio proximal de la diáfisis, pero en MACN 19249 no es distinguible.

La forma y el desarrollo relativo de la cresta deltoidea son los rasgos más variables en la morfología humeral de las especies analizadas. C. flamarioni, C. leucodon y C. australis poseen una cresta deltoidea relativamente delgada y con escaso engrosamiento del borde proximal libre, en el cual está poco desarrollada el área rugosa longitudinal indicadora de inserciones musculares (ver V.1.2.4. Análisis funcional de la morfología humeral y Apéndice III). En el resto de las especies estudiadas, el borde proximal libre de la cresta deltoidea está engrosado y presenta una superficie rugosa bien definida, que puede ser corta y restringida al ápice de la cresta (e.g. C. "vista", C. frater, C. maulinus, C. conoveri, †Ctenomys sp. 2) o bien extenderse longitudinalmente sobre una mayor proporción del borde libre (C. rionegrensis, C. dorbignyi, C. opimus, C. steinbachi). La posición de la cresta deltoidea sobre la diáfisis también presenta 
notables variaciones interespecíficas (Fig. 25). La cresta está ubicada más próxima a la cabeza humeral en C. flamarioni, C. fulvus y C. australis, mientras que su posición es más distal en las otras especies, llegando a ubicarse prácticamente en la mitad de la diáfisis en C. conoveri, C. lewisi, C. "mármol", y C. steinbachi. En otras especies examinadas, la posición de la cresta deltoidea sobre la diáfisis es intermedia entre estos extremos, lo que genera un gradiente de variación casi continuo (ver V.1.2.3. Análisis estadístico descriptivo). La cresta deltoidea de $† C$. chapalmalensis es más pequeña que en las especies vivientes y ocupa una posición más proximal, al menos en el ejemplar MMP 358-S; sin embargo, la reconstrucción de MACN 19249 sugiere una posición de la misma dentro del rango de variación de las especies vivientes. Los Ctenomys pleistocénicos analizados exhiben un rango de variación semejante al de las especies vivientes, a excepción de †Ctenomys sp. 1, en la cual la cresta es relativamente pequeña y se ubica más cerca del extremo proximal del húmero que en los actuales. La bien desarrollada cresta deltoidea de †Ctenomys sp. 2 tiene una morfología particular, ya que el plano de la cresta se curva terminando en un extremo ganchoso; en esta especie la posición de la cresta deltoidea es algo más distal que en $† C$. chapalmalensis. La morfología de la cresta deltoidea de †Ctenomys sp. 3 no difiere de la de las especies vivientes. En †C. subassentiens la cresta deltoidea está rota, pero su posición sobre la diáfisis es comparable a la de las especies vivientes.

Los epicóndilos están bien desarrollados en todas las especies, pero existen diferencias moderadas entre las mismas. Entre las especies vivientes, el menor desarrollo de los epicóndilos se observó en C. flamarioni, C. "perucho", C. "monte" y C. fulvus, mientras que C. conoveri, C. frater y C. lewisi poseen los epicóndilos más desarrollados y expandidos lateralmente. En la mayoría de las especies extintas analizadas, el desarrollo de los epicóndilos es semejante al de las especies vivientes. En †C. subassentiens la epífisis distal rota no permite evaluar este rasgo (Fig. 27). 
La presencia del foramen supratroclear es variable entre las especies, e incluso presenta variaciones individuales en algunas de ellas. Ninguno de los especímenes examinados de C. dorbignyi, C. steinbachi, C. "mármol", †Ctenomys sp. 2 o †Ctenomys sp. 4 presenta foramen supratroclear. En C. maulinus, C. lewisi, y C. talarum la presencia o ausencia de este foramen es variable. Esta podría ser también la condición en †C. chapalmalensis, a juzgar por los dos especímenes conocidos: MMP 358-S no presenta foramen supratroclear, mientras que en la epífisis distal del ejemplar MACN 19249 (reconstruída) hay un pequeño orificio de borde liso y cóncavo que podría corresponder a un pequeño foramen supratroclear. En las restantes especies el foramen supratroclear está siempre presente. Con respecto a su desarrollo, el foramen supratroclear de C. fulvus es relativamente mayor que el de las demás especies estudiadas, mientras que en †Ctenomys sp. 3 éste es muy pequeño.

\section{V.1.2.1.b. Comparación con otros géneros de ctenominos}

El húmero de †Praectenomys rhombidens (Fig. 28a, tomado de Quintana, 1994, fig. 8) posee la diáfisis con robustez similar a la de los Ctenomys más gráciles, como †Ctenomys sp. 2. El único ejemplar conocido (GB 012) carece de la región proximal. La posición de la cresta deltoidea es comparativamente proximal, similar a la de $† C$. chapalmalensis, pero con una superficie de inserción muscular más desarrollada que en esta última especie. El desarrollo de los epicóndilos es menor que en Ctenomys.

Hasta el momento, el húmero de †Eucelophorus sólo se conocía en forma fragmentaria, a través de una diáfisis incompleta de $†$. chapalmalensis (=†Eucelophorus zaratei, MMP 603-S) ilustrada por Reig y Quintana (1992, fig. 8). Estos autores describieron su robustez como similar a la de Ctenomys, y señalaron que el borde posterior de la diáfisis forma un arco cóncavo en vista lateral, a diferencia del borde posterior recto de la diáfisis humeral de 
Ctenomys La cresta deltoidea es fuerte y saliente, formando una extensa lámina triangular.

Nuevos materiales de †Eucelophorus del Plioceno de Córdoba ( $\mathrm{N}^{\circ}$ Prov. 4419), posiblemente representantes de una nueva especie, con elementos poscraneanos en excelente estado de conservación permiten describir por primera vez un húmero casi completo de este género (Fig. 28b y c). En este nuevo material el húmero es muy similar al de los Ctenomys vivientes en robustez y difiere del previamente descripto ya que no muestra perfil cóncavo en la diáfisis. La cabeza articular es levemente alongada, semejante a la de Ctenomys, y la cresta deltoidea ocupa una posición más distal que en la mayoría de las especies de Ctenomys examinadas; esta cresta es fuerte y presenta el borde libre engrosado, siendo morfológicamente muy similar a la de C. frater. El desarrollo epicondilar de †Eucelophorus es al menos semejante al de C. fulvus y C. leucodon, y podría ser mayor, ya que el epicóndilo medial está parcialmente dañado. Posee un foramen supratroclear pequeño.

El húmero de †Actenomys priscus fue descripto por Fernández et al. (2000, fig. 2). En este género el húmero es más generalizado que el de Ctenomys (Fig. 28d); presenta menor robustez, tuberosidades humerales relativamente menos desarrolladas, y la cabeza humeral no presenta un "beaking" definido, aunque en vista lateral resulta bastante saliente con respecto a la diáfisis. La cresta deltoidea está menos distalizada, y el área de inserción del $\mathrm{m}$. teres major forma una superficie rugosa que es relativamente más corta que en Ctenomys y no está marcada por una depresión. La epífisis distal tiene menor desarrollo, tanto en el ancho a nivel epicondilar como la morfología de la superficie articular distal. La tróclea es relativamente más corta y el foramen supratroclear es amplio. 


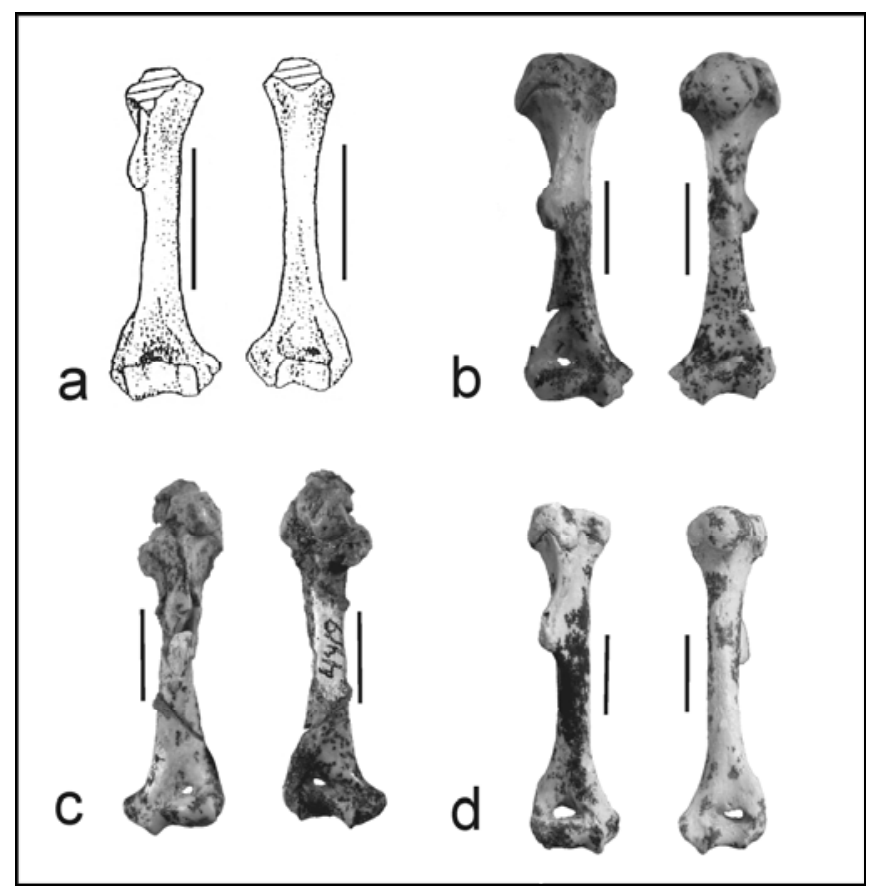

Figura 28. Húmero derecho en vista anterior (izquierda) y posterior (derecha) de ctenominos extintos. a. †Praectenomys rhombidens GB 012; b. †Eucelophorus $\mathrm{sp}\left(\mathrm{N}^{\mathrm{o}}\right.$ prov. 4419); c. $†$ Eucelophorus sp. ( $\mathrm{N}^{\mathrm{o}}$ prov. 4419); d. $\dagger$ Actenomys priscus MLP 91-IV-5-255. Escala: $1 \mathrm{~cm}$.

\section{V.1.2.1.c. Comparación con otros caviomorfos}

En los restantes octodontoideos examinados (Fig. 29) el húmero es igualmente robusto, o aún menos robusto que en las especies de Ctenomys examinadas con excepción de C. leucodon; sólo Myocastor coypus presenta húmero muy robusto, semejante en este aspecto al de las especies más robustas de Ctenomys. La cabeza articular es generalmente más redondeada y de mayor tamaño con respecto al desarrollo de las tuberosidades, en contraste con el gran desarrollo relativo de las tuberosidades en Ctenomys. La proyección posterior de la cabeza humeral formando beaking se observa en algunos octodontinos (Aconaemys y Octodon), y algunos equímidos (Thrichomys y Euryzygomatomys), mientras que en los restantes octodontoideos examinados la cabeza humeral termina en forma redondeada.

La cresta deltoidea forma en la mayoría de los casos una lámina triangular más delgada que en Ctenomys y ubicada en una posición más proximal sobre la diáfisis. La epífisis distal es menos robusta, con menor 
expansión de los epicóndilos y área articular más estrecha. El foramen supratroclear está presente y es generalmente pequeño, aunque es amplio en Abrocoma (Fig. 29 h).

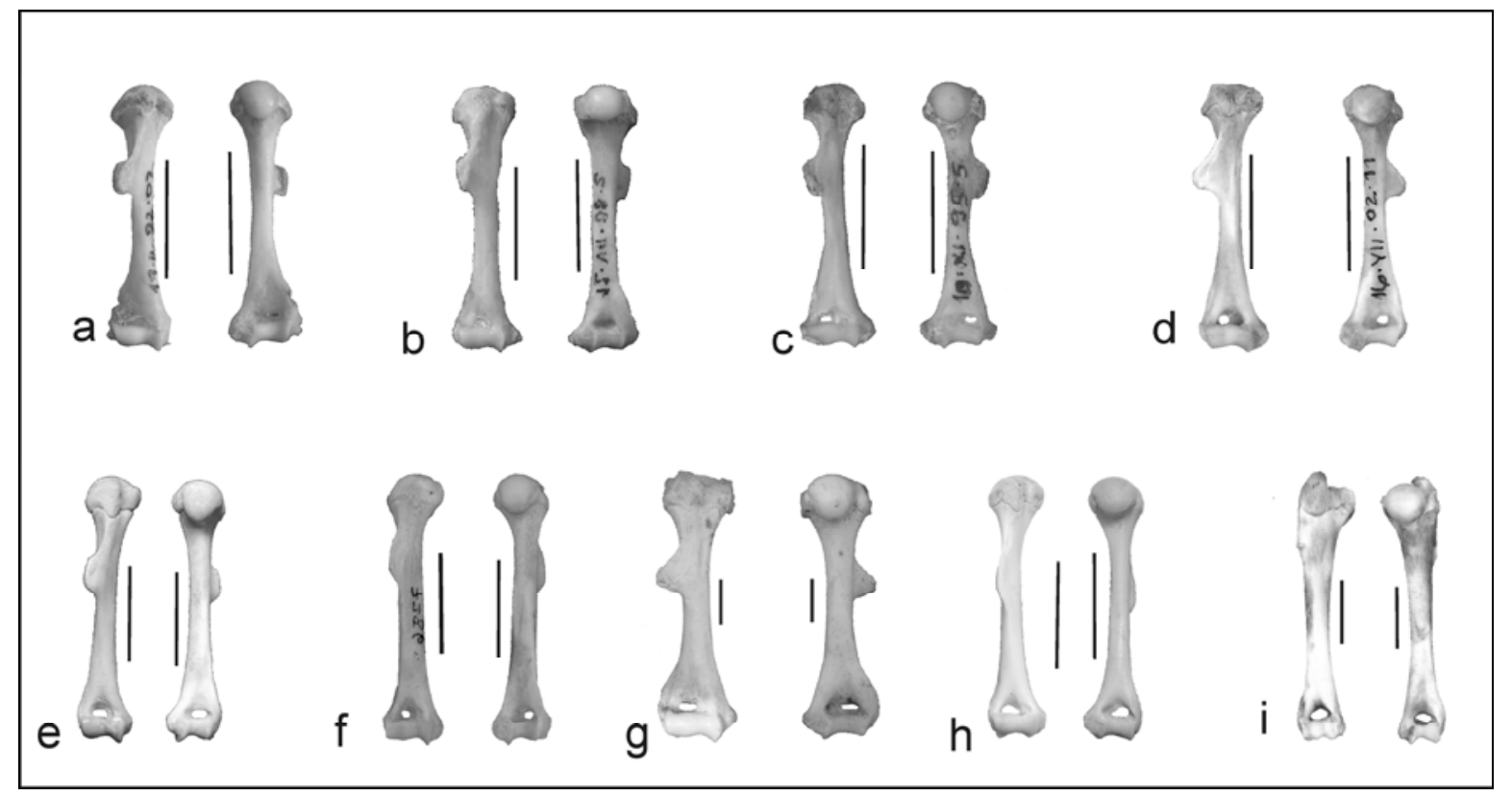

Figura 29. Húmero derecho (excepto c, f, g, i, húmero izquierdo invertido) en vista anterior (izquierda) y posterior (derecha) de Octodontoidea (a-h) y Caviidae (i). a. Aconaemys sp. b. Octodon sp.; c. Spalacopus cyanus; d. Euryzygomatomys spinosus; e. Thrichomys apereoides; f. Proechimys poliopus; g. Myocastor coypus; h. Abrocoma sp.; i. Cavia aperea. Escala: $1 \mathrm{~cm}$.

El húmero de Cavia (Fig. 29i) es muy diferente al de Ctenomys. Es relativamente más largo y grácil, y la tuberosidad mayor está notoriamente más desarrollada que la tuberosidad menor. La cabeza articular es redondeada o ligeramente ovoidal y no presenta beaking. En esta especie cursorial, la cresta deltoidea está poco desarrollada y forma una arista alongada sobre la diáfisis, muy distinta de la lámina triangular saliente de Ctenomys. La epífisis distal es angosta, y presenta fosas radial y olecraneana profundas, con un foramen supratroclear amplio. En la superficie articular distal, el cóndilo no es redondeado, sino que forma un relieve recto paralelo a la tróclea, casi como una segunda tróclea. 


\section{V.1.2.2. Análisis cuantitativo general}

Un ACP de índices humerales de Ctenomys, otros miembros de la superfamilia Octodontoidea y Cavia aperea (Fig. 30, Tabla 8) mostró que las especies de Ctenomys se distribuyen en un extremo del morfoespacio. La mayoría de las especies quedaron separadas de otros octodontoideos y claramente alejadas de Cavia, pero C. flamarioni y †C. chapalmalensis, mostraron valores cercanos a los de los octodontinos, mientras que C. lewisi se ubicó en el extremo opuesto del morfoespacio.

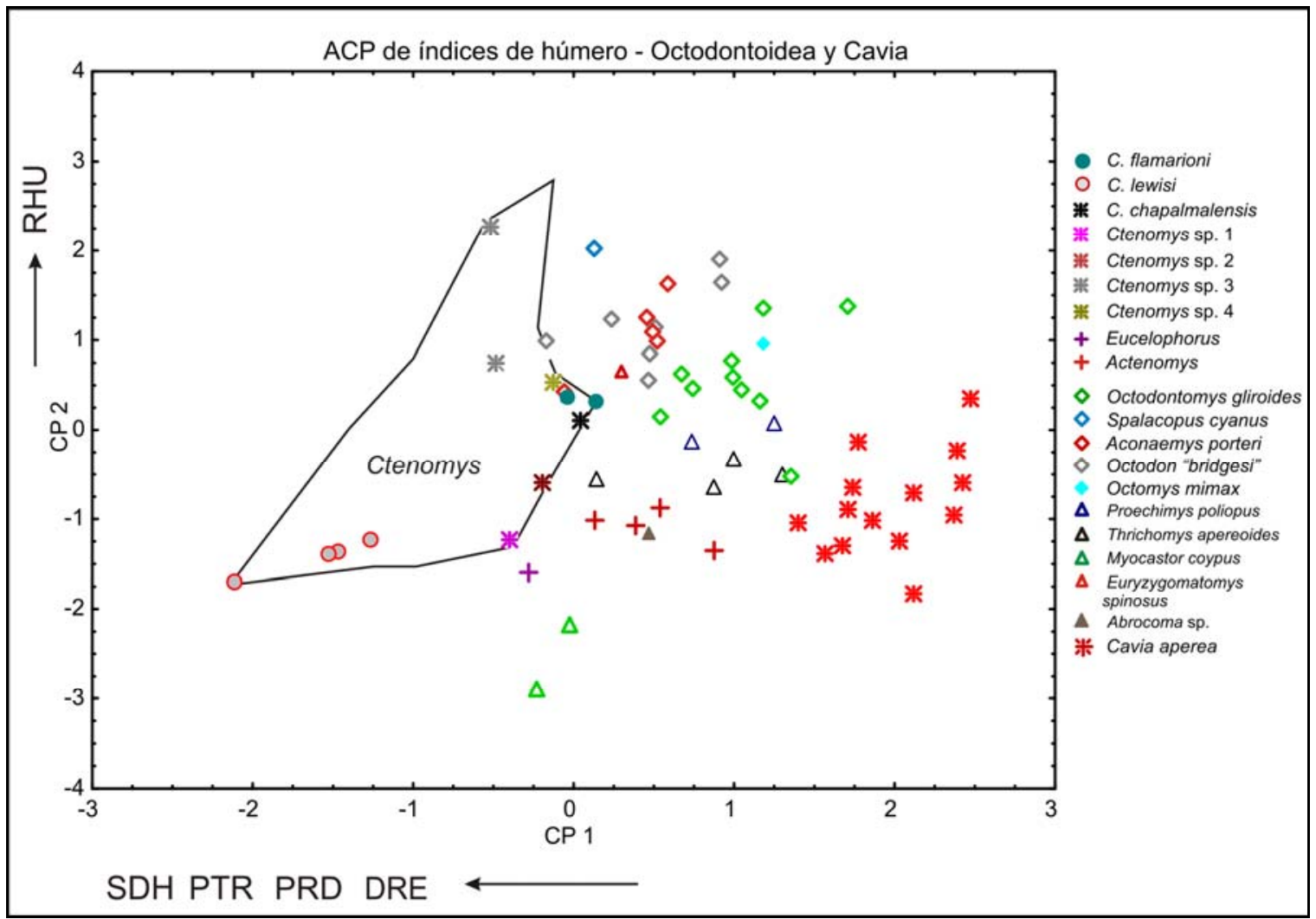

Figura 30. ACP de índices humerales de Ctenomys (polígono) y otros caviomorfos.

En este análisis, los dos primeros componentes explicaron el 79,36\% de la variación observada (Tabla 8). Las especies de Ctenomys se agruparon en el extremo negativo del primer componente (CP 1). El CP $1(62,65 \%$ de la variación observada) expresó primariamente la variación de los índices de 
ancho relativo a nivel de los epicóndilos (DRE), posición relativa de la cresta deltoidea (PRD), ancho relativo de la superficie articular distal (SDH), y largo relativo de la tróclea (PTR), mientras que el CP 2, con relativamente bajo valor explicativo (autovalor=1) reflejó primariamente la variación en robustez (RHU).

El CP 1 puede ser interpretado como un gradiente morfo-funcional, en el cual algunas especies de Ctenomys, con valores más altos en todos los índices, representan el extremo de mayor especialización humeral para la excavación (e.g. C. lewisi). De todas maneras, el rango de variación de Ctenomys a lo largo de este $\mathrm{CP}$ es amplio y se solapa con $†$ Actenomys y algunos octodontinos; de hecho, $C$. flamarioni presentó valores más bajos que $† C$. chapalmalensis y similares a los de Octodon y Spalacopus. Por su parte, el ctenomino extinto †Eucelophorus se ubicó dentro del rango de variación de Ctenomys.

Tabla 8. Correlaciones Factor-Variable (factor loadings) y porcentaje de variación explicada para los 2 primeros Componentes Principales (CP) del ACP de Fig. 30.

\begin{tabular}{ccc}
\hline Índice & CP 1 & CP 2 \\
\hline RHU & $-0,60$ & $\mathbf{- 0 , 7 2}$ \\
\hline DRE & $\mathbf{- 0 , 9 6}$ & 0,023 \\
\hline PRD & $\mathbf{- 0 , 8 2}$ & $-0,20$ \\
\hline PTR & $\mathbf{- 0 , 7 4}$ & 0,11 \\
\hline SDH & $\mathbf{- 0 , 9 2}$ & 0,08 \\
\hline DRT & $-0,64$ & 0,65 \\
\hline Autovalor & 3,76 & 1,00 \\
\hline \% variación explicada & 62,65 & 16,71 \\
\hline \% acumulativo & 62,65 & 79,36 \\
\hline
\end{tabular}

\section{V.1.2.3. Análisis cuantitativo de la variabilidad morfológica en Ctenomys} Análisis multivariado

Un ACP de índices humerales de especies vivientes y extintas de Ctenomys, dio como resultado una distribución de las especies en un amplio 
rango en el morfoespacio representado por los 2 primeros componentes principales (Fig. 31, Tabla 9).

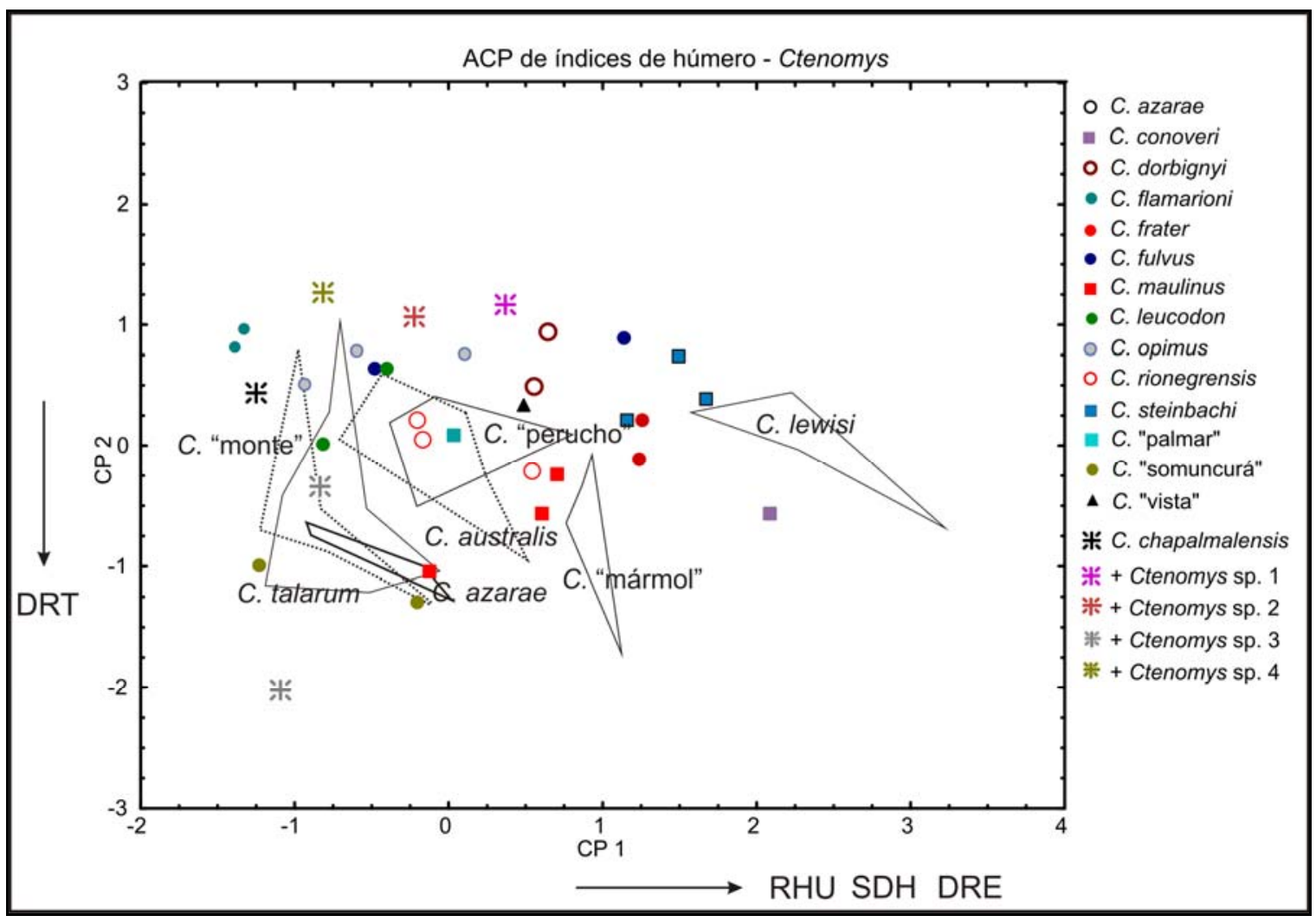

Figura 31. ACP de índices humerales de especies de Ctenomys.

Tabla 9. Correlaciones Factor-Variable (factor loadings) y porcentaje de variación explicada para los 2 primeros Componentes Principales (CP) del ACP de Fig. 31.

\begin{tabular}{ccc}
\hline Índice & CP 1 & CP 2 \\
\hline RHU & $\mathbf{0 , 7 4}$ & 0,34 \\
\hline DRE & $\mathbf{0 , 8 4}$ & $-0,08$ \\
\hline PRD & 0,52 & 0,21 \\
\hline PTR & 0,41 & $-0,50$ \\
\hline SDH & $\mathbf{0 , 6 9}$ & $-0,51$ \\
\hline DRT & $-0,35$ & $\mathbf{- 0 , 7 4}$ \\
\hline Autovalor & 2,29 & $\mathbf{1 , 2 2}$ \\
\hline
\end{tabular}




\begin{tabular}{lll}
\hline $\begin{array}{l}\text { \% variación } \\
\text { explicada }\end{array}$ & 38,28 & 20,35 \\
\hline \% acumulativo & 38,28 & 58,64 \\
\hline
\end{tabular}

Los dos primeros componentes explicaron el 58,64 \% de la variación observada. El CP 1 (38,28\% de la variación) resumió la influencia de los índices RHU, DRE, SDH, y en menor medida PRD y PTR. Esto sugiere que el CP 1 representa un gradiente morfo-funcional desde el extremo positivo, donde se ubicaron las especies con húmero más especializado en los rasgos mencionados (C. lewisi, C. conoveri, C. steinbachi) hasta el extremo negativo con especies más generalizadas (C. flamarioni y †C. chapalmalensis). De todas maneras, el análisis muestra también considerable variabilidad intraespecífica y la distribución de especies no muestra discontinuidades. El segundo componente principal (CP 2; 20,35 \% de la variación observada) expresó mayoritariamente la variación en el índice RTD. Este índice mostró alometría negativa dentro del género Ctenomys, por lo cual la disposición de las especies a lo largo de este eje podría estar influenciada por el tamaño corporal (ver Alometrías en el húmero de Ctenomys).

\section{Análisis estadístico descriptivo}

El análisis estadístico descriptivo de la morfología humeral en las especies de Ctenomys se ilustra en las Figuras 32 a 37. Se observó una variación casi continua dentro del rango de valores para cada índice morfofuncional. Algunas especies ocuparon las posiciones extremas con respecto a todos los índices (C. lewisi, C. frater, C. steinbachi, con valores máximos; C. flamarioni, †C. chapalmalensis, C. fulvus, con valores mínimos), y el resto ocupó diferentes posiciones según el índice considerado, sugiriendo un patrón de especialización humeral tipo mosaico para la mayoría de las especies analizadas. El índice de desarrollo de las tuberosidades humerales (DRT, Fig. 37) muestra una discontinuidad (aproximadamente en el valor 0,065) que 
separa especies en dos grupos; las especies con valores menores de DRT son aquéllas de mayor tamaño corporal, mientras que los valores más altos corresponden a especies más pequeñas. Este patrón se discute en el próximo apartado (Alometrías en el húmero de Ctenomys).

Las especies extintas de Ctenomys se distribuyeron dentro del rango de variación de las especies vivientes.

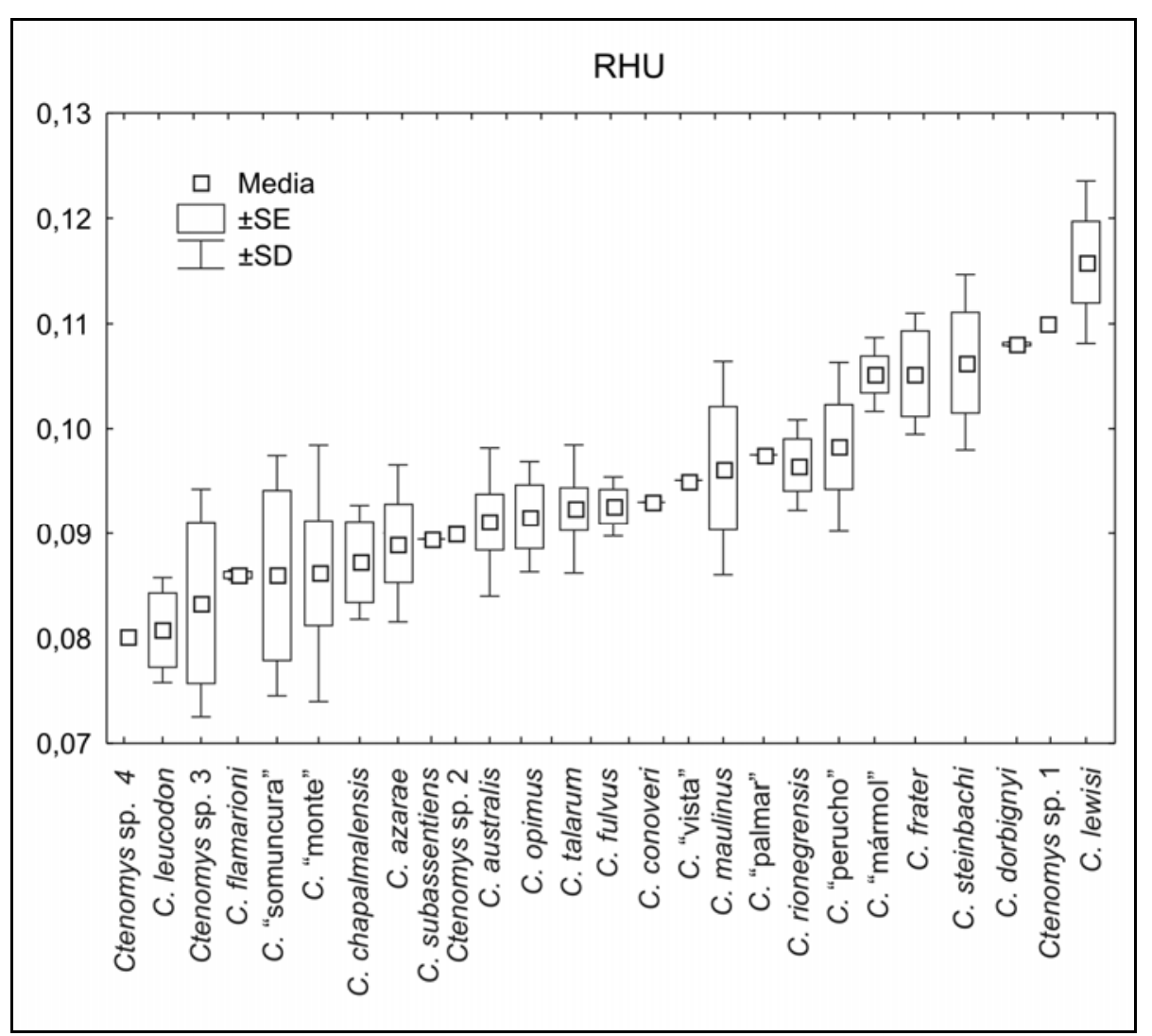

Figura 32. Índice de robustez (RHU) por especie. 


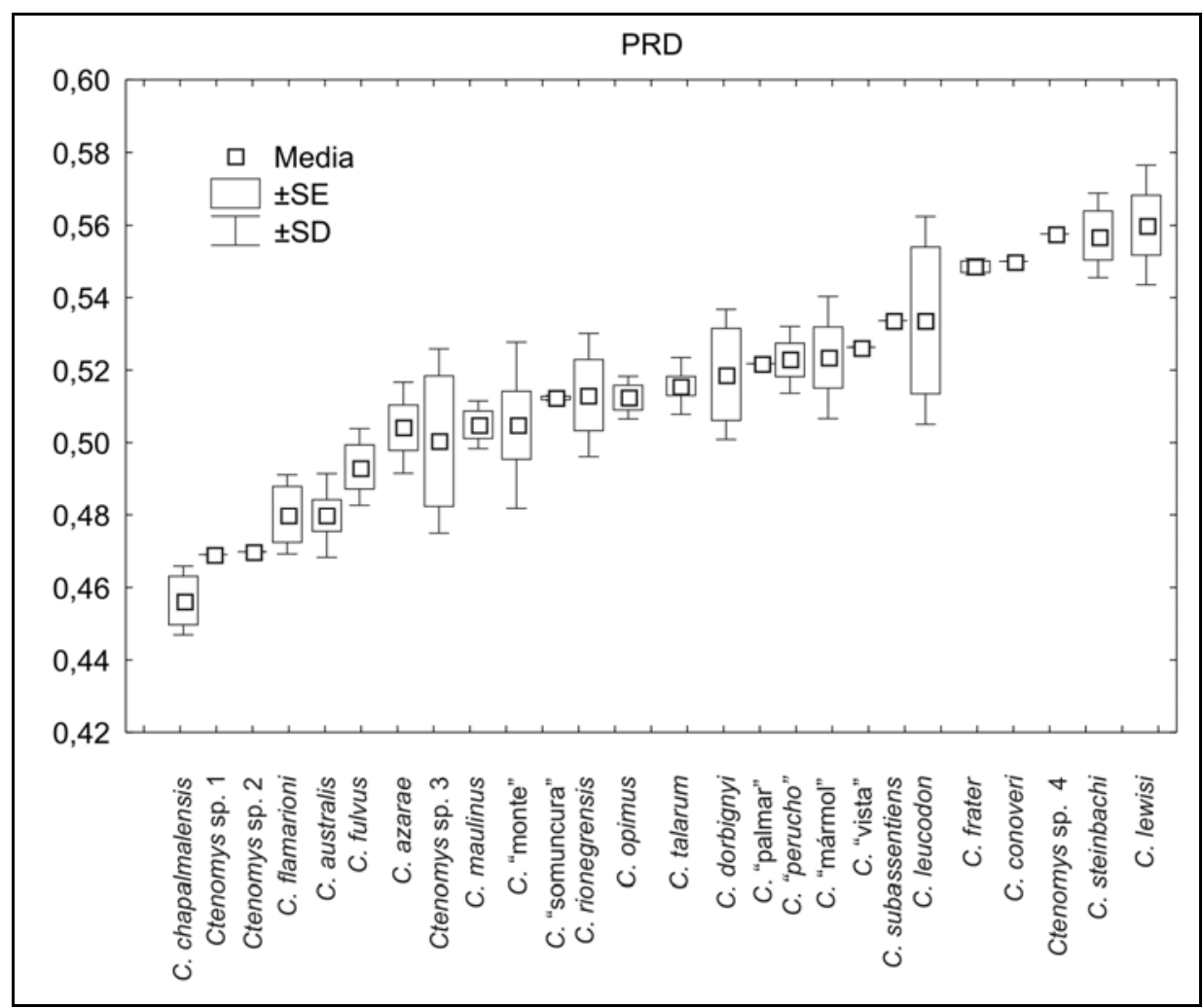

Figura 33. Posición relativa de la cresta deltoidea (PRD) por especie de Ctenomys.

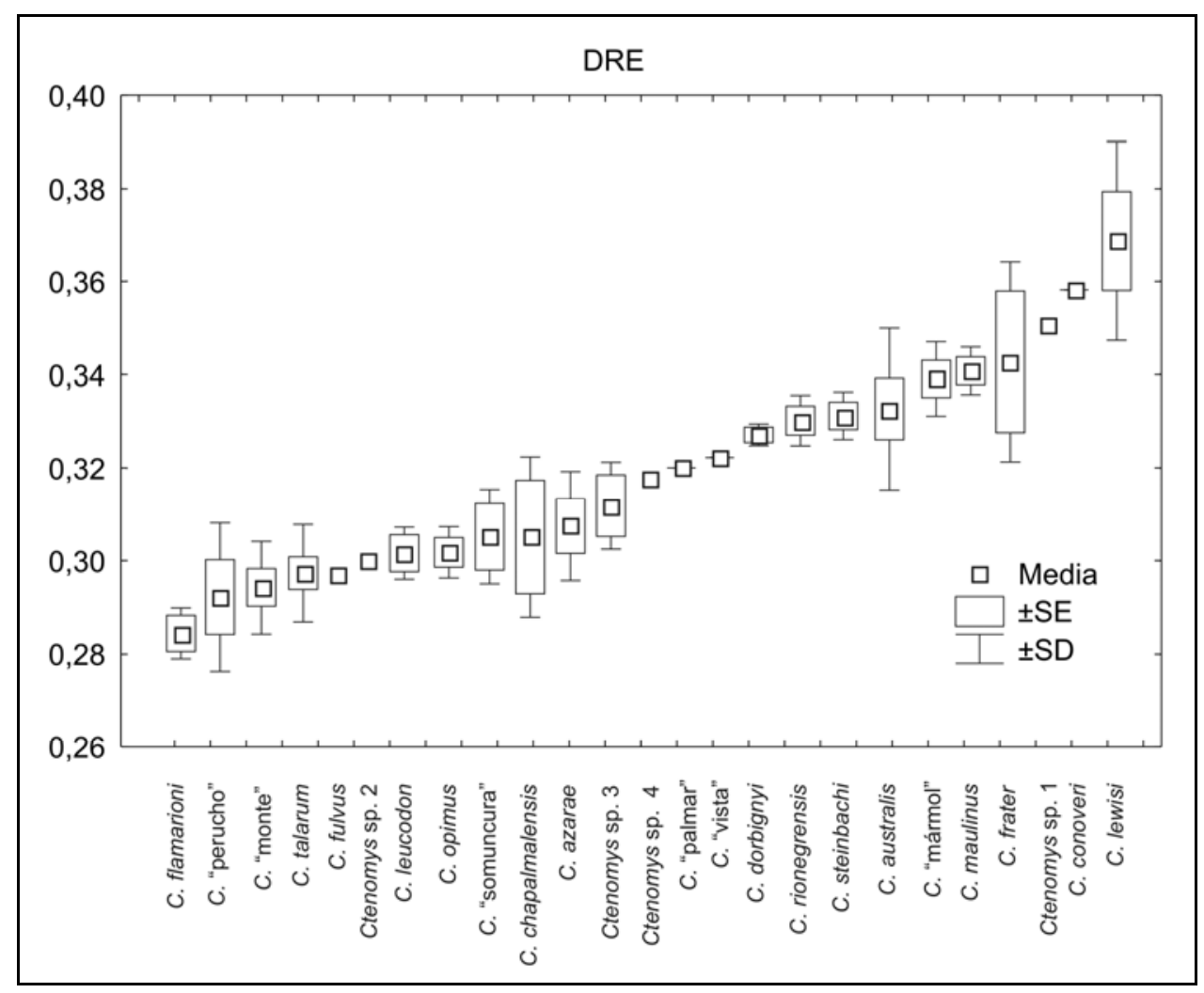

Figura 34. Desarrollo de epicóndilos (DRE) por especie. 


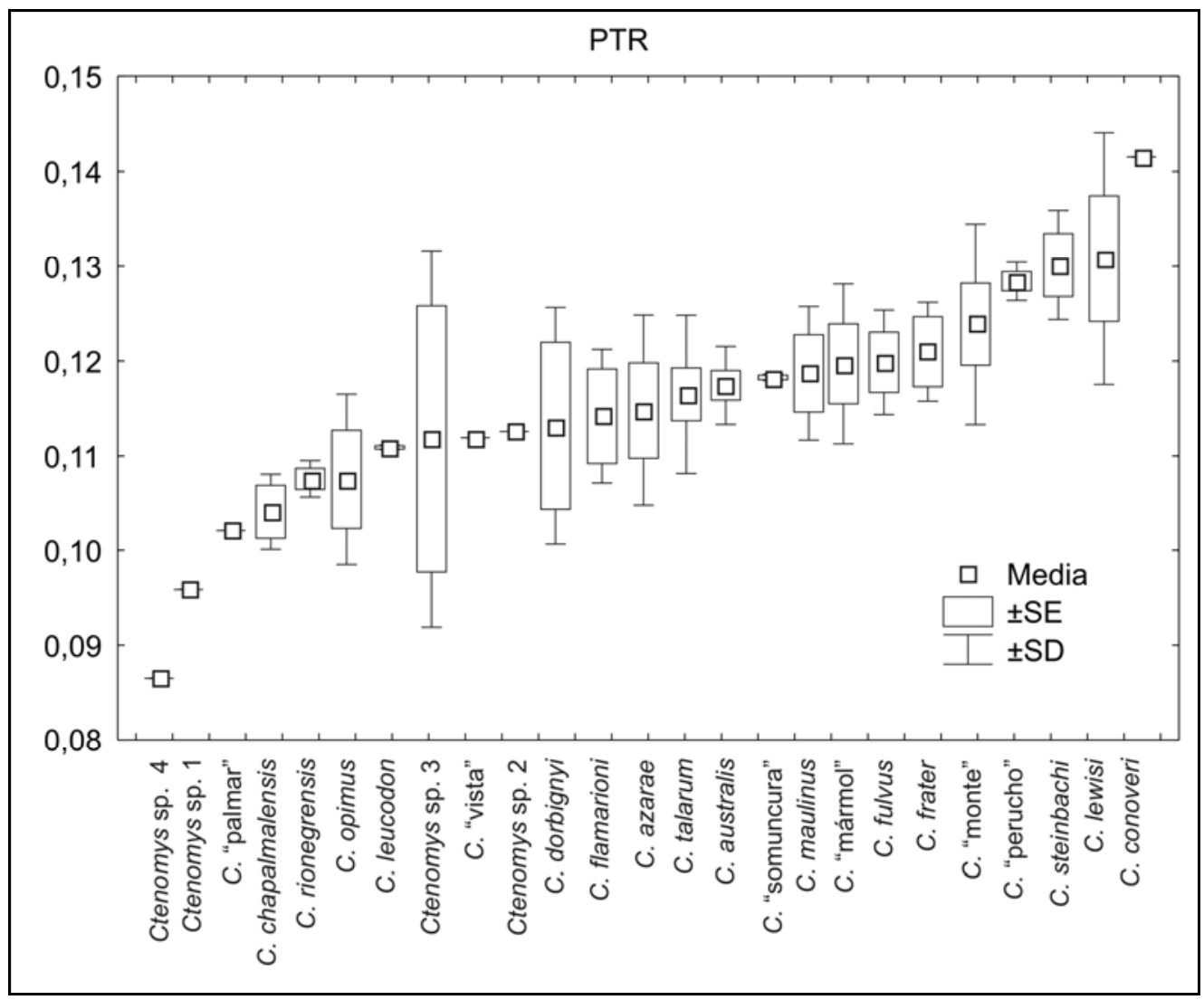

Figura 35. Profundidad relativa de la tróclea (PTR) por especie.

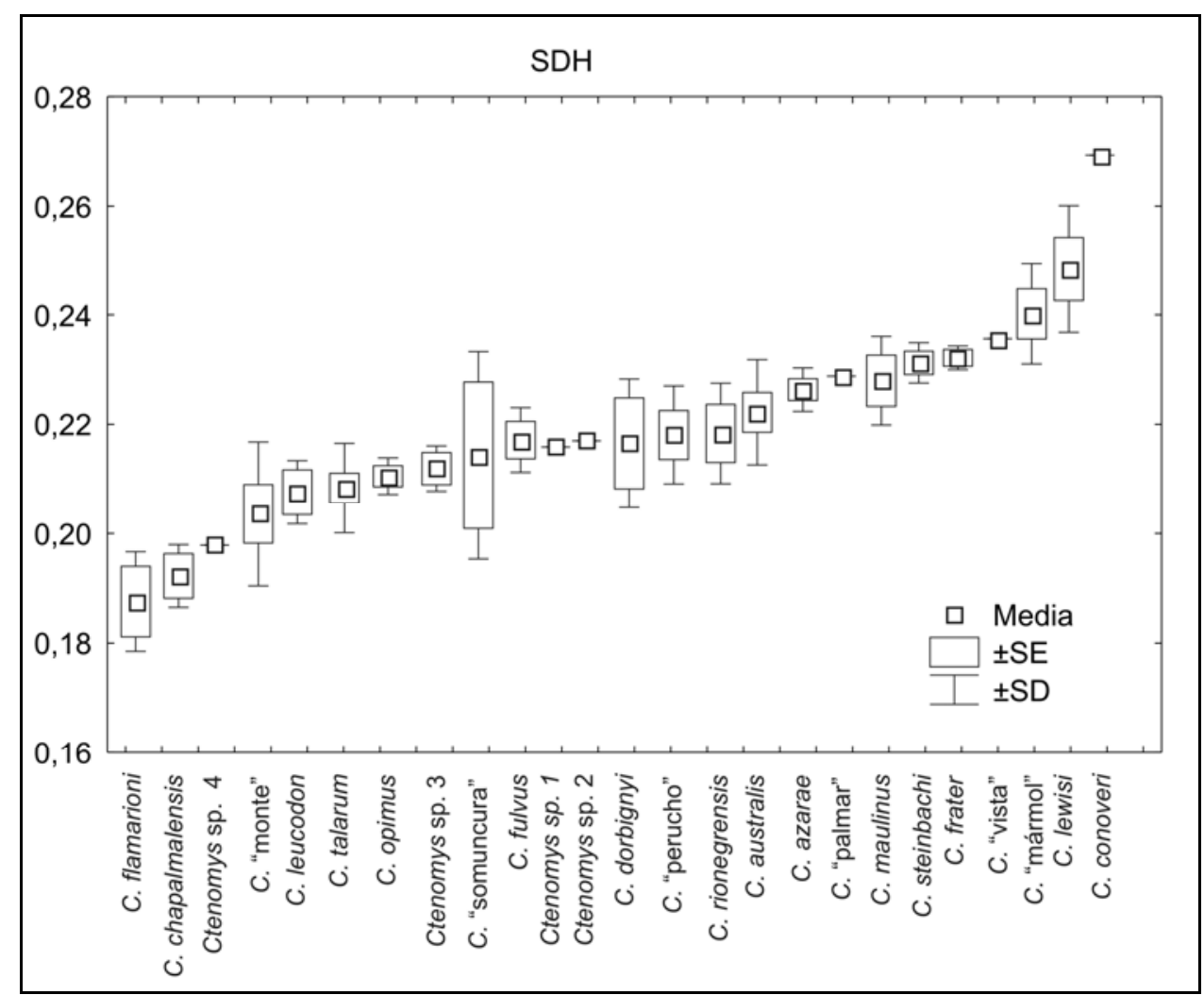

Figura 36. Ancho relativo de la superficie articular distal (SDH) por especie. 


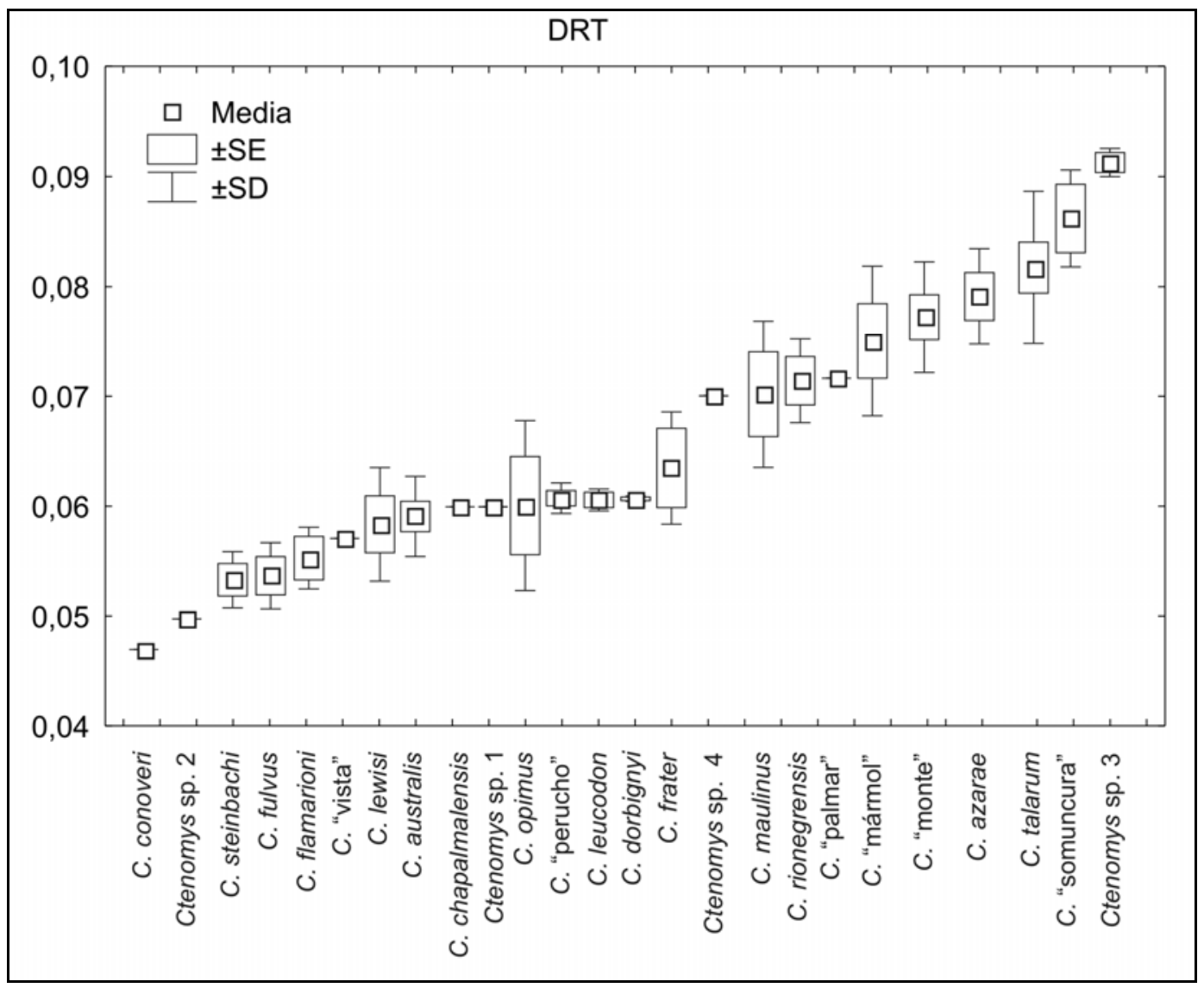

Figura 37. Desarrollo de las tuberosidades humerales (DRT) por especie.

\section{Alometrías en el húmero de Ctenomys}

Los resultados del análisis alométrico se muestran en las Tablas 10 y 11. Las medidas lineales mostraron ligera alometría positiva $(1,15<b<1,57)$ y buen ajuste $(0,7<r<0,91)$, siendo el largo total del húmero (LTH) el más cercano a la isometría con respecto al tamaño corporal. La mayor tasa de crecimiento corresponde al diámetro anteroposterior del húmero (DAPH).

La mayoría de los índices analizados mostró muy baja correlación con el tamaño corporal. La excepción estuvo dada por el índice de desarrollo de las tuberosidades (DRT), que presentó alta correlación negativa con el tamaño corporal $(\mathrm{r}=-0,81)$. La fuerte alometría negativa de este índice coincide con los resultados previamente discutidos (ver apartado anterior). 
Tabla 10. Ecuaciones alométricas (regresión Modelo II, método de ejes principales) para medidas del húmero de Ctenomys vs. DP4-M2.

\begin{tabular}{llllll}
\hline $\begin{array}{l}\text { Variable } \\
\text { regresionada } \\
\mathrm{x}\end{array}$ & $\begin{array}{l}\text { Ecuación }(\log \mathrm{y}=\mathrm{a}+\mathrm{b} \log \\
\text { AEPI }\end{array}$ & $\mathrm{n}$ & $\mathrm{r}$ & $\mathrm{r} 2$ & $\begin{array}{l}\text { Intervalos } \\
\text { confianza }\end{array}$ \\
\hline & & & & & deg $\mathrm{y}=-0,43+1,46 \log \mathrm{x}$ \\
\hline TUB & 67 & 0,90 & 0,81 & $\mathrm{a}=-0,60--0,29$ \\
\hline & $\log \mathrm{y}=-0,34+1,30 \log \mathrm{x}$ & 67 & 0,78 & 0,60 & $\mathrm{a}=-0,61--0,14$ \\
\hline ASAD & $\log \mathrm{y}=-0,50+1,36 \log \mathrm{x}$ & 55 & 0,86 & 0,73 & $\mathrm{a}=-0,72--0,32$ \\
\hline & & & & & $\mathrm{b}=1,16-1,60$ \\
\hline DELT & $\log \mathrm{y}=0,04+1,27 \log \mathrm{x}$ & 69 & 0,88 & 0,77 & $\mathrm{a}=-0,20-0,09$ \\
\hline & & & & & $\mathrm{b}=1,12-1,45$ \\
\hline DAP & $\log \mathrm{y}=-1,05+1,57 \log \mathrm{x}$ & 67 & 0,84 & 0,70 & $\mathrm{a}=-1,30--0,84$ \\
\hline & & & & & $\mathrm{b}=1,34-1,86$ \\
\hline DLMH & $\log \mathrm{y}=-0,91+1,44 \log \mathrm{x}$ & 69 & 0,70 & 0,49 & $\mathrm{a}=-1,30--0,64$ \\
\hline & & & & & $\mathrm{b}=1,13-1,87$ \\
\hline LTH & $\log \mathrm{y}=0,35+1,15 \log \mathrm{x}$ & 69 & 0,91 & 0,83 & $\mathrm{a}=0,23-0,46$ \\
\hline & & & & & $\mathrm{b}=1,03-1,28$ \\
\hline HTRO & $\log \mathrm{y}=-0,75+1,36 \log \mathrm{x}$ & 55 & 0,82 & 0,67 & $\mathrm{a}=-1,02--0,54$ \\
\hline & & & & & $\mathrm{b}=1,12-1,66$ \\
\hline
\end{tabular}

Tabla 11. Ecuaciones alométricas (regresión Modelo II, método de ejes principales) para índices morfo-funcionales del húmero de Ctenomys vs. DP4M2.

\begin{tabular}{llllll}
\hline $\left.\begin{array}{l}\text { Variable } \\
\text { regresionada }\end{array}\right)$ & $\begin{array}{l}\text { Ecuación }(\log y=\mathrm{a}+\mathrm{b} \log \\
\text { ) }\end{array}$ & & $r$ & $r^{2}$ & $\begin{array}{l}\text { Intervalos de } \\
\text { confianza }\end{array}$ \\
\hline RHU & $\mathrm{y}=-1,76+0,82 \log \mathrm{x}$ & 68 & 0,35 & 0,12 & $\mathrm{a}=-2,46--1,36$ \\
\hline & $\mathrm{p}=0,002$ & & & & $\mathrm{~b}=0,38-1,61$ \\
\hline DRE & $\mathrm{y}=-0,71+0,24 \log \mathrm{x}$ & 66 & 0,25 & 0,06 & $\mathrm{a}=-0,93--0,51$ \\
\hline & $\mathrm{p}=0,023$ & & & & $\mathrm{~b}=0,02-0,48$ \\
\hline PRD & $\mathrm{y}=-0,33+0,04 \log \mathrm{x}$ & 68 & 0,08 & 0,01 & $\mathrm{a}=-0,44--0,21$ \\
\hline & $\mathrm{p}=0,26$ & & & & $\mathrm{~b}=-0,08-0,17$ \\
\hline PTR & $\mathrm{y}=-1,08+0,17 \log \mathrm{x}$ & 68 & 0,09 & 0,01 & $\mathrm{a}=-1,59--0,64$ \\
\hline
\end{tabular}




\begin{tabular}{llllll}
\hline & $\mathrm{p}=0,24$ & & & $\mathrm{~b}=-0,32-0,75$ \\
\hline DRT & $\mathrm{y}=0,18-1,51 \log \mathrm{x}$ & 67 & $-0,81$ & 0,66 & $\mathrm{a}=-0,03-0,44$ \\
\hline & $\mathrm{p}=0,001$ & & & & $\mathrm{~b}=-1,82--1,28$ \\
\hline $\mathrm{SDH}$ & $\mathrm{y}=-0,74+0,009 \log \mathrm{x}$ & 61 & 0,1 & 0,01 & $\mathrm{a}=-0,95-0,53$ \\
\hline & $\mathrm{p}=0,209$ & & & & $\mathrm{~b}=-0,14-0,33$ \\
\hline
\end{tabular}

\section{V.1.2.4. Análisis funcional de la morfología humeral}

El húmero es un elemento rico en información funcional (Laville, 1990), que no solamente participa en el sostén del cuerpo en posición normal y durante la marcha, sino que es una herramienta activa en la braquioexcavación, y soporta las fuerzas de reacción del sustrato durante la dentoexcavación (Nevo, 1979; Hildebrand, 1985). Las principales modificaciones músculo-esqueletarias del húmero en los mamíferos fosoriales proveen mayor fuerza para flexionar los dígitos, flexionar la muñeca, extender el codo, flexionar el húmero sobre la escápula y estabilizar el hombro (Hildebrand, 1985).

Los resultados muestran que, en el contexto de los caviomorfos, la especialización morfológica del húmero de Ctenomys es heterogénea. Mientras que algunas especies (C. lewisi, C. frater, C. conoveri, C. steinbachi, C. "mármol") muestran una combinación de rasgos especializados para el desarrollo de fuerzas favorables en la braquioexcavación, el húmero de otras especies ( $C$. flamarioni, C. fulvus, C. opimus, †C. chapalmalensis) es generalizado, no muy diferente del de octodontinos fosoriales. Además, más allá de la marcada especialización de las especies mencionadas anteriormente, las características de la disparidad morfológica, observables al menos desde el Pleistoceno, muestran que estos rasgos no están correlacionados. En este contexto de variabilidad interespecífica amplia y desacoplada, los siguientes rasgos están presentes en las especies de Ctenomys con mayor especialización en su morfología humeral: a. gran robustez; b. epicóndilos de gran desarrollo; c. cresta deltoidea prominente y en posición distalizada; d. carilla articular distal amplia y profunda. 
Desde una perspectiva funcional, la mayor robustez es ventajosa porque aumenta la resistencia del hueso ante las cargas impuestas por la acción muscular y por el sustrato (Casinos et al., 1993; Fernández et al,. 2000; Stein, 2000), al igual que la mayor rigidez del hueso cortical del húmero de Ctenomys (Biknevicius, 1993). Es importante destacar la considerable variabilidad de este rasgo; el húmero de especies como †C. chapalmalensis y $C$. flamarioni no es significativamente más robusto que el de otros octodontoideos (Figs. 25 y 28), mientras que la robustez humeral de C. lewisi es mayor que la de cualquier caviomorfo analizado.

Los epicóndilos constituyen la superficie de origen de los músculos flexores y extensores de la mano, los cuales están muy desarrollados en Ctenomys (Hildebrand 1985, Vassallo, 1998). El desarrollo y expansión del epicóndilo medial altera la línea de acción de los m. epitrochleus-anconeus y m. pronator teres, además de proporcionar mayor superficie de origen a los demás flexores originados a este nivel (Fig. 38; Hildebrand, 1985). El índice de desarrollo de los epicóndilos (DRE) es también variable dentro del género, pero siempre igual o mayor que en los demás caviomorfos analizados (ver Análisis estadístico descriptivo y Apéndice IV ).

La posición más distal de la cresta deltoidea (PRD) proporciona mayor ventaja mecánica a la musculatura deltoidea (Fig. 38), debido al aumento del brazo de palanca interno (Li) de la misma (Hildebrand, 1985; Stein, 2000; Fernández et al., 2000). En Ctenomys los valores máximos de distalización (PRD), representados por C. steinbachi, C. lewisi, †Ctenomys sp. 1, C. conoveri y C. frater, son incluso mayores a los de †Eucelophorus, un género altamente especializado para la excavación. En ambos casos, la cresta se ubica cerca de la mitad de la diáfisis (PRD<0,56); es posible que el desarrollo de los m. brachialis y biceps brachii, ubicados a ambos lados de la cresta deltoidea (Fig. 38) influya sobre la forma del plano de la cresta, que se curva lateralmente sobre el vientre del m. brachialis. 


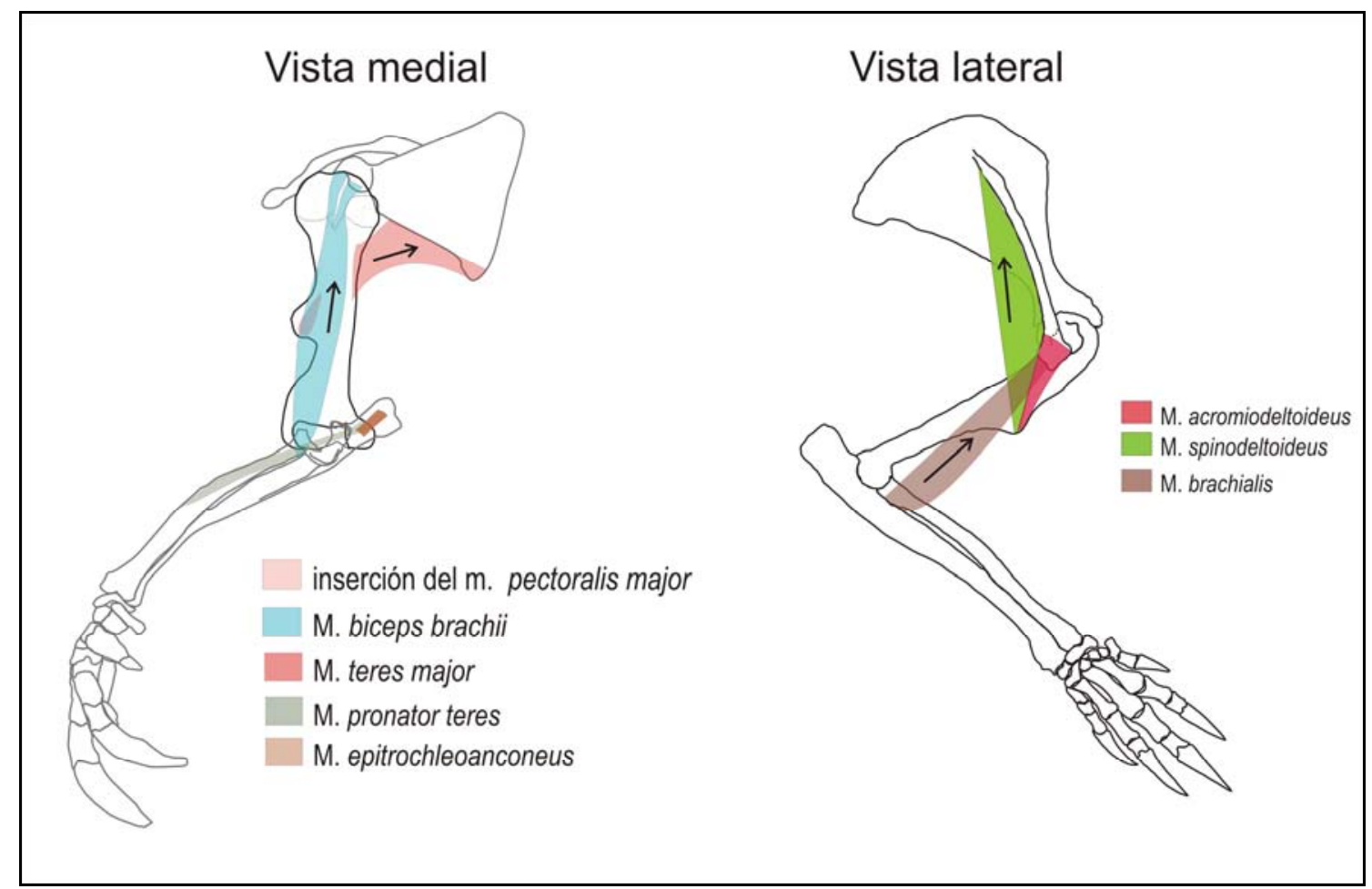

Fig. 38. Representación esquemática de los principales músculos asociados con el húmero en Ctenomys.

La fosa articular profunda de la articulación húmero-ulnar de Ctenomys previene la dislocación durante el golpe de la mano; las carillas articulares amplias estabilizan la articulación sin restringir el rango de movimientos (Argot, 2001), y dispersan la carga mecánica sobre una superficie mayor (Szalay y Sargis, 2001). También a este respecto, C. lewisi y C. conoveri representan el extremo de máxima especialización, mientras que $† C$. chapalmalensis y C. leucodon mostraron los valores mínimos de largo de la tróclea (PRT) y ancho de la superficie articular distal (SDH).

Otro rasgo característico de Ctenomys es el gran tamaño relativo de las tuberosidades humerales, las cuales restringen el movimiento de la articulación gleno-humeral al plano parasagital, probablemente en relación con el requerimiento de estabilización del hombro (Szalay y Sargis, 2001). En Ctenomys, ambas tuberosidades presentan áreas de inserción muscular grandes que reflejan el importante desarrollo de todos los músculos que participan en la estabilización del hombro. La alometría negativa detectada 
dentro del género podría estar vinculada a la existencia de una restricción mecánica (ver VI. Discusión).

De modo general, estos resultados muestran que el grado de expresión de las especializaciones humerales es variable en Ctenomys. Teniendo en cuenta que el género ha sido considerado primariamente como un braquioexcavador completamente subterráneo, se esperaría que dichas especializaciones, vinculadas primariamente a estos hábitos (Hill, 1937; Lehmann, 1963; Biknevicius, 1993; Stalheim-Smith, 1984; Hildebrand, 1985; Laville et al., 1989; Lessa y Stein, 1992; Vassallo, 1998; Stein, 2000; Elissamburu y Vizcaíno, 2004) fuesen homogéneas. Sin embargo, el análisis comparativo muestra que, al menos en algunas especies, el mayor desarrollo de los epicóndilos representa la única especialización braquioexcavadora en comparación con otros ctenominos y octodontinos fosoriales (†Actenomys, Octodon), mientras que el resto de las especializaciones se manifiestan de modo desacoplado. La morfología humeral de Ctenomys no presenta un grado de especialización equivalente a la de otros roedores subterráneos (Hildebrand, 1985, Fig. 6-4, Tabla 6-2), tales como Spalax (cf. Fig. 25 y Özkan, 2002, Figs. 1 y 2), Myospalax (Hildebrand, 1985, Fig. 6-4), Geomys (Hildebrand, 1985, Fig. 6-4; Rose y Chinnery, 2004, Fig. 2) o Arvicola (Muroidea, Cricetidae; Lessertisseur y Saban, 1967, Fig. 529). Estos últimos presentan mayor robustez, epicóndilos más ensanchados y cresta deltoidea de gran tamaño, fuerte y más distalizada.

\section{V.1.3. Antebrazo}

\section{V.1.3.1. Análisis cualitativo}

\section{V.1.3.1.1. Radio}

\section{V.1.3.1.1.a. Morfología radial en Ctenomys (Fig. 39)}

El radio es un hueso fuerte y curvado, relativamente más grácil en $C$. azarae, C. "mármol", C. leucodon y †Ctenomys sp. 1, y variablemente robusto en las demás especies examinadas; dentro de esta variación continua, C. lewisi 
posee un radio notablemente más robusto que el de las demás especies examinadas.

La fóvea radial tiene contorno ovoidal, con algunas diferencias interespecíficas. La forma general varía desde menos alongada en C. talarum, C. "vista" y †Ctenomys sp. 1, hasta especialmente alongada en C. frater, C. maulinus y C. fulvus. Este contorno es uniformemente ovoidal en C. leucodon y C. lewisi, mientras que en otras especies es algo asimétrico a ligeramente piriforme, con la mitad medial de mayor tamaño que la lateral (C. australis, $C$. flamarioni, C. rionegrensis). En las especies con contorno piriforme, el margen dorsal de la fóvea puede presentar una zona cóncava entre las mitades lateral y medial (C. australis, C. "somuncurá", C. flamarioni, C. rionegrensis). Esta concavidad está apenas insinuada en C. azarae, y no aparece en especies con fóvea de contorno uniforme como C. dorbignyi, C. leucodon, y C. lewisi.

El grado de curvatura dorsal y lateromedial de la diáfisis varía ampliamente. En todas las especies examinadas existe cierta convexidad dorsal (o aproximadamente ánteroposterior, si se considera la posición anatómica del radio), que varía desde poco acentuada en C. australis, C. fulvus, o C. dorbignyi, hasta más acentuada en C. talarum y C. lewisi. Esta convexidad no es uniforme, sino que presenta un punto de máxima inflexión de posición variable: en la mayoría de las especies se ubica en la mitad proximal de la diáfisis, aunque en C. "mármol" y C. azarae la inflexión se observa en el tercio proximal del radio; una posición más distal (en la mitad de la longitud total del radio) se observó en C. dorbignyi, C. lewisi, C. maulinus, C. australis y †Ctenomys sp. 1, mientras que en †C. subassentiens (Fig. 40) la mayor inflexión de la diáfisis se halla en posición aún más distal. Por su parte, la curvatura lateromedial, que otorga un contorno sigmoideo a la diáfisis radial, está poco marcada en C. leucodon, C. australis, C. lewisi, C. opimus y C. dorbignyi, en comparación con las demás especies examinadas. El radio de $† C$. chapalmalensis sólo se conoce en forma fragmentaria; en el ejemplar MMP 358- 
$\mathrm{S}$ tiene aspecto sigmoideo, convexo dorsal y lateromedialmente, mientras que MACN 19249 presenta sólo curvatura dorsal.

La tuberosidad bicípita (sitio de inserción del m. biceps brachii) se observa como un área ligeramente sobreelevada en C. talarum, C. "monte", C. rionegrensis, C. "mármol", C. fulvus y C. australis, mientras que en C. lewisi, C. dorbignyi, C. steinbachi, y C. conoveri la misma se presenta como un área rugosa pero no sobresaliente de la diáfisis radial. En todas las especies, el sitio de inserción del m. brachialis está marcado por un área rugosa muy próxima a la tuberosidad bicípita.

La epífisis distal es más gruesa que la diáfisis en todas las especies examinadas. Este extremo no se ha conservado en $\dagger C$. chapalmalensis, pero la porción subdistal del radio de MMP 358-S está menos engrosada que en las demás especies. El radio termina en dos procesos o apófisis bien desarrollados: el proceso estiloide en posición medial, y un proceso pseudoestiloide en posición lateral, que se proyecta más centralmente, adyacente al proceso estiloide de la ulna; ambos articulan con los elementos proximales del carpo (Forsyth Major, 1899; Lehmann, 1963). Estos dos procesos son de tamaño muy similar, aunque el proceso pseudoestiloide es más aguzado y de base algo más angosta. 


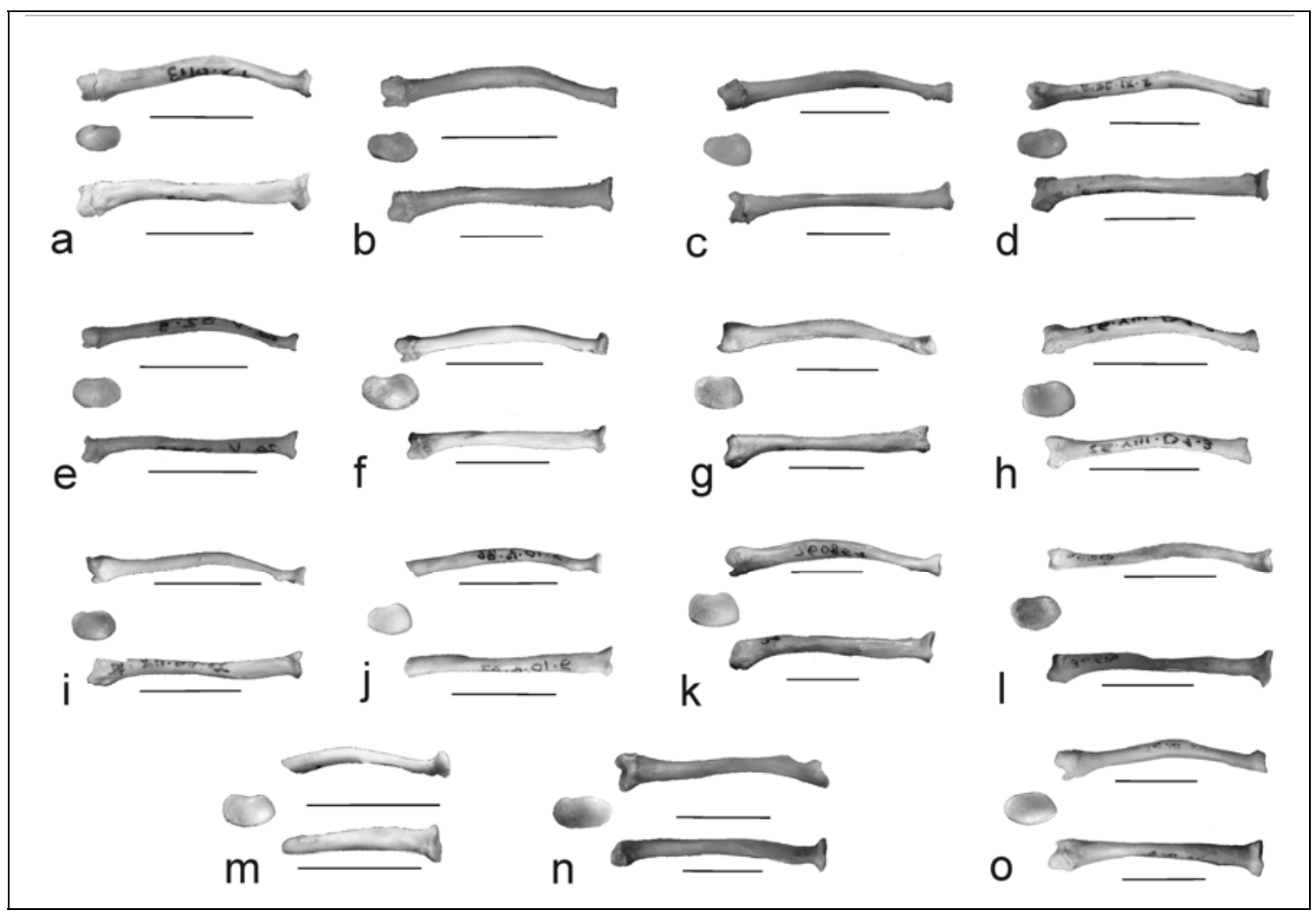

Figura 39. Radio izquierdo (derecho invertido en $\mathrm{d}, \mathrm{h}$ y $\mathrm{m}$ ) de Ctenomys en vista medial (arriba), superior (debajo), y fóvea (no a escala). a. C. maulinus, b. C. "mármol", c. C. australis, d. C. fulvus, e. C. azarae, f. C. "palmar", g. C. dorbignyi, h. C. talarum, i. C. "monte", j. C. flamarioni (incompleto), i, k. C. steinbachi, 1. C. leucodon, m. C. "somuncura" (incompleto), n. C. frater; o. C. lewisi. Escala: $1 \mathrm{~cm}$.

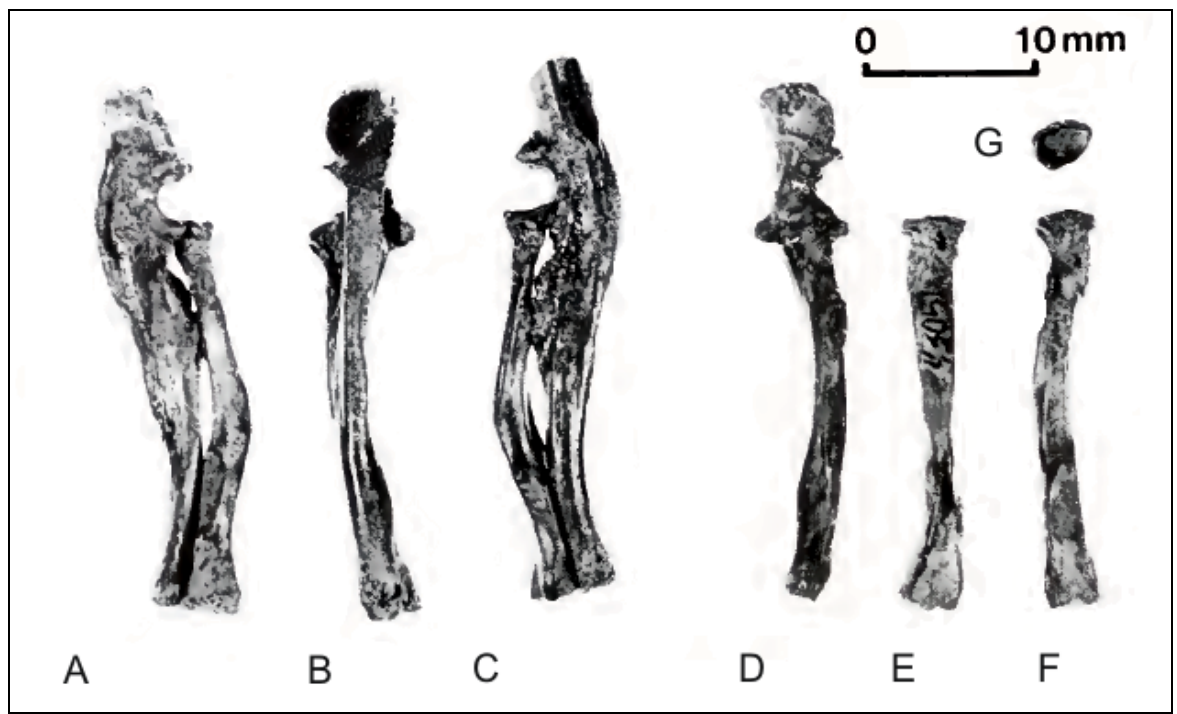

Figura 40. Ulna y radio de †C. subassentiens KUVP 43051. A-C, Radio y ulna articulados; A. Vista medial; B. Vista posterior; C. Vista lateral; D. Ulna izquierda, vista dorsal; E-G, Radio izquierdo; E. Vista anterior; F. Vista posterior; G. Fóvea radial. Tomado de Frailey et al. (1980). 


\section{V.1.3.1.1.b. Comparación con otros géneros de ctenominos}

El radio de †Actenomys (Fig. 41) es más grácil que el de Ctenomys y presenta una leve curvatura dorsal, pero no lateral. El contorno de la fóvea es más cuadrangular que en Ctenomys, especialmente en el sector medial del margen articular. Posee proceso estiloide y pseudoestiloide de menor tamaño que los de Ctenomys.

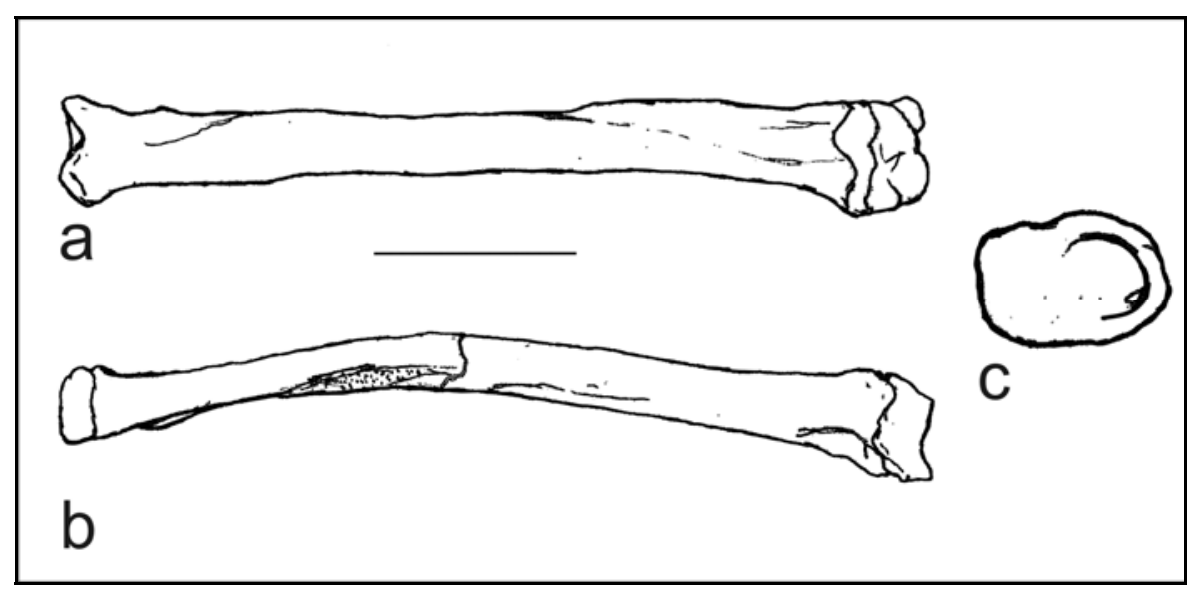

Figura 41. Radio derecho de $\dagger$ Actenomys priscus MLP 803-M en vista dorsal (a), medial (b) y detalle de la fóvea (c, no a escala). Escala: $1 \mathrm{~cm}$.

\section{V.1.3.1.1.c. Comparación con otros caviomorfos (Fig. 42)}

En los restantes octodontoideos analizados, a excepción de Euryzygomatomys, el radio es en general menos robusto (especialmente en sentido dorsoventral). La curvatura del radio es también menos acentuada, y se observa principalmente en el plano dorsoventral, mientras que la curvatura láteromedial es muy leve o inexistente (a excepción de Aconaemys), de manera que la diáfisis radial es recta en vista dorsal. La forma de la fóvea varía desde reniforme, con perfil ovoidal y concavidad dorsal (Euryzygomatomys; concavidad poco marcada en Spalacopus y Thrichomys), ovoidal (Octodon), a casi cuadrangular (Proechimys, Aconaemys), pero nunca asimétrica (piriforme) como en Ctenomys. Existe un proceso estiloide de menor desarrollo, y en ningún caso existe un proceso pseudoestiloide diferenciado. 
El radio de Cavia aperea es más alongado y grácil que el de Ctenomys, con cierta curvatura dorsal pero prácticamente carente de curvatura lateromedial. La fóvea es cuadrangular, y su superficie articular no es uniformemente cóncava, sino que presenta una articulación de tipo troclear para el húmero. La epífisis distal termina en un proceso estiloide pero no presenta proceso pseudoestiloide como en Ctenomys.

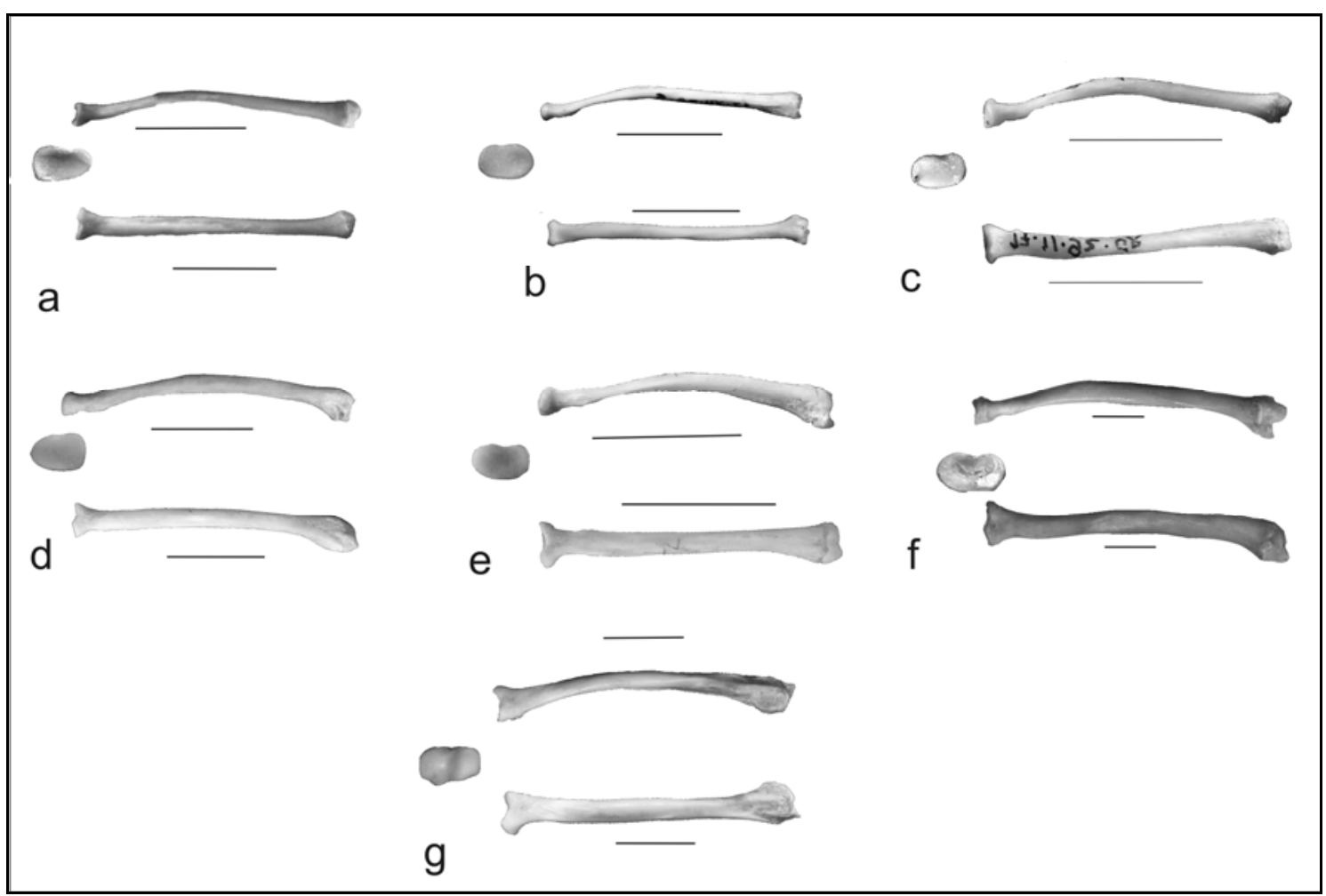

Figura 42. Radio derecho de octodontoideos (a-f) y Cavia (g) en vista lateral (arriba), dorsal (abajo) y detalle de la fóvea radial (no a escala). a. Octodontomys gliroides, b. Octodon "bridgesi", c. Aconaemys sagei, d. Thrichomys apereoides, e. Euryzygomatomys spinosus; f. Myocastor coypus; g. Cavia aperea. Escala: $1 \mathrm{~cm}$.

\section{V.1.3.1.2. Ulna}

\section{V.1.3.1.2.a. Morfología ulnar en Ctenomys (Fig. 43)}

La ulna de Ctenomys es un hueso robusto, lateralmente comprimido y uniformemente curvado. La robustez de la misma presenta variación interespecífica; es más robusta en C. "vista", C. lewisi, C. steinbachi y C. conoveri, y más grácil en C. opimus, C. azarae y C. "palmar". 
El olécranon está bien desarrollado y presenta amplias superficies para inserción muscular. En todas las especies está curvado medialmente, continuando con el arco de curvatura de la diáfisis ulnar; esta inflexión es menor en C. fulvus, C. australis y C. "mármol" con respecto a las demás especies analizadas. El olécranon presenta máxima longitud y robustez en $C$. conoveri y C. steinbachi, mientras que C. opimus y C. fulvus presentan el menor desarrollo olecraneano. El olécranon de $† C$. chapalmalensis y $†$. subassentiens sólo se conoce en forma parcial (Figs. 44 y 40, respectivamente); en ambas especies es relativamente más corto que en Ctenomys vivientes, siendo más robusto en $\uparrow C$. subassentiens que en $\uparrow C$. chapalmalensis.

La muesca sigmoidea (=semilunar o troclear) es profunda en todas las especies vivientes y $† C$. subassentiens, mientras que parece ser relativamente menos profunda en $\uparrow C$. chapalmalensis; está limitada posteriormente por el proceso ancóneo del olécranon y anteriormente por la apófisis coronoides, la cual se prolonga medialmente en un labio que articula con la porción troclear del húmero. La forma y amplitud de la muesca sigmoidea no presenta variaciones interespecíficas destacables, con excepción de un reborde olecraneano relativamente más bajo en C. leucodon. La muesca radial es uniformemente cóncava.

La diáfisis está poco curvada en C. fulvus, C. lewisi, C. leucodon, C. australis y $† C$. chapalmalensis, mientras que presenta curvatura lateromedial moderada en C. opimus, C. flamarioni, C. talarum, C conoveri y C. "palmar", y más acentuada en C. frater, C. maulinus, C steinbachi, C. "mármol", C. azarae y †C. subassentiens. Lateralmente sobre la misma, se observa la fosa alongada correspondiente a la inserción de músculos extensores del autopodio (m. abductor pollicis longus, m. extensor indicis, y m. extensor carpi ulnaris); este surco está menos definido en C. australis, C. lewisi, C. flamarioni y C. azarae, mientras que en las restantes especies está bien definido, pero su extensión a lo largo de la diáfisis varía: alcanza la mitad de la diáfisis en C. fulvus, C. talarum, C. maulinus, C. leucodon y $† C$. chapalmalensis, mientras que se prolonga más 
distalmente en C. "palmar", C. conoveri, C. steinbachi, C. frater y C. "mármol". Sobre la cara medial de la diáfisis, la fosa medial está menos definida que la lateral y se extiende en la mitad proximal de la diáfisis.

La ulna se adelgaza en dirección distal y finalmente se ensancha ligeramente formando la base del proceso estiloide, cónico y de extremo bulboso.

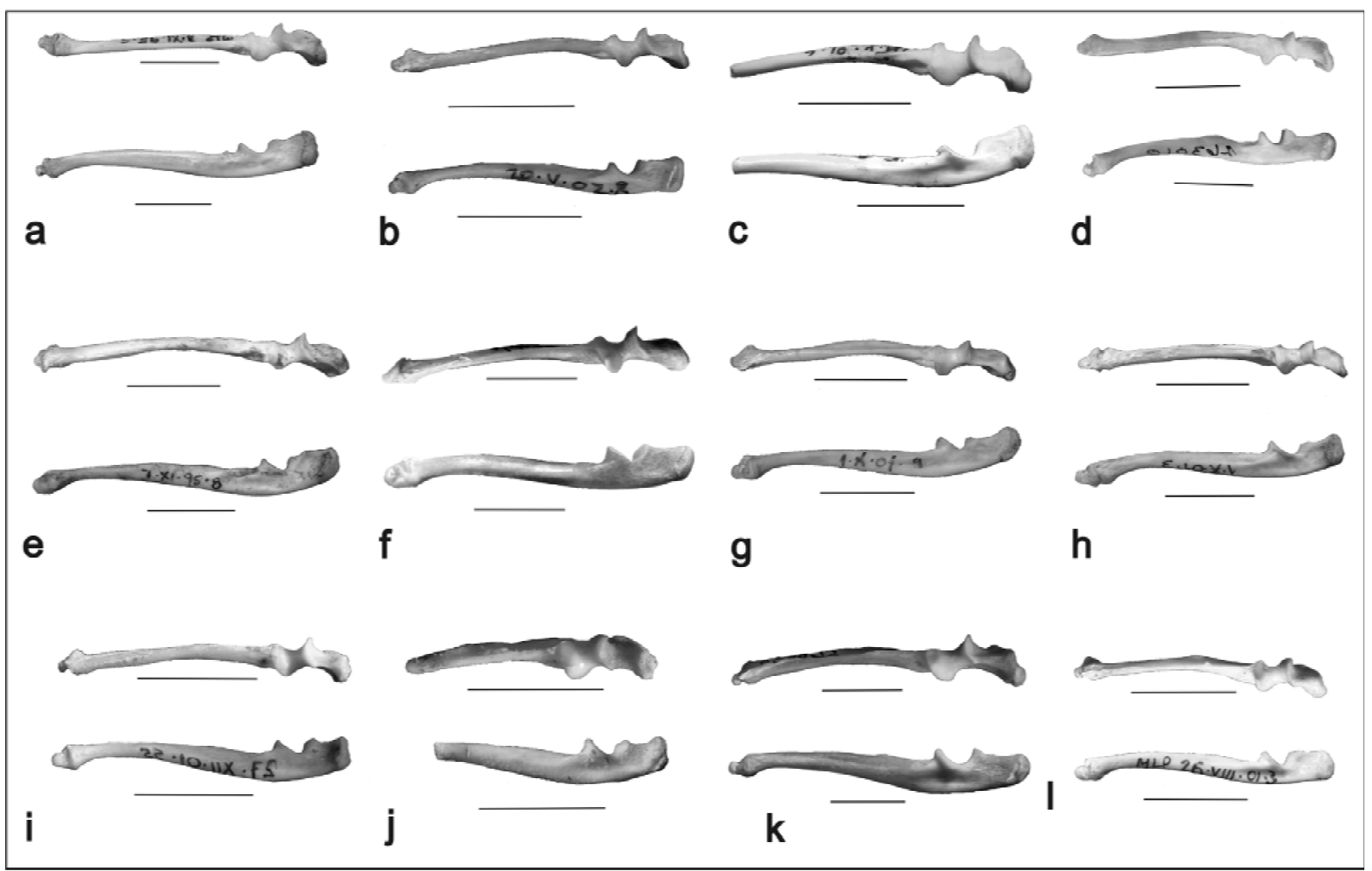

Figura 43. Ulna derecha en vista dorsal (arriba) y medial (debajo) (izquierda invertida en d, f, i, k y l) de especies de Ctenomys: a. C. australis; b. C. azarae; c. C. flamarioni (incompleto); d. C. frater; e. C. fulvus; f. C. lewisi; g. C. "mármol"; h. C. maulinus; i. C. "monte"; j. C. "somuncurá" (incompleto); k. C. steinbachi; 1. C. talarum. Escala: $1 \mathrm{~cm}$. 


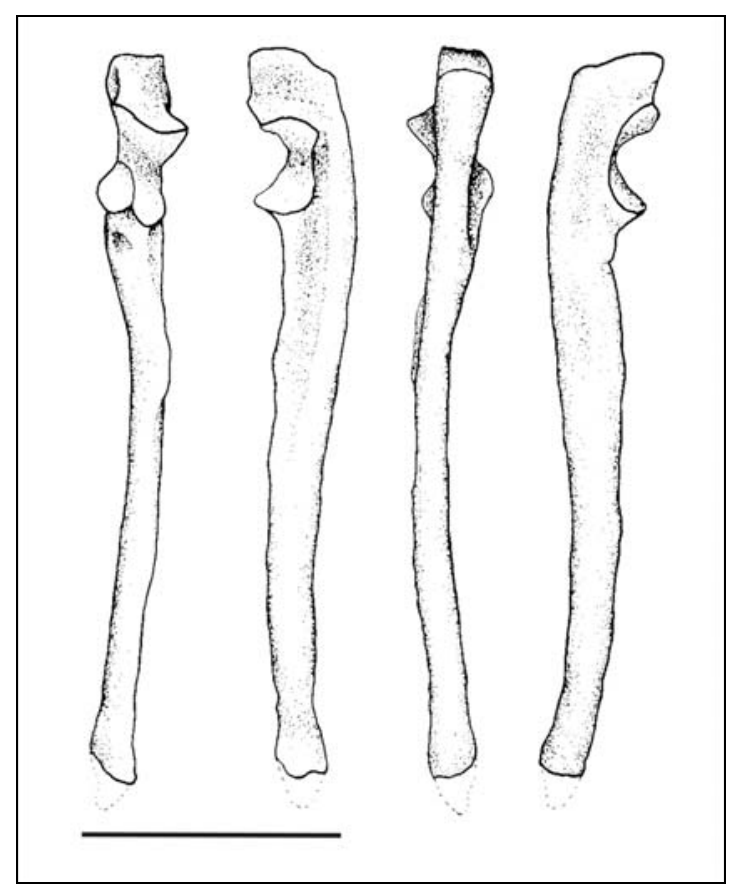

Figura 44. Ulna izquierda de †Ctenomys chapalmalensis MMP 358-S. A, Vista anterior; B, Vista lateral; C, Vista posterior; D, Vista medial. Escala: $1 \mathrm{~cm}$. Dibujo inédito de C. Quintana.

\section{V.1.3.1.2.b. Comparación con otros géneros de ctenominos}

La ulna de †Actenomys (Fig. 45) es más grácil que la de Ctenomys y sólo presenta una leve curvatura lateral (Fernández et al., 2000). La fosa sigmoidea es menos profunda que en Ctenomys. El olécranon es más corto que en Ctenomys y no presenta una inflexión marcada (Fernández et al., 2000).

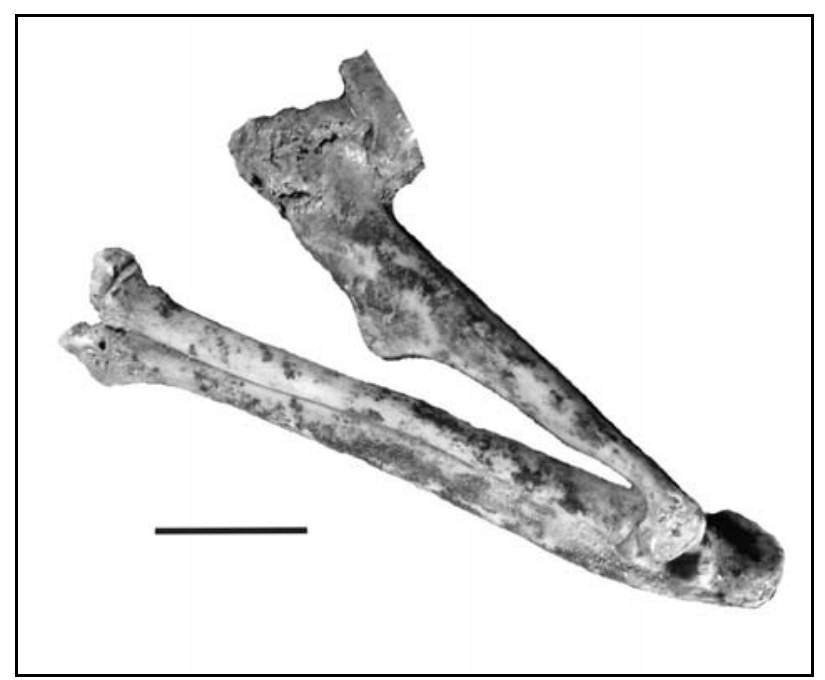

Figura 45. Brazo izquierdo de †Actenomys priscus MMP 703-S en vista lateral. Escala: $1 \mathrm{~cm}$. 
La ulna de †Praectenomys rhombidens sólo se conoce en forma fragmentaria sobre la base de la epífisis proximal del ejemplar GB 012 (Quintana, 1994). De acuerdo con la descripción publicada, este fragmento presenta cavidad sigmoidea dispuesta en posición anterior, y la faceta de articulación con el radio es poco amplia y poco definida; no es posible comparar otros rasgos con los presentes en Ctenomys.

\section{V.1.3.1.2.c. Comparación con otros caviomorfos (Fig. 46)}

La ulna de los octodontoideos analizados es algo más grácil, con excepción de Spalacopus, cuya ulna es tan robusta como la de Ctenomys. El proceso olecraneano es relativamente más corto que en Ctenomys y la fosa sigmoidea es relativamente más pequeña. La curvatura lateral de la ulna también es menor que la de Ctenomys.

Por su parte, la morfología ulnar de Cavia es marcadamente diferente de la de Ctenomys. La ulna es moderadamente robusta, su diáfisis es recta y su diámetro dorsoventral aumenta abruptamente a nivel de la mitad de su longitud (Fig. 46g). El olécranon es más corto que en Ctenomys. La muesca troclear es menos profunda y su borde anterior (apófisis coronoides) es muy bajo, de manera que la superficie articular es más abierta, muy diferente de la profunda muesca troclear de Ctenomys. La epífisis distal es roma y casi tan gruesa como la porción adyacente de la diáfisis, a diferencia de la morfología alongada y bulbosa de la apófisis estiloides de Ctenomys. 


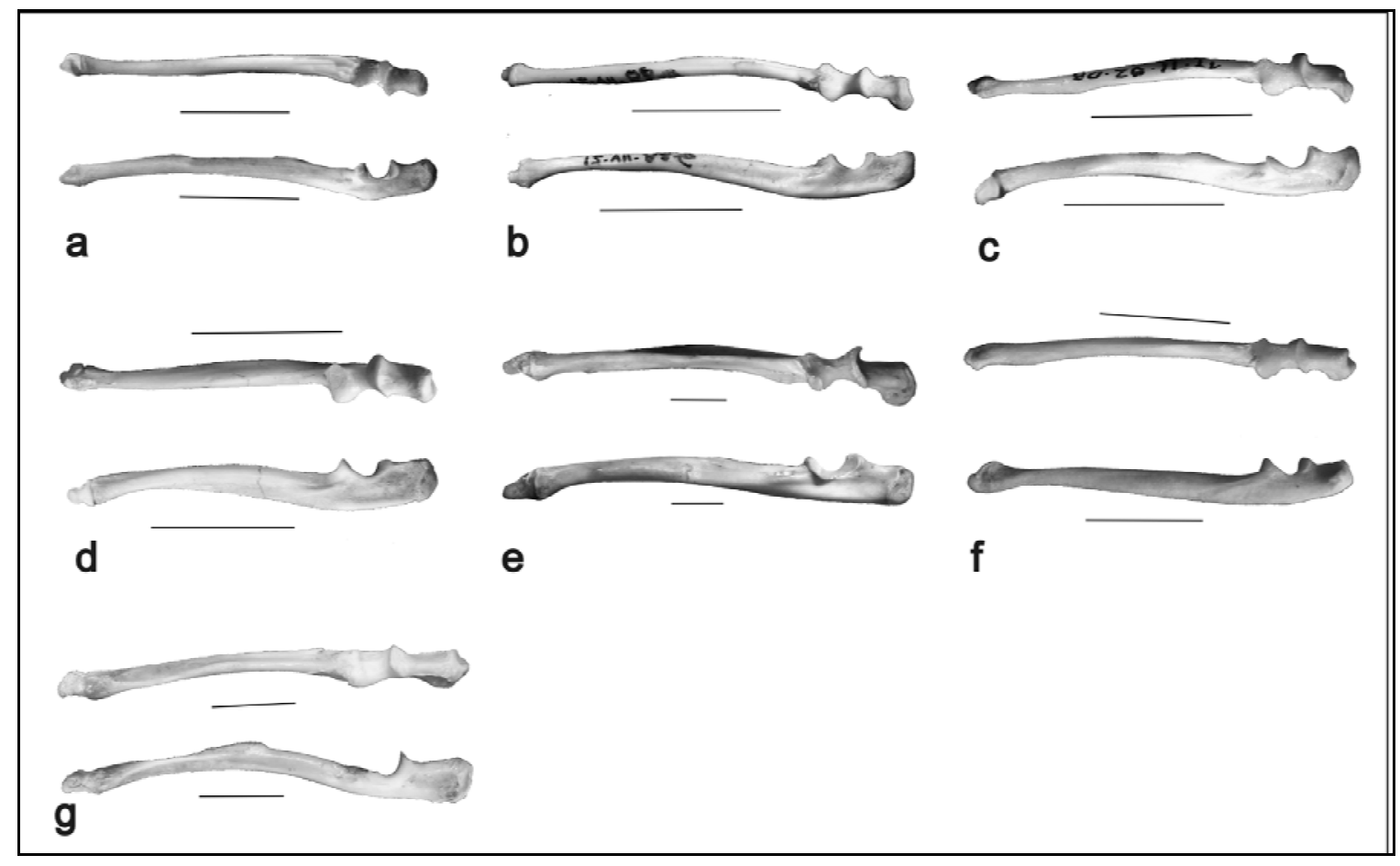

Figura 46. Ulna derecha (izquierda invertida en $\mathrm{a}, \mathrm{b}$ y g) en vista dorsal (arriba) y medial (abajo) de octodontoideos (a-f) y Cavia. a. Octodontomys gliroides; b. Octodon "bridgesi"; c. Aconaemys porteri; d. Euryzygomatomys spinosus; e. Myocastor coypus; f. Thrichomys apereoides; g. Cavia aperea. Escala: 1 $\mathrm{cm}$.

\section{V.1.3.2. Análisis cuantitativo general}

Un ACP de índices morfo-funcionales del antebrazo (ver IV.3.2.b. Índices morfo-funcionales) que incluyó a Ctenomys, otros miembros de la superfamilia Octodontoidea y Cavia aperea mostró cierta separación de Ctenomys con respecto a los otros caviomorfos analizados, aunque con áreas de superposición en el morfoespacio (Fig. 47, Tabla 12). Los dos primeros CP resumieron el 85,64\% de la variación. C. lewisi, ocupó el extremo negativo a lo largo del $\mathrm{CP} 1$, mientras que $C$. fulvus se dispuso en el extremo positivo junto con los restantes octodontoideos; este eje resumió principalmente la robustez del radio y de la ulna, así como el desarrollo del olécranon (59,81\% de la variación explicada). El CP 2 (25,82\% de la variación explicada) reflejó diferencias en la forma de la fóvea radial (FFOV); si bien Ctenomys se distribuyó mayoritariamente en los valores neutros y positivos de este eje, el rango de variación del género excedió al de los demás taxones analizados. 
Cavia ocupó una posición intermedia y superpuesta con el morfoespacio de Ctenomys sobre ambos ejes. Esto se debe a los elevados valores de RULN, OLR y FFOV en Cavia; sin embargo, esta similitud cuantitativa no refleja una similitud morfológica con los Octodontoidea (ver V.1.3.1.2.c. Comparación con otros caviomorfos).

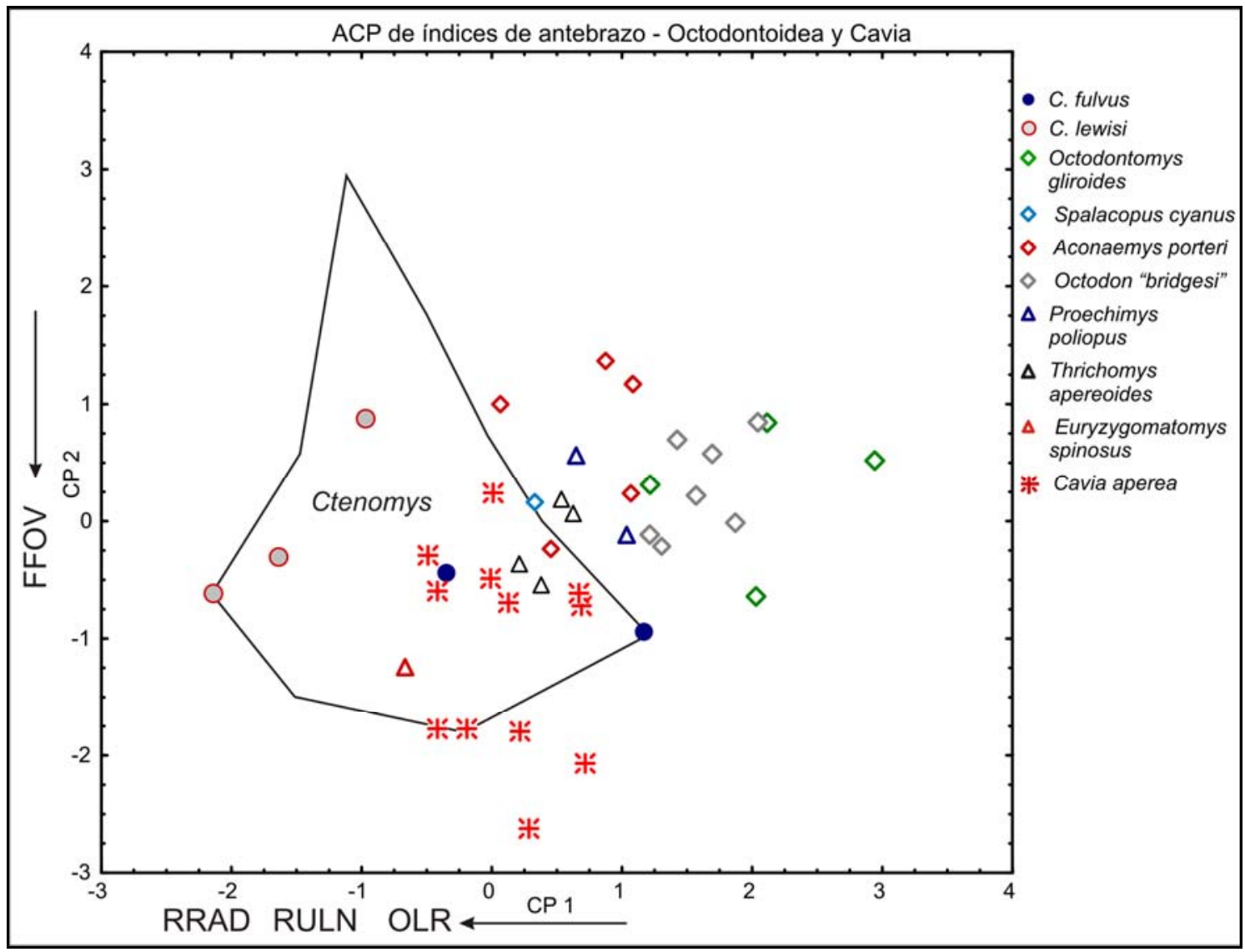

Figura 47. ACP de índices morfo-funcionales de radio y ulna para especies de Ctenomys (polígono), otros octodontoideos y Cavia.

Tabla 12. Correlaciones Factor-Variable (factor loadings) y porcentaje de variación explicada para los 2 primeros Componentes Principales del ACP de Fig. 47.

\begin{tabular}{ccc}
\hline Índice & CP 1 & CP 2 \\
\hline RULN & $\mathbf{- 0 , 8 3}$ & $-0,31$ \\
\hline OLR & $\mathbf{- 0 , 9 1}$ & $-0,08$ \\
\hline RRAD & $\mathbf{- 0 , 9 0}$ & 0,11 \\
\hline FFOV & 0,25 & $\mathbf{- 0 , 9 5}$ \\
\hline autovalor & 2,42 & 1,03 \\
\hline $\begin{array}{c}\text { \% variación } \\
\text { explicada }\end{array}$ & 60,45 & 25,64 \\
\hline
\end{tabular}


\begin{tabular}{lll} 
\% acumulativo $\quad 60,45 \quad 86,09$ \\
\hline
\end{tabular}

\section{V.1.3.3. Análisis cuantitativo de la variabilidad morfológica en Ctenomys Análisis multivariado}

El ACP realizado con especies de Ctenomys (Fig. 48, Tabla 13) mostró un patrón de carga de las variables similar al del ACP realizado con otros caviomorfos (ver V.1.3.2. Análisis cuantitativo general). La robustez de ambos huesos (RRAD y RULN), así como el tamaño relativo del olécranon (OLR), cargaron principalmente sobre el CP 1, el cual explicó un 48,93\% de la variación observada. Las especies de Ctenomys se distribuyeron a lo largo de todo este eje, en un rango continuo sin un patrón definido. El CP 2 reflejó diferencias en la forma de la fóvea, con las especies de fóvea más alongada (FFOV más alto) ubicadas en el extremo negativo de este segundo eje.

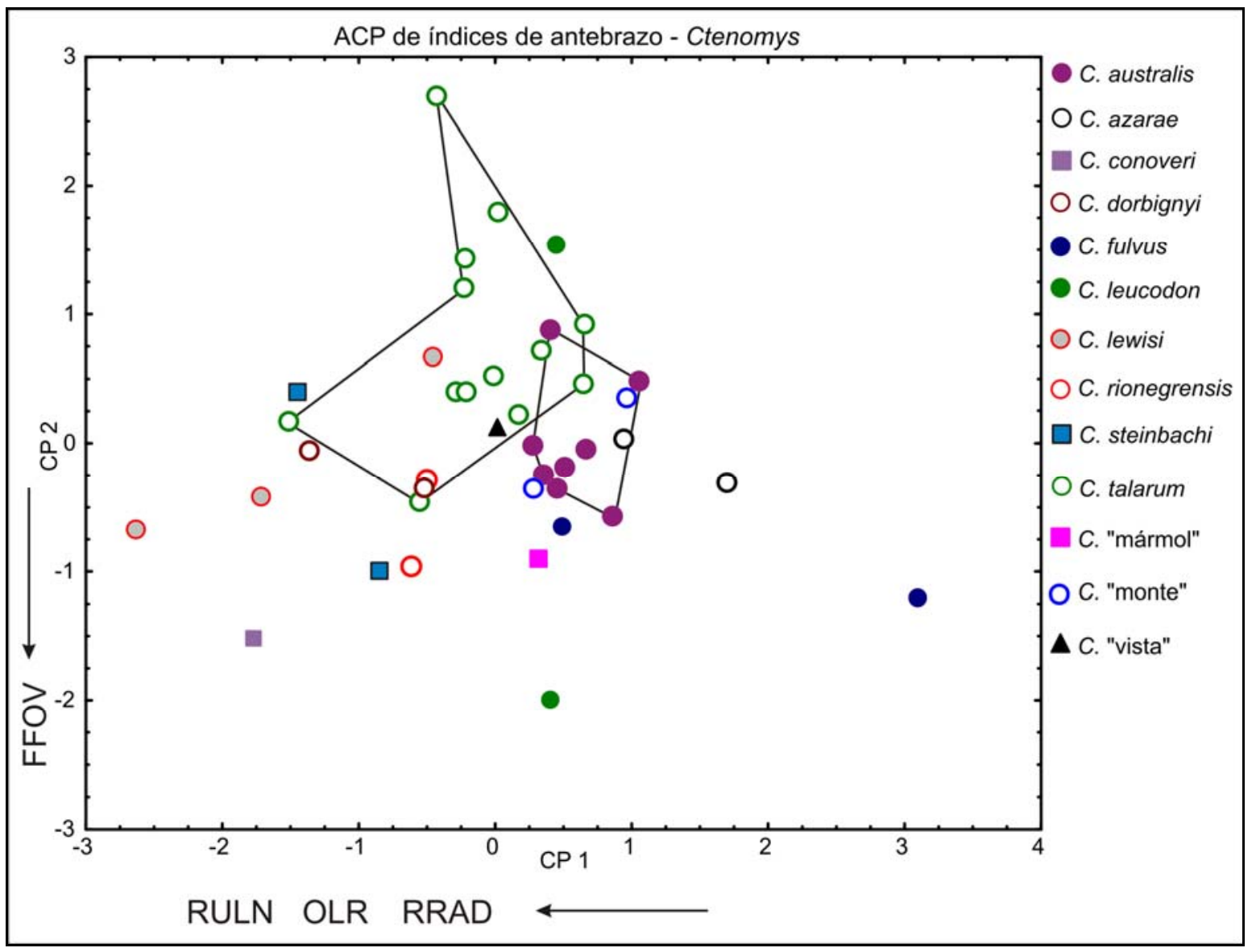

Figura 48. ACP de índices morfo-funcionales de antebrazo para especies de Ctenomys. 
Tabla 13. Correlaciones Factor-Variable (factor loadings) y porcentaje de variación explicada para los 2 primeros Componentes Principales del ACP de Fig. 48.

\begin{tabular}{cll}
\hline Índice & CP 1 & $\mathbf{C P} \mathbf{2}$ \\
\hline RULN & $\mathbf{- 0 , 8 2}$ & $-0,25$ \\
\hline OLR & $\mathbf{- 0 , 8 1}$ & $-0,00$ \\
\hline RRAD & $\mathbf{- 0 , 7 3}$ & 0,14 \\
\hline FFOV & 0,11 & $\mathbf{- 0 , 9 7}$ \\
\hline Autovalor & 1,89 & 1,03 \\
\hline $\begin{array}{c}\text { \% variación } \\
\text { explicada }\end{array}$ & 47,35 & 25,80 \\
\hline \% acumulativo & 47,35 & 73,15 \\
\hline
\end{tabular}

\section{Análisis estadístico descriptivo}

Los resultados del análisis estadístico descriptivo de las especies de Ctenomys para los índices estudiados se presentan en las Figuras 49 a 52. Los valores para cada índice variaron de manera continua entre las especies analizadas, si bien la robustez del radio resultó muy similar para la mayoría de ellas (Fig. 49). En conjunto, C. lewisi, C. conoveri, y en menor medida C. steinbachi, C. dorbignyi y C. rionegrensis, presentaron valores máximos o cercanos al máximo en cada rasgo, mientras que C. azarae, C. opimus y C. fulvus presentaron los valores más bajos, y las demás especies exhibieron variado grado de especialización en diferentes rasgos. Lamentablemente, la falta de material óseo para varias de las especies analizadas restringió el tamaño muestral de estos análisis. 


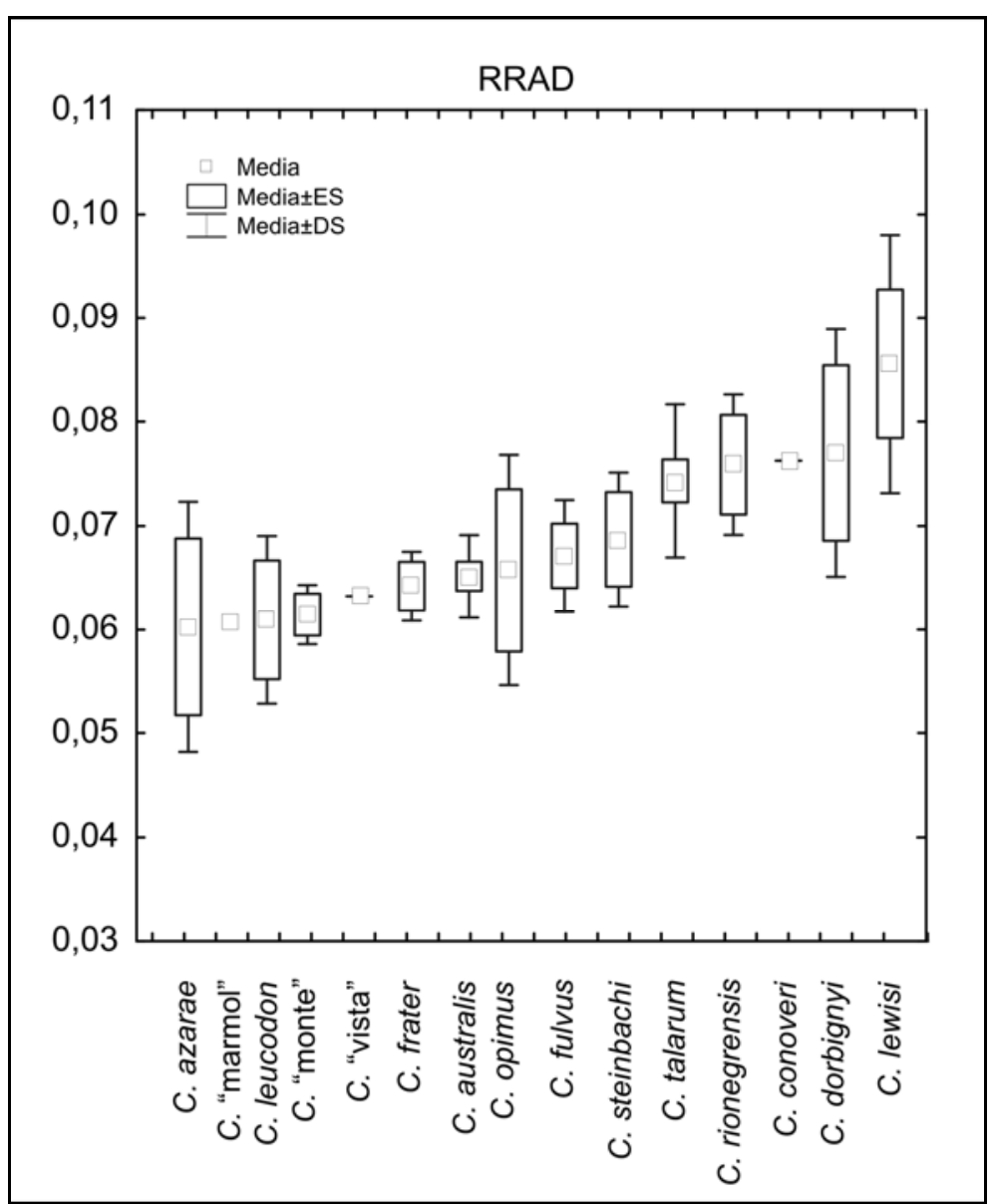

Figura 49. Índice de robustez del radio (RRAD) por especie.

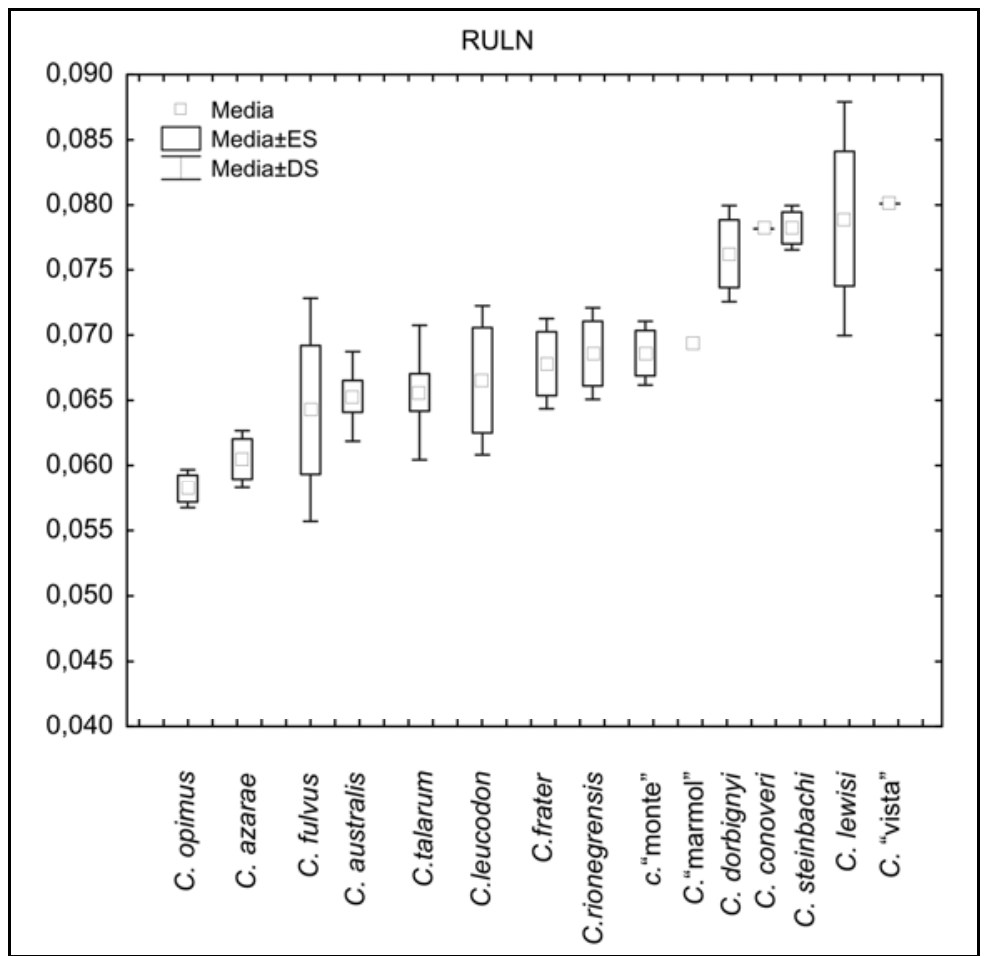

Figura 50. Índice de robustez de la ulna (RULN) por especie. 


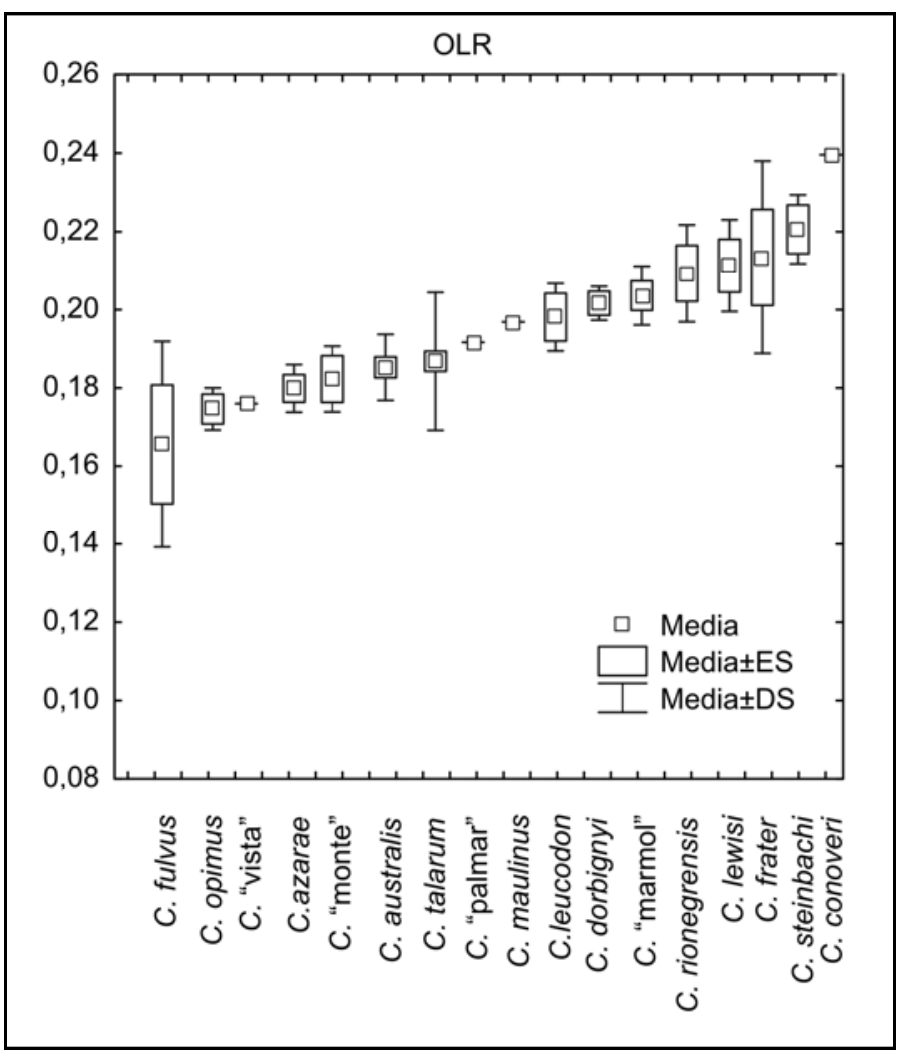

Figura 51. Desarrollo del olécranon (OLR) por especie

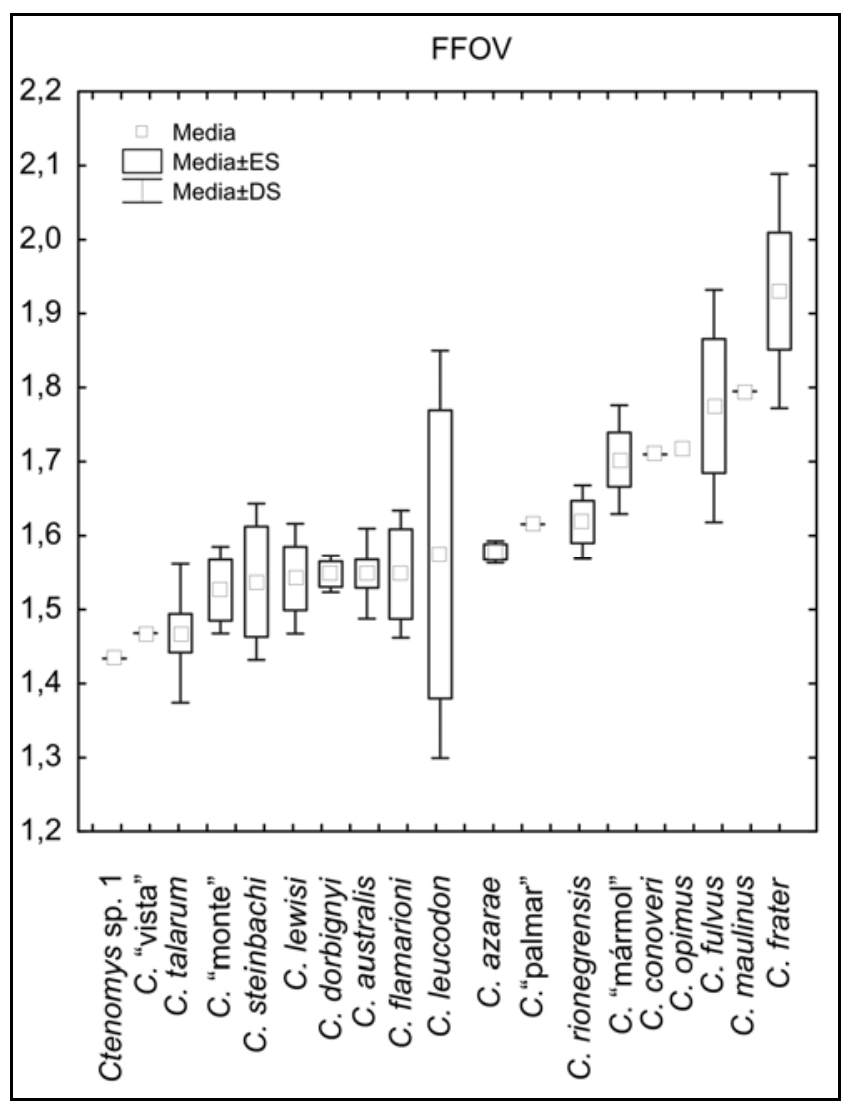

Figura 52. Elongación relativa de la fóvea radial (FFOV) por especie. 


\section{$\underline{\text { Alometrías en el antebrazo de Ctenomys }}$}

El análisis de alometrías en las medidas de radio y ulna mostró buen ajuste $(0,70<r<0,81)$ y alometría positiva (Tabla 14). Al igual que en el caso del húmero, la más alta tasa de crecimiento corresponde al diámetro dorsoventral (DMR). El análisis mostró buen ajuste también para las medidas de longitud y de espesor dorsoventral (DMU). Los resultados evidenciaron que el proceso olecraneano (LOL) presenta una alometría positiva mayor que la del largo total de la ulna (LTU), y la medida DMU mostró una elevada alometría positiva. Por otra parte, la medida de espesor láteromedial (DLMU) mostró menor ajuste (Tabla 14).

Los índices morfo-funcionales presentaron baja correlación con el estimador de tamaño corporal (Tabla 15). El coeficiente de determinación $\left(\mathrm{r}^{2}\right)$ resultó muy bajo en todos los casos $\left(r^{2} \leq 0,03\right)$. Estos resultados indican que no hay influencia significativa del tamaño corporal sobre los índices estudiados.

Tabla 14. Ecuaciones alométricas (regresión Modelo II, método de ejes principales) para medidas del antebrazo de Ctenomys vs. DP4-M2.

\begin{tabular}{|c|c|c|c|c|c|}
\hline Variable & $\begin{array}{c}\text { Ecuación } \\
(\log y=a+b \log x)\end{array}$ & $n$ & $r$ & $r^{2}$ & $\begin{array}{c}\text { Intervalos de } \\
\text { confianza }\end{array}$ \\
\hline \multirow[t]{2}{*}{ DMR } & $\log y=-1,59+1,98 \log x$ & 56 & 0,71 & 0,51 & a: $-2,36--1,13$ \\
\hline & & & & & b: $1,47-2,84$ \\
\hline \multirow[t]{2}{*}{ DLMR } & $\log y=-1,52+1,88 \log x$ & 56 & 0,70 & 0,49 & a: $-2,11--1,14$ \\
\hline & & & & & b: $1,46-2,55$ \\
\hline \multirow[t]{2}{*}{ LTR } & $\log y=0,13+1,37 \log x$ & 56 & 0,81 & 0,66 & a: $-0,14-0,34$ \\
\hline & & & & & b: $1,13-1,67$ \\
\hline \multirow[t]{2}{*}{ DMIF } & $\log y=-0,8+1,33 \log x$ & 56 & 0,75 & 0,56 & a: $-1,21--0,62$ \\
\hline & & & & & b: $1,06-1,71$ \\
\hline \multirow[t]{2}{*}{ DMAF } & $\log y=-0,86+1,53 \log x$ & 56 & 0,78 & 0,61 & a: $-1,21--0,60$ \\
\hline & & & & & b: $1,24-1,93$ \\
\hline \multirow[t]{2}{*}{ LTU } & $\log y=0,20+1,42 \log x$ & 56 & 0,85 & 0,72 & a: $-0,04-0,40$ \\
\hline & & & & & b: $1,20-1,70$ \\
\hline
\end{tabular}




\begin{tabular}{llllll}
\hline DMU & $\log y=-1,67+2,20 \log x$ & 56 & 0,75 & 0,56 & a: $-2,40--1,22$ \\
\hline & & & & & b: $1,69-3,01$ \\
\hline DLMU & $\log y=-1,59+1,92 \log x$ & 54 & 0,64 & 0,41 & a: $-2,38--1,14$ \\
\hline & & & & & b: $1,41-2,81$ \\
\hline LOL & $\log y=-0,82+1,77 \log x$ & 56 & 0,76 & 0,56 & a $=-1,27--0,51$ \\
\hline & & & & & b $=1,41-2,27$ \\
\hline
\end{tabular}

Tabla 15. Ecuaciones alométricas (regresión Modelo II, método de ejes principales) para índices morfo-funcionales del antebrazo de Ctenomys vs. DP4-M2.

\begin{tabular}{llllll}
\hline Variable & $\begin{array}{l}\text { Ecuación } \\
(\log y=\mathrm{a}+\mathrm{b} \log x)\end{array}$ & $n$ & $r$ & $r^{2}$ & $\begin{array}{l}\text { Intervalos de } \\
\text { confianza }\end{array}$ \\
& & & & & \\
\hline RULN & $\log \mathrm{y}=-0,98+0,30 \log \mathrm{x}$ & 57 & 0,18 & 0,03 & $\mathrm{a}:-1,50-0,60$ \\
\hline OLR & $\log \mathrm{y}=-1,44+0,28 \log \mathrm{x}$ & 54 & 0,11 & 0,01 & $\mathrm{a}:-2,48--0,79$ \\
\hline & & & & & $\mathrm{b}:-0,44-1,43$ \\
\hline FFOV & $\log \mathrm{y}=-0,02+0,24 \log \mathrm{x}$ & 50 & 0,16 & 0,026 & $\mathrm{a}=-0,47-0,35$ \\
\hline & & & & & $\mathrm{b}=-0,17-0,75$ \\
\hline RRAD & $\log \mathrm{y}=-35,51+38,23 \log \mathrm{x}$ & 41 & 0,007 & $0,049 \mathrm{x}$ & - \\
\hline & & & & & - \\
\hline
\end{tabular}

\section{V.1.3.4. Análisis funcional de la morfología del antebrazo}

En Ctenomys, como en otros mamíferos cavadores, las elevadas fuerzas de flexión que se ejercen a nivel del antebrazo y la muñeca se reflejan en especializaciones morfológicas en el radio y la ulna (Hildebrand, 1985). Los resultados de los análisis cuali- y cuantitativos indican que, en el contexto de los Octodontoidea, los huesos del antebrazo de Ctenomys se caracterizan por: a. considerable robustez, especialmente en el radio; b. diáfisis curva; c. fosa sigmoidea profunda; d. fóvea radial ovoidal; e. olécranon ulnar bien desarrollado y f. articulación distal radio-carpal especializada con proceso pseudoestiloide. Sin embargo, sólo este último rasgo es exclusivo de Ctenomys, mientras que el rango de variación de los caracteres es continuo y 
coincide parcialmente con el de los otros caviomorfos analizados; sólo algunas especies poseen rasgos morfológicos claramente diferenciados. De acuerdo con esto, la siguiente discusión se enfoca en los rasgos de importancia morfofuncional presentes en las especies de morfología más especializada, i.e. C. lewisi, C. conoveri, C. frater y C. steinbachi.

La robustez del radio y la ulna está vinculada al desarrollo de las fuertes tensiones generadas por los músculos flexores del carpo y los dedos durante el cavado. Los análisis alométricos mostraron que el diámetro dorsoventral de estos huesos aumenta con una tasa mayor que la del diámetro lateromedial, de manera que la resistencia mecánica es reforzada en el plano sobre el cual se ejercen las principales cargas durante el cavado. Las especies con radio más robusto presentan, además, las epífisis proporcionalmente más grandes (cf. especies de tamaño similar como C. australis vs. C. dorbignyi o C. fulvus vs. C. lewisi, Fig 39), lo cual probablemente proporcione mayor estabilidad a sus articulaciones de codo y muñeca.

Estudios previos han señalado que en roedores excavadores, tales como Ctenomys y Geomys, los huesos del antebrazo presentan mayor grado de curvatura lateral (Lehmann, 1963; Hildebrand, 1985; Stein, 2000). La forma del radio es un arco que alcanza su máxima curvatura en un punto situado aproximadamente en la mitad de su longitud (Vassallo, 1998); esta curvatura está en relación directa con el enorme desarrollo de los músculos flexores del carpo y dedos, que ocupan un amplio volumen del antebrazo de Ctenomys (Fig. 53), ya que el crecimiento coordinado de los músculos y el esqueleto conduce a la remodelación de los huesos largos (Hall, 2005). En particular, la doble flexión que da forma sigmoidea al radio de algunas especies en vista dorsal refleja la posición de los mm. flexor digitorum profundus (cabeza radial) y m. supinator, medial y lateral, respectivamente; en este sentido, las diferencias interespecíficas observadas en el grado de curvatura lateral podrían reflejar el desarrollo relativo de estos flexores. Dado que la curvatura lateral es menos conspicua en especies de tamaño corporal relativamente grande (C. leucodon, 
C. australis, C. lewisi, C. opimus, C. dorbignyi), esto sugiere que los requerimientos de espacio físico de los músculos en desarrollo podrían afectar la forma del radio con mayor intensidad en las especies más pequeñas. También la curvatura de la ulna, que ha sido señalada como una especialización morfológica (Vassallo, 1998), mostró variabilidad interespecífica. En este punto, es necesario distinguir entre la curvatura del proceso olecraneano y la curvatura general de los huesos del antebrazo (tanto ulna como radio), ya que cada una tiene implicaciones biomecánicas diferentes. Mientras que la curvatura de la ulna está relacionada principalmente con el enorme desarrollo de las masas musculares relacionadas, tal como ocurre en el radio, la curvatura medial del proceso olecraneano, que es común entre los mamíferos braquioexcavadores (Hildebrand, 1985), tiene implicaciones biomecánicas específicas. Esta inflexión del olécranon, junto con el gran desarrollo del epicóndilo medial del húmero discutido anteriormente, incrementa el área de origen de los músculos flexores del carpo y los dedos, i.e. m. palmaris longus, m. flexor carpi ulnaris, y cabeza ulnar del m. flexor digitorum profundus (Fig. 53). Con respecto a este rasgo, Vasallo (1998: 423) afirma que "the olecranon process is medially curved, thus providing major effective forces for carpal flexors like M. palmaris longus and M. flexor carpi ulnaris by altering their lines of action (Hildebrand, 1985)." Sin embargo, si bien esta morfología especializada del olécranon aporta mayor superficie para la fijación de estos músculos, la inflexión del olécranon no necesariamente altera la línea de acción de los flexores en general, dado que estos músculos tienen un recorrido paralelo al antebrazo y atraviesan el túnel carpiano (como tendones), de manera que su línea de acción no se vería significativamente alterada por esta flexión del olécranon. Sí podría haber una alteración de la línea de acción del m. epitrochleus-anconeus, que se origina en el epicóndilo medial y se inserta en el olécranon, alterando su potencial como estabilizador de la articulación del codo. Por otro lado, el hecho de que el proceso olecraneano sea relativamente 
largo como en muchos mamíferos braquioexcavadores (Hildebrand, 1985), aumenta el brazo de palanca interno del $\mathrm{m}$. triceps brachii, responsable de la poderosa extensión del antebrazo necesaria para que la mano ejerza la fuerza del golpe sobre el sustrato (Biknevicius, 1993). La ventaja mecánica conferida por esta estructura es máxima en $C$. conoveri, siendo también elevada en $C$. steinbachi, C. lewisi y C. frater con respecto a las demás especies analizadas.

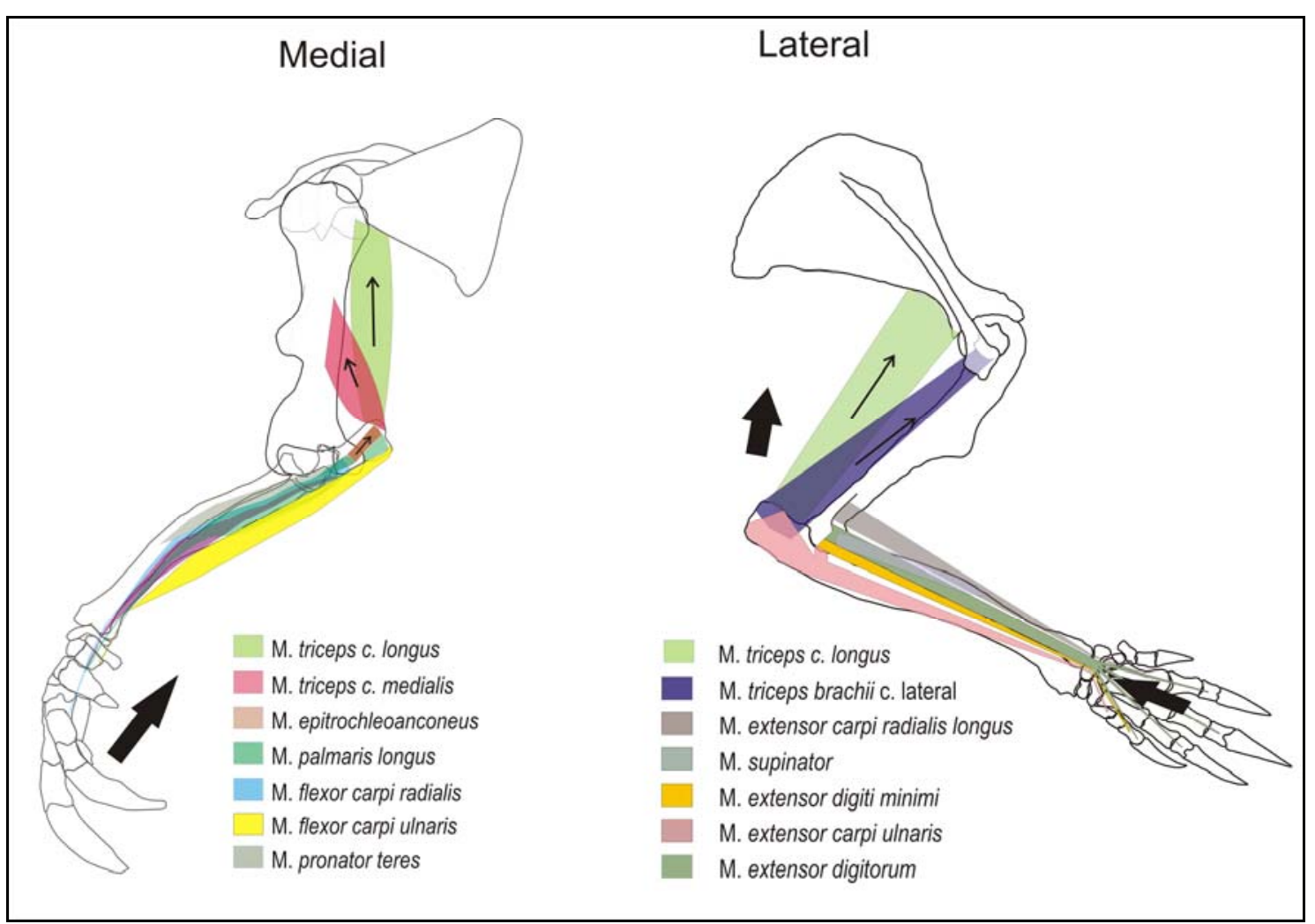

Figura 53. Representación esquemática de los principales músculos asociados con el antebrazo y la mano en Ctenomys.

Las superficies articulares del radio y la ulna están morfológicamente especializadas para resistir las fuerzas de tensión generadas durante la braquioexcavación. La profunda fosa sigmoidea de Ctenomys brinda mayor estabilidad a la articulación del codo y proporciona una amplia superficie que permite la dispersión de las fuerzas generadas en esa zona durante el cavado (Szalay y Sargis, 2001) a la vez que evita el dislocamiento (Argot, 2001). La profundidad de esta estructura está correlacionada con la tróclea humeral alta discutida previamente (ver V.1.2.4. Análisis funcional de la morfología 
humeral). La fóvea ovoidal restringe la extensión de los movimientos rotatorios en el codo; sin embargo, aunque esta forma ovoide ha sido mencionada como característica de los roedores fosoriales (Stein, 2000), en Ctenomys no se trata de una especialización braquioexcavadora, ya que también se registra en roedores caviomorfos con otros hábitos (Candela y Picasso, 2008). Además, la convexidad homogénea de la fóvea de Ctenomys permite el deslizamiento del radio sobre el capítulo humeral, y su margen convexo no reduce marcadamente el arco de rotación del radio (MacLeod y Rose, 1993). La movilidad proximal del radio es importante, ya que es probable que la rotación del radio sobre la ulna a nivel distal esté restringida por la estrecha unión entre ambos huesos, tal como ocurre en los geómidos (Hill, 1937) y en algunas ardillas voladoras (Rodentia, Sciuromorpha, Pteromyini); en estas últimas la pronación y supinación ocurren exclusivamente por rotación del brazo al nivel de la articulación del codo (Thorington, 1984; Thorington et al., 1998). Un mecanismo similar podría estar presente en Ctenomys, capaz de llevar las manos a una posición semisupina al manipular tallos para alimentarse (obs. pers.) a pesar de la escasa movilidad de la articulación de la muñeca (ver V.1.4.4. Análisis funcional de la morfología de la mano).

La restricción de movimientos a nivel de la muñeca está asegurada por los procesos estiloide y pseudoestiloide del radio (este último distintivo de Ctenomys entre los caviomorfos, Lehmann, 1963), que articulan en forma de cuña entre los huesos de la serie carpiana proximal, determinando una articulación de tipo bisagra que sólo permite movimientos de flexión y extensión. De esta manera, la morfología distal del radio estabiliza el carpo y restringe movimientos de la muñeca no favorables para el cavado (Lehmann, 1963). Un proceso pseudoestiloide, si bien ligeramente más pequeño que el estiloide, está presente también en la familia Geomyidae (Geomys, Thomomys y Cratogeomys) y en los pocket mice del género Perognathus (Castorimorpha Heteromyidae; Hill, 1937). 
En el contexto de otros roedores excavadores del mundo (Lehman, 1963; Lessertisseur y Saban, 1967; Hildebrand, 1985; Stein, 2000), la especialización morfológica del antebrazo de Ctenomys es menor que la presente en especies subterráneas de otros subórdenes, tales como Spalax (cf. Figs. 39 y 43 y Özkan, 2002, Fig. 3), Geomys o Bathyergus (Hystricomorpha, Bathyergidae; Hildebrand, 1985, Tabla 6-2). En estos últimos, el desarrollo y longitud del olécranon son mayores que en Ctenomys y la movilidad relativa de radio y ulna está más restringida, hasta el punto de presentar fusión de ambos huesos en algunos especímenes de Spalax leucodon (Özkan, 2002).

\section{V.1.4. Mano}

\section{V.1.4.1. Análisis cualitativo}

\section{V.1.4.1.a. Morfología de la mano en Ctenomys (Fig. 54 y 55a)}

La mano es fuerte y grande con respecto al tamaño corporal. El dedo III, a través del cual pasa el eje de la mano, es el de mayor tamaño, mientras que los dedos II y IV son algo menores y subiguales y los dedos I y V son más cortos, especialmente el dedo I ("mesaxonia" de Lessertisseur y Jouffroy, 1973). Tanto el carpo como los metacarpianos son relativamente cortos y robustos; también lo son las falanges, con excepción de las falanges terminales (ungueales), las cuales son largas, curvadas y aguzadas.

La morfología esqueletaria de la mano de Ctenomys fue descripta por Forsyth Major (1899) y Ubilla y Altuna (1990). La estructura del carpo responde al plan básico del orden Rodentia (Lessertisseur y Saban, 1967). El escafolunar es un hueso grande de forma irregular, que articula proximalmente con el radio y distalmente con el trapecio y trapezoide; su superficie articular proximal presenta un área convexa que encaja entre los procesos estiloide y pseudoestiloide del radio. El piramidal, más pequeño, articula proximalmente con la ulna y el pisiforme, y distalmente con el unciforme. El prepólex (sesamoideo radial) está bien desarrollado; es de forma alongada y aplanada, y su tamaño es aproximadamente el doble que el 
del pisiforme (sesamoideo ulnar). Este sesamoideo articula con el escafolunar y el metacarpiano I, ubicándose en posición medial sobre la cara ventral de la palma, con aspecto de ser un pequeño radio adicional (Forsyth Major, 1899; Ubilla y Altuna, 1990). El central es muy pequeño; está comprimido entre el escafolunar, el grande y el trapezoide, y es triangular en vista dorsal. En la hilera distal, el trapecio y trapezoide son subiguales y articulan distalmente con los metacarpianos I y II, respectivamente; el grande, que articula con el metacarpiano III, es algo más grande que los anteriores, y el unciforme, que articula con los metacarpianos IV y V, es el más grande de los carpianos distales, aunque ligeramente menor que el escafolunar (Ubilla y Altuna, 1990). En †Ctenomys chapalmalensis (Fig. 55a) el escafolunar y el pisiforme son de tamaño similar, como en las especies vivientes. Aunque no se observaron diferencias cualitativas evidentes en el carpo de las especies examinadas, la extensión del contacto entre el escafolunar y el unciforme fue relativamente mayor (aproximadamente $1 / 4$ de la longitud del margen distal del escafolunar) en C. australis, C. maulinus, C. frater, C. fulvus, C. lewisi, C. "palmar", C. "monte" y C. dorbignyi, comparada con el contacto relativamente menor (aprox. 1/5 de la misma longitud) en C. "mármol", C. opimus, C. talarum, C. leucodon, C. steinbachi y C. azarae. En †C. chapalmalensis el tamaño relativo y la conformación del escafolunar son similares a los de las especies vivientes, pero el estado de preservación no permite inferir el grado de contacto con el unciforme (Fig. 55a).

Los metacarpianos son cortos y robustos (Ubilla y Altuna, 1990), especialmente en C. dorbignyi y C. "mármol", y presentan epífisis distales ensanchadas. El metacarpiano I es corto y de forma irregular, morfológicamente diferente de los metacarpianos II-V; articula firmemente sobre el escafolunar y el trapecio. Los metacarpianos II-V no son rectos sino que el extremo proximal de los mismos presenta una flexión en dirección lateral, de manera que la articulación proximal de cada metacarpiano forma una cuña entre el carpiano distal y los metacarpianos adyacentes. En el 
extremo distal ensanchado, la articulación con la falange proximal se efectúa mediante una doble tróclea amplia, cuyas carillas articulares están separadas por una cresta longitudinal media bien definida. En $† C$. chapalmalensis, los metacarpianos son también robustos, pero relativamente más cortos con respecto al carpo, en comparación con las especies vivientes.

Las falanges proximales e intermedias son más cortas que las falanges ungueales; estas últimas últimas son largas y aguzadas como las garras que portan, y presentan un proceso próximo-dorsal que envuelve parcialmente el extremo distal de la falange intermedia (Ubilla y Altuna, 1990). La morfología de las falanges ungueales varía desde relativamente largas y gráciles en $C$. australis, hasta más cortas, altas y fuertes en C. lewisi. En †C. chapalmalensis, la única falange preservada (falange proximal del dedo IV) es más larga comparada con las de Ctenomys vivientes.

El autopodio de Ctenomys incluye huesos sesamoideos de variado desarrollo. Además de los ya descriptos pisiforme y prepólex, hay un par de pequeños sesamoideos ventrales en el extremo distal de los metacarpianos IIV. El sesamoideo palmar, impar, es de tamaño comparativamente grande en C. lewisi, mientras que es más pequeño en C. leucodon. El tamaño del sesamoideo palmar varía dentro de estos extremos en otras especies, aunque no fue posible evaluar su morfología en muchos casos por estar ausente o parcialmente cubierto por restos de tejidos (tendones y tegumento). Adicionalmente, existe un muy pequeño sesamoideo ubicado dorsalmente sobre el metacarpiano I (Forsyth Major, 1899) que pudo ser observado en la mayoría de las especies; es posible que la no detección del mismo en $C$. australis, C, azarae y $C$. fulvus se deba a que este hueso se pierde frecuentemente durante la preparación del material (tal como comentara Forsyth Major, 1899). 


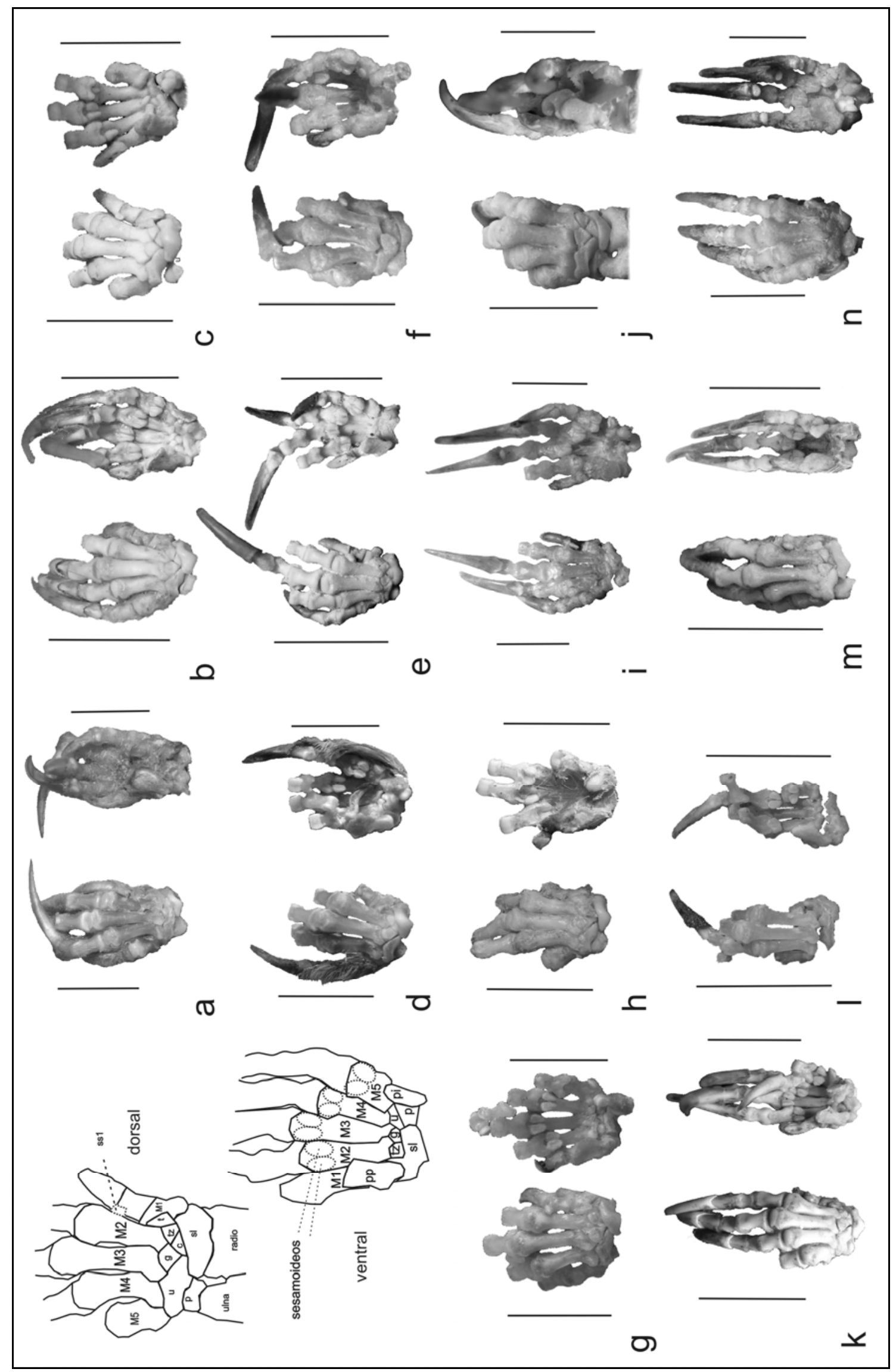


Figura 54 (página anterior). Mano izquierda (derecha invertida en $\mathrm{m}$ y n; completa en $a, b, j, m$ y n) de especies vivientes de Ctenomys en vista dorsal (izquierda) y ventral (derecha). a. C. australis; b. C. "mármol"; c. C. maulinus; d. C. opimus; e. C. talarum; f. C. leucodon; g. C. frater; h. C. fulvus; i. C. steinbachi; j. C. lewisi; k. C. "palmar"; 1. C. azarae; m. C. "monte"; n. C. dorbignyi. Referencias para el esquema ilustrativo: $\mathrm{c}=$ central; g=grande; $\mathrm{MC1}-5=$ metacarpianos I-V; $\mathrm{p}=$ piramidal; $\mathrm{pi}=$ pisiforme; $\mathrm{pp}=$ prepólex; $\mathrm{sl}=$ escafolunar; $\mathrm{ss}=$ sesamoideo dorsal del MI; $\mathrm{t}=$ trapecio; $\mathrm{t} z=$ trapezoide; $\mathrm{u}=$ unciforme. Las líneas punteadas indican la posición de sesamoideos menores. Escala: $1 \mathrm{~cm}$.

\section{V.1.4.1.b. Comparación con otros géneros de ctenominos (Fig. 55)}

Sólo se conoce el metacarpiano III de †Praectenomys rhombidens (Fig. 55c; Quintana, 1994, fig. 11), el cual es robusto y presenta epífisis distal ensanchada como en Ctenomys. La configuración de las áreas articulares también es similar a la de Ctenomys, con el extremo proximal flexionado y doble tróclea en la articulación distal.

La mano de †Eucelophorus se conoce en forma fragmentaria a través de un único espécimen (Fig. 55b, tomada de Reig y Quintana, 1992, fig. 9a). Los huesos carpianos preservados son similares a los de Ctenomys. De acuerdo con la descripción original, los metacarpianos son cortos y un poco menos robustos que los de Ctenomys; no están ensanchados distalmente ni presentan la quilla para articulación de los sesamoideos como en este último género. El patrón de tamaños relativos de los metacarpianos es similar al de Ctenomys, pero el metacarpiano II es relativamente más largo, casi tanto como el metacarpiano III.

La morfología de la mano de †Actenomys priscus puede evaluarse sólo parcialmente, debido a que en el único material conocido (MMP 703 S, Fig. 55d) que conserva la mano articulada, el carpo está parcialmente cubierto por sedimento. La morfología de los metacarpianos es similar a la de Ctenomys, y su robustez es comparable a la de algunas especies vivientes con metacarpianos relativamente gráciles (e.g. C. frater y C. opimus). 


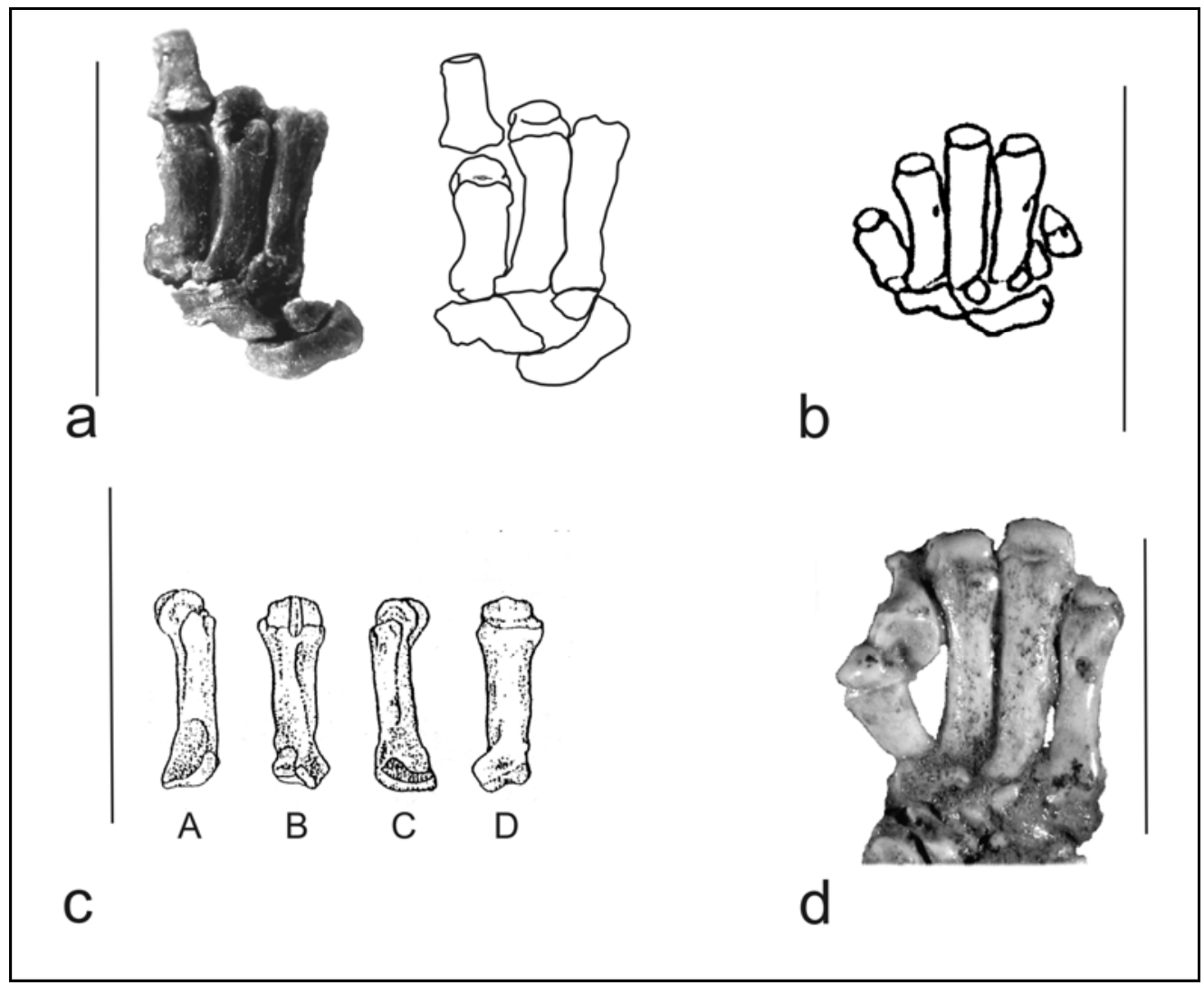

Figura 55. Autopodio izquierdo fragmentario de especies extintas de ctenominos. a. $† C$. chapalmalensis MACN 19249; fotografía del material en su estado actual (izquierda), y esquema mostrando la posición correcta de los huesos carpianos (derecha); b. †Eucelophorus MACN 7294 (tomado de Reig y Quintana, 1992), vista dorsal; c. Metacarpiano III de †Praectenomys rhombidens (tomado de Quintana, 1994); A. vista lateral, B. vista ventral, C. vista medial, D. vista dorsal; d. †Actenomys priscus MMP $703 \mathrm{~S}$, vista dorsal. Escala: $1 \mathrm{~cm}$.

\section{V.1.4.1.c. Comparación con otros caviomorfos (Fig. 56)}

En los octodontinos examinados, Octodon y Octodontomys, los dedos III y IV son de tamaño subigual (Pocock, 1922; "paraxonia" de Lessertisseur y Jouffroy, 1973), a diferencia de la condición en Ctenomys. El dedo I está muy reducido y el dedo V es más corto que el II. A diferencia de Ctenomys, el escafolunar es más pequeño que el unciforme y presenta una morfología más simple, con superficies articulares subparalelas, con concavidad suave y homogénea. El prepólex es algo más grande que el pisiforme. Los metacarpianos son más gráciles que en Ctenomys y presentan escasa 
expansión del extremo distal; la flexión lateral se presenta en el extremo proximal de los metacarpianos II y III, pero no en el metacarpiano IV.

La mano de los equímidos es más grácil que la de Ctenomys, y en la mayoría de los géneros analizados el patrón de desarrollo relativo de los dedos es similar al de los octodontinos, con los dedos III y IV de tamaño subigual; el dedo V es bastante más corto que el IV. La morfología del carpo es similar a la de los octodontinos, con escafolunar relativamente más pequeño y de forma menos angulosa que en Ctenomys. El carpiano grande es relativamente más grande que en Ctenomys y el trapecio es de mayor tamaño que el trapezoide. El prepólex es más pequeño que el pisiforme y ambos sesamoideos son relativamente más pequeños que en Ctenomys; el pisiforme es algo más grande en Euryzygomatomys que en los demás equímidos examinados, pero tiene forma más roma que el pisiforme de Ctenomys. La flexión proximal de los metacarpianos II y III es menor que la de Ctenomys, y los sesamoideos asociados a los metacarpianos son relativamente pequeños comparados con los de Ctenomys. La morfología de Myocastor se aparta de la de otros equímidos por poseer un escafolunar de forma similar al de Ctenomys. Las falanges ungueales son mucho más pequeñas que en Ctenomys, de largo igual o menor al de las respectivas falanges intermedias.

En Cavia la mano es mucho más pequeña con respecto al tamaño corporal que en Ctenomys. El carpo es más corto que en Ctenomys, con los carpianos proximales subiguales y de contorno rectangular en vista dorsal. A diferencia de Ctenomys, el central es más grande que el trapezoide y el trapecio, y estos dos últimos carpianos contactan con el dedo II. También presenta diferencias en cuanto a la alineación de los carpianos, que no es alternada entre la serie proximal y la distal, sino que el piramidal está alineado con el unciforme y el escafolunar con el central, grande, trapezoide y trapecio. Las superficies articulares entre los carpianos, así como las articulaciones entre carpianos y metacarpianos, son morfológicamente más sencillas que en Ctenomys, El pisiforme es grande y el prepólex más pequeño 
comparados con Ctenomys. Los metacarpianos son de diámetro casi uniforme en toda su longitud y mucho más largos que los de Ctenomys, y las falanges ungueales son mucho más cortas que en Ctenomys.

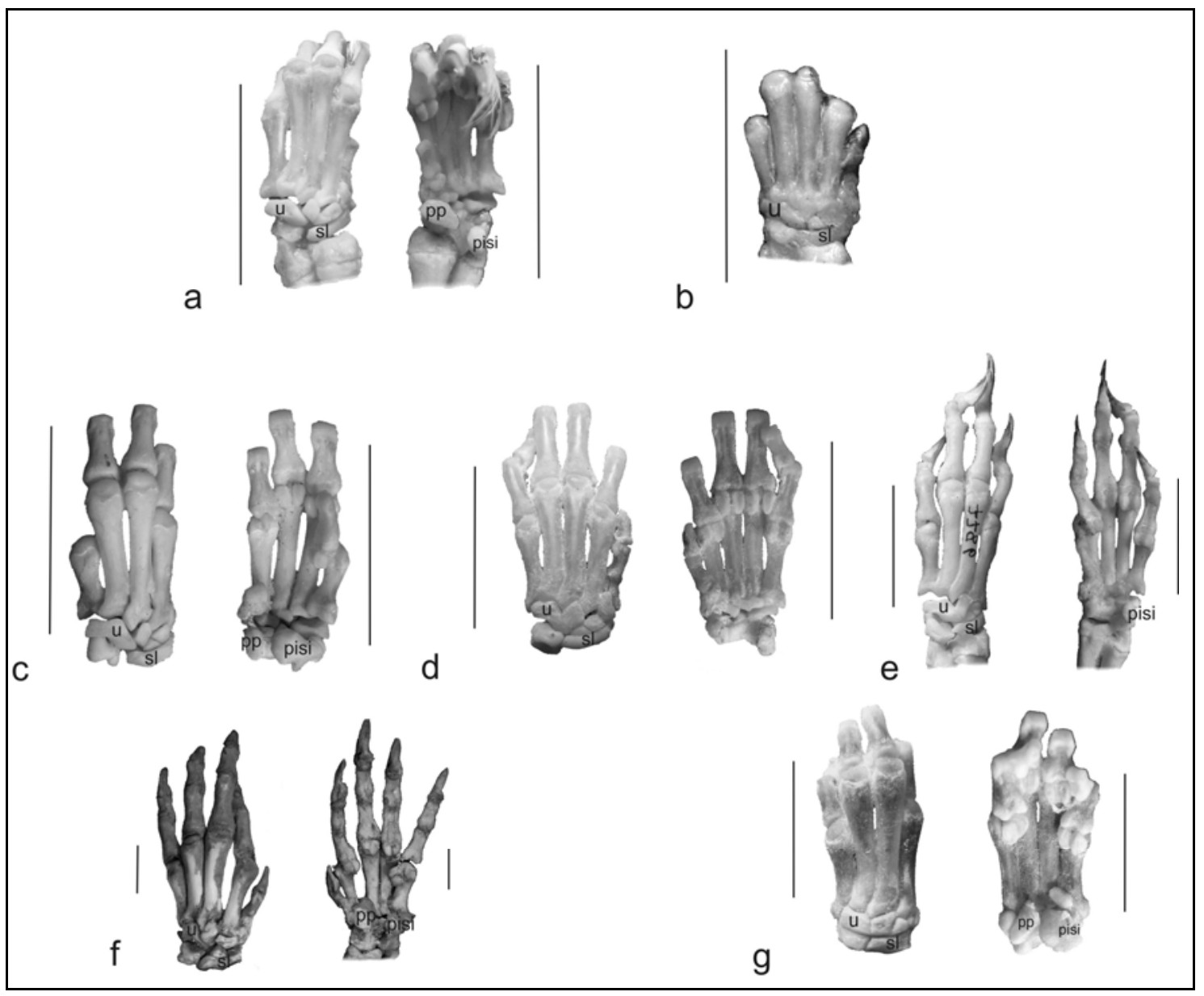

Figura 56. Mano izquierda en vista dorsal (izquierda) y ventral (derecha) de Octodontoidea (a-f) y Caviidae. a. Octodontomys gliroides; b. Octodon "bridgesi" (sólo vista dorsal); c. Euryzygomatomys spinosus d. Thrichomys apereoides; e. Proechimys poliopus; f. Myocastor coypus; g. Cavia aperea. Referencias: pi= pisiforme; $\mathrm{pp}=$ prepólex; $\mathrm{sl}=$ escafolunar; $\mathrm{u}=$ unciforme. Escala: $1 \mathrm{~cm}$.

\section{V.1.4.2. Análisis cuantitativo general}

Debido al bajo número de especímenes, los índices morfo-funcionales de la mano no pudieron ser evaluados mediante un análisis multivariado. La comparación de los índices morfo-funcionales de Ctenomys con otros caviomorfos (Tabla 16) concuerda con los resultados del análisis cualitativo. 
Tabla 16. Índices morfo-funcionales de la mano en Ctenomys y otros caviomorfos analizados.

\begin{tabular}{lrrrrrr}
\hline \multirow{1}{*}{ especie } & \multicolumn{3}{c}{ RMC3 } & \multicolumn{3}{c}{ FCARP } \\
\cline { 2 - 8 } & media & N & DS & media & N & DS \\
\hline Ctenomys* & 0,19 & 31 & 0,04 & 1,94 & 29 & 0,22 \\
\hline O. gliroides & 0,13 & 4 & 0,01 & 1,99 & 4 & 0,09 \\
\hline O. "bridgesi" & 0,18 & 1 & 0,00 & 1,84 & 1 & 0,00 \\
\hline O. degus & 0,15 & 1 & 0,00 & 1,74 & 1 & 0,00 \\
\hline M. coypus & 0,14 & 1 & 0,00 & 1,78 & 1 & 0,00 \\
\hline P. poliopus & 0,15 & 2 & 0,01 & 1,84 & 2 & 0,12 \\
\hline E. spinosus & 0,14 & 1 & 0,00 & 1,98 & 1 & 0,00 \\
\hline Cavia aperea & 0,16 & 11 & 0,02 & 1,56 & 11 & 0,37 \\
\hline * Promedio para el género & & & & &
\end{tabular}

* Promedio para el género

\section{V.1.4.3. Análisis cuantitativo de la variabilidad morfológica en Ctenomys} Análisis estadístico descriptivo

Los resultados del análisis estadístico descriptivo de la mano en Ctenomys se presentan en las Figs. 57 y 58. A pesar de que la muestra sólo incluyó pocas especies, el patrón de variación continua dentro del rango de valores para cada índice es similar al que exhiben otras variables analizadas. 


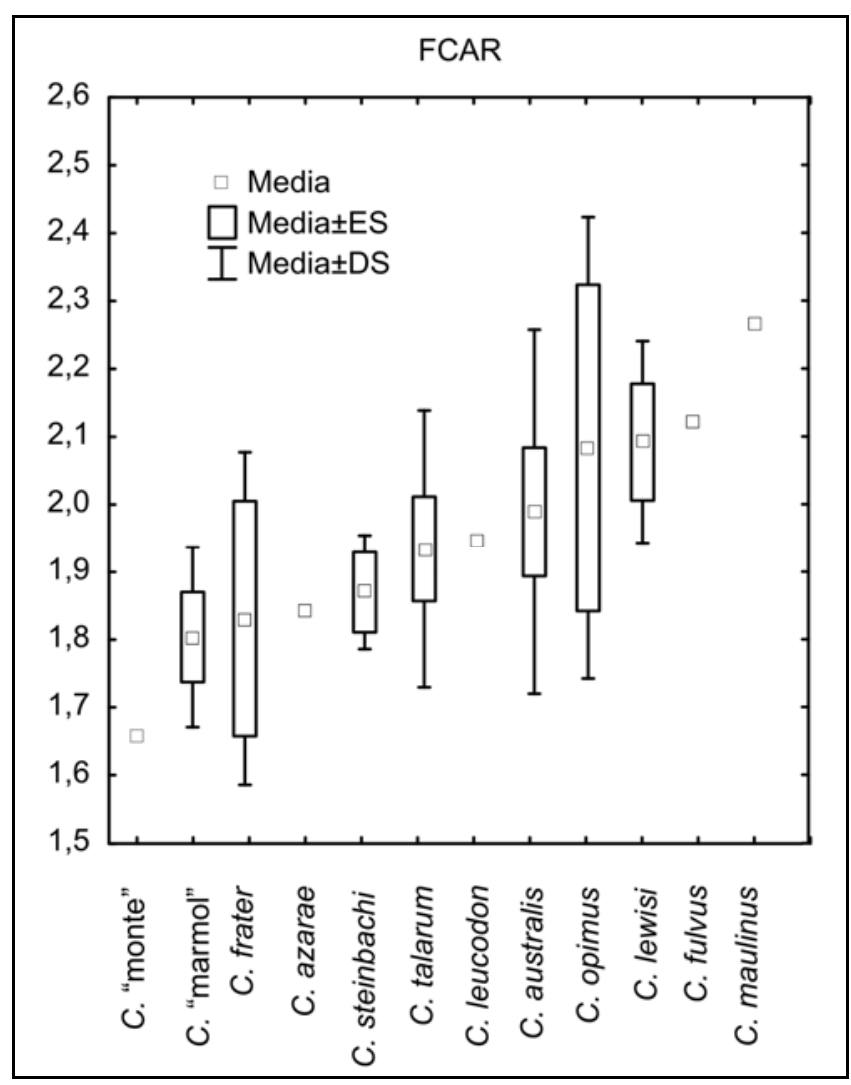

Figura 57. Índice de forma del carpo (FCAR) por especie.

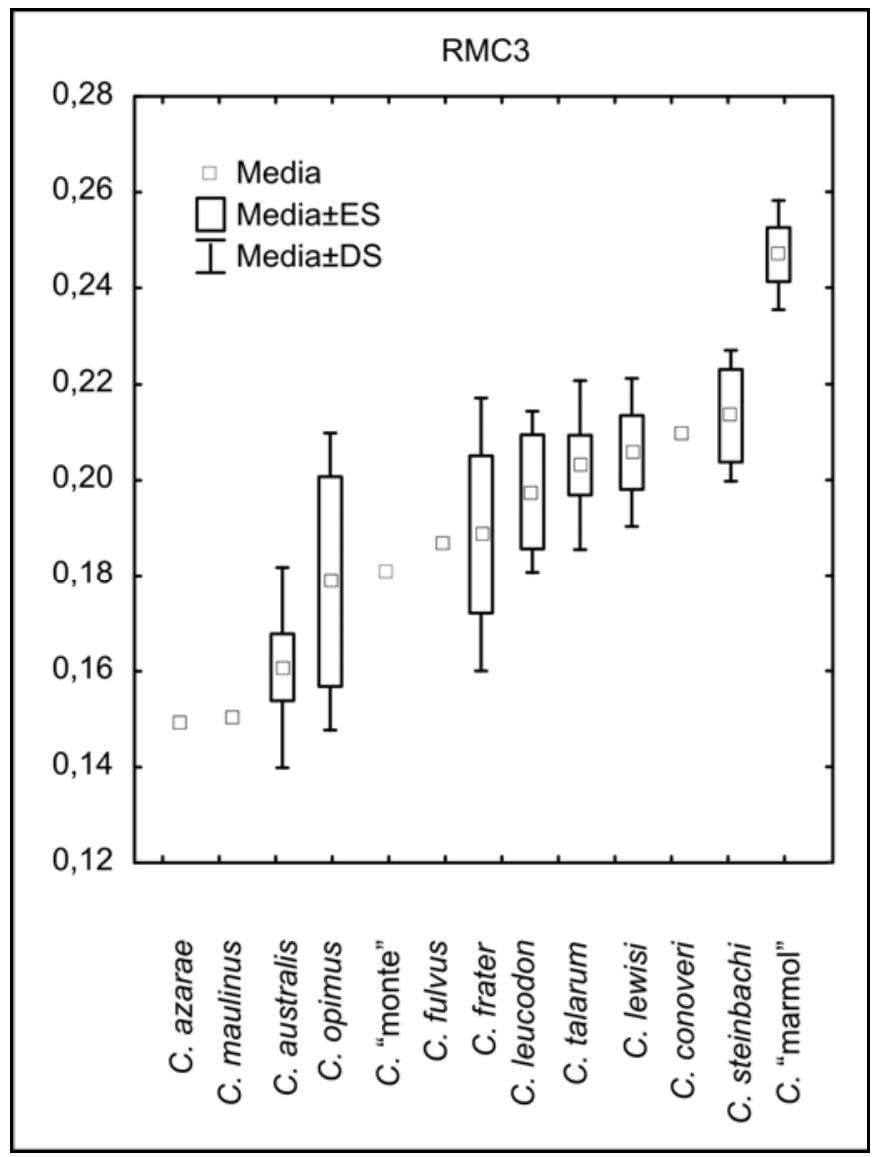

Figura 58. Índice de robustez del metacarpiano III (RMC3) por especie. 


\section{Alometrías en la mano de Ctenomys}

Los resultados del análisis alométrico se muestran en las Tablas 17 y 18. Las medidas lineales (Tabla 17) mostraron alometría positiva (b>1). Los resultados muestran fuerte alometría positiva del ancho del metacarpiano III; de todos modos el ajuste con el tamaño resultó bajo. Por su parte, los índices analizados mostraron muy baja correlación con el tamaño corporal (Tabla 18).

Tabla 17. Ecuaciones alométricas (regresión Modelo II, método de ejes principales) para medidas de la mano de Ctenomys vs. DP4-M2.

\begin{tabular}{llllll}
\hline $\begin{array}{l}\text { Variable } \\
\text { regresionada }\end{array}$ & $\begin{array}{l}\text { Ecuación }(\log \mathbf{y}=\mathbf{a}+\mathbf{b} \\
\log \mathbf{x})\end{array}$ & $\mathbf{r}$ & $\mathbf{r} 2$ & $\begin{array}{l}\text { Intervalos de } \\
\text { confianza }\end{array}$ \\
\hline ACAR & $\log \mathrm{y}=-0,49+1,37 \log \mathrm{x}$ & 28 & 0,83 & 0,69 & $\mathrm{a}:-0,90--0,21$ \\
& & & & & $\mathrm{~b}: 1,06-1,81$ \\
\hline LCAR & $\log \mathrm{y}=-0,78+1,37 \log \mathrm{x}$ & 28 & 0,68 & 0,46 & $\mathrm{a}=-1,55--0,35$ \\
& & & & & $\mathrm{~b}=0,90-2,22$ \\
\hline AMC3 & $\log \mathrm{y}=-1,66+1,98 \log \mathrm{x}$ & 30 & 0,56 & 0,31 & $\mathrm{a}:-3,65--0,94$ \\
& & & & & $\mathrm{~b}: 1,18-4,16$ \\
\hline LMC3 & $\log \mathrm{y}=-0,74+1,75 \log \mathrm{x}$ & 30 & 0,81 & 0,66 & $\mathrm{a}:-1,31--0,36$ \\
& & & & & $\mathrm{~b}: 1,34-2,38$ \\
\hline
\end{tabular}

Tabla 18. Ecuaciones alométricas (regresión Modelo II, método de ejes principales) para índices morfo-funcionales de la mano de Ctenomys vs. DP4M2.

\begin{tabular}{llllll}
\hline $\begin{array}{l}\text { Variable } \\
\text { regresionada }\end{array}$ & $\begin{array}{l}\text { Ecuación }(\log y=\mathbf{a}+\mathbf{b} \\
\log x)\end{array}$ & $\mathbf{r}$ & $\mathbf{r}^{2}$ & $\begin{array}{l}\text { Intervalos } \\
\text { confianza }\end{array}$ \\
\hline FCAR & $\log y=-0,33+0,68 \log x$ & 28 & 0,26 & 0,07 & a: $-3,66-0,42$ \\
& & & & & b: $-0,15-4,34$ \\
\hline RMC3 & $\log y=1,95-2,93 \log x$ & 30 & $-0,30$ & 0,09 & a: $0,34--18,29$ \\
& & & & & b: $19,34--1,16$ \\
\hline
\end{tabular}




\section{V.1.4.4. Análisis funcional de la morfología de la mano}

Los roedores braquioexcavadores tienen manos relativamente anchas, que brindan mayor superficie para remover el sustrato (Pocock, 1922; Hildebrand, 1985; Stein, 2000). Además, las grandes fuerzas producidas por el miembro anterior requieren mecanismos para resistir la hiperextensión, dislocación y deflexión a nivel de la muñeca (Hildebrand, 1985). Ubilla y Altuna (1990) analizaron la mano de Ctenomys sobre la base de tres especies (C. rionegrensis, C. pearsoni y C. torquatus) e identificaron características especializadas vinculadas con la actividad excavadora, incluyendo acortamiento de todos los elementos excepto las falanges ungueales, articulaciones metacarpo-falangianas especializadas y gran desarrollo de huesos sesamoideos (especialmente el prepólex). En el presente trabajo se estudiaron mayor cantidad de especies y fue posible compararlas con taxones emparentados. De acuerdo con este análisis, la mano de Ctenomys presenta las siguientes características, que pueden representar especializaciones vinculadas con la braquioexcavación: a. predominancia del dedo III ("mesaxonia"); b. articulación carpiana proximal de superficie compleja; c. carpo reforzado y rígido, con escafolunar grande en amplio contacto con el unciforme, y central reducido; $\mathrm{d}$. metacarpianos robustos con articulaciones especializadas; e. sesamoideos bien desarrollados, especialmente el prepólex.

La "mesaxonia" implica que las fuerzas generadas durante el movimiento del brazo se ejercen en forma concentrada primariamente a nivel del dedo III, maximizando la presión ejercida sobre el sustrato. La morfología de la porción distal del antebrazo (proceso estiloides de la ulna, y procesos estiloide y pseudoestiloide del radio) proporciona una ajustada articulación con los carpianos escafolunar y piramidal, limitando la dorsiflexión a nivel de esta articulación e impidiendo la circumducción. Debido a esta escasa movilidad, cualquier movimiento de rotación de la mano debe realizarse a nivel de la articulación proximal entre radio y ulna. 
El escafolunar de gran tamaño y morfología compleja asegura una articulación firme a nivel carpiano proximal, condición que se asemeja a la observada en tenrecoideos fosoriales (Salton y Sargis, 2008, figs. 6 y 7). Desde una perspectiva funcional, la diferencia de tamaño entre el escafolunar y el relativamente menor piramidal da como resultado una mayor carga de fuerzas sobre el eje radio-escafolunar en comparación con la menos robusta articulación ulnar-piramidal. Además, la articulación entre los dos carpianos proximales es prácticamente inmóvil, coincidiendo con la condición descripta por Thorington y Darrow (2000) para ardillas voladoras. En estas especies, no se requieren movimientos relativos entre el escafolunar y el piramidal durante la pronación y supinación, debido a la inmovilidad de la articulación entre los extremos distales del radio y ulna (ver V.1.3.4. Análisis funcional de la morfología del antebrazo).

Por otra parte, el gran tamaño del escafolunar aumenta la superficie de su contacto con el unciforme en la serie distal, reforzando la estructura de la palma con respecto a lo observado en los octodontinos (Fig. 59). Una condición similar ha sido descripta para algunos marsupiales, en los cuales el unciforme está en extenso contacto con el escafoides proporcionando una firme conexión entre las hileras proximal y distal del carpo (Weisbecker y Archer, 2008). Esta morfología podría representar una especialización morfológica de Ctenomys. Sin embargo, la mayor área relativa de contacto entre estos dos carpianos se observó en las especies C. dorbignyi, C. "palmar", C. australis, C. fulvus y C. frater, que son de tamaño mediano a grande, por lo cual no puede descartarse que este rasgo esté sometido a requerimientos mecánicos vinculados con el tamaño corporal.

El carpiano central funciona como "bisagra" en los mamíferos en los cuales está muy desarrollado, ('cóndilo medio-carpiano' de Lessertisseur y Saban, 1967), de manera que la marcada reducción del mismo en Ctenomys también contribuye a disminuir la movilidad intracarpiana. Además, con excepción del unciforme, los huesos carpianos distales tienen tamaños muy 
similares, formando una serie donde cada carpiano está sólidamente encajado entre los otros y la base de los metacarpianos. En conjunto, esta estructura del carpo resulta en una palma rígida que funciona como "pala" durante la actividad excavatoria.
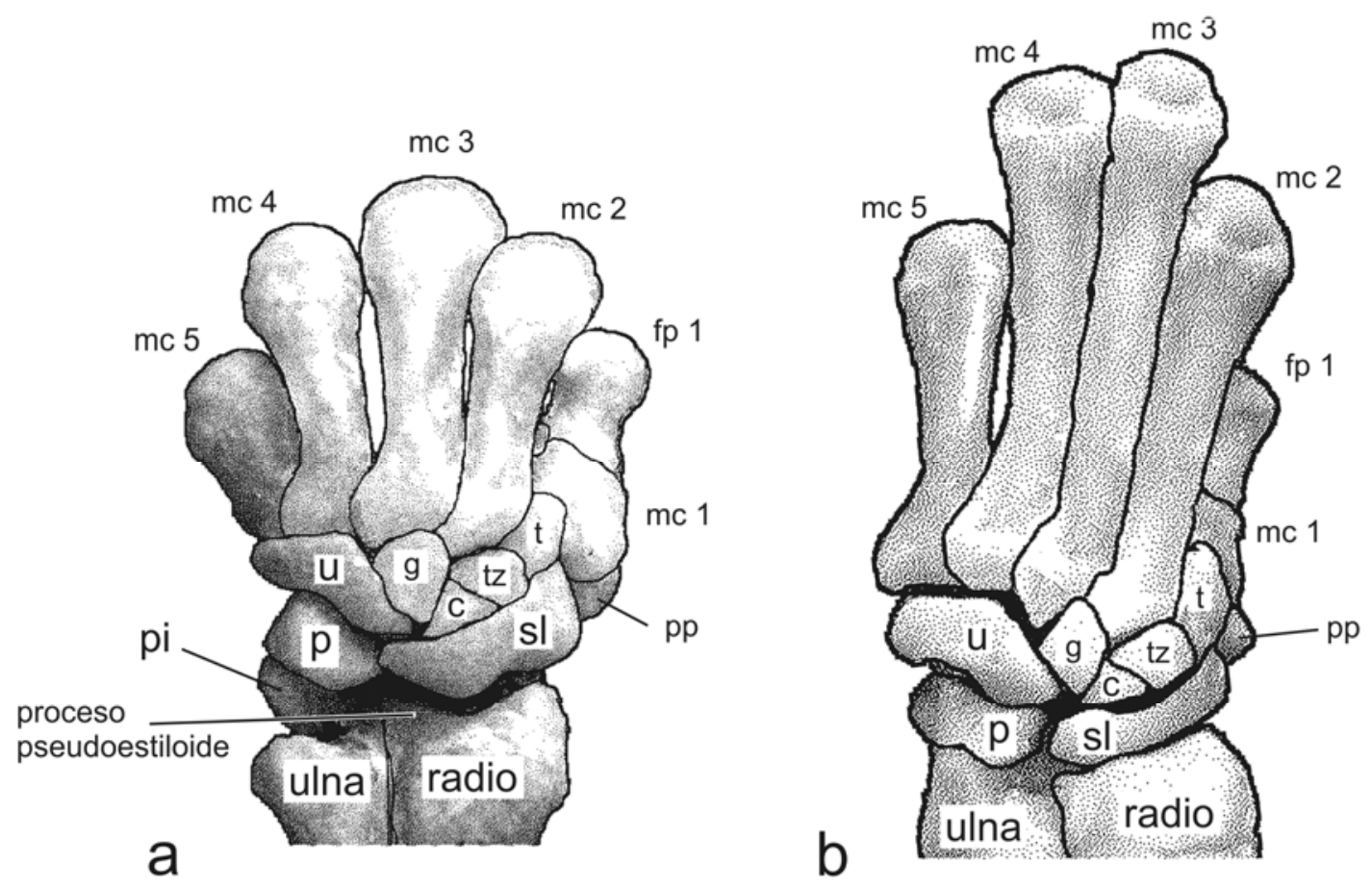

Figura 59. Esquema de carpo y metacarpo izquierdo de Ctenomys (a) y Octodontomys (b) en vista dorsal, mostrando las diferencias de forma y tamaño entre los carpianos y metacarpianos. Abreviaturas: $c=$ central; $f p 1=$ falange proximal del dedo I; g=grande; mc $1-5=$ metacarpianos I-V; $\mathrm{p}=$ piramidal; $\mathrm{pi}=$ pisiforme; $\mathrm{pp}=$ prepólex; $\mathrm{sl}=$ escafolunar; $\mathrm{t}=$ trapecio; $\mathrm{t} \mathrm{z}=$ trapezoide; $\mathrm{u}=$ unciforme.

La morfología de la articulación proximal de los metacarpianos II a IV también aumenta la rigidez de estas articulaciones y dificulta el movimiento entre carpo y metacarpo. Una morfología semejante se ha observado en el metacarpiano III de algunos marsupiales (Vombatidae y Macropodoidea), para los cuales se ha sugerido también un papel estabilizador de las articulaciones metacarpianas proximales (Weisbecker y Archer, 2008). 
Por último, la presencia de huesos sesamoideos bien desarrollados es común en muchos taxones subterráneos; estos elementos aumentan la fuerza generada durante la contracción muscular, al aumentar el ángulo de inserción de los tendones de los $\mathrm{m}$. flexores sobre la mano (Stein, 2000), y refuerzan las articulaciones metacarpo-falangianas de los dedos II a IV (Ubilla y Altuna, 1990). Con respecto a los sesamoideos principales, cabe señalar que, aunque en general los mamíferos fosoriales tienen un pisiforme largo (Hildebrand, 1985), sitio de inserción del m. flexor carpi ulnaris, en Ctenomys este hueso no está tan desarrollado como el prepólex. Sobre este último se insertan los $\mathrm{mm}$. abductor pollicis longus y palmaris longus, dos flexores de la mano. En este rasgo, Ctenomys se asemeja a otros mamíferos fosoriales, como Bathyergus y los Chrysochloridae (Afrosoricida). Aunque el significado funcional del desarrollo de estos sesamoideos no ha sido dilucidado, el largo del pisiforme y el prepólex podría ser indicador del desarrollo de los $\mathrm{m}$. flexores correspondientes, como sugieren Salton y Sargis (2008) para tenrecoideos. Además, el prepólex de Ctenomys sostiene la base de la eminencia tenar que se opone a los dedos II-IV durante la flexión y es utilizada para sostener el alimento (Ubilla y Altuna, 1990). Un prepólex bien desarrollado existe también en otros roedores fosoriales como Geomys, en el cual está cubierto por una almohadilla carpal tenar (Hill, 1937) y en Bathyergus (Tullberg, 1899, citado por Ubilla y Altuna, 1990); e incluso en otros mamíferos cavadores, como Talpa (Soricomorpha, Talpidae), en donde forma el llamado "hueso falciforme" o sexto dedo (Lessertisseur y Saban, 1967).

La actividad braquioexcavadora requiere la producción de grandes fuerzas externas (Fo); en Ctenomys, los metacarpianos y falanges relativamente cortos y robustos resultan en un brazo externo de palanca (Lo) más corto que permite ejercer mayor fuerza sobre el sustrato durante el golpe de cavado. En coincidencia con lo observado en este trabajo, Samuels y Van Valkenburgh (2008) hallaron mayor longitud del metacarpiano III con respecto a la falange proximal del mismo dedo en su análisis de roedores fosoriales, como ya 
describiera Hill (1937) para Geomyidae; en Ctenomys, estas falanges proximales y medias cortas contrastan con las muy desarrolladas falanges ungueales. Estas últimas no son bífidas, a diferencia de lo que ocurre en otros caviomorfos como Myocastor y Dolichotis e incluso otros mamíferos braquioexcavadores tales como Talpidae y Chrysochloridae (Hildebrand, 1985; Ubilla y Altuna, 1990), en los cuales se ha interpretado como un mecanismo que mejora el encastre entre las garras y las falanges ungueales.

Cabe señalar que las interpretaciones de "fusiones" o "pérdidas" de huesos del carpo no se basan en datos ontogenéticos ni han sido suficientemente testeadas en mamíferos (Thorington y Darrow, 2000; Salton y Sargis, 2008). Forsyth Major (1899) propuso la hipótesis de que el sesamoideo dorsal del metacarpiano I podría ser la falange "faltante" del pólex, y que la apófisis pseudoestiloide del radio (ver V.1.3.1.1.a. Morfología radial en Ctenomys) sería resultado de la reducción y fusión del lunato con el radio, mientras que el hueso considerado tradicionalmente como escafolunar sería un escafoides agrandado. Dentro de los roedores, sólo algunos miembros de las familias Bathyergidae y Ctenodactylidae poseeen escafoides y lunato separados, mientras que en la mayoría de los roedores existe un "escafolunar", para el cual tradicionalmente se asume un origen por fusión de escafoides y lunato (Thorington y Darrow, 2000)

La escasa variabilidad interespecífica observada en el carpo de las especies de Ctenomys estudiadas en este trabajo podría ser explicada por la hipótesis de la versatilidad de Vermeij (1973). De acuerdo con esta hipótesis, la diversidad morfológica potencial de una estructura es una función de dos factores: la variación potencial de cada elemento, y la independencia de los mismos. En el caso de estructuras en las cuales hay múltiples elementos que deben funcionar juntos, tales como el carpo, el rango de estados compatibles con un funcionamiento eficaz está restringido. De todas maneras, dado el bajo tamaño muestral y las frecuentemente desfavorables condiciones de preservación de este material esqueletario (cubierto por tendones, ligamentos 
e incluso piel), no se puede descartar la futura detección de posibles diferencias cuantitativas en una muestra mayor.

\section{V.2. Análisis de patrones de especialización morfológica vinculados con la excavación}

Para analizar posibles patrones de especialización excavadora en Ctenomys se exploraron correlaciones entre rasgos especializados de cráneo y poscráneo. En primer lugar se realizaron análisis multivariados independientes de cráneo y miembro anterior, y luego los índices que resultaron significativos se incluyeron en un ACP conjunto. Los patrones detectados son discutidos en el contexto de la subfamilia Ctenomyinae.

\section{2. 1. Patrones de especialización en el miembro anterior}

Se realizó un ACP incluyendo todos los índices funcionales del miembro anterior que mostraron alta carga $(>0,7)$ sobre el primer $\mathrm{CP}$ en cada análisis previo: DEP, LRBV y LRES para la escápula, RHU, DRE, PRD y SDH para el húmero, y RULN, OLR y RRAD para el antebrazo. Los índices morfofuncionales de la mano no se incluyeron en el análisis debido al bajo tamaño muestral de los mismos.

Como en los análisis multivariados previos, las especies se distribuyeron en el morfoespacio de manera continua (Fig. 60). Los resultados muestran que la mayor variación explicada corresponde a los índices que expresan especializaciones del húmero y el antebrazo (CP 1, Tabla 19), mientras que las variaciones morfológicas de la escápula tienen menor valor explicativo, y cargan sobre el CP 2 sin un patrón claro. 


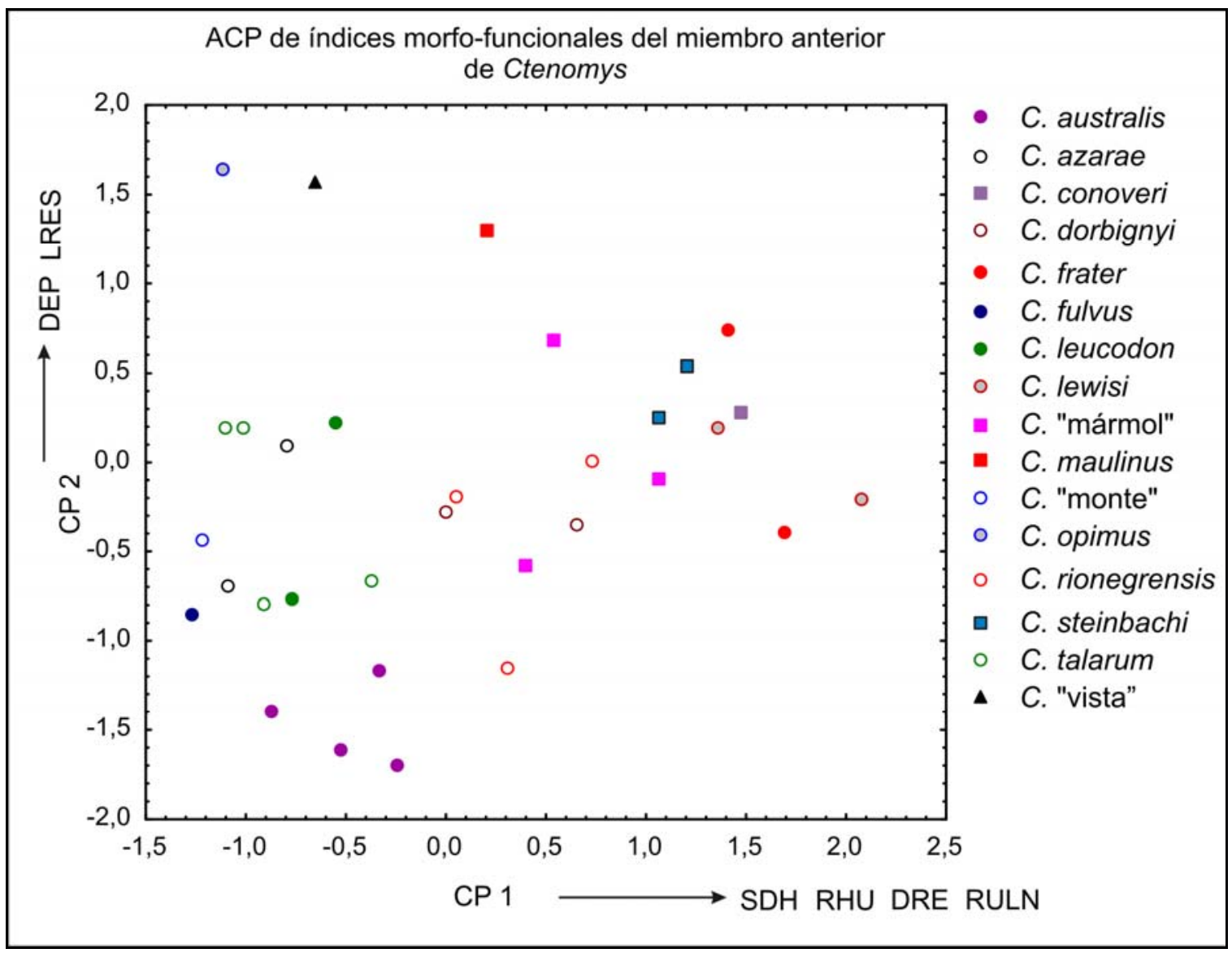

Figura 60. ACP de índices de miembro anterior para especies de Ctenomys.

Tabla 19. Correlaciones Factor-Variable (factor loadings) y porcentaje de variación explicada para los 2 primeros Componentes Principales del ACP de Fig. 60.

\begin{tabular}{cll}
\hline Índice & CP 1 & CP 2 \\
\hline DEP & $-0,19$ & $\mathbf{0 , 6 8}$ \\
\hline LRBV & $-0,24$ & 0,49 \\
\hline LRES & $-0,26$ & $\mathbf{0 , 8 4}$ \\
\hline RHU & $\mathbf{0 , 6 2}$ & 0,29 \\
\hline DRE & $\mathbf{0 , 7 9}$ & $-0,07$ \\
\hline PRD & 0,54 & 0,43 \\
\hline SDH & $\mathbf{0 , 6 8}$ & $-0,31$ \\
\hline RULN & $\mathbf{0 , 7 7}$ & $-0,08$ \\
\hline OLR & 0,59 & 0,43 \\
\hline RRAD & 0,24 & 0,54 \\
\hline Autovalor & 2,92 & 2,25 \\
\hline $\begin{array}{c}\text { \% variación } \\
\text { explicada }\end{array}$ & 29,17 & 22,53 \\
\hline $\begin{array}{c}\text { \% } \\
\text { acumulativo }\end{array}$ & 29,17 & 51,70 \\
\hline
\end{tabular}


En primer lugar, el valor explicativo general de este análisis es menor que el del ACP realizado con cada hueso, lo cual sugiere un acoplamiento relativamente bajo entre las especializaciones esqueletarias de cada elemento del miembro anterior. Los índices escapulares que cargaron sobre el CP 2 presentaron muy baja correlación con respecto a los otros índices evaluados y no marcaron ningún patrón claro de separación o agrupamiento de especies.

En todos los mamíferos fosoriales, el miembro anterior tiene gran ventaja mecánica (Hildebrand, 1985), es decir que las proporciones existentes entre sus componentes enfatizan la producción de fuerzas de extensión más que la velocidad del movimiento (Maynard-Smith y Savage, 1956; Polly, 2007). Los huesos del miembro anterior de los braquioexcavadores tienden a ser relativamente cortos y robustos (Hildebrand, 1985; Price, 1993), lo cual se refleja en la carga significativa de la robustez del húmero (RHU) y de la ulna (RULN) en el CP 1. Coincidentemente, Elissamburu y Vizcaíno (2004) y Samuels y Van Valkenburgh (2008) hallaron correlación positiva entre valores altos de ancho de epicóndilos (DRE), robustez humeral (RHU) y robustez de la ulna (RULN) en un análisis de roedores fosoriales; sin embargo, estos autores también encontraron una correlación positiva entre estos índices y el mayor desarrollo del olécranon (OLR) más elevada que la observada en este estudio (Tabla 19). En el mismo sentido, Lessa et al. (2008) también hallaron correlación significativa entre índices morfo-funcionales del húmero y la ulna (correlación positiva entre OLR y DRE, OLR y PRD).

\section{V.2.2. Patrones de especialización en el cráneo}

Como se indicó previamente (ver III. Antecedentes), las especializaciones morfológicas en el cráneo de roedores excavadores, y en particular de Ctenomys, se encuentran bien estudiadas. En este apartado se discuten los resultados de los análisis disponibles; posteriormente se aplica un modelo morfo-funcional reciente para seleccionar las variables del cráneo 
consideradas mejores indicadores de hábitos dentoexcavadores, las cuales luego son incluidas en un modelo más amplio de contrastación de especializaciones craneanas y del miembro anterior.

La particular morfología del cráneo de los roedores dentoexcavadores ha sido estudiada en considerable profundidad, y las completas síntesis de Dubost (1968), Hildebrand (1985), Lessa (1990, 1993, 2000), Nevo (1979, 1999) y Stein (2000) describen las especializaciones morfológicas presentes en estos grupos. De acuerdo con estos autores, el cráneo de los roedores dentoexcavadores presenta modificaciones vinculadas con el requerimiento de producción de elevadas fuerzas externas (Fo) para penetrar y remover el sustrato usando los incisivos. Estas modificaciones incluyen tanto el desarrollo de grandes áreas para la unión de los músculos involucrados en el cavado, como la estabilización de las articulaciones y la mayor resistencia de las herramientas de cavado a las fuerzas de tensión y compresión: incisivos grandes, fuertes y procumbentes, con elevadas tasas de crecimiento especialmente en los incisivos inferiores; cráneo relativamente grande, con rostro fuerte; forámenes palatinos pequeños; arcos zigomáticos fuertes y generalmente salientes; crestas sagital y nucal bien desarrolladas, correlacionadas con músculos cervicales fuertes, y mandíbula más corta y alta.

De acuerdo con lo anterior, algunos rasgos presentes en el cráneo de Ctenomys, por ejemplo arcadas zigomáticas fuertes y salientes, mandíbula alta con cresta masetérica muy saliente, incisivos de implantación profunda y con procumbencia moderada a alta, forámenes incisivos e interpremaxilar reducidos (Reig et al., 1990; Vassallo, 1998; Verzi, 2002; Mora et al., 2003; Verzi y Olivares, 2006), son especializaciones universales entre los roedores subterráneos.

Las especies de Ctenomys muestran diferencias en las especializaciones morfológicas descriptas, relacionadas con la capacidad para utilizar los incisivos en la construcción de túneles (Lessa, 1993; Vassallo, 1998; Mora et al., 
2003). La diversidad interespecífica de Ctenomys tanto en el grado de fosorialidad y de actividad en superficie (Pearson, 1984; Lessa, 1993), como en su variación morfológica y las diferentes combinaciones de rasgos especializados en diferentes especies (Lessa, 1993), se ha reconocido desde hace tiempo. A partir de este reconocimiento, la diversidad morfológica interespecífica de Ctenomys ha sido explorada en numerosos trabajos, incluyendo análisis enfocados en las especializaciones craneanas para la dentoexcavación (Vassallo, 1998; Mora et al., 2003; Verzi y Olivares, 2006). Vassallo (1998) analizó las especializaciones cráneo-dentarias para la dentoexcavación de C. talarum y C. australis. Este autor encontró, dentro de la morfología típica del género, diferencias en el grado de procumbencia de los incisivos superiores (mayor en C. talarum que en C. australis), las cuales no estuvieron asociadas a diferencias interespecíficas en el largo de la diastema ni en la ubicación de las raíces de los incisivos.

Mora et al. (2003) analizaron la versatilidad morfológica de 23 especies de Ctenomys, teniendo en cuenta la procumbencia y numerosas medidas craneanas. Los resultados del análisis de estos autores mostraron que la procumbencia es independiente del tamaño corporal, y sugirieron que la alta variabilidad de este rasgo es explicada por el diseño estructural del cráneo de Ctenomys, y, en menor medida, por fenómenos de alometría. Mientras que en especies no procumbentes como $C$. australis la raíz de los incisivos se ubica entre el premolar y los molares, en las procumbentes como C. leucodon la misma se halla entre el M1 y M2 (Mora et al., 2003). Estos autores señalan que este desplazamiento es posible porque las vainas de las raíces de los incisivos son laterales con respecto a aquellas de los molariformes, por lo cual su posición puede cambiar libremente en relación con los cambios en la curvatura de los incisivos (Lessa, 1990). Aternativamente, Verzi (2008) sugirió que la implantación de los incisivos superiores de Ctenomys presenta una especialización particular vinculada con la dentoexcavación, ya que el fondo de la vaina alveolar está alojado en una cavidad del maxilar, por delante de la 
vaina alveolar del M1. Esta disposición protege a la zona generativa basal del incisivo, que puede resultar dañada por las grandes presiones ejercidas a nivel de la punta de los incisivos en especies dentoexcavadoras (Zuri y Terkel, 2001). Aun en C. leucodon, la base del I1 se dispone en la cavidad por delante de la vaina alveolar del M1 descripta por Verzi (2008).

Mora et al. (2003) detectaron, además, alometría positiva del ancho y espesor de los incisivos en Ctenomys, lo cual le permitiría resistir mayores fuerzas de tensión y compresión (no únicamente para atacar el sustrato, que puede ser friable, sino también raíces y otros materiales vegetales fibrosos). En síntesis, los resultados de Mora et al. (2003) apoyan las observaciones previas de que las especies de Ctenomys difieren en su capacidad para utilizar los incisivos en el cavado (Lessa, 1993).

Recientemente, Verzi y Olivares (2006) describieron la especialización a nivel de la fosa postglenoidea presente en Ctenomys y †Eucelophorus; ésta es exclusiva del clado y parcialmente convergente con modificaciones similares presentes en roedores dentoexcavadores de otros continentes (Verzi y Olivares, 2006; Verzi, 2008). Esta región de articulación postglenoidea está delimitada dorsalmente por la fosa postglenoidea y ventralmente por el meato auditivo externo (tubo horizontal prominente); por su parte, el proceso postcondíleo de la mandíbula de Ctenomys presenta una fuerte apófisis lateral que está relacionada funcionalmente con esta zona articular postglenoidea. Funcionalmente, esta región postglenoidea representa una tercera posición mandibular que estabiliza la articulación, evitando la dislocación del cóndilo cuando se ejercen fuerzas en el extremo de los incisivos durante el ataque al sustrato $\mathrm{u}$ obstáculos duros. Utilizando índices morfo-funcionales en un análisis multivariado, estos autores hallaron un eje de diferenciación morfológica en el cual las especies con especializaciones morfológicas dentoexcavadoras fuertes y moderadas, asociadas al desarrollo del área articular postglenoidea, se ubicaron en extremos opuestos. Este eje estuvo dado por diferencias en largo del cóndilo, procumbencia de los incisivos 
superiores, ancho de la fosa postglenoidea, concavidad del meato auditivo externo, grosor de la apófisis paraoccipital, desarrollo del proceso postcondíleo, profundidad de la región articular postglenoidea, ancho de la bula auditiva y profundidad de implantación del i1. Por el contrario, el ancho mandibular y el largo del diastema, dos rasgos considerados significativos dentro de las especializaciones dentoexcavadoras de roedores en general, no influyeron en esta discriminación morfo-funcional. Estos resultados también sugieren que la posición de la base de los incisivos está más estrechamente ligada a la frecuencia de uso de los incisivos, y es por lo tanto mejor indicador de dentoexcavación, que la procumbencia. Sobre la base de estos resultados, Verzi y Olivares (2006) describieron dos morfotipos que responden a diferente grado de especialización morfológica para la dentoexcavación. En estos morfotipos, la morfología más especializada de la región postglenoidea está asociada con otras típicas especializaciones para la dentoexcavación: mayor procumbencia de los incisivos superiores, inserción más profunda de los incisivos inferiores, además de una apófisis paraoccipital más grande formando una cresta occipital y menor altura de la bula a nivel anterior. Estos dos últimos rasgos se relacionan con requerimientos y restricciones biomecánicas. La fuerte cresta en la apófisis paraoccipital es el sitio de origen del vientre posterior del m. digastricus (Woods, 1972; De Santis et al., 1998), que también interviene en el movimiento de ataque al sustrato mediante los incisivos; por su parte, el ancho de las bulas restringe el ángulo de apertura de la boca cuando el cóndilo se halla en la fosa postcondílea, de manera que bulas más angostas resultan ventajosas en especies con mayor especialización dentoexcavadora (Verzi y Olivares, 2006; Verzi, 2008). 
Análisis multivariado de índices morfo-funcionales cráneo-dentarios (Fig. 61, Tabla 20)

Las especializaciones dentoexcavadoras de las especies de Ctenomys estudiadas en este trabajo se analizaron mediante un ACP de las variables morfo-funcionales propuestas por Verzi y Olivares (2006).

Los dos primeros CP resumieron el 53,77 \% de la variación explicada. El CP 1 (38,92\% de la variación) resumió los cambios morfológicos a lo largo de un eje de especialización vinculado con la procumbencia, el ancho de la apófisis poscondílea, la implantación del incisivo inferior, el ancho de la fosa postglenoidea, la concavidad del meato auditivo externo, y el alto de la bula. El CP 2 (14,85\% de la variación) resumió los cambios en la longitud del cóndilo y el desarrollo del proceso paraoccipital. A pesar de algunas diferencias en la carga de las variables, el patrón de distribución de las especies sobre el primer eje resultó similar al detectado por Verzi y Olivares (2006), con C. leucodon, C. "perucho", C. "vista" y C. lewisi, en un extremo de mayor especialización, y C. fulvus, C. flamarioni, C. azarae y C. opimus en el otro extremo, mientras que las demás especies se distribuyeron en el morfoespacio intermedio. 


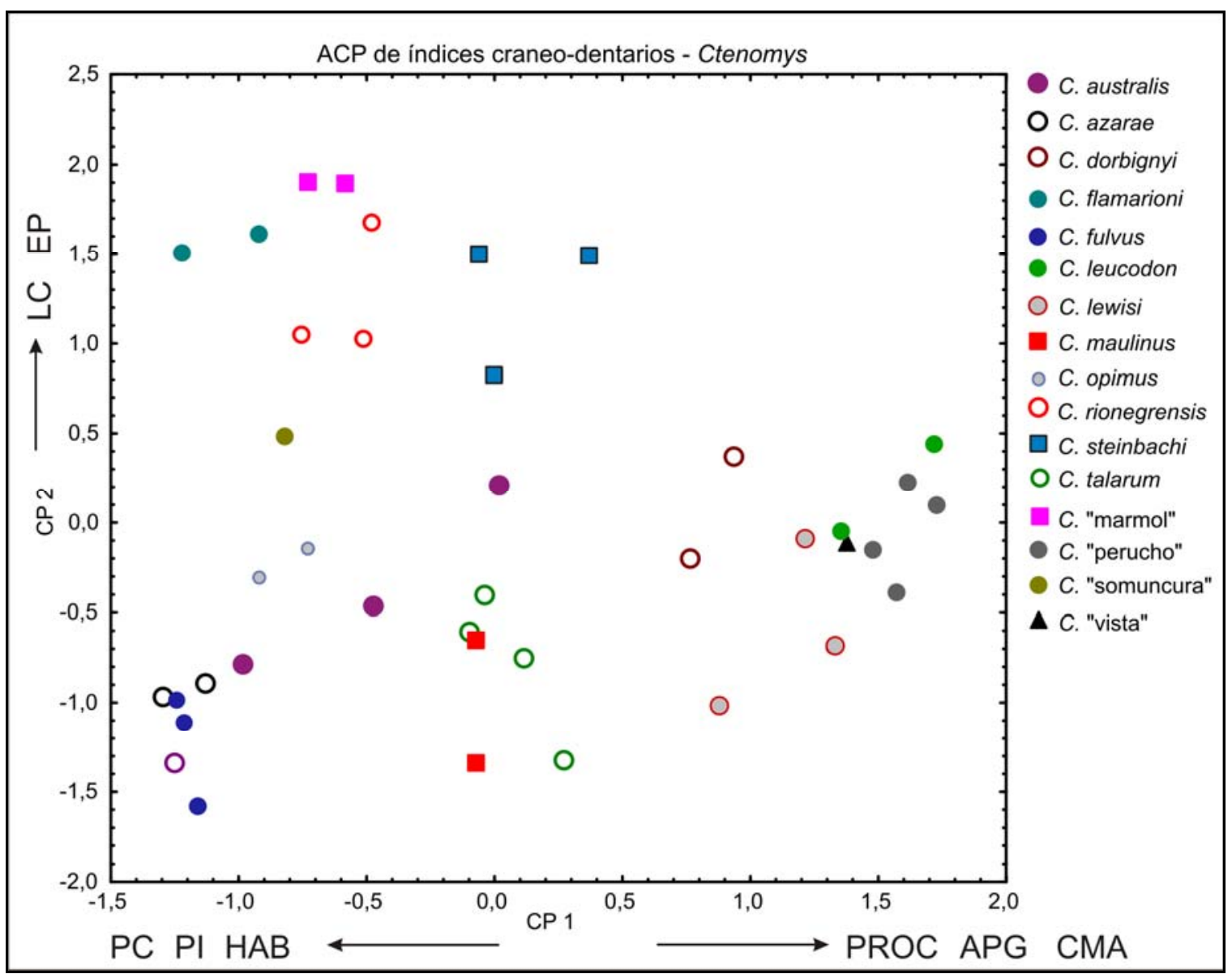

Figura 61. ACP de índices morfo-funcionales de cráneo vinculados con la especialización dentoexcavadora en especies de Ctenomys.

Tabla 20. Correlaciones Factor-Variable (factor loadings) y porcentaje de variación explicada para los 2 primeros Componentes Principales del ACP de Fig. 61.

\begin{tabular}{cll}
\hline Índice & CP 1 & CP 2 \\
\hline PROC & $\mathbf{0 , 8 5}$ & $-0,06$ \\
\hline AB & $-0,07$ & $-0,23$ \\
\hline AMD & $-0,38$ & 0,12 \\
\hline LC & 0,35 & $\mathbf{0 , 6 2}$ \\
\hline DIAST & 0,28 & $-0,49$ \\
\hline PC & $\mathbf{- 0 , 8 4}$ & 0,31 \\
\hline PI & $\mathbf{- 0 , 9 1}$ & 0,21 \\
\hline APG & $\mathbf{0 , 6 2}$ & 0,45 \\
\hline CMA & $\mathbf{0 , 6 6}$ & $-0,27$ \\
\hline HPG & $-0,57$ & $-0,45$ \\
\hline HAB & $\mathbf{- 0 , 8 3}$ & 0,25 \\
\hline EP & 0,46 & $\mathbf{0 , 6 5}$ \\
\hline autovalor & 4,66 & 1,78 \\
\hline $\begin{array}{c}\text { \% variación } \\
\text { explicada }\end{array}$ & 38,92 & 14,85 \\
\hline & & \\
\hline
\end{tabular}




\begin{tabular}{lll}
\hline$\%$ acumulativo & 38,92 & 53,77 \\
\hline
\end{tabular}

\section{V.2.3. Análisis multivariado de especializaciones craneanas y del} miembro anterior (Fig. 62, Tabla 21)

Sobre la base de los resultados obtenidos en los análisis independientes de cráneo y miembro anterior, el ACP de especializaciones de ambos componentes esqueletarios solamente incluyó los índices que mostraron carga elevada en el primer CP de los análisis originales (ver Tablas 3, 9 y 13). Para poder incluir la mayor cantidad de individuos posibles, los datos ausentes se reemplazaron por el valor promedio para cada variable (Legendre y Legendre, 1998); aunque este procedimiento reduce en cierta medida la precisión del resultado, el foco del análisis fue obtener una perspectiva general del patrón morfo-funcional en las especies analizadas.

Los dos primeros CP explicaron 62,95 \% de la variación. Mientras que el CP 1 resumió principalmente la influencia de los índices PROC, PC, PI y $\mathrm{HAB}$, con contribución menor de APG, la variación en el CP 2 corresponde a los índices DRE y SDH, con contribuciones algo menores de RHU y RULN. De esta manera, el CP 1 resume la especialización morfológica dentoexcavadora (mayor especialización en el extremo negativo del eje), mientras que el CP 2 resume principalmente especializaciones braquioexcavadoras (mayor especialización hacia el extremo negativo). Tal como muestra la Fig. 62, si bien muchas de las especies analizadas se agruparon en los valores medios, las especies que ocupan las posiciones extremas del morfoespacio representan diferentes combinaciones de especialización braquio- y dentoexcavadora. 


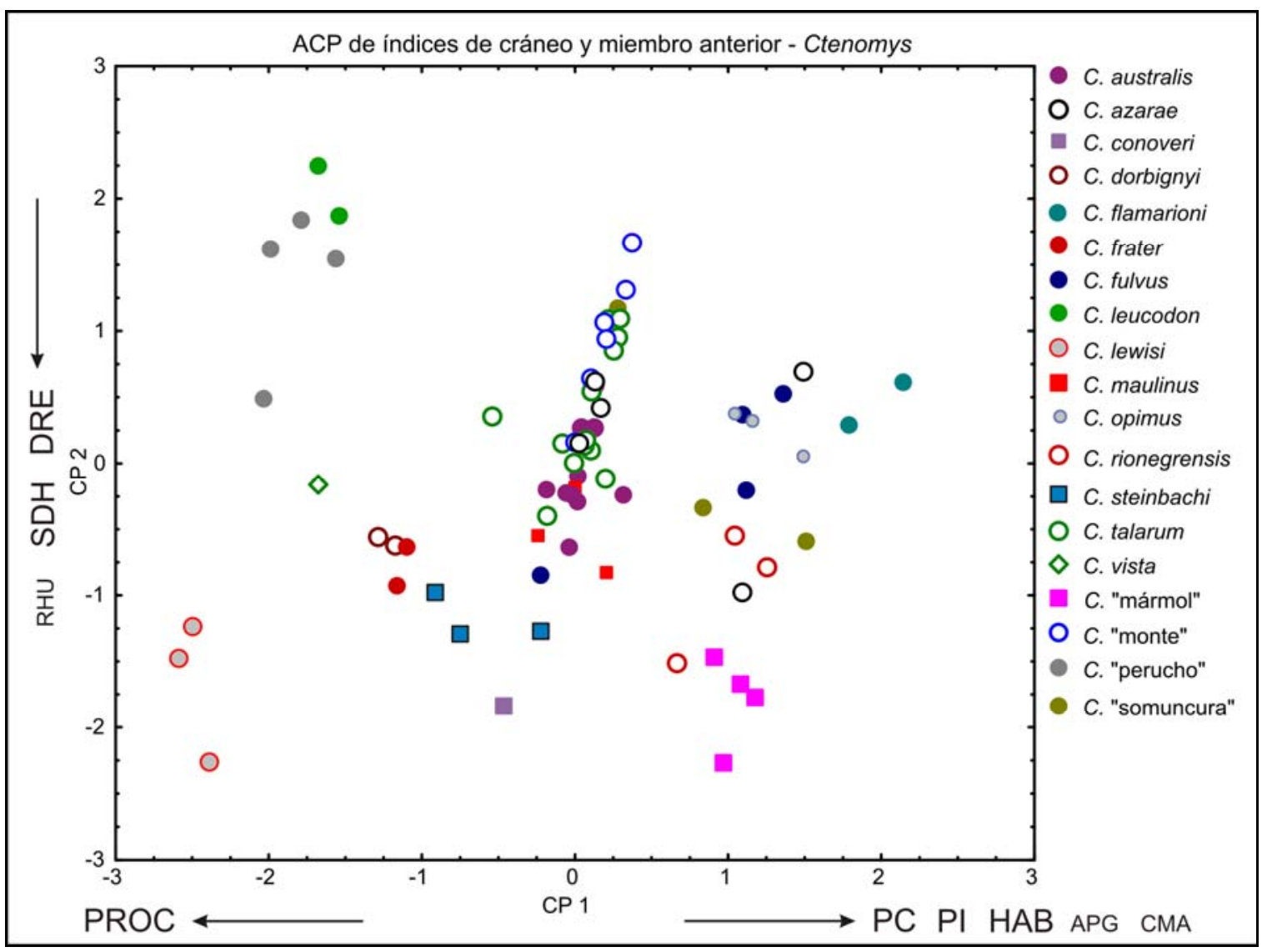

Figura 62. ACP de índices morfo-funcionales de cráneo y poscráneo en especies de Ctenomys. Las abreviaturas de menor tamaño indican índices con carga menor sobre cada CP.

Tabla 21. Correlaciones Factor-Variable (factor loadings) y porcentaje de variación explicada para los 2 primeros Componentes Principales del ACP de Fig. 62.

\begin{tabular}{ccc}
\hline Índice & CP 1 & CP 2 \\
\hline RHU & $-0,32$ & $-0,57$ \\
\hline DRE & $-0,30$ & $-0,82$ \\
\hline SDH & $-0,31$ & $-0,72$ \\
\hline RULN & $-0,43$ & $-0,49$ \\
\hline PROC & $-0,88$ & 0,16 \\
\hline PC & 0,82 & $-0,33$ \\
\hline PI & 0,92 & $-0,25$ \\
\hline APG & $-0,65$ & $-0,20$ \\
\hline CMA & $-0,57$ & 0,17 \\
\hline HAB & 0,84 & $-0,29$ \\
\hline autovalor & 4,19 & 2,10 \\
\hline \% variación explicada & 41,93 & 21,03 \\
\hline \% acumulativo & 41,93 & 62,95 \\
\hline
\end{tabular}


Como se mostró en el apartado anterior, el ACP de variables craneanas mostró ordenamiento de las especies a lo largo de un eje, cuyos extremos opuestos fueron considerados por Verzi y Olivares (2006) como dos morfotipos definidos por su grado de especialización dentoexcavadora. Estos autores caracterizaron un morfotipo "C. dorbignyi" con mayor concavidad del meato auditivo (CMA), mayor desarrollo de la fosa postglenoidea (APG) y del largo del cóndilo (LC), así como un menor desarrollo del proceso postcondíleo (PC) y del ancho dorsoventral de la región articular postglenoidea (HPG), asociadas con una mayor procumbencia de los incisivos superiores (PROC) e implantación más profunda de los incisivos inferiores (PI) (rasgos típicos de los roedores dentoexcavadores), mayor desarrollo de las apófisis paraoccipitales (EP) y menor altura de la bula a nivel anterior (HAB). Este morfotipo incluyó a las especies C. dorbignyi, C. leucodon, C. lewisi, C. tucumanus, C. "vista" y C. "perucho". Por su parte, las especies del menos especializado morfotipo "C. fulvus", (C. fulvus, C. australis, C. azarae y C. opimus) mostraron mayor desarrollo del proceso postcondíleo (PC), y área articular postglenoidea más amplia (HPG), junto con menores valores de los índices CMA, APG, LC, PROC, PI y EP, y una bula más inflada (mayor HAB). Las otras especies analizadas por estos autores, C. maulinus, C. steinbachi y C. talarum, ocuparon una posición intermedia en el CP 1.

En el presente análisis, la distribución de especies en este morfoespacio revela un panorama más complejo en cuanto a la especialización morfológica para la excavación en las especies de Ctenomys, sugiriendo la existencia de morfotipos con diverso grado de especialización dento- y braquioexcavadora. De esta manera, estos resultados complementan aquellos obtenidos por Verzi y Olivares (2006), permitiendo distinguir cuatro extremos en el continuo de especializaciones morfológicas para la braquio- y dentoexcavación (Tabla 22, Fig. 63). La mayoría de las especies estudiadas ocupan el morfoespacio central en una gradación continua, ya que presentan especializaciones heterogéneas en diferentes rasgos y sus valores para los diferentes índices son, en general, 
cercanos al promedio. Por otra parte, las especies con mayores especializaciones en uno $\mathrm{u}$ otro sentido (enumeradas en la Tabla 22), que representan los extremos del continuo de disparidad morfológica de Ctenomys, pueden ser consideradas como morfotipos: morfotipo lewisi, morfotipo "perucho'", morfotipo "mármol"” y morfotipo flamarioni.

Tabla 22. Especies de Ctenomys clasificadas de acuerdo con su grado de especialización morfológica.

\begin{tabular}{|l|l|l|}
\hline $\begin{array}{l}\text { Gradiente de } \\
\text { especialización } \\
\text { morfológica }\end{array}$ & Dentoexcavación (+) & Dentoexcavación (-) \\
\hline $\begin{array}{l}\text { Braquioexcavación } \\
\mathbf{( + )}\end{array}$ & $\begin{array}{l}\text { C. lewisi, C. conoveri, C. C. } \\
\text { frater, C. dorbignyi, C. C. } \\
\text { steinbachi }\end{array}$ & Cármol", C. rionegrensis \\
\hline $\begin{array}{l}\text { Braquioexcavación } \\
(-)\end{array}$ & C. "perucho", C. leucodon & $\begin{array}{l}\text { C. flamarioni, C. fulvus, C. } \\
\text { opimus, †C. chapalmalensis }\end{array}$ \\
\hline
\end{tabular}

Las características esqueletarias morfo-funcionales de estos morfotipos son las siguientes:

Morfotipo lewisi - especies con rasgos especializados tanto a nivel craneano (dentoexcavación) como en el miembro anterior (braquioexcavación). En la morfología craneana corresponden al "morfotipo C. dorbignyi" de Verzi y Olivares (2006). A nivel poscraneano, presentan escápula relativamente alongada (borde axilar largo), con proceso teres major de base larga, tipo "talarum", y fosa glenoidea alongada dorsoventralmente. El húmero es robusto, con cresta deltoidea fuerte y distalizada, epicóndilos salientes, tróclea profunda y amplia; huesos del antebrazo robustos y olécranon relativamente largo.

Morfotipo flamarioni - especies con escasas especializaciones relacionadas con la excavación tanto en el cráneo ("morfotipo C. fulvus" de Verzi y Olivares, 2006) como en el miembro anterior. Escápula alta y corta, 
proceso teres major tipo "rionegrensis", húmero relativamente grácil con cresta deltoidea delgada y ubicada más cerca de la cabeza humeral, y escaso ensanchamiento en los epicóndilos; ulna con diáfisis recta y olécranon más corto. Aunque por la naturaleza fragmentaria de los materiales $† C$. chapalmalensis no fue incluido en los análisis multivariados, su pertenencia a este morfotipo es clara de acuerdo a la evaluación cualitativa de sus rasgos.

Morfotipo "mármol" - especies con miembro anterior especializado para el cavado (ver arriba), pero sin especializaciones craneanas importantes para la dentoexcavación ("morfotipo C. fulvus" de Verzi y Olivares, 2006).

Morfotipo "perucho" - especies con marcadas especializaciones craneanas para la dentoexcavación ("morfotipo C. dorbignyi" de Verzi y Olivares, 2006), pero con miembro anterior relativamente poco especializado (ver arriba).

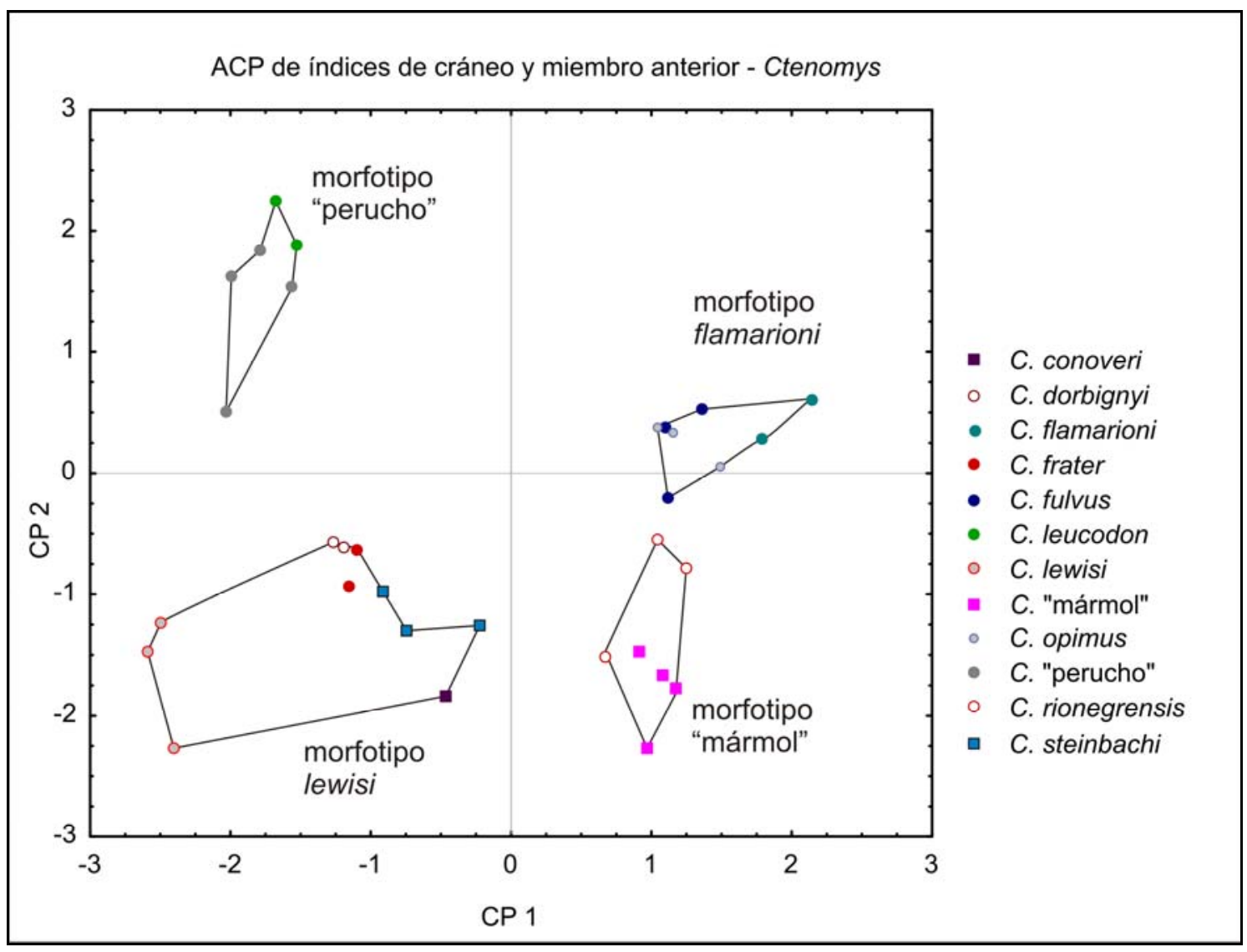


Figura 63 (página anterior). Distribución de los morfotipos en el morfoespacio de los dos primeros $\mathrm{CP}$ del análisis de índices morfo-funcionales de cráneo y miembro anterior (el ACP es el mismo que en la Fig. 62).

\section{V.2.4. Patrón de especialización de Ctenomys en el contexto de la subfamilia Ctenomyinae}

En la Fig. 64 se muestra de modo resumido el patrón de especialización de Ctenomys en el contexto de la subfamilia Ctenomyinae.

En la subfamilia Ctenomyinae se registra disparidad morfológica desde el Plioceno, asociada con diferentes grados de adaptación al hábito subterráneo y la especialización excavadora en los cuatro linajes reconocidos dentro del clado (Reig y Quintana, 1992; Lessa, 1993; Fernández et al., 2000; Verzi, 2002). La información disponible acerca de la especialización morfológica de los diferentes géneros (Reig y Quintana, 1992; Quintana, 1994; De Santis y Moreira, 2000; Fernández et al., 2000; Vieytes et al., 2007; Verzi y Olivares, 2006; Verzi, 2008), junto con la resultados obtenidos en este trabajo, permiten obtener una perspectiva más completa del patrón de especialización dento- y braquioexcavadora dentro de la subfamilia.

En el clado †Xenodontomys- $\nmid$ Actenomys no hay especializaciones dentoexcavadoras; por otra parte, los materiales disponibles de miembro anterior, correspondientes a $\nmid$ Actenomys, indican especialización morfológica braquioexcavadora bastante menor que la de Ctenomys y comparable a la de los octodontinos, lo cual ha llevado a interpretar este género como una forma fosorial (Fernández et al., 2000; Verzi, 2002, 2008). De todas maneras, incluso una especialización morfológica relativamente menor en el miembro anterior podría estar asociada a una actividad braquioexcavadora significativa (Lessa et al., 2008), en concordancia con los sistemas de cuevas conocidos para este ctenomino (Genise, 1989).

Las especializaciones cráneo-dentarias vinculadas con la dentoexcavación presentes en los linajes de †Eucelophorus, †Praectenomys, y Ctenomys son numerosas (ver V.2.2. Patrones de especialización en el cráneo). 
†Eucelophorus es el más especializado dentoexcavador dentro de los roedores sudamericanos (Verzi y Olivares, 2006); presenta profundas fosas y fuertes crestas craneanas para la sujeción de la poderosa musculatura masetérica, así como los incisivos más procumbentes entre los caviomorfos (Reig y Quintana, 1992; Mora et al., 2003), y microestructura del esmalte especializada (Vieytes et al., 2007). Además, el tamaño relativamente pequeño de la órbita indica hábito subterráneo para este taxón (Verzi, 2008). Con respecto al miembro anterior, los nuevos materiales examinados muestran que la especialización braquioexcavadora de †Eucelophorus era similar a la de las especies vivientes de Ctenomys, pero menor que la de los miembros más especializados de este último género (húmero robusto con cresta deltoidea fuerte y muy distalizada, epicóndilos expandidos aunque no tanto como los Ctenomys vivientes más especializados, carpo similar al de Ctenomys pero metacarpianos algo menos robustos y no ensanchados distalmente).

En †Praectenomys, el grupo hermano de Ctenomys, se encuentran algunos rasgos que sugieren especialización dentoexcavadora, pero los materiales craneanos conocidos son incompletos (Verzi, 2002, 2008). Los fragmentarios restos poscraneanos sugieren especialización morfológica braquioexcavadora menor que la de Ctenomys (húmero relativamente grácil, cresta deltoidea más proximal, menor expansión de epicóndilos; aunque el metacarpiano III es robusto y su morfología es similar a la de Ctenomys); todo esto conduce a asignar tentativamente a esta especie un hábito al menos fosorial (Verzi, 2008). 


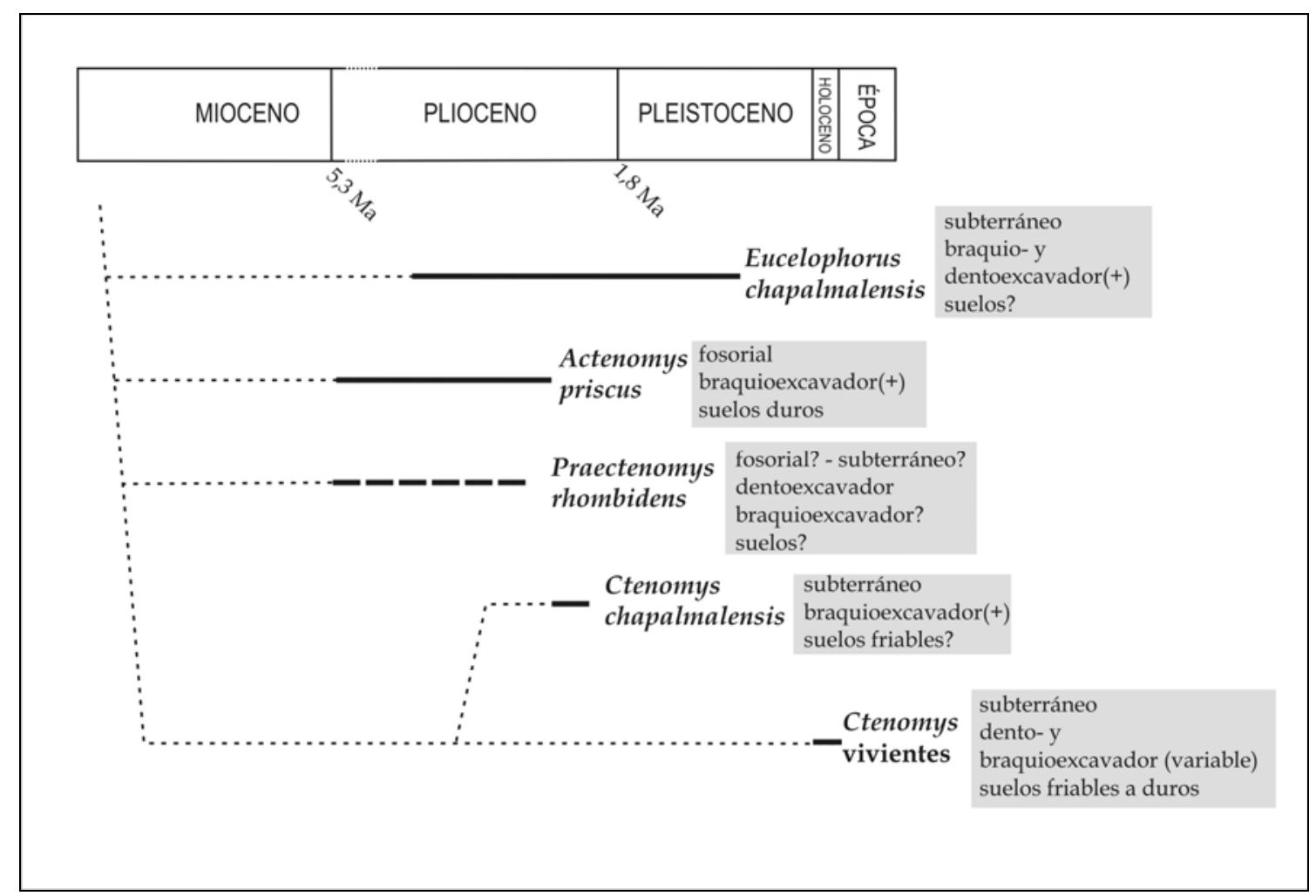

Figura 64. Hábitos conocidos o inferidos, modalidad de excavación y tipo de suelos ocupados por los ctenominos analizados en este trabajo (ver fuentes en el texto). Relaciones filogenéticas (líneas punteadas) y biocrones (líneas sólidas) según Verzi (2008). El signo (+) indica modalidad excavadora predominante. Modificado de Vieytes et al. (2007).

\section{V.3. Grados de variabilidad en cráneo y miembro anterior}

Investigaciones previas han sugerido que la diversidad de funciones cumplidas por las partes del cuerpo utilizadas como herramientas de cavado imponen restricciones a la especialización para este fin, ya que el desempeño de distintas funciones implica requerimientos biomecánicos que podrían entrar en conflicto (Lessa, 1990). A la vez, el grado de integración, especialización y compromiso entre las partes que cumplen determinadas funciones puede ser diferente para distintas regiones del organismo. La existencia de fuerte integración ontogenética y funcional podría implicar niveles de restricción más intensos ya que existe menor cantidad de partes que puedan cambiar independientemente (Vermeij, 1973; Lauder, 1981; Liem, 1987; Zelditch, 1996). 
En un estudio en geómidos, Lessa y Stein (1992) propusieron que en el cráneo la especialización dentoexcavadora está restringida por la necesidad de una masticación efectiva (Lessa, 1990); por el contrario, a nivel del poscráneo, sugirieron que la especialización braquioexcavadora del miembro anterior estaría menos restringida por otras funciones, tales como la locomoción y la manipulación del alimento.

La comparación de coeficientes de variación entre diferentes elementos estructurales permite estimar la variabilidad relativa de los mismos (Cullinane, 2000), la cual es uno de los componentes de la versatilidad evolutiva (recíproco de la restricción; Lauder, 2000). Los resultados de este trabajo muestran valores más altos de Coeficiente de Variación (CV) para las variables craneanas con respecto a las del miembro anterior (Fig. 65 y 66), pero las diferencias entre la variabilidad de cráneo y miembro anterior no resultaron significativas (test $\mathrm{T}, \mathrm{df}=38, \mathrm{t}=0,72 ; \mathrm{p}=0,47$ ).

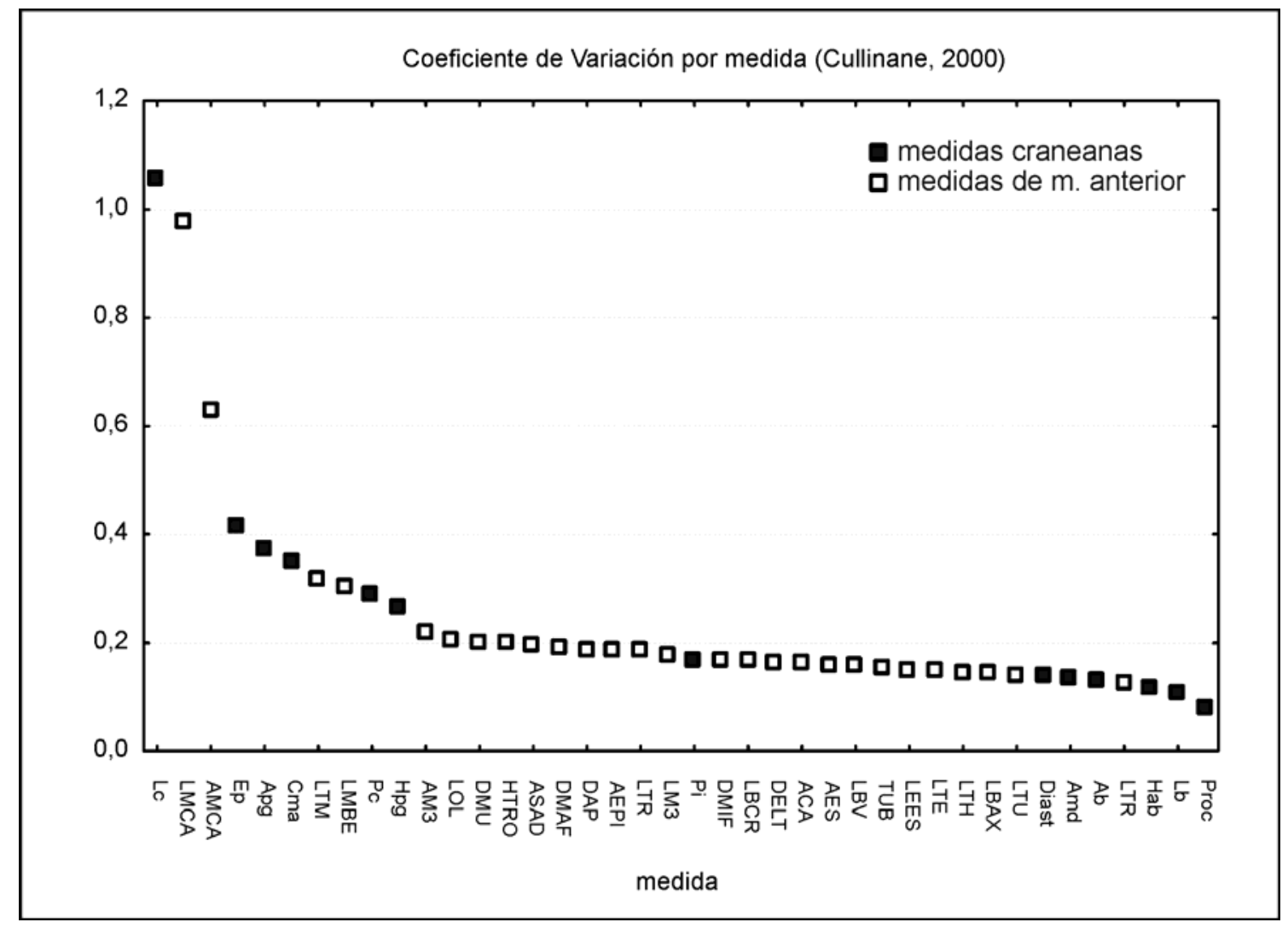

Figura 65. Coeficientes de variación (CV) para las medidas utilizadas en este trabajo. 


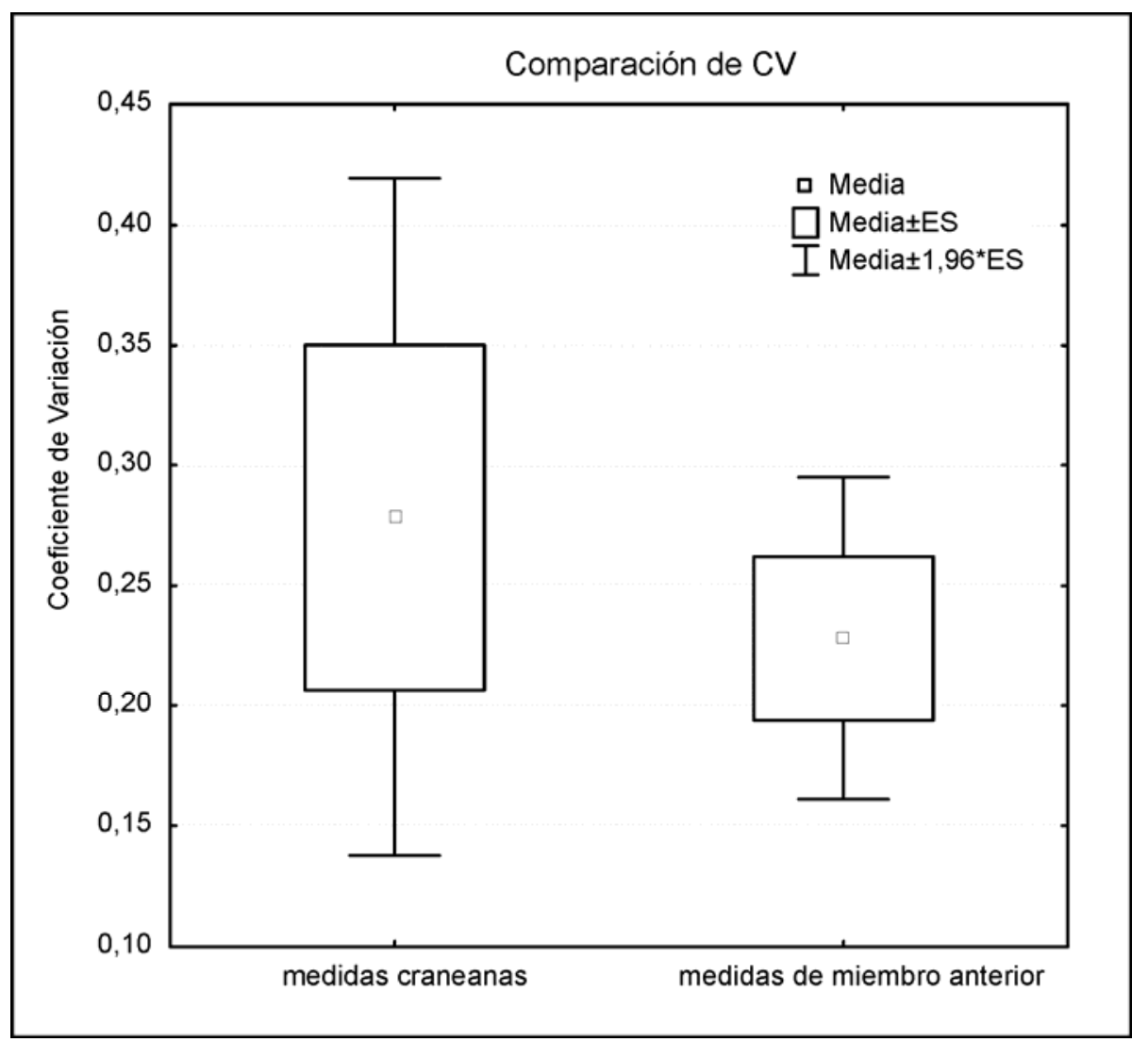

Figura 66. Comparación de CV promedio para medidas craneanas y del miembro anterior.

\section{V.4. Análisis filogenético comparativo}

Las relaciones entre los índices morfo-funcionales craneanos y poscraneanos se evaluaron sobre la base de análisis de correlación, usando contrastes filogenéticamente independientes (CI, Felsenstein, 1985). El método de CI requiere el uso de filogenias completamente resueltas, lo cual resultó problemático en este estudio. Por un lado, no existen propuestas filogenéticas que incluyan a todas las especies de Ctenomys; por otra parte, en este trabajo se analizaron varias especies no descriptas formalmente (C. "monte", $C$. "palmar", C. "perucho", C. "somuncurá", C. "vista"), cuya posición filogenética dentro del género se desconoce. Estas especies fueron agregadas a la politomía basal en un esquema filogenético de consenso elaborado sobre la base de las propuestas de Castillo et al. (2005). Existen diferentes propuestas 
para el abordaje de politomías en filogenias inciertas; aquí se optó por resolver las politomías en forma aleatoria, ya que estudios previos (Ackerly y Donoghue, 1998; Ackerly y Reich, 1999) han mostrado que los resultados de análisis de correlación son muy similares para todos los árboles filogenéticos alternativos derivados de la resolución aleatoria de politomías; esto sugirie que esta resolución aleatoria es mejor que tratar a cada politomía como un contraste único (procedimiento sugerido por Harvey y Pagel, 1991, y Pagel, 1992), dado que lo último genera una rápida pérdida de grados de libertad y poder del análisis.

Para disminuir la incertidumbre introducida por la resolución aleatoria de estas politomías, algunas especies de Ctenomys no fueron incluidas en el análisis. Los criterios usados para descartar especies fueron los siguientes: 1) especies con gran cantidad de datos faltantes debidos a falta de material, y 2) especies con posición filogenética incierta. De este modo, las especies $C$. conoveri, C. "monte", C. "somuncurá" y C. "palmar" no fueron incluidas en el análisis de CI. Una vez reducida la cantidad de especies, las politomías se resolvieron introduciendo ramas de largo cero en forma aleatoria usando la función multi2di del paquete 'ape' (Paradis, 2006). Mediante este procedimiento se obtuvieron 100 árboles filogenéticos completamente resueltos que fueron utilizados para calcular los CI. En cada árbol se asignaron largos de rama iguales, ya que trabajos previos han mostrado que los resultados son muy similares sin importar el método usado para realizar este procedimiento (Ackerly y Donoghue, 1998).

Este análisis se enfocó en las correlaciones (y no en regresiones) para evitar la asignación a priori de un valor explicativo (dependiente o independiente) a las variables. Se calcularon los coeficientes de correlación de Pearson para las variables consideradas sin tener en cuenta la filogenia (correlación ahistórica), y estos valores se compararon con las correlaciones de los CI (coeficiente de correspondencia, que mide la correlación entre contrastes o evolutiva), promediadas a partir de los resultados para los 100 
árboles resueltos. El análisis de correlaciones múltiples entre los caracteres estudiados permite explorar la covariación entre rasgos y comparar la integración morfológica relativa de diferentes elementos. Si existen niveles altos de integración morfológica y funcional, el elemento estudiado tiene menor cantidad de partes que pueden cambiar independientemente, lo cual puede restringir la diversidad morfológica potencialmente realizable (Vermeij, 1973; Liem, 1987).

Como resultado del análisis se obtuvieron correlaciones evolutivas con valores generalmente más bajos que los de las correlaciones ahistóricas (Tabla 23), indicando que estas últimas están explicadas al menos parcialmente por la similitud entre especies más estrechamente emparentadas. Los resultados interesantes son aquellos casos en los cuales la correlación se mantuvo, dado que en ausencia de una explicación para estas similitudes basada en el parentesco filogenético, la asociación entre índices morfo-funcionales puede sugerir patrones adaptativos relacionados con la capacidad fosorial.

En este sentido, las correlaciones filogenéticas entre variables morfofuncionales de cráneo y poscráneo disminuyeron considerablemente con respecto a los valores crudos (Tabla 23), pero algunas de las correlaciones entre los diferentes huesos del brazo se mantuvieron, tal como se vio reflejado en el ACP general (ver V.2.3. Análisis multivariado de especializaciones craneanas y del miembro anterior). Esto indica que en las especies estudiadas, la mayor robustez de los huesos largos del brazo (RHU, RRAD, RULN, RMC3) ocurre en forma coincidente, sugiriendo un refuerzo uniforme de la resistencia del miembro anterior. De la misma manera, el desarrollo de los epicóndilos (DRE) resultó correlacionado positivamente no sólo con la robustez del húmero (RHU), sino también con la de la ulna (RULN), en concordancia con la vinculación común de ambos índices con el desarrollo de la musculatura del antebrazo. La correlación positiva entre la amplitud de la superficie articular distal del húmero $(\mathrm{SDH})$ y el desarrollo de los epicóndilos (DRE) es esperable a este nivel de análisis, ya que ambos índices miden 
estructuras ubicadas sobre el extremo distal del húmero; SDH también se correlacionó positivamente con RULN. Asimismo, estos resultados mostraron alta correlación entre la robustez de la ulna y la del metacarpiano III. Por último, la distalización de la cresta deltoidea (PRD) resultó positivamente correlacionada tanto con la robustez de la ulna como con el desarrollo del proceso olecraneano (OLR), a pesar de que estas estructuras no están directamente relacionadas biomecánicamente por medio de músculos.

Por su parte, las correlaciones significativas entre índices craneales se mantuvieron (coef. de correspondencia $>0,69$, ver Tabla 23), sugiriendo que la integración entre los rasgos especializados del cráneo no se debe al efecto de la filogenia.

Tabla 23. Comparación entre las correlaciones entre datos crudos y entre los contrastes independientes (coeficiente de correspondencia). Sólo se incluyen las correlaciones significativas $(\mathrm{p}<0,05)$

\begin{tabular}{ccc}
\hline & $\begin{array}{c}\text { Coeficiente de } \\
\text { correlación (datos } \\
\text { crudos) }\end{array}$ & $\begin{array}{c}\text { Coeficiente de } \\
\text { correspondencia } \\
\text { (media) }\end{array}$ \\
\hline LRBV vs. PROC & $-0,68$ & $-0,30$ \\
\hline LRBV vs. PC & 0,68 & 0,03 \\
\hline RHU vs. DRE & 0,75 & $\mathbf{0 , 6 5}$ \\
\hline RHU vs.RULN & 0,73 & $\mathbf{0 , 6 3}$ \\
\hline RHU vs. RRAD & 0,67 & $\mathbf{0 , 6 0}$ \\
\hline DRE vs. SDH & 0,81 & $\mathbf{0 , 7 7}$ \\
\hline DRE vs. RULN & 0,73 & $\mathbf{0 , 6 8}$ \\
\hline PRD vs. RULN & 0,69 & 0,51 \\
\hline PRD vs. OLR & 0,78 & $\mathbf{0 , 6 3}$ \\
\hline PRD vs. PROC & 0,63 & 0,49 \\
\hline SDH vs. RULN & 0,66 & 0,55 \\
\hline RULN vs. OLR & 0,87 & 0,30 \\
\hline RULN vs. RMC3 & 0,66 & $\mathbf{0 , 6 3}$ \\
\hline RULN vs. PROC & 0,64 & 0,47 \\
\hline RULN vs. APG & 0,87 & 0,50 \\
\hline OLR vs. LC & 0,66 & 0,49 \\
\hline OLR vs. APG & 0,86 & $\mathbf{0 , 6 3}$ \\
\hline RRAD vs. HAB & $-0,64$ & $-0,35$ \\
\hline RMC3 vs. HPG & $-0,76$ & $-0,55$ \\
\hline
\end{tabular}




\begin{tabular}{ccc}
\hline RMC3 vs. EP & 0,75 & 0,52 \\
\hline FCAR vs. AB & 0,68 & 0,17 \\
\hline PROC vs. PC & $-0,89$ & $-0,69$ \\
\hline PROC vs. PI & $-0,95$ & $-0,82$ \\
\hline PROC vs. HAB & $\mathbf{- 0 , 8 1}$ & $-0,72$ \\
\hline PC vs. PI & $\mathbf{0 , 9 0}$ & $\mathbf{0 , 8 9}$ \\
\hline PC vs. HAB & $\mathbf{0 , 7 9}$ & $\mathbf{0 , 7 8}$ \\
\hline PI vs. HAB & $\mathbf{0 , 8 9}$ & $\mathbf{0 , 8 7}$ \\
\hline HPG vs. EP & $\mathbf{- 0 , 7 6}$ & $\mathbf{- 0 , 6 5}$
\end{tabular}

Como se mencionó en Materiales y Métodos (ver IV.6. Métodos filogenéticos comparativos), la "corrección filogenética" proporcionada por los métodos filogenéticos comparativos es un complemento que permite estimar la correlación entre la variación observada y la filogenia. Esto no significa que la correlación vinculada con la filogenia deba descartarse (Westoby et al., 1995; Ackerly y Donoghue, 1995; Ricklefs, 1996). Por el contrario, resulta particularmente interesante analizar el mantenimiento de determinadas correlaciones entre rasgos en linajes particulares, lo cual podría involucrar fuerzas selectivas (Lande y Arnold, 1983; Losos y Miles, 1994). El análisis aquí realizado representa una primera aproximación, y la obtención de resultados más robustos depende de la existencia de filogenias mejor resueltas, la inclusión de más especies, y la disponibilidad de materiales más completos para todas las especies consideradas. 


\section{DISCUSIÓN}

Los resultados de este trabajo permitieron evaluar la diversidad morfológica del miembro anterior y cráneo de Ctenomys relacionada con la braquio- y dentoexcavación. El género Ctenomys posee varios rasgos craneanos especializados para la dentoexcavación, incluyendo acentuada histricognatía vinculada a una particular trayectoria alométrica de la cresta masetérica (Vassallo y Mora, 2007; Verzi et al., en prensa), incisivos robustos (Vassallo y Mora, 2007), región articular postglenoidea especializada (Verzi y Olivares, 2006) y morfología característica de la vaina alveolar del incisivo, la cual protege a la zona basal generativa del mismo (Verzi, 2008). Estos rasgos son exclusivos de Ctenomys en el marco de los octodontoideos, y aún de los caviomorfos vivientes, y sólo son compartidos por el ctenomino extinto †Eucelophorus, el roedor sudamericano con mayor especialización dentoexcavadora (Verzi y Olivares, 2006; Vieytes et al., 2007). En contraste, a nivel del esqueleto del miembro anterior, las diferencias existentes con respecto a otros octodontoideos son en gran medida cuantitativas, con pocos caracteres exclusivos del género. Los resultados de este trabajo sugieren que los siguientes rasgos del miembro anterior son exclusivos de Ctenomys en el marco de la superfamilia Octodontoidea: extremo libre de la espina escapular redondeado y sin metacromion; gran muesca escapular muy amplia; proceso pseudoestiloide en la epífisis distal del radio (rasgo compartido con el ctenomino †Actenomys), y escafolunar grande y de forma compleja.

El rango de variación de los demás caracteres examinados en Ctenomys es amplio y se superpone con el de otros caviomorfos. Los resultados mostraron que Ctenomys, como género, no presenta especialización mayor que la de octodontoideos fosoriales como Aconaemys, en rasgos funcionalmente significativos tales como el largo de la espina escapular, el tamaño del proceso teres major, la robustez de los huesos largos, la distalización de la cresta deltoidea humeral, o el desarrollo de los epicóndilos (ver Tablas 4, 5, 6, 7 y 8 en Apéndice IV). 
Dentro de la variabilidad interespecífica del género, los rasgos funcionalmente ventajosos mostraron un patrón de distribución de tipo mosaico, tanto en las especializaciones dento- como braquioexcavadoras. Sobre la base de la detección de diferentes combinaciones de estos rasgos, se definieron cuatro morfotipos que resumen los extremos de la disparidad morfológica asociada a la dento- y braquioexcavación en el género (ver apartado V.2.3. Análisis multivariado general). El morfotipo flamarioni reúne a las especies con rasgos más generalizados, cuyo grado de especialización no es mucho mayor que el de otros octodontoideos analizados; en el lado opuesto, el morfotipo lewisi posee las mayores especializaciones tanto en el cráneo como en el miembro anterior, y representa el extremo de variación morfológica del género que se diferencia claramente de los demás caviomorfos analizados. Este último morfotipo reúne rasgos especializados vinculados con la dentoexcavación (mayor procumbencia de los incisivos superiores, implantación más profunda de los incisivos inferiores, fosa postglenoidea más amplia, bula auditiva relativamente pequeña y piriforme, meato auditivo externo más cóncavo y apófisis postcondílea más corta), así como características vinculadas con la especialización braquioexcavadora, representadas por gran robustez de la escápula y los huesos largos del miembro anterior, articulaciones fuertes que restringen el movimiento a nivel del codo y la muñeca (y en menor medida en el hombro), y proporciones de los brazos de palanca más importantes del brazo (representados por la cresta deltoidea y el olécranon ulnar) favorables para la producción de grandes fuerzas externas a nivel de la mano (V.1.1.4. Análisis funcional de la morfología escapular, V.1.2.4. Análisis funcional de la morfología humeral, V.1.3.4. Análisis funcional de la morfología del antebrazo, V.1.4.4. Análisis funcional de la morfología de la mano y V.2.1. Patrones de especialización en el miembro anterior). 
El análisis de posibles restricciones a la variabilidad morfológica del miembro anterior mostró que el tamaño corporal no ejerce una influencia directa sobre la gran mayoría de los índices analizados. A nivel cuantitativo, sólo el desarrollo relativo de las tuberosidades humerales mostró correlación con el tamaño corporal y alometría negativa (ver Alometrías en el húmero de Ctenomys, pág. 81), sugiriendo que podría existir un umbral y un rango estrecho de tamaños posibles, como consecuencia de los cuales estas estructuras resultan proporcionalmente más grandes en especies más pequeñas. Asimismo, la curvatura de los huesos del antebrazo y el grado de contacto entre las series de carpianos podrían estar influidos por el tamaño (ver Alometrías en el antebrazo de Ctenomys, pag. 102 y Alometrías en la mano de Ctenomys, pág. 118), aunque esto sólo fue controlado cualitativamente.

La evaluación de la restricción histórica sugirió que la filogenia ejerce influencia al menos parcial, y diferencial, sobre la morfología (V. 4. Análisis filogenético comparativo). Algunas correlaciones entre rasgos especializados de los huesos largos se mantuvieron luego de la corrección filogenética, sugiriendo que los requerimientos biomecánicos de mayor resistencia y producción de fuerzas afectan por igual a todos los huesos del miembro anterior, más allá del parentesco entre las especies. Por otra parte, una vez removida la influencia filogenética, se evidenció desacoplamiento entre los rasgos morfo-funcionales de la escápula y los del miembro anterior, en coincidencia con los resultados del análisis exploratorio (ACP) del miembro anterior (V.2.1. Patrones de especialización en el miembro anterior). La especialización morfológica vinculada a la braquioexcavación se manifestó más claramente a nivel de los huesos largos, mientras que los rasgos escapulares mostraron un patrón menos claro que podría estar asociado con demandas funcionales complejas $\mathrm{y} / \mathrm{o}$ con la fuerte inercia filogenética detectada para este elemento (V.1.1.3.2. Análisis morfométrico geométrico). 
La influencia filogenética resultó escasa en los rasgos craneanos; esto, junto con la menor variabilidad detectada a nivel del cráneo en comparación con el miembro anterior, sugiere una más fuerte integración entre los rasgos del cráneo. Esta integración a nivel craneano podría estar siendo mantenida por requerimientos funcionales y/o reflejar una mayor integración ontogenética.

Más allá de estos resultados, las restricciones no son absolutas (Budd, 2006), y la conservación de la correlación entre rasgos mediante un mecanismo restrictivo no significa que ésta no sea también mantenida por selección natural estabilizadora. Por ejemplo, una explicación alométrica para la variación morfológica no implica que no exista presión selectiva para mantener esa relación alométrica (Lessa, 2000). De igual modo, tampoco la similitud dada por una historia filogenética común y aquella correlacionada con factores ecológicos (adaptativos) son mutuamente excluyentes. En muchos casos, los patrones de variación de rasgos están correlacionados con la filogenia y a la vez mantenidos por fuerzas selectivas vinculadas con los hábitos y ecología de los taxones emparentados (Westoby et al., 1995; Ricklefs, 1996). En el caso de la escápula de Ctenomys, que mostró elevada inercia filogenética, la morfología típica de la superfamilia Octodontoidea (gran muesca escapular amplia y espina larga) podría haber facilitado (canalizado) la evolución de rasgos favorables para la braquioexcavación en todo el clado y particularmente en Ctenomys (Morgan, 2008); de este modo, más allá de restricciones históricas, no puede descartarse la participación de fuerzas selectivas.

Con respecto a la distribución de los rasgos morfo-funcionales en la filogenia, en general las especies del grupo "mendocinus" (sensu Massarini et al., 1991) mostraron morfología generalizada, mientras que las especies del clado formado por C. lewisi, C. conoveri, y C. frater (reconocido por Castillo et al., 2005 y autores previos allí citados; ver Fig. 8) correspondieron al morfotipo lewisi, con fuertes especializaciones. Más allá de esto, las características de C. 
rionegrensis, otra especie del grupo "mendocinus", correspondieron al morfotipo "mármol"' por su importante especialización a nivel del miembro anterior, de manera que la tendencia general en un clado no parece representar una restricción en este sentido. El conocimiento acerca de las relaciones filogenéticas entre las especies de Ctenomys es todavía demasiado incompleto como para permitir un análisis más robusto de los patrones históricos de especialización en el género. De la misma forma, no hay información precisa acerca del hábitat de muchas de las especies analizadas, por lo que no es posible aún evaluar patrones de correlación entre características del suelo y la distribución de rasgos en diferentes morfotipos (comparar Tabla 1 y Fig. 63). No obstante, de acuerdo con los datos disponibles (Tabla 1), los altamente especializados C. lewisi y C. frater ocupan suelos maduros, mientras que el hábitat de las especies más generalizadas (morfotipo flamarioni) se caracteriza por suelos arenosos y poco desarrollados, lo cual sugiere una posible correlación entre factores ecológicos y rasgos morfológicos.

La identificación de los cuatro morfotipos de Ctenomys permite contrastar el patrón detectado con otros patrones propuestos para roedores subterráneos del mundo. Las modalidades excavadoras y las especializaciones morfológicas asociadas podrían haber evolucionado siguiendo diferentes vías. Una alternativa posible es que la especialización braquioexcavadora alcance su máxima expresión antes de que surja la especialización dentoexcavadora; esta última especialización permitiría ampliar el nicho ecológico, mientras que las formas braquioexcavadoras quedarían restringidas a suelos friables (Lessa, 1990). Una segunda alternativa es que a partir de una morfología generalizada se alcanzara la especialización dento- o braquioexcavadora, siendo ambas tendencias esencialmente "excluyentes". Este segundo modelo se asemeja al patrón de especializaciones dento- y braquioexcavadoras de la familia Geomyidae, que ha sido ampliamente analizado (Lessa y Patton, 1989; Lessa y Thaeler, 1989; Lessa y 
Stein, 1992; Lessa, 2000). En esta familia, las dos tendencias de especialización morfológica - dento- y braquioexcavadora - se manifiestan como extremos opuestos de un mismo eje de variación morfológica mio-esqueletaria (Lessa y Stein, 1992; Lessa, 2000). Algunos géneros presentan mayores especializaciones dentoexcavadoras y escasa especialización braquioexcavadora (Thomomys, Cratogeomys), mientras que otros tienen características opuestas (Geomys). En términos de la diversidad detectada en Ctenomys, este patrón sería equivalente a la existencia de un patrón generalizado con pocas especializaciones en ambos sentidos (morfotipo flamarioni) y dos morfotipos derivados, i.e. morfotipo "perucho'", y morfotipo "mármol". Sin embargo, dentro de Ctenomys existen también especies con fuertes especializaciones braquio- y dentoexcavadoras (morfotipo lewisi). Los morfotipos detectados en Ctenomys ofrecen una visión diferente que amplía las posibilidades de estos modelos: las especializaciones morfológicas braquio- y dentoexcavadoras no están necesariamente correlacionadas (alternativa 1), ni tampoco son necesariamente excluyentes (alternativa 2).

En la historia evolutiva de Ctenomys, una órbita relativamente pequeña, indicadora de hábitos subterráneos, está presente ya en los registros más antiguos del género (Verzi, 2002; Morgan y Verzi, 2006; Verzi, 2008). La escasez de materiales no permite evaluar la variabilidad morfológica existente en ese momento de la historia del género; †C. chapalmalensis, la única especie pliocénica conocida a través de restos craneanos y poscraneanos, fue incluida en el morfotipo flamarioni sobre la base de su escasa especialización. Ya en el Pleistoceno, el rango de disparidad morfológica es comparable con el actual, tal como lo evidencian los materiales de †C. subassentiens, †Ctenomys sp. 1, †Ctenomys sp. 2, y †Ctenomys sp. 3 (ver V.1.2. Húmero y V.1.3. Antebrazo). De este modo, las evidencias disponibles sugieren una edad mínima cercana al Pleistoceno medio para el origen de dicha disparidad. 
Dentro de Ctenomyinae se incluyen también otros géneros extintos con especializaciones braquioexcavadoras (†Actenomys), dentoexcavadoras (†Praectenomys) o de ambos tipos (†Eucelophorus), lo cual muestra que los cambios asociados con la vida subterránea también presentan un patrón en mosaico a nivel de la subfamilia (Lessa et al., 2008). En este sentido, la evolución de la vida subterránea y especializaciones morfológicas asociadas en los Ctenomyinae y la subfamilia hermana Octodontinae muestra ciertas diferencias (Lessa et al., 2008). En los octodontinos la especialización morfológica vinculada con el cavado está mayormente restringida a la braquioexcavación, con excepción del dentoexcavador Spalacopus. De todas maneras, las diferencias entre ambas subfamilias son más bien cuantitativas y no cualitativas; el grado de especialización alcanzado por los ctenominos es mayor que el de los octodontinos, tanto a nivel craneano como en el miembro anterior.

Los resultados permiten interpretar en forma preliminar la evolución del hábito excavador y de los rasgos morfológicos vinculados al mismo en Ctenomys. En principio, la modalidad primaria de cavado para los roedores, como para otros mamíferos, es la braquioexcavación (Nevo, 1979; Hildebrand, 1985; Polly, 2007; Lessa et al., 2008). Por otra parte, la construcción de galerías complejas no requiere la posesión de especializaciones morfológicas marcadas en el esqueleto (Lessa et al., 2008). Dado que la capacidad braquioexcavadora no se refleja necesariamente en la morfología esqueletaria del miembro anterior, sino que comienza siendo una pauta comportamental (Lessa et al., 2008), formas ancestrales a Ctenomys podrían haber tenido hábito fosorial a semi-subterráneo y haber usado los miembros anteriores para excavar, sin que su morfología mostrase indicaciones claras en este sentido.

Este planteo tiene dos consecuencias. Por un lado, sugiere que no sería posible estimar una edad mínima para la adopción del hábito fosorial en el origen del género a través de la morfología de los fósiles. Por otro lado, plantea que cualquier rasgo esqueletario que represente una especialización 
braquio- o dentoexcavadora, como los de los morfotipos "mármol", "perucho" y lewisi, estaría señalando la ocupación de suelos más resistentes y/o mayor frecuencia de uso del miembro anterior y/o el aparato masticatorio para el cavado; esta mayor frecuencia derivaría de una mayor proporción de funciones biológicas realizadas bajo tierra (Genise, 1989; Stein, 2000; Lessa et al., 2008). A partir de un morfotipo ancestral con hábito fosorial, primariamente braquioexcavador y sin modificaciones esqueletarias, distintas presiones selectivas generadas por diferentes hábitats, o aún factores estocásticos (Reig et al., 1990), pudieron dar como resultado la fijación de especializaciones braquio- $\mathrm{y} / \mathrm{o}$ dentoexcavadoras.

Como se discutió anteriormente, aunque Ctenomys es un género subterráneo estricto (sensu Lacey et al., 2000; Lessa et al., 2008) a nivel comportamental, este hábito sólo se refleja parcialmente en su morfología esqueletaria. La mayor diferenciación morfológica presente en roedores de las familias Spalacidae, Geomyidae y Bathyergidae (Lessertisseur y Saban, 1967; Özkan, 2002; Lessa y Thaeler, 1989; Samuels y Van Valkenburgh, 2008), en comparación con Ctenomys, podría estar relacionada con la antigüedad de los grupos. El género Ctenomys es relativamente joven, con registros desde el Plioceno tardío (Cook et al., 2000; Verzi, 2002, 2008), y el registro fósil de la subfamilia Ctenomyinae comienza recién en el Mioceno tardío. En contraste, en otros clados de roedores se conocen representantes presuntamente subterráneos desde el Oligoceno (Geomyidae), Mioceno más temprano (Bathyergidae), y Mioceno temprano (Spalacidae) (Cook et al., 2000, figura 9.1). De esta manera, el grado de especialización excavadora alcanzado por los ctenominos, y en particular por las especies de Ctenomys, podría estar limitado por un factor temporal (Verzi y Olivares, 2006).

\section{Perspectivas}

Reig y Quintana (1992) relacionaron la explosiva especiación de Ctenomys con procesos estocásticos de fijación de reacomodamientos 
cromosómicos; en ese contexto, la diversidad morfológica del género sería resultado de tal proceso, a partir de una morfología ancestral en la que las adaptaciones esenciales habrían estado ya fijadas. Más allá de la aleatoriedad que podría afectar los patrones morfológicos de Ctenomys, las estrategias evolutivas características de éste y otros roedores fosoriales (especialización, aislamiento entre poblaciones locales, estructura genética) hacen esperable la existencia de numerosas adaptaciones ecotípicas a los ambientes locales que habitan (Nevo, 1979).

Los resultados de este trabajo revelaron un panorama de amplia disparidad que sugiere una interacción compleja entre los factores históricos y selectivos. El estudio de otros elementos del esqueleto poscraneano en estas y otras especies probablemente revelará patrones interesantes a otros niveles; además, la obtención de información precisa sobre el comportamiento y las características del microhábitat de cada una, permitirán contrastar las hipótesis planteadas acerca de posibles restricciones, adaptación local y amplitud del nicho (Lessa, 1990). 


\section{CONCLUSIONES}

1. El grado de especialización morfológica vinculada a la capacidad excavadora del género Ctenomys es moderado. Mientras que a nivel craneano el género presenta varios rasgos distintivos, en el miembro anterior los únicos detectados como exclusivos, en el contexto de los octodontoideos, son la forma del extremo de la espina escapular carente de metacromion, la gran amplitud de la gran muesca escapular, el proceso pseudoestiloide de la epífisis distal del radio y el gran escafolunar de forma compleja. El género no difiere significativamente de otros octodontoideos en otros caracteres de importancia morfo-funcional del esqueleto del miembro anterior.

2. Existe amplia variabilidad interespecífica en cuanto al grado de especialización morfológica del miembro anterior en las especies de Ctenomys:

- La escápula presentó diferencias en forma, tamaño relativo de las fosas supra- e infraespinosa, elongación, longitud de la espina y amplitud de la gran muesca escapular. El proceso teres major presentó dos morfologías básicas, "tipo rionegrensis" y “tipo talarum".

- La especialización morfológica del húmero resultó heterogénea. En C. lewisi, C. frater, C. conoveri, C. steinbachi y C. "mármol" este hueso presentó una combinación de rasgos especializados única entre los roedores caviomorfos: gran robustez, cresta deltoidea distalizada, epicóndilos bien desarrollados, y superficie articular distal alta y ancha; sin embargo, en la mayoría de las especies estos rasgos se distribuyeron en forma desacoplada.

- A nivel del antebrazo, el radio y ulna mostraron diferencias en robustez, curvatura y desarrollo del olécranon; la fóvea radial ovoidal mostró diferente elongación según las especies.

- En la mano, se detectó variación en el grado de contacto entre el escafolunar y el unciforme, así como en la robustez de los metacarpianos. 
3. La estrategia excavatoria de Ctenomys es dual, pero el grado de expresión de las especializaciones braquio- y dentoexcavadoras varió entre las especies estudiadas, y esta variabilidad ha estado presente al menos desde el Pleistoceno. De acuerdo con la distribución de rasgos especializados, se definieron cuatro morfotipos: morfotipo flamarioni con cráneo y miembro anterior más generalizados; morfotipo "perucho" con especializaciones esencialmente dentoexcavadoras, morfotipo "mármol" con especializaciones esencialmente braquioexcavadoras, y morfotipo lewisi con fuertes especializaciones en ambos sentidos. Este último morfotipo reunió los siguientes rasgos morfológicos derivados:

- Mayor procumbencia de los incisivos superiores, que proporciona un ángulo más ventajoso para atacar el sustrato durante la dentoexcavación.

- Incisivos inferiores de implantación más profunda, con la base de los mismos muy cercana al cóndilo mandibular, lo cual refleja el aumento de longitud del incisivo relacionado con una mayor frecuencia de uso.

- Especialización morfológica en la región postglenoidea, incluyendo fosa postglenoidea más amplia, bula auditiva menos inflada y típicamente piriforme, mayor concavidad del meato auditivo externo y apófisis postcondílea más corta; esta morfología evita la dislocación del cóndilo durante la dentoexcavación.

- Escápula muy robusta, con proceso coracoides largo y curvado, espina larga, robusta y curvada con respecto al plano escapular, proceso teres major bien desarrollado, características que le otorgan resistencia, mayor superficie para unión de músculos, y restricción de movimientos en la articulación gleno-humeral.

- Húmero robusto, con cresta deltoidea distalizada, epicóndilos bien desarrollados, y superficie articular distal alta y ancha; rasgos que le 
dan resistencia y estabilidad a nivel articular, así como mayor ventaja mecánica para músculos flexores del miembro anterior.

- Radio y ulna robustos, con diáfisis curvada, articulaciones profundas y bien definidas, y porción distal engrosada; la epífisis distal del radio con un proceso pseudoestiloide adicional; estos rasgos otorgan resistencia a los huesos y amplio espacio para los músculos flexores y extensores de la mano, a la vez que limitan los movimientos a nivel de la articulación antebrazo-mano.

- Carpo con escafolunar relativamente grande y con superficie articular irregular, en contacto amplio con el unciforme; central muy reducido. Los robustos metacarpianos II-V encajan firmemente entre el carpiano distal y los metacarpianos adyacentes. Estas características aseguran gran rigidez y estabilidad de las articulaciones internas de la mano.

4. Las especializaciones morfológicas braquio- y dentoexcavadoras de las especies de Ctenomys no están necesariamente correlacionadas ni son necesariamente excluyentes entre sí, tal como es evidenciado por la existencia de los morfotipos definidos anteriormente.

5. La variabilidad detectada en los rasgos estudiados del miembro anterior es algo mayor que la de los rasgos craneanos, aunque la diferencia no es estadísticamente significativa. Los índices morfo-funcionales de cráneo presentaron alta correlación, posiblemente debida a la acentuada integración entre los mismos.

6. Desde una perspectiva histórica, los patrones morfo-funcionales de especialización excavadora no se distribuyen al azar en la filogenia del grupo. Se detectaron fuertes especializaciones excavadoras en un clado de especies bolivianas (C. frater, C. conoveri, y C. lewisi), y escasa especialización morfológica en especies del grupo "mendocinus" (C. australis, C. azarae, C. flamarioni). La existencia de estos grupos de especies, en los cuales el patrón genealógico es congruente con el morfo-funcional, sugiere que la disparidad 
en estas especializaciones excavadoras se fijó tempranamente en la evolución del género.

7. Las especializaciones braquioexcavadoras de Ctenomys, y al menos parte de las dentoexcavadoras, son moderadas en el contexto de los roedores subterráneos del mundo. La antigüedad de los taxones puede jugar un papel importante en esta diferencia, ya que la subfamilia Ctenomyinae es relativamente joven con respecto a otros clados de roedores subterráneos. 


\section{BIBLIOGRAFÍA}

Ackerly, D. D. y Donoghue, M. J. 1995. Phylogeny and ecology reconsidered. Journal of Ecology 83: 730-733.

Ackerly, D. D. y Donoghue, M. J. 1998. Leaf size, sapling allometry, and Corner's rules: Phylogeny and correlated evolution in maples (Acer). American Naturalist 152: 767-791.

Ackerly, D. D. y Reich, P. B. 1999. Convergence and correlations among leaf size and function in seed plants: a comparative test using independent contrasts. American Journal of Botany 86: 1272-1281.

Addinsoft. 2004. XLStat. Your data analysis solution. Versión 7.5.2. Software disponible en http:/ / www.xlstat.com.

Altuna, C. A. 1983. Sobre la estructura de las construcciones de Ctenomys pearsoni Lessa y Langguth, 1983 (Rodentia, Octodontidae). Resúmenes y Comunicaciones de las III Jornadas de Ciencias Naturales de Montevideo 3: 7072.

Anderson, S. A. 1997. Mammals of Bolivia, taxonomy and distribution. Bulletin of the American Museum of Natural History 231: 1-652.

Antinuchi, C. D. y Busch, C. 1992. Burrow structure in the subterranean rodent Ctenomys talarum. Zeitschrift für Säugetierkunde 57: 163-168.

Argot, C. 2001. Functional-adaptive anatomy of the forelimb in the Didelphidae, and the palaeobiology of the Paleocene marsupials Mayulestes ferox and Pucadelphys andinus. Journal of Morphology 247: 51-79.

Arnold, S. J. 1983. Morphology, performance and fitness. American Zoologist 23: 347-361.

Bidau, C. J. 2006. Ctenomyidae. En Bárquez, R. M., Díaz, M. M. y Ojeda, R. A. (Eds.). Mamíferos de Argentina, sistemática y distribución (p. 212-231). Mendoza: SAREM (Sociedad Argentina para el Estudio de los Mamíferos).

Biknevicius, A. R. 1993. Biomechanical scaling of limb bones and differential limb use in caviomorph rodents. Journal of Mammalogy 74: 95-107.

Blainville, H. M. D. de. 1826. Sur une nouvelle espèce de rongeur fouisseur du Brésil. Nouveau Bulletin des Sciences par la Société Philomatique de Paris, pp. 62-64.

Bock, W. J. 1980. The definition and recognition of biological adaptation. American Zoologist 20: 217-227.

Bock, W. J. 1994. Concepts and methods in ecomorphology. Journal of Biosciences 19 (4): 403-413.

Bookstein, F. L. 1991. Morphometric Tools for Landmark Data. New York: Cambridge University Press. 435 pp. 
Bookstein, F. L. 1997. Landmark methods for forms without landmarks: Localizing group differences in outline shape. Medical Image Analysis 1: 225-243.

Brashear, K. y Yahnke, C. 2004. Ctenomys conoveri (On-line), Animal Diversity Web. Consultado marzo 2008 en http://animaldiversity.ummz.umich.edu/site/accounts/information/Cte nomys_conoveri.html

Budd, G. E. 2006. On the origin and evolution of major morphological characters. Biological Reviews 81(4): 609-628.

Candela, A. M. y Picasso, M. B. J. 2008. Functional anatomy of the limbs of Erethizontidae (Rodentia, Caviomorpha): Indicators of locomotor behavior in Miocene porcupines. Journal of Morphology 269: 552-593.

Casinos, A., Quintana, C. y Viladiu, C. 1993. Allometry and adaptation in the long bones of a digging group of rodents (Ctenomyinae). Zoological Journal of the Linnean Society 107: 107-115.

Castillo, A. H., Cortinas, M. N. y Lessa, E. P. 2005. Rapid diversification of South American tuco-tucos (Ctenomys; Rodentia, Ctenomyidae): contrasting mitochondrial and nuclear intron sequences. Journal of Mammalogy 86: 170179.

Charron, S. 2002. Ctenomys fulvus (On-line), Animal Diversity Web. Consultado marzo 2008 en

http:/ / animaldiversity.ummz.umich.edu/site/accounts/information/Cte nomys_fulvus.html.

Chebez, J. C. y Nigro, N. A. 2008. “Tucotuco guaraní”. En Chebez, J. C. (Ed.). Los que se van. Fauna argentina amenazada. Tomo 3 (p. 323-324). Buenos Aires: Albatros.

Cheverud, J. M, Dow, M. M. y Leutenegger, W. 1985. The quantitative assessment of phylogenetic constraints in comparative analyses: sexual dimorphism in body weight among primates. Evolution 39(6): 1335-1351.

Claude, J. 2004. Phylogenetic comparative methods and the evolution of morphological integration. Revue de Paléobiologie, Genève Vol. spéc. 9: 169178.

Contreras, J. R. 1973. El tucu-tuco y sus relaciones con los problemas del suelo en la Argentina. INTA IDIA Suplemento 29: 14-36.

Contreras L. C., Torres-Mura, J. C. y Yañez, J. L. 1987. Biogeography of octodontid rodents: an eco-evolutionary hypothesis. En Patterson, B. D. y Timm, R. M. (Eds.). Studies in Neotropical Mammalogy: Essays in Honor of Philip Hershkovitz. Fieldiana Zoology 39: 401-441. USA: Field Museum of Natural History.

Cook, J. A., Anderson, S. y Yates, T. L. 1990. Notes on Bolivian mammals 6: The genus Ctenomys. American Museum Novitates 2980: 1-27. 
Cook, J. A., Lessa, E. P. y Hadly, E. A. 2000. Paleontology, phylogenetic patterns and macroevolutionary processes in subterranean rodents. En Lacey, A.E., Patton, J.L. y Cameron, G.N. (Eds.). Life underground. The biology of subterranean rodents (p. 19-61). Chicago: The University of Chicago Press.

Corruccini, R. S. 1975. Multivariate Analysis in Biological Anthropology: Some Considerations. Journal of Human Evolution London 4(1): 1-19. Citado en: Lemen, C. L. 1983. The effectiveness of methods of shape analysis. Fieldiana Zoology 15: 1-17.

Cullinane, D. M. 2000. Axial versus appendicular: constraint versus selection. American Zoologist 40 (1): 136-145.

De Santis, L. J. M. y Moreira, G. J. 2000. El aparato masticador del género extinto Actenomys Burmeister 1888 (Rodentia, Ctenomyidae): inferencias sobre su modo de vida. Estudios Geológicos 56: 63-72.

De Santis, L. J. M., Moreira, G. J. y Justo, E. R. 1998. Anatomía de la musculatura branquiomérica de algunas especies de Ctenomys Blainville, 1826 (Rodentia, Ctenomyidae): caracteres adaptativos. Boletín de la Sociedad de Biología de Concepción, Chile 69: 89-107.

De Santis, L. J. M., Moreira, G. J. y García Esponda, C. M. 2001. Microestructura del esmalte de los incisivos superiores de Ctenomys azarae y C. talarum (Rodentia, Ctenomyidae). Mastozoología Neotropical 8(1): 5-14.

Desdevises, Y., Legendre, P., Azouzi, L., y Morand, S. 2003. Quantifying phylogenetically structured environmental variation. Evolution 57(11): 2647-2652.

Dubost, G. 1968. Les mammifères souterrains. Revue d'Ecologie et de Biologie du sol 5: 99-133.

Eisenberg, J. F. y Redford, K. H. 1999. Mammals of the Neotropics. The central Neotropics: Ecuador, Peru, Bolivia, Brasil. Vol. 3. Chicago: The University of Chicago Press. 609 pp.

Elissamburu, A. y Vizcaíno, S. F. 2004. Limb proportions and adaptations in caviomorph rodents (Rodentia: Caviomorpha). Journal of Zoology (London) 262: 145-159.

Felsenstein, J. 1985. Phylogenies and the comparative method. American Naturalist 125: 1-15.

Fernández, M. E., Vassallo, A. I. y Zárate, M. 2000. Functional morphology and palaeobiology of the pliocene rodent Actenomys (Caviomorpha: Octodontidae): the evolution to a subterranean mode of life. Biological Journal of the Linnean Society 71: 71-90.

Fernandes, F. A., Fernández-Stolz, G. P., Lopes, C. M. y Freitas, T. R. O. 2007. The conservation status of the tuco-tucos, genus Ctenomys (Rodentia: Ctenomyidae), in southern Brazil. Brazilian Journal of Biology 67(4, Suppl.): 839-847. 
Ferry-Graham, L., Bolnick, D. L. y Wainwright, P. C. 2002. Using functional morphology to examine the ecology and evolution of specialization. Integrative and Comparative Biology 42: 265-277.

Forsyth Major, C. I. 1899. Remarks upon the carpus of the fossorial rodent Ctenomys. Proceedings of the Zoological Society of London, pp. 428-437.

Frailey, D., Campbell, K. E. y Wolff, R. G. 1980. Additions to the knowledge of Hyppocamelus, Ctenomys and Myocastor from the middle Pleistocene of the Tarija Basin, Bolivia. Occasional Papers of the Museum of Natural History, University of Kansas 85: 1-14.

Freitas, T. R. O. 1995. Geographic distribution and conservation of four species of the genus Ctenomys in southern Brazil. Studies on Neotropical fauna and environment 30(1): 53-59.

Galewski, T., Mauffrey, J. F., Leite, Y. L. R., Patton, J. L. y Douzery, E. J. P. 2005. Ecomorphological diversification among South American spiny rats (Rodentia: Echimyidae): a phylogenetic and chronological approach. Molecular Phylogenetics and Evolution 34: 601-615.

Gallardo, M. H. y Kirsch, J. A. W. 2001. Molecular relationships among Octodontidae (Mammalia:Rodentia:Caviomorpha). Journal of Mammalian Evolution 8: 73-89.

Genise, J. F. 1989. Las cuevas de Actenomys (Rodentia, Octodontidae) de la Formación Chapadmalal (Plioceno superior) de Mar del Plata y Miramar (Provincia de Buenos Aires). Ameghiniana 26: 33-42.

Grafen, A. 1989. The Phylogenetic Regression. Philosophical Transactions of the Royal Society of London. Series B, Biological Sciences 326 (1233): 119-157

Hall, B. K. 2005. Bones and Cartilage. Developmental Skeletal Biology. London: Elsevier Academic Press. 760 pp.

Harvey, P. H. y Pagel, M. D. 1991. The comparative method in evolutionary biology. Oxford Series in Ecology and Evolution, vol. 1. Oxford: Oxford University Press. 239 pp.

Hildebrand, M. 1985. Digging of quadrupeds. En Hildebrand, M., Bramble, D. M., Liem, K. F. y Wake, D.B. (Eds.). Functional Vertebrate Morphology (pp. 90-108). Cambridge: Belknap Press of Harvard University.

Hildebrand, M. 1988. Analysis of vertebrate structure ( $3^{\mathrm{a}}$ ed.). New York: Wiley \& Sons. $701 \mathrm{pp}$.

Hill, J. E, 1937. Morphology of the pocket gopher mammalian genus Thomomys. University of California Publications in Zoology 42: 81-172.

Honeycutt, R. L., Rowe, D. L. y Gallardo, M. H. 2003. Molecular systematics of the South American caviomorph rodents: relationships among species and genera in the family Octodontidae. Molecular Phylogenetics and Evolution 26: 476-489.

Hoyle, B. H. 2004. Chinchilla rats (Abrocomidae). En Hutchins, M., Kleiman, D. 
G., Geist, V. y McDade, M. C. (Eds.) Grzimek's Animal Life Encyclopedia, $2^{\circ}$ ed. Vol. 16, Mammals V (p. 443-448). Farmington Hills: Gale Group.

Houchon, D. y Douzery, E. J. P. 2001. From the Old World to the New World: a molecular chronicle of the phylogeny and biogeography of hystricognath rodents. Molecular Phylogenetics and Evolution 20: 238-251.

Jackson, D. A. y Somers, K. M. 1991. The spectre of 'spurious' correlations. Oecologia 86: 147-151.

Jolly, C. J. 1967. The evolution of the baboons. En Vagtborg, H. (Ed.). The Baboon in Medical Research, Vol. II (p. 427-457). Austin: University of Texas Press.

Jungers, W. L., Falsetti, A. B. y Wall, C. E. 1995. Shape, relative size, and sizeadjustments in morphometrics. Yearbook of Physical Anthropology 38: 137161.

Jurich, N. y Myers, P. 2006. Ctenomys talarum (On-line), Animal Diversity Web. Consultado marzo 2008 en http:/ / animaldiversity.ummz.umich.edu/site/accounts/information/Cte nomys_talarum.html.

Justo, E. R., Bozzolo, L. y De Santis, L. J. M. 1995. Microstructure of the enamel of the incisors of some ctenomyid and octodontid rodents (Rodentia, Caviomorpha). Mastozoología Neotropical 2: 43-51.

Kardong, K. V. 1999. Vertebrados: anatomía comparada, función, evolución (2a ed.). Madrid, Buenos Aires: McGraw-Hill Interamericana. 731 pp.

Koenigswald, W. V., Sander, M. P., Leite, M., Mors, T., y Santel, W. 1994. Functional symmetries in the schmelzmuster and morphology in rootless rodent molars. Zoological Journal of the Linnean Society 110: 141-179.

Koehl, M. A. 1996. When does morphology matter? Annual Review of Ecology and Systematics 27: 501-542.

Lacey, A. E, Patton, J. L. y Cameron, G. N. 2000. Introduction. En Lacey, A. E., Patton, J. L. y Cameron, G. N (Eds.). Life Underground. The Biology of Subterranean Rodents (p. 1-14). Chicago: The University of Chicago Press.

Lacey, E. A. 2000. Spatial and social systems of subterranean rodents. En Lacey, A. E., Patton, J. L. y Cameron, G. N (Eds.). Life Underground. The Biology of Subterranean Rodents (p. 257-296). Chicago: The University of Chicago Press.

Lande, R. y Arnold, S. J. 1983. The measurement of selection on correlated characters. Evolution 37(6): 1210-1226.

Lauder, G. V. 1981. Form and function: structural analysis in evolutionary morphology. Paleobiology 7 (49): 430-442.

Lauder, G.V. 1990. Functional morphology and systematics: studying functional patterns in an historical context. Annual Review of Ecology and Systematics 21: 317-340. 
Lauder, G. V. 2000. Function of the caudal fin during locomotion in fishes: kinematics, flow visualization, and evolutionary patterns. Integrative and Comparative Biology 40(1): 101-122.

Laville, E., Casinos, A., Gasc, J. P., Renous, S. y Bou, J. 1989. Les mecanismes du fouissage chez Arvicola terrestris et Spalax ehrenbergi: étude fonctionelle et évolutive. Anatomische Anzeiger Jena 169: 131-144.

Laville, E. 1990. Etude morphofonctionelle comparative des structures osseuses impliquées dans le fouissage d'Arvicola terrestris Scherman (Rodentia, Arvicolidae). Canadian Journal of Zoology 68: 2437-2444.

Legendre, P. y Legendre, L. 1998. Numerical ecology. 2nd Ed. Amsterdam: Elsevier. 853 pp.

Legendre, P. 2001. Model II regression - User's guide. Département de sciences biologiques, Université de Montréal. Montréal, Canada, 23 pp.

Lehmann, W. H. 1963. The forelimb architecture of some fossorial rodents. Journal of Morphology 113: 59-76.

Lemen, C. L. 1983. The effectiveness of methods of shape analysis. Fieldiana Zoology 15: 1-17.

Lessa, E. P. 1990. Morphological evolution of subterranean mammals: integrating structural, functional, and ecological perspectives. En Nevo, E. y Reig, O.

A. (Eds.). Evolution of Subterranean Mammals at the Organismal and Molecular Levels (p. 211-230). New York: Wiley-Liss.

Lessa, E. P. 1993. Patrones de evolución morfológica en roedores subterráneos americanos. Boletín de la Sociedad Zoológica del Uruguay, 2a época, 8: 37-46.

Lessa, E. P. 2000. The evolution of subterranean rodents: a synthesis. En Lacey, A. E., Patton, J. L. y Cameron, G. N (Eds.). Life Underground. The Biology of Subterranean Rodents (p. 389-407). Chicago: The University of Chicago Press.

Lessa, E. P. y Patton, J. L. 1989. Structural constraints, recurrent shapes, and allometry in pocket gophers (genus Thomomys). Biological Journal of the Linnean Society 36: 349-363.

Lessa, E. P. y Stein, B. R. 1992. Morphological constraints in the digging apparatus of pocket gophers (Mammalia: Geomyidae). Biological Journal of the Linnean Society 47: 439-453.

Lessa, E. P. y Thaeler, Jr, C. S. 1989. A reassessment of morphological specializations for digging in pocket gophers. Journal of Mammalogy 70: 689-700.

Lessa, E. P., Vassallo, A. I., Verzi, D. H. y Mora, M. S. 2008. Evolution of morphological adaptations for digging in living and extinct ctenomyid and octodontid rodents. Biological Journal of the Linnean Society 95: 267-283. 
Lessertisseur, J. y Saban, R. 1967. Squelette appendiculaire. En Grassé, P.-P. (Ed.). Traité de Zoologie. T. 16 fasc 1. Mammiferes - téguments - squelette (p. 709823). Paris: Masson et Cie.

Lessertisseur, J. y Jouffroy, F. K. 1973. Tendances locomotrices des primates traduites par les proportions du pied. L'adaptation à la bipédie. Folia Primatologica 20: 125-160.

Levinton, J. 1988. Genetics, paleontology and macroevolution. Cambridge: Cambridge University Press. 656 pp.

Liang, K. y Zeger, S. L. 1986. Longitudinal data analysis using generalized linear models. Biometrika 73: 13-22.

Liem, K. F. 1987. Functional design of the air ventilation apparatus and overland excursions by teleosts. Fieldiana (Zoology) NS 37: 1-29.

Losos, J. B. y Miles, D. B. 1994. Adaptation, constraint and the comparative method: phylogenetic issues and methods. En Reilly, S. M. (Ed.) Ecological Morphology: Integrative Organismal Biology (p. 60-98). Chicago: University of Chicago Press.

Luna, F. y Antinuchi, C. D. 2006. Cost of foraging in the subterranean rodent Ctenomys talarum: Effect of soil hardness. Canadian Journal of Zoology 84: 661-666.

MacLeod, N. y Rose, K. D. 1993. Inferring locomotor behaviour in Paleogene mammals via eigenshape analysis. American Journal of Science 293-A: 300355.

Mares, M. A. y Ojeda, R. A. 1982. Patterns of diversity and adaptation in South American Hystricognath rodents. En Mares, M. A. y Genoways, H. H. (Eds.). Mammalian biology in South America (p. 393-432). Special Publication Series Pymatuning Laboratory of Ecology. Linesville: University of Pittsburgh.

Martin, T. 1992. Schmelzmikrostruktur in den inzisiven alt- und neuweltlicher hystricognather nagetiere. Paleovertebrata, Memoire extraordinaire 1-68.

Massarini, A. I., Barros, M. A., Ortells, M. O. y Reig, O. A. 1991. Chromosomal polymorphism and small karyotypic differentiation in a group of Ctenomys species from Central Argentina (Rodentia: Octodontidae). Genetica 83: 131144.

Maynard-Smith, J. y Savage, R. J. G. 1956. Some locomotory adaptations in mammals. Journal of the Linnean Society of London Zoological Series A 42: 603-22.

Meiri, S., Dayan, T. y Simberloff, D. 2005. Variability and correlations in carnivore crania and dentition. Functional Ecology 19: 337 - 343.

Microsoft. 2003. Excel SP 3. Microsoft, Redmond, Washington.

Montalvo, C. I. y Casadío, S. 1988. Presencia del género Palaeoctodon (Rodentia, Octodontidae) en el Huayqueriense (Mioceno tardío) de la Provincia de la 
Pampa. Ameghiniana 25 (2): 111-114.

Monteiro, L. R. y Abe, A. S. 1999. Functional and historical determinants of shape in the scapula of xenarthran mammals: the evolution of a complex morphological structure. Journal of Morphology 241: 251-263.

Monteiro, L. R. y Dos Reis, S. F. 1999. Princípios de morfometria geométrica. Holos Editora, Ribeirão Preto. 188 pp.

Mora, M., Olivares, A. I. y Vassallo, A. I. 2003. Size, shape and structural versatility of the skull of the subterranean rodent Ctenomys (Rodentia, Caviomorpha): functional and morphological analysis. Biological Journal of the Linnean Society 78: 85-96.

Morgan, C. C. 2008. Geometric morphometrics of the scapula of South American caviomorph rodents (Rodentia: Hystricognathi): Form, function and phylogeny. Mammalian Biology. En prensa.

doi:10.1016/j.mambio.2008.09.006

Morgan, C. C. y Verzi, D. H. 2006. Morphological diversity of the humerus of the South American subterranean rodent Ctenomys (Rodentia, Ctenomyidae). Journal of Mammalogy 87: 1252-1260.

Mosimann, J. E. 1970. Size allometry: Size and shape variables with characterizations of the lognormal and generalized gamma distributions. Journal of the American Statistical Association 65: 930-945.

Nevo, E. 1979. Adaptive convergence and divergence of subterranean mammals. Annual Review of Ecology and Systematics 10: 269-308.

Nevo, E. 1999. Mosaic evolution of subterranean mammals. Regression, progression, and global convergence. Oxford: Oxford University Press. 413 pp.

Nowak, R. M. 1991. Walker's Mammals of the World (5ed.). Baltimore: Johns Hopkins University Press. 642 pp.

Opazo, J. C. 2005. A molecular timescale for caviomorph rodents (Mammalia, Hystricognathi). Molecular Phylogenetics and Evolution 37: 932-937.

Özkan, Z. E. 2002. Macro-anatomical investigations on the forelimb skeleton of mole-rat (Spalax leucodon Nordmann). Veterinarski Arhiv 72 (2): 91-99.

Pagel, M. 1992. A method for the analysis of comparative data. Journal of Theoretical Biology 156: 431-442.

Paradis, E. 2006. Analysis of Phylogenetics and Evolution with R. Use R! series. Springer Science and Business Media. 211 pp.

Paradis, E. y Claude, J. 2002. Analysis of comparative data using generalized estimating equations. Journal of Theoretical Biology 218: 175-185.

Paradis, E., Claude, J. y Strimmer, K. 2004. APE: Analyses of Phylogenetics and Evolution in R language. Bioinformatics 20 (2): 289-290. 
Pearson, O. P. 1959. Biology of the subterranean rodents, Ctenomys, in Perú. Memorias del Museo de Historia Natural " "Javier Prado"'" 9: 1-56. Lima Universidad Nacional Mayor de San Marcos.

Pearson, O. P. 1984. Taxonomy and natural history of some fossorial rodents of Patagonia, southern Argentina. Journal of Zoology (London) 202: 225-237.

Pocock, R. 1922. On the external characters of some histricomorphous rodents. Proceedings of the Zoological Society of London 1922: 365-472.

Polly, P. D. 2007. Limbs in mammalian evolution. En Hall, B. K. (Ed.). Fins into Limbs: Evolution, Development, and. Transformation (p. 245-268). Chicago: University of Chicago Press.

Price, M. V. 1993. A functional-morphometric analysis of forelimbs in bipedal and quadrupedal heteromyid rodents. Biological Journal of the Linnean Society 50: 339-360.

Quintana, C. A. 1994. Sistemática y anatomía funcional del roedor Ctenomyinae Praectenomys (Caviomorpha: Octodontidae) del Plioceno de Bolivia. Revista Técnica de YPFB, Vol. 15 (1-2): 175-185.

R Development Core Team. 2005. R: A language and environment for statistical computing. R Foundation for Statistical Computing, Vienna, Austria. ISBN 3-900051-07-0, URL http:/ / www.R-project.org.

Reeve, H. K. y Sherman, P. W. 1993. Adaptation and the goals of evolutionary research. The Quarterly Review of Biology 68(1): 1-32.

Reig, O. A. 1986. Diversity patterns and differentiation of high Andean rodents. En Vuilleumier, F. y Monasterio, M. (Eds.) High Altitude Tropical Biogeography (p. 404-439). Oxford: Oxford University Press.

Reig, O. A. 1989. Karyotypic repatterning as one triggering factor in cases of explosive speciation. En Fontdevila, A. (Ed.). Evolutionary biology of transient unstable populations (p. 246-289). Berlin: Springer-Verlag.

Reig, O. A. y Quintana, C. A. 1992. Fossil ctenomyine rodents of the genus Eucelophorus from the Pliocene and Early Pleistocene of Argentina (Caviomorpha: Octodontidae). Ameghiniana 29: 363-380.

Reig, O. A., Busch, C., Ortells, M. O. y Contreras, J. R. 1990. An overview of evolution, systematics, molecular biology and speciation in Ctenomys. En Nevo, E. y Reig, O. A. (Eds.). Evolution of subterranean mammals at the organismal and molecular levels (p. 71-96). New York: Wiley-Liss.

Ricklefs, R. E. 1996. The economy of nature: a textbook in basic ecology. $4^{\circ} \mathrm{ed}$. New York: Freeman \& Company. 692 pp.

Rose, K. D. y Chinnery, B. J. 2004. The postcranial skeleton of early Eocene rodents. Bulletin of the Carnegie Museum of Natural History 36: 211-244.

Rosi, M. I., Cona, M. I. y Roig, V. G. 2002. Estado actual del conocimiento del roedor fosorial Ctenomys mendocinus Philippi 1869 (Rodentia: Ctenomyidae). Mastozoología Neotropical 9: 277-295. 
Rosi, M. I., Cona, M. I., Videla, F., Puig, S., Monge, S. A. y Roig, V. G. 2003. Diet selection by the fossorial rodent Ctenomys mendocinus inhabiting an environment with low food availability (Mendoza, Argentina). Studies on Neotropical Fauna and Environment 38(3): 159-166.

Salton, J. A. y Sargis, E. J. 2008. Evolutionary Morphology of the Tenrecoidea (Mammalia) Forelimb Skeleton. En: Sargis, E. J. y Dagosto, M. (Eds.). Mammalian Evolutionary Morphology. A Tribute to Frederick S. Szalay (p. 5171). New York: Springer Science + Business Media.

Samuels, J. X. y Van Valkenburgh, B. 2008. Skeletal indicators of locomotor adaptations in living and extinct rodents. Journal of Morphology 269: 13871411.

Sargis, E. J. 2002. Functional morphology of the forelimb of tupaiids (Mammalia, Scandentia) and its phylogenetic implications. Journal of Morphology 253: $10-42$.

Schwilk, D. W. y Ackerly, D. D. 2001. Flammability and serotiny as strategies: correlated evolution in pines. Oikos 94: 326-336.

Simpson, G. G., Roe, A. y Lewontin, R. C. 1960. Quantitative Zoology. Nueva York, Hircourt, Brace and World Inc. 440 pp. Citado en: Lemen, C. L. 1983. The effectiveness of methods of shape analysis. Fieldiana Zool. 15: 1-17.

Slamovits, C. H., Cook, J. A., Lessa, E. P. y Rossi, M. S. 2001. Recurrent amplifications and deletions of satellite DNA accompanied chromosomal diversification in South American tuco-tucos (genus Ctenomys, Rodentian: Octodontidae): A phylogenetic approach. Molecular Biology and Evolution 18 (9): 1708-1719.

Sokal, R. R. y Rohlf, J. F. 1981. Biometry: the principles and practice of statistics in biological research. 2nd ed. San Francisco: W. H. Freeman and Company. $857 \mathrm{pp}$.

Sokal, R. R. y Rohlf, J. F. 1995. Biometry ( $3^{\circ}$ ed.). New-York: Freeman WH. and Company. 887 pp.

Stalheim-Smith, A. 1984. Comparative study of the forelimbs of the semifossorial prairie dog, Cynomys gunnisoni, and the scansorial fox squirrel, Sciurus niger. Journal of Morphology 180: 55-68.

StatSoft, Inc. 2004. STATISTICA (data analysis software system), version 7. www.statsoft.com.

Stein, B. R. 2000. Morphology of subterranean rodents. En Lacey, A. E., Patton, J. L. y Cameron, G. N (Eds.). Life Underground. The Biology of Subterranean Rodents (p. 19-61). Chicago: The University of Chicago Press.

Szalay, F. S. y Sargis, E. J. 2001. Model-based analysis of postcranial osteology of marsupials from the Palaeocene of Itaboraí (Brazil) and the phylogenetics and biogeography of Metatheria. Geodiversitas 23 (2): 139-302. 
Thompson, D. W. 1917. On Growth and Form. Cambridge: Cambridge University Press. 793 pp.

Thorington, R. W., Jr. 1984. Flying squirrels are monophyletic. Science 225 (4666):1048-1050.

Thorington, R. W., Jr., Darrow, K. y Anderson, C. G. 1998. Wing tip anatomy and aerodynamics in flying squirrels. Journal of Mammalogy 79(1): 245-250.

Thorington, R. W., Jr. y Darrow, K. 2000. Anatomy of the squirrel wrist: bones, ligaments, and muscles. Journal of Morphology 246(2): 85-102.

Tonni, E. P., Alberdi, M. T., Prado, J. L., Bargo, M. S. y Cione, A. L. 1992. Changes of mammal assemblages in the Pampean Region (Argentina) and their relation with the Plio-Pleistocene boundary. Palaeogeography, Palaeoclimatology, Palaeoecology 95: 179-194.

Tullberg, T. 1899. Über das System der Nagetiere: eine phylogenetische Studie. Nova Acta Regiae Societatis Scientiarum Upsaliensis 3: 1-514. Citado en: Ubilla, M. y Altuna, C. A. 1990. Analyse de la morphologie de la main chez des espèces de Ctenomys de l'Uruguay (Rodentia: Octodontidae). Adaptations au fouissage et implications évolutives. Mammalia 54: 107117.

Udrizar Sauthier, D. E., Abba, A. M., Bender, J. B. y Simon, P. M. 2008. Mamíferos del arroyo Perucho Verna, Entre Ríos, Argentina. Mastozoología Neotropical 15:75-84.

Ubilla, M. y Altuna, C. A. 1990. Analyse de la morphologie de la main chez des espèces de Ctenomys de l'Uruguay (Rodentia: Octodontidae). Adaptations au fouissage et implications évolutives. Mammalia 54: 107-117.

Vassallo, A. I. 1998. Functional morphology, comparative behaviour, and adaptation in two sympatric subterranean rodent genus Ctenomys (Rodentia: Octodontidae). Journal of Zoology 244: 415-427.

Vassallo, A. I. y Mora, M. S. 2007. Interspecific scaling and ontogenetic growth patterns of the skull in living and fossil ctenomyid and octodontid rodents (Caviomorpha: Octodontoidea). En Kelt, D.A., Lessa, E.P., Salazar-Bravo, J., Patton, J.L. (Eds.), The quintessential naturalist: honoring the life and legacy of Oliver P. Pearson (p. 945-968). California: University of California Publications in Zoology.

Vermeij, G. J. 1973. Adaptation, versatility and evolution. Systematic Zoology 22(4): 466-477.

Verzi, D. H. 1999. The dental evidence on the differentiation of the ctenomyine rodents (Caviomorpha, Octodontidae, Ctenomyinae). Acta Theriologica 44 (3): 263-282.

Verzi, D. H. 2001. Phylogenetic position of Abalosia and the evolution of the extant Octodontinae (Rodentia, Caviomorpha, Octodontidae). Acta Theriologica 46 (3): 243-268. 
Verzi, D. H. 2002. Patrones de evolución morfológica en Ctenomyinae (Rodentia, Octodontidae). Mastozoología Neotropical 9 (2): 309-328.

Verzi, D. H. 2008. Phylogeny and adaptive diversity of rodents of the family Ctenomyidae (Caviomorpha): delimiting lineages and genera in the fossil record. Journal of Zoology (London) 274: 386-394

Verzi, D. H. y Olivares, A. I. 2006. Craniomandibular joint in South American burrowing rodents (Ctenomyidae): adaptations and constraints related to a specialised mandibular position in digging. Journal of Zoology (London) 270: 488-501.

Verzi, D. H., Montalvo, C. J. y Vucetich, M. G. 1991. Nuevos restos de Xenodontomys simpsoni Kraglievich y la sistemática de los más antiguos Ctenomyinae (Rodentia, Octodontidae). Ameghiniana 28 (3-4): 325-331.

Verzi, D. H, Olivares, A. I. y Morgan, C. C. The oldest South American tuco-tuco (Pliocene, Northwestern Argentina) and the boundaries of genus Ctenomys (Rodentia, Ctenomyidae). Mammalian Biology. En prensa.

Vieytes, E. C. 2003. Microestructura del esmalte de roedores Hystricognathi sudamericanos fósiles y vivientes. Significado morfofuncional y filogenético. Facultad de Ciencias Naturales y Museo, Universidad Nacional de La Plata. Tesis inédita, 350 pp.

Vieytes, E. C., Morgan, C. C. y Verzi, D. H. 2007. Adaptive diversity of incisor enamel microstructure in South American burrowing rodents (family Ctenomyidae, Caviomorpha). Journal of Anatomy 211(3): 296-302.

Villarroel, A. C. 1975. Dos nuevos Ctenomyinae (Caviomorpha, Rodentia) en los estratos de la Formación Umala (Plioceno superior) de Vizcachani (Prov Aroma, Dpto. La Paz, Bolivia). Actas I Congreso Argentino de Paleontología y Bioestratigrafía 2: 495-502.

Warton, D. I., Wright, I. J., Falster, D. S. y Westoby, M. 2006. Bivariate line-fitting methods for allometry. Biological Reviews 81(2): 259-291.

Weir, B. J. 1974. The tuco-tuco and plains vizcacha. En Rowlands, I. W. y Weir, B. J. (Eds.). The biology of hystricomorph rodents (pp. 113-130). Symposia of the Zoological Society of London, 34. London: Academic Press.

Weisbecker, V. y Schmid, S. 2007: Autopodial skeletal diversity in hystricognath rodents: Functional and phylogenetic aspects. Mammalian Biology 72: 2744.

Weisbecker V. y Archer, M. 2008. Parallel evolution of hand anatomy in kangaroos and vombatiform marsupials: functional and evolutionary implications. Palaeontology 51(2): 321-338.

Westoby, M., Leishman, M. R. y Lord, J. M. 1995. On misinterpreting the 'phylogenetic correction'. Journal of Ecology 83: 531-534.

Winge, H. 1941. Vol. 2, Rodentia, Carnivora, Primates. En Jensen, A. S., Spärck, R. y H. Volsoe, H. (Eds). The interrelationships of the mammalian genera. 
Copenhagen: Reitzels Forlag.

Wood, A. E. y Patterson, B. 1959. The Rodents of the Deseadan Oligocene of Patagonia and the Beginings of South American Rodent Evolution. Bulletin of the Museum of Comparative Zoology 120 (3): 281-428.

Woods, C. A. 1972. Comparative myology of jaw, hyoid, and pectoral appendicular regions of New and Old World Hystricomorph rodents. Bulletin of the American Museum of Natural History 147(3): 115-198.

Woods, C. A. y Howland, E. B. 1979. Adaptive radiation of capromyid rodents: anatomy of the masticatory apparatus. Journal of Mammalogy 60: 95-116.

Woods, C. A. y Kilpatrick, C. W. 2005. Infraorder Hystricognathi Brandt, 1855. En Wilson, D. E. y D. M. Reeder (Eds). Mammal species of the World (p. 15381600). Baltimore: Johns Hopkins University Press.

Zar, J. H. 1998. Biostatistical Analysis. New Jersey: Prentice-Hall International Editions. 718 pp.

Zelditch, M. L. 1996. Introduction to the Symposium: Historical Patterns of Developmental Integration. American Zoologist 36:1-3.

Zelditch, M. L., Swiderski, D., Sheets, D. H. y Fink, W. 2004. Geometric Morphometrics for Biologists: A Primer. New York: Elsevier Academic Press. 443 pp.

Zuri, I. y Terkel, J. 2001. Reversed palatal perforation by upper incisors in ageing blind mole-rats (Spalax ehrenbergi). Journal of Anatomy 199: 591-598. 